Illinois State University

ISU ReD: Research and eData

Theses and Dissertations

3-13-2014

\title{
A Multi-method Examination of Pre-service Teacher Attitudes toward Gay and Lesbian Parents
}

Julie Herbstrith

Illinois State University, jc-herbstrith@wiu.edu

Follow this and additional works at: https://ir.library.illinoisstate.edu/etd

Part of the Lesbian, Gay, Bisexual, and Transgender Studies Commons, and the Psychology Commons

\section{Recommended Citation}

Herbstrith, Julie, "A Multi-method Examination of Pre-service Teacher Attitudes toward Gay and Lesbian Parents" (2014). Theses and Dissertations. 72.

https://ir.library.illinoisstate.edu/etd/72

This Dissertation is brought to you for free and open access by ISU ReD: Research and eData. It has been accepted for inclusion in Theses and Dissertations by an authorized administrator of ISU ReD: Research and eData. For more information, please contact ISUReD@ilstu.edu. 


\title{
A MULTI-METHOD INVESTIGATION OF PRE-SERVICE TEACHER ATTITUDES TOWARD GAY AND LESBIAN PARENTS
}

\author{
Julie C. Herbstrith
}

273 Pages

August 2010

An increasing number of children are being raised by gay and lesbian parents, but there is a dearth of literature that examines the challenges they face as they navigate the school system. The negative stigma of homosexuality and the increased visibility of these families suggest that research on teacher attitudes toward homosexual parents is needed. Using implicit, explicit, and behavioral measures, pre-service teacher attitudes toward gay and lesbian parents were assessed. Individual differences that influence the expression of sexual prejudice were also examined. Specifically, this study examined the relation between implicit and explicit measures. Also, implicit and explicit measures were used to predict prejudice behavior. Finally, the link between Agreeableness and prejudice was explored. Broadly, participants rated homosexual targets more negatively than they rated heterosexual targets, and they rated targets of gay men more negatively than they rated lesbians; however, response patterns varied by participant sex. Our findings indicated that implicit and explicit prejudice measures were positively related and that Agreeableness was related to prejudice. Exploratory analyses revealed complex 
relations between implicit prejudice, explicit prejudice, and motivation to control prejudice.

\section{APPROVED:}

\begin{tabular}{ll}
\hline Date & Renée M. Tobin, Chair \\
\hline Date & John B. Pryor \\
\hline Date & Matthew S. Hesson-McInnis \\
\hline Date & Christopher D. Horvath
\end{tabular}




\title{
A MULTI-METHOD INVESTIGATION OF PRE-SERVICE TEACHER ATTITUDES TOWARD GAY AND LESBIAN PARENTS
}

\author{
JULIE C. HERBSTRITH
}

A Dissertation Submitted in Partial Fulfillment of the Requirements for the Degree of

DOCTOR OF PHILOSOPHY

Department of Psychology

ILLINOIS STATE UNIVERSITY

2010 


\section{ACKNOWLEDGEMENTS}

To begin, I dedicate this dissertation to the women in my family: my grandmothers Viola and Sofie, my mother, Sue Ellen, and my daughter, Brooke Ellen. Each in her own way has given me the resolve to reach this goal, and because of them, I have never felt alone on the journey.

I have several acknowledgements. First, I thank Renée Tobin, chair of my committee, for her unwavering commitment to my training. She has been a mentor in every sense of the word. Without her expertise, guidance, and endless patience, I am certain I would not be as prepared as I am to take on my own career in academe. It has been a true pleasure working with Renée and I sincerely look forward to being her friend and colleague for years to come.

I thank my committee members. John Pryor listened to my early research ideas and guided me in the development of a very rewarding project. In addition to lending his expertise, he helped me discover the role that creativity plays in addressing research questions. It was a privilege to learn from such an accomplished scholar. Matthew Hesson-McInnis was an absolute pleasure to work with on this project. His expertise, patience, and understanding as I tackled statistical analyses and data interpretation were greatly appreciated, not to mention his enthusiasm and wonderful sense of humor. Christopher Horvath provided valuable feedback on this dissertation, and his expertise and thoughtfulness made it a better project. It was a genuine pleasure to work with him. 
I would be remiss if I did not thank Joel Schneider for his time, effort, and willingness to share his knowledge of data analysis with me. I learned so much from him, and I will always be grateful. I also thank Ryan Tobin-Schneider for sharing his mom and dad with me as willingly as he did. I sincerely enjoyed my time with him.

I extend my gratitude to the Personality and Social Development Research Team at ISU for their considerable efforts in data collection and entry. Without their dedication, this project would not have been successful. I owe special thanks to Katherine Hartman and Daniel Gadke for their leadership skills and willingness to step up when needed.

I also acknowledge Faye Plascak-Craig who became my mentor during my undergraduate studies many years ago. She showed me by example that this achievement was possible; if not for her, I almost certainly would not have taken the leap.

Thank you to all of my graduate school friends. Many memories have been made and will be cherished for years to come. In particular, I wish to thank Arpita Bavishi and Trisha Mann, two people who I came to count among my closest friends.

Thank you to my circle of friends and family who have consistently supported me throughout this process. They seemed to know when to ask me how it was going......and when not to ask me how it was going. They listened to me when I needed them to, and they understood when I didn't have words. Throughout this process, I always knew I had someone in my corner cheering me on, and that kind of comfort cannot be measured.

Without a doubt, I could not have completed this degree without the support of my parents, Roland and Sue Herbstrith. Behind every effort I made to accomplish this goal were the efforts of my mom and dad who helped me to keep the pieces of my life together. No small feat! There is nowhere near enough room to list all the ways they 
helped me so I will name just a few. Thank you to my mom for taking care of my kids until I got home each night, for sending me home with countless tuna noodle casseroles and party pizza turnovers, and for having faith that I could pull this off. Thank you to my dad for driving the kids to and from school and practice, for the home repairs he singlehandedly completed for me as I sat at my desk writing, and for his unwavering support of me.

Last but not least, I thank my children, who I will address directly. Thank you, Brooke and Drew, for your love, patience, and understanding. I set out to get this degree when you were both in elementary school. Hard to believe, given that you are now teenagers who have outgrown me! But even back then, when you were young, you understood that what I was working on was no "cupcake city." You recognized my difficult days and requested the bare minimum from me. You accepted that things weren't perfect in our house. You didn't show your frustration when I forgot to give you lunch money and when there weren't any clean socks that actually matched. You trusted that, no matter what, I would do anything I had to do to attend every game, musical performance, and fine arts show that I could. Thank you for that trust. As much as this achievement has been a personal one for me, make no mistake: it has also been about you. I sincerely hope that you have learned that you can do anything - ANYTHING you put your mind to. Finally and perhaps most importantly, thank you both for the laughter. When we are together and laughing it feels so good. Without those moments, I don't know where I'd be.

J.C.H. 


\section{CONTENTS}

Page

ACKNOWLEDGEMENTS

CONTENTS iv

TABLES $\quad v$

FIGURES $\quad$ ix

CHAPTER

I. INTRODUCTION 1

II. LITERATURE REVIEW 9

$\begin{array}{ll}\text { III. RESEARCH DESIGN } & 48\end{array}$

IV. ANALYSIS OF THE DATA

V. SUMMARY, CONCLUSIONS, AND RECOMMENDATIONS 141

$\begin{array}{ll}\text { REFERENCES } & 158\end{array}$

$\begin{array}{ll}\text { APPENDIX A: Questionnaires } & 173\end{array}$

$\begin{array}{ll}\text { APPENDIX B: Regression Tables } & 177\end{array}$

$\begin{array}{ll}\text { APPENDIX C: Correlation Matrix } & 230\end{array}$ 


\section{TABLES}

1. Race/Ethnicity and Sex of Phase 1 Participants 50

2. Participants by Sex and Major for Phase $1 \quad 50$

3. Race/Ethnicity and Sex for Phase 2 Participants 51

4. Participants by Sex and Major for Phase 2

5. Means and Standard Deviations of Phase 1 Variables by Participation in Phase 1 Only or Phase 1 and Phase 2

6. Cronbach's Alpha for AMP Photographs by Person and Activity 54

7. Number of Known Gay Men and Lesbians by Phase 1 Participants 57

8. Number of Known Gay Men and Lesbians by Phase 2 Participants 58

9. Means and Standard Deviations of Education and Non-education Majors for Agreeableness, MHNS-G, MHNS-L, Internal and External MRWP Scales, Suppression of Prejudice, and Social Distance

10. Means and Standard Deviations for Social Distance across Photographs and Sexual Orientation of Parents

11. Partner Abandonment Decisions across Sexual Orientation and Photograph Viewed

12. Means and Standard Deviations on Social Distance by Sex and Parent Interviewee Sexual Orientation in Similar Condition 
13. Means and Standard Deviations on Social Distance by Sex and Parent Interviewee Sexual Orientation in Dissimilar Condition

14. Means for AMP Responses in Descending Order

15. Means and Standard Deviations for AMP Responses by Type of Prime

16. Means and Standard Deviations for MHNS Scales

17. Intercorrelations for AMP responses and MHNS Scales

18. Multiple Regression Analyses of Agreeableness and Sexual Orientation of Interviewee Predicting Social Distance

19. Multiple Regression Analyses of Agreeableness, Implicit Measure, Sexual Orientation of Interviewee, and Social Distance

20. Multiple Regression Analyses of AMP Gay All, Internal Motivation, and Explicit Measures

21. Multiple Regression Analyses of AMP Gay All, External Motivation, and Explicit Measures

22. Multiple Regression Analyses of AMP Gay All, Suppression of

Prejudice, and Explicit Measures

23. Multiple Regression Analyses of AMP Lesbians Kissing, Suppression of Prejudice, and MHNS-G

24. Multiple Regression Analyses of Agreeableness, AMP Gay All, Internal Motivation, and MHNS-G

25. Multiple Regression Analyses of Agreeableness, AMP Gay Families, Internal Motivation, and MHNS-G

26. Multiple Regression Analyses of Agreeableness, AMP Gay All, Internal Motivation, and Social Distance

27. Multiple Regression Analyses of Agreeableness, AMP Gay All, External Motivation, and MHNS-G

28. Multiple Regression Analyses of Agreeableness, AMP Gay Families, External Motivation, and MHNS-G 
29. Multiple Regression Analyses of Agreeableness, AMP Heterosexual Families, External Motivation, and Social Distance

30. Multiple Regression Analyses of Agreeableness, AMP Gay All, Suppression of Prejudice, and MHNS-G

31. Multiple Regression Analyses of Agreeableness, AMP Lesbians Kissing, Suppression of Prejudice, and MHNS-G

32. Multiple Regression Analyses of Agreeableness, AMP Gay All, Suppression of Prejudice, and Social Distance

33. Multiple Regression Analyses of Implicit Measure for All Lesbian Photographs, Participant Sex, and the MHNS-L Explicit Measure

34. Multiple Regression Analyses of Agreeableness, Participant Sex, and MHNS-G

35. Multiple Regression Analyses of Implicit Prejudice, Participant Sex, and Social Distance

36. Multiple Regression Analyses of Agreeableness, Sexual Orientation of Interviewee, Participant Sex, and Social Distance

37. Multiple Regression Analyses of AMP Gay All, Sexual Orientation of Interviewee, Participant Sex, and Social Distance

38. Multiple Regression Analyses of AMP Lesbian All, Sexual Orientation of Interviewee, Participant Sex, and Social Distance

39. Multiple Regression Analyses of AMP Gay All, Internal Motivation, Participant Sex, and MHNS-G

40. Multiple Regression Analyses of AMP Gay All, Internal Motivation, Participant Sex, and MHNS-L

41. Multiple Regression Analyses of AMP Gay All, External Motivation, Participant Sex, and MHNS-G

42. Multiple Regression Analyses of AMP Gay All, External Motivation, Participant Sex, and MHNS-L

43. Multiple Regression Analyses of AMP Lesbians Kissing, External Motivation, Participant Sex, and MHNS-G 
44. Multiple Regression Analyses of AMP Lesbians Kissing, External Motivation, Participant Sex, and MHNS-L

45. Multiple Regression Analyses of AMP Gay All, Suppression of Prejudice, Participant Sex, and MHNS-G

46. Multiple Regression Analyses of AMP Gay All, Suppression of Prejudice, Participant Sex, and MHNS-L

47. Multiple Regression Analyses of AMP Gay Men Kissing, Suppression of Prejudice, Participant Sex, and MHNS-G 


\section{FIGURES}

Figure

Page

1. AMP responses to photographs of gay men, lesbians, and heterosexuals by activity.

2. AMP responses to photographs of couples kissing or in families.

3. AMP responses of male and female participants.

4. The interaction of AMP responses and sexual orientation of interviewee as a predictor of social distance.

5. The Interaction between AMP Gay all, external motivation, and MHNS-G.

6. Interaction of AMP lesbians kissing and suppression of prejudice predicting MHNS-G.

7. Interaction of Agreeableness, AMP gay families, and internal motivation as a predictor of MHNS-G.

8. Interaction of Agreeableness, AMP Gay All, and internal motivation as a predictor of social distance.

9. Interaction of Agreeableness, AMP lesbian families, and internal motivation as a predictor of social distance.

10. Interaction of AMP gay all and external motivation as a predictor of MHNS-G.

11. Three-way interaction for Agreeableness, AMP gay families, and external motivation

12. Three-way interaction of Agreeableness, AMP heterosexual families, and external motivation predicting social distance

13. Three-way interaction of Agreeableness, AMP lesbians kissing, suppression, and MHNS-G. 
14. Interaction of AMP responses to all lesbian photographs and participant sex as predictors of MHNS-L.

15. Interaction of AMP responses to all lesbian photographs and participant sex as predictors of social distance.

16. Interactions of participant sex, external motivation, and AMP responses to lesbians kissing as predictors of MHNS-G.

17. Interaction of AMP responses to gay kissing, suppression of prejudice, and participant sex as predictors of MHNS-G. 


\section{CHAPTER I}

\section{INTRODUCTION}

An increasing number of children are being raised by same-sex parents (Human Rights Campaign, n.d.). According to the U.S. Census Bureau (2000), 500,000 same-sex households exist in the United States. It is estimated that one-third of lesbian households and one-fifth of gay male households are currently raising children. Although it is well documented that gay men and lesbians experience prejudice (Herek, 2000; Herek, 2005; Meyer, 2003; Stein, 2004), it is not well documented how prejudice influences gay and lesbian parents. Further, a substantial body of literature examines the influence of gay and lesbian parents on issues such as their children's sexual orientation (Bailey, Bobrow, Wolfe, \& Mikach, 1995; Flaks, Ficher, Masterpasqua, \& Joseph, 1995; Golombok \& Tasker, 1996; Green, 1978) and emotional and mental health status (Golombok, Spencer, \& Rutter, 1983; Huggins, 1989; Murray \& McClintock, 2005); however, there is a paucity of published research that examines the influence of other, outside factors on these children. Said differently, researchers have examined the influences of gay and lesbian parents on the world (e.g., outcomes for the children they raise) but have essentially ignored the influence of the world on them, namely prejudice.

The focus of the present research is on a single, important potential source of prejudice toward gay and lesbian parents: prejudice from their children's teachers. Because children typically spend the majority of their time in the school setting (Fagan \& 
Wise, 2000), it is important to consider how prejudice manifests itself in the relations between these nontraditional families and their children's teachers. From this perspective, this study examined (a) prevailing teacher attitudes toward gay and lesbian parents; (b) variables that moderate teachers' motivation to express or suppress this form of prejudice; and (c) the relation between implicit and explicit measures of sexual prejudice, or negative attitudes toward non-heterosexual people. Using implicit and explicit prejudice measures and methods selected from previous social-experimental research designs (e.g., Fazio \& Olson, 2003; Greenwald, McGhee, \& Schwartz, 1998; Payne, Cheng, Govorun, \& Stewart, 2005), this study advanced current knowledge on the mechanisms of prejudice and contributed to the diversity literature that informs education.

Many teacher training programs now include courses in diversity and multiculturalism so that their graduates are better prepared when they enter the workforce as elementary or secondary educators (Middleton, 2002; Schweickart, 1988; Singer \& Smith, 2002). It is unclear, however, whether these teachers are adequately prepared to work with families whose heads of household are gay or lesbian (Bigner, 2004). Despite efforts to infuse diversity topics into education curricula, there is evidence that preservice teacher attitudes toward sexual orientation remain significantly more negative than attitudes toward other diversity issues such as race and ethnicity (Taylor, 2001). One explanation for this difference may rest with the fact that issues covered in multicultural courses often exclude sexual orientation as an element of diversity (Herek, 1989). Another contributing factor may be a lack of dissemination of information on 
homosexuality to teachers and staff (Ray \& Gregory, 2001). A 1994 survey of pre-service teachers found that a significant majority held homophobic attitudes, were misinformed about gay and lesbian sexuality, and were generally unwilling to address gay/lesbian issues in school or behave in a manner that was supportive of gays and lesbians (Butler, 1994).

Sexual orientation is stigmatized in the United States (Herek, 2005; 2007). Referred to as heterosexism, the stigma placed on gay and lesbian individuals has historically reinforced the notion that heterosexual orientation is the norm and that nonheterosexual orientation is abnormal, unnatural, and inferior to heterosexual orientation (Herek, 2007). Given the negative implication associated with heterosexism, gay men and lesbians are frequently confronted with decisions on whether to disclose their sexual orientation to others. These decisions are particularly difficult when children are involved because disclosure could lead to bullying by peers and prejudicial behavior by school personnel (Ray \& Gregory, 2001). For example, Kozik-Rosabal (2001) conducted a series of interviews of gay and lesbian parents and found that their greatest concerns were (a) the physical and emotional safety of their children at school and (b) the unwillingness of the school to acknowledge existing problems with bullying and harassment of their children. Ray and Gregory found that one-third of all students ranging in age from 14 to 21 reported having been teased or bullied because of their parents' sexuality. Further, teacher responses to these incidents were described by parents and children as nonexistent or ineffectual. Given these risks, some gay and lesbian parents choose not to disclose the nature of their families to the school. This decision may result in high levels 
of anxiety and low self-esteem in their children (Murray \& McClintock, 2005). Further, it may jeopardize the relationship between the family and the school system by creating a sense of distrust.

The importance of a positive and collaborative relationship between home and school is well documented (Swap, 1992; Vickers \& Minke, 1995). An essential component of this relationship is trust. Parents must be confident that the school system acts in ways that are supportive and in the best interest of their children. When gay and lesbian parents decide to disclose the same-sex composition of their families to their children's school, this trust is often violated. Instead of support, disclosure is often met with negative reactions that significantly affect the home-school relationship (Butler, 1994; Kozik-Rosabal, 2001; Middleton, 2002; Ray \& Gregory, 2001), thereby placing their children at further risk for other problems such as emotional and social maladjustment (Hughes, Hasbrouck, Serdahl, Heidgerken, \& McHaney, 2001).

The aforementioned findings suggest that a poor home-school relationship exists for gay and lesbian families. Non-communicative relationships between the systems in which children operate (e.g., home, school, community) is a documented risk factor (Pianta \& Walsh, 1996) and adds to the list of potential disadvantages children of gay and lesbian parents face at school. These findings, particularly in light of federal legislation such as No Child Left Behind (NCLB; US Department of Education, n.d.) that mandates equal opportunities to learn for all students, suggest the need for systemic changes in teacher education curricula and school policy regarding tolerance and harassment to 
afford children of gays and lesbians the same opportunities to learn in a safe environment as children who are raised by heterosexual parents.

Prejudice, in its broadest sense, has received considerable attention in the psychological literature, particularly since Allport's (1954) influential book, The Nature of Prejudice. Researchers have focused on issues such as how prejudice develops and is internalized (see Crandall \& Eshleman, 2003), how it can be measured (Fazio \& Olson, 2003; Payne et al., 2005; Plant \& Devine, 1998), what personality traits are associated with it (Ekehammar \& Akrami, 2003; Graziano, Bruce, Sheese, \& Tobin, 2007), how prejudice is sometimes suppressed (Crandall \& Eshleman, 2003; Crandall, Eshleman, \& O'Brien, 2002), and, of course, the various targets of prejudice (e.g., racial or ethnic minorities).

Research suggests that prejudice toward gay men, lesbian women, bisexual people, and transgendered people is a commonly held prejudice (Crandall, et al., 2002). Among others, Herek (e.g., Herek, 2000; Herek, 2002; Herek, Gillis, \& Cogan, 1999) has provided social scientists with the historical backdrop through which to examine mechanisms of hostility toward gay men and lesbian women. Herek (2000) documented that sexual prejudice remains widespread in the United States and that lesbian women, gay men, and bisexual people routinely experience violence. In 1997, a total of 1,102 hate crimes based on sexual orientation were reported. Furthermore, a substantial proportion of such crimes probably go unreported, making these figures low estimates of the true crime rate (Herek et al., 1999). As of yet, however, little research has been conducted in the area. 
Although a great deal of literature focuses on well-substantiated methods for studying other types of prejudice and attitude formations, there is a paucity of research that uses paradigms to examine sexual prejudice. The literature that specifically addresses prejudice toward gay and lesbian parents is even sparser. Given the rising number of children who are being raised by gay men and lesbian women and the extant, though meager, literature on the negative experiences of these families, additional sexual prejudice research is clearly warranted.

To study sexual prejudice in light of the absence of much prior research in the area, it is necessary to turn to the literature that examines other kinds of prejudice in an effort to build our understanding of the phenomenon. One focus of research has been on the link between personality and prejudice. For example, Graziano et al. (2007) conducted a series of studies that examined the relation between anti-fat prejudice and Agreeableness, one of the Big Five dimensions of personality. They defined Agreeableness in terms of social motivation, or the desire to maintain positive relations with others (Graziano \& Eisenberg, 1997). In terms of prejudice, then, persons who are high in Agreeableness may be more apt to hold fewer prejudices than persons low in Agreeableness; they may be more positive toward others in general; or they may hold similar prejudices as persons low in Agreeableness but actively suppress them to maintain positive relations. Based on the Graziano et al. (2007) study, Agreeableness will be examined in this study as a potential moderator of the expression of sexual prejudice.

To examine this hypothesis, multiple measures of prejudice were used. Similar to other prejudice research (Dovidio, Kawakami, \& Gaertner, 2002; Dovidio, Kawakami, 
Johnson, Johnson, \& Howard, 1997; Dunton \& Fazio, 1997; Payne et al., 2005), implicit and explicit measures were used. Implicit measures evaluate participant responses in ways that make it difficult for them to monitor and control (Dovidio et al., 2002). Response latencies are often calculated for implicit measures and perceived as indicators of participants' cognitive processing of stimuli that are presented. Explicit measures are measures such as observations of overt behavior, self-report ratings, or other responses for which persons have the opportunity to consider the costs and benefits of the chosen response.

The relations between implicit and explicit measures vary across studies (Hoffman, Gawronski, Gshwendner, Le, \& Schmitt, 2005). Within the domain of prejudice research, correlations between implicit and explicit measures tend to be low (Dovidio et al., 1997; Dovidio et al., 2002; Fazio \& Olson, 2003). However, there is evidence that these correlations may be situation specific. For example, Franco and Maass (1999) found that when an outgroup (i.e., Jews) was normatively protected from discrimination, there was no significant correlation between implicit and explicit measures. However, when it was deemed socially acceptable to be prejudiced against an outgroup (i.e., Islamic Fundamentalists), implicit and explicit measures were strongly correlated. Also, more recent research (Payne, Burkley, and Stokes, 2008) showed that the relation between implicit and explicit measures may be influenced by the structural similarity of the measures (e.g., similar task, similar metrics used).

Using Crandall et al.'s (2002) distinction between the social acceptability of prejudice toward a specific social group and an individual's personal attitudes toward that 
social group, the relations between implicit and explicit measures of sexual prejudice can be more closely examined. Crandall et al. (2002) found that ratings of the normative appropriateness of prejudice toward gay men and lesbian women raising children were high relative to the normative appropriateness of other social groups. That is, prejudice toward homosexual parents was rated as more socially appropriate compared to ratings of other social groups. Therefore, there may be a positive correlation between implicit and explicit measures of sexual prejudice because expressing this type of prejudice is normatively appropriate. Individual differences may also influence the relation between implicit and explicit measures. Therefore, personality measures are included in the present study to further explore these complex relations.

The goal of the present study was to examine pre-service teachers' attitudes and behaviors toward gay and lesbian parents. Sexual prejudice was measured by replicating two unique experimental paradigms. The first paradigm was the Affect Misattribution Procedure (AMP; Payne et al., 2005) that was employed as a measure of implicit attitudes toward gay and lesbian parents. The second paradigm, previously employed by Graziano et al. (2007), involved measuring participant behavior under circumstances in which they believed they were paired with a gay man for a brief activity. In addition, questionnaires were used to collect explicit measures of prejudice, prejudice suppression, and individual difference measures that we predicted would moderate prejudice expression. 


\section{CHAPTER II}

\section{LITERATURE REVIEW}

\section{Gay Men and Lesbian Women as Parents}

It is estimated that between one-fifth and one-third of gays and lesbians are currently raising children (U.S. Census Bureau, 2000). Prior to the late 1970s, most of these children were from prior heterosexual relationships. Since that time, gay and lesbian couples have increasingly opted to have children via adoption, surrogacy, or artificial insemination (Parks, 1998). Therefore, gay- and lesbian-led families are becoming more common and more visible in society.

For many years, parents who are gay and lesbian and their children lived in secrecy, especially in light of the many court cases that have challenged their abilities as parents (McCann \& Delmonte, 2005). Today, although they are not afforded the same rights and protection under the law as men and women who are heterosexual, gay men and lesbians are increasingly choosing to disclose their sexual orientations (KozikRosabal, 2000). While there is evidence that disclosure has important mental health benefits (Murray \& McClintock, 2005), it also sharpens the focus on socially sensitive issues surrounding homosexuality.

Several concerns have been voiced for children raised by parents who are homosexual, including their sexual orientation, social-emotional adjustment, quality of relationship and attachment patterns, and the lack of opposite gender role models 
(McCann \& Delmonte, 2005). Anderssen, Amlie, and Ytteroy (2002) performed a comprehensive review of outcome studies from 1978 to 2000 . The results indicated that children with parents who are homosexual did not systematically differ from other children in terms of social-emotional functioning, sexual preference, behavioral adjustment, or cognitive functioning. Similarly, the National Longitudinal Study of Adolescent Health (Wainright, Russell, \& Patterson, 2004) compared 44 teenagers with parents who are homosexual to an equal number of teenagers with parents who are heterosexual and found no significant differences in functioning. The study indicated no differences in depression symptoms, self-esteem, or academic functioning (e.g., grade point average). Bos, van Balen, and van den Boom (2007) found no differences in the prevalence of several behavior problems of children raised by lesbian or heterosexual families. Erich, Kanenberg, Case, Allen, \& Bogdanos (2009) examined attachment patterns of children adopted by same-sex parents and heterosexual parents. They found no relation between adolescent attachment and parent sexual orientation. In another longitudinal study with lesbian families who had children via donor insemination, results indicated that the prevalence of physical and sexual abuse of these children was lower than national norms (Gartrell, Deck, Roda, Peyser, \& Banks, 2005). Wainright and Patterson (2008) found that peer relations among adolescents with lesbian parents did not differ significantly from peer relations among their same-age counterparts who had heterosexual parents. Rivers, Poteat, and Noret (2008) investigated the psychological and social functioning of children raised by same- or opposite-sex couples. They found no differences in peer victimization or psychological functioning. 
The most common concern cited by parents who are homosexual is that their children will be victimized and harassed at school and in the community (Clark, Kitzinger, \& Potter, 2004; McCann \& Delmonte, 2005; Ray \& Gregory, 2001). Ray and Gregory (2001) found that $73 \%$ of homosexual parents were worried that their children would be teased or bullied. Despite the evidence that most homosexual parents identify the fear of harassment and bullying as their primary concern, the evidence that children of gay men and lesbian women actually are harassed and bullied because of their parents' sexual orientation is unclear. Ray and Gregory (2001) reported that $18 \%$ of primary school students and $28 \%$ of secondary school students reported actually having been bullied. These percentages seem low in relation to the concern reported by their parents. Unfortunately, no comparison data on children of heterosexual parents were collected. Gartrell et al (2005) reported that nearly half of their sample of 10 -year-old children in lesbian families they interviewed had experienced homophobia. Most of the data in this body of literature were self-reports and were collected via unstructured interviews and other unstandardized methods. Therefore, no conclusions can be drawn as to how problematic bullying and harassment were for the children in this sample.

There are other reasons it is difficult to determine whether children of gays and lesbians undergo more harassment and bullying than their peers. First, children of gays and lesbians may be less likely to report these incidents. Kozik-Rosabal (2000) found evidence that teachers largely ignored bullying behaviors and verbal abuse directed at these children. It is possible that many children do not report future incidents because no action was taken in the past. Second, many children may not disclose their parents' 
homosexuality to avoid these incidents. Kozik-Rosabal (200) and Ray and Gregory (2001) found that children of gays and lesbians reported the fear of "outing" their families as one of their primary concerns. Lindsay et al. (2006) reported that secrecy was a key strategy they employed as they navigated the school system. Further, they emphasized that children of lesbian families shared the stigma of their parents and were thus more likely to engage in "information management." That is, based on the behaviors observed in their parents, these children tended to be extremely cautious about disclosing any information about their families.

To summarize, the literature on the risks for children of gay men and lesbians is inconclusive. Long-term psycho-social outcomes for these children are not significantly different from those of their peers (Wainright et al., 2004; Wainright \& Patterson, 2008). The majority of homosexual parents and their children, however, hold fears about the ramifications of parental sexual orientation. Future research to explore these issues in more depth is warranted.

\section{Teacher Attitudes}

The role that teachers play in a child's education extends beyond imparting academic knowledge and skills. Children also learn social norms and values that are modeled by educators and peers. Therefore, it is not surprising that along with concerns about homophobic harassment by peers, gay and lesbian parents also have concerns regarding how their children will be treated by their teachers.

The student body of today's public schools is increasingly diverse (Frisby \& Reynolds, 2005). The same, however, cannot be said of the teacher population, which 
has remained relatively homogeneous. According to the National Center for Education Statistics, (NCES; 2006), 84\% of the K - 12 teacher population for the 2003-2004 school year was of White, non-Hispanic origin. In light of this statistic, one of the major challenges for teacher educators has been to prepare future teachers to interact effectively with a diverse array of students. Teacher educators have attempted to prepare teachers to interact adequately with students in a multiculturally competent way. To that end, preservice teachers are often required to enroll in diversity courses offered as part of their program curricula. Despite the responsiveness of teacher preparation programs, however, little is known about teacher attitudes toward diversity and the extent to which courses in multiculturalism are effective (Vogt \& McKenna, 1998; Vogt, 1997). Further, little is known about teacher attitudes toward specific diverse populations, such as gay men and lesbian women. The limited research examining the relationships of homosexual parents and teachers has focused on the perceptions of homosexual parents. For example, KozikRosabal (2000) found that homosexual parents perceived that school personnel were misinformed about homosexuality. Further, these parents believed that school officials felt that there were no problems related to homosexuality in their schools. An additional concern reported by more than half of the parents interviewed was that children would be forced to answer difficult questions about their families. Given these risks, some parents choose not to reveal their sexual orientation to their children's school administrators and teachers.

There are two potential ramifications of this decision. First, previous research indicates that when parents choose not to disclose their sexual orientation, higher levels 
of anxiety and lower levels of self-esteem may result for their children (Murray \& McClintock, 2005). Second, non-communicative relations between families and schools are a documented risk factor for negative academic outcomes (Pianta \& Walsh, 1996). If parents choose not to disclose their sexual orientation to the school, it is unlikely that they would fully participate in school activities ranging from extracurricular activities (e.g., sporting events, art, music) to parent-teacher conferences.

Another concern raised by $62 \%$ of gay and lesbian parents interviewed by Ray and Gregory (2001) was that diverse family constellations such as theirs would not be represented in the school curriculum. According to Kozik-Rosabal (2000), when children of lesbian women and gay men see only heterosexual relationships acknowledged, they often conclude that their parents' relationship is not legitimate or healthy.

The research evidence on teacher attitudes about homosexuality is relatively sparse. Butler (1994) measured pre-service teacher attitudes toward homosexuality in the schools. The questionnaires included the Attitudes toward Lesbians and Gay Men Scale (Herek, 1988), the Homosexual Information Scale (Wells \& Franken, 1987), and a modified version of the Professional Attitude Index (Sears, 1991). The results indicated that, in general, pre-service teachers held negative stereotyped beliefs about gays and lesbians, lacked knowledge about homosexuality, and indicated a lack of willingness to address or be supportive of gay and lesbian issues at school.

Based on Sears' (1991) finding that 8 out of 10 pre-service teachers harbored negative feelings toward gay men and lesbian women, Bliss and Harris (1999) predicted that surveys of teachers would indicate little or no professional exposure to sexual 
orientation issues and that teachers would have incomplete knowledge of homosexuality. Their findings indicated that overall exposure to issues of sexual orientation was limited. More importantly, no teachers reported having received any education related to gay parenting issues. Further, most teachers stated that their school had no clear policy in place for how to work with and support homosexual parents and their school children.

Vogt and McKenna (1998) compared teacher attitudes toward social diversity with attitudes held by the general public. Using a 40 -item questionnaire on political and social attitudes, they found that educators held significantly more intolerant beliefs and negative attitudes toward groups such as homosexual people than the general public. Middleton (2002) examined pre-service teacher participation in a diversity course in which they were asked to state their beliefs about racism, sexism, disabilities, and homophobia. The results indicated that many pre-service teachers began the course at a low level of awareness of the beliefs they held toward diverse persons. Further, some participants indicated that they were generally willing to teach from a multicultural perspective. Teachers in this sample, however, limited this commitment with regard to homosexuality, indicating that they would not be willing to include issues related to it.

The finding that teachers may be resistant to the inclusion of issues related to homosexuality in their teaching practice is not surprising in light of evidence that homosexuality is often excluded from the list of diverse cultures (Butler, 1994; Herek, 2005). Butler (1994) reported that many teacher education programs have incorporated multiculturalism into their training curricula, but gay men and lesbian women are often ignored in terms of having a unique culture of their own. In 1991, Uribe and Harbeck 
stated that "the educational system in the United States is blind-folded and mute on the subject of adolescent, educator, and parental homosexuality" (p. 11). Other publications (e.g., Bliss \& Harris, 1999; Fontaine, 1997; Tatto, 1996) indicate that little progress has been made in this regard.

\section{Prejudice}

In the social psychological literature, prejudice is generally considered a negative attitude toward a social group and its members (Esses, Haddock, \& Zanna, 1993). Devine (1989) posited that as a result of years of exposure to biased and stereotypical information, all individuals experience stereotype activation, or prejudicial thoughts toward a social group or one of its members. Once activated, individuals must manage cognitive processes in relation to the social context in which the stereotype activation occurs. Essentially, Devine (1989) argued that prejudice is a macro-level process in which individuals, as social perceivers, must manage the interface between their cognitive and social worlds.

According to Devine (1989), perceived social norms play a major role in determining whether individuals will express or suppress prejudice. Devine (1989) introduced the construct of motivation to control prejudice to help explain why stereotype activation does not always result in prejudicial behaviors. Further, Devine argued that the source of motivation to express or suppress prejudice has important behavioral consequences. She theorized that stereotyping some groups is more socially acceptable than stereotyping other groups. That is, when a social perceiver believes that prejudice 
directed at particular social group is acceptable, he or she is less likely to suppress a prejudiced response.

Whether this motivation is internal (e.g., based on personal beliefs and values) or external (e.g., imposed by external norms) has implications for the consequences of the expression of prejudice. That is, when motivation is internal, expressing prejudice leads to guilt and self-recrimination. When motivation is external, however, responding in a prejudiced manner may lead to reactance and frustration with oneself for conforming to external social norms. Monteith, Sherman, and Devine (1998) suggested that this frustration may result in a backlash that leads to increased levels of prejudice expression.

Crandall et al. (2002) examined prejudice in relation to group norm theory (Sherif \& Sherif, 1953) which describes how prejudice develops within the context of social groups and the pressures placed on individuals to conform to group norms. Group norm theory states that attitudes are developed at the group, not the individual, level; therefore, group norm theory predicts that changing group norms is more effective at prejudice reduction than changing individual attitudes.

Using group norm theory as a central premise, Crandall et al. (2002) conceptualized prejudice as a negative attitude that is formed and maintained at the group level by group norms. For individuals, then, prejudice is a negative attitude that is formed by adopting a valued group's attitude. Based on this idea, Crandall et al. (2002) conducted a study in which they first measured the normative appropriateness of prejudice toward a large set of social groups and then compared these ratings to a different set of participants' personal attitudes toward the same set of social groups. The 
researchers hypothesized that the prejudice expressed toward each group would be a function of the normative appropriateness of each specific prejudice. As an example, more prejudice would be reported for rapists than African-Americans because it is more socially acceptable to express prejudice for the former group than for the latter group.

As predicted, the results indicated that individuals reported their own prejudices according to the normative appropriateness of the prejudice. Taking this line of research a step further, Crandall et al. (2002) next examined individual differences in prejudice suppression. They posited that the underlying motivation of prejudice suppression was the desire to conform to group attitudes about the appropriateness of a given prejudice.

Crandall et al. (2002) developed and tested a scale to measure individual differences in the motivation to suppress prejudice. Unlike other theories that differentiate between internal and external motivation to suppress prejudice (e.g., Plant \& Devine, 1998), Crandall et al. posited that any motivation on behalf of an individual to inhibit a prejudiced response is a direct result of that individual's desire to fit his or her attitude to a prevailing group norm. Based on this hypothesis, these researchers developed the Suppression of Prejudice Scale.

Using this scale, Crandall et al. (2002) found that individuals who scored high on suppression reported more prejudice toward groups for whom it was more normatively appropriate to do so. That is, when it was socially acceptable to have negative attitudes toward a target group (e.g., rapists), high suppressors reported more prejudice than low suppressors. For normatively inappropriate target groups (e.g., African-Americans), on the other hand, high suppressors reported less prejudice. Taken together, these findings 
suggest that high suppressors are selective in their endorsement of prejudices. They appear to be able to respond to prejudice cues according to the degree of normative appropriateness associated with them. High suppressors also appear to be willing to respond in this manner.

Crandall and Eshleman (2003) stated that all theories of prejudice share the same central tenant that people acquire prejudice toward outgroups early on and, as they mature, individuals become motivated to suppress prejudice, especially those prejudices that are not socially acceptable (e.g., Crandall et al., 2002). According to Crandall and Eshleman (2003), the tension between the desire to express acquired prejudice and the desire to suppress it is an almost inevitable process that individuals undergo prior to responding to a given stimulus.

Crandall and Eshleman (2003) espoused a two-factor model of prejudice to explain this process. Similar to Devine's (1989) theory that individuals undergo multiple simultaneous processes (e.g., social and cognitive) when they encounter a stereotype, they theorized that people attempt to satisfy motivations both to suppress and to feel prejudice simultaneously. The first factor, labeled genuine prejudice, is primary, automatic, and affectively negative. The second factor is the motivation to control genuine prejudice. According to Crandall and Eshleman (2003), each instance of prejudice expression is the result of genuine prejudice and the motivation to control it.

In a recent study, Son Hing, Chung-Yan, Hamilton, and Zanna (2008) conceptualized prejudice using a two-dimensional model. Essentially, they proposed four types of people: modern racists, aversive racists, truly low prejudiced people, and 
principled conservatives. Modern racists were defined as people who do not believe their attitudes are prejudiced and therefore would score high on explicit and implicit measures of prejudice. Aversive racists were defined as individuals who sincerely hold nonprejudiced values but who also have high prejudiced implicit values due to years of exposure (i.e. Devine, 1989); these individuals would score low on explicit measures but high on implicit measures. Truly low prejudiced people were defined as individuals who truly value equality for all people and would score low on both explicit and implicit measures. Finally, principled conservatives were defined as individuals who do not feel negative toward outgroups but who value tradition and resent upsetting the status quo. Such individuals would score high on explicit measures and low on implicit measures. In a series of four studies that examined prejudice toward Asian targets, Son Hing et al. (2008) found support for their model and asserted that future research work toward making even finer distinctions between these four groups.

\section{Sexual Prejudice}

Herek (2000) used the term sexual prejudice to describe negative attitudes based on sexual orientation. Similar in nature to other forms of prejudice, he defined sexual prejudice as having three principal features: "it is an attitude (i.e., an evaluation or judgment); it is directed at a social group and its members; and it is negative, involving hostility or dislike" (p. 19).

In relation to other types of prejudice (e.g., racial or ethnic), sexual prejudice has been understudied. Herek (2000) documented that heterosexual people's attitudes were more negative toward gay men than lesbian women and that adoption rights were less 
supported for gay men than lesbian women. Further, heterosexual men were less supportive than heterosexual women of the recognition of same-sex relationships and adoption rights for gay men, suggesting a possible gender difference in the way gay men and lesbian women are perceived (Herek, 2002).

More recent research (e.g., Barron, Struckman-Johnson, Quevillon, \& Banka, 2008) has provided potential explanations for heterosexual male attitudes toward gay men. Specifically, Barron et al. (2008) posited that prejudice toward gay men may be a function of ideas of masculinity in the dominant culture of the United States. That is, heterosexual men who place high values on characteristics such as aggression and toughness may have especially negative attitudes toward gay men because they perceive that gay men do not possess these characteristics. Barron et al. (2008) also pointed out that heterosexual men may view heterosexuality as a fundamental component of masculinity.

Shifting to the examination of heterosexual women's attitudes toward homosexuality, Parrot and Gallagher (2008) investigated their negative responses to lesbians. Based on the findings that traditional role beliefs have been linked to attitudes toward gay men and lesbians (Herek, 1988; Kite \& Whitley, 1996), these researchers found that traditional female gender role beliefs were correlated with negative attitudes toward lesbians and that these attitudes predicted feelings of anger when viewing videotaped lesbian interactions. Parrot and Gallagher (2008) concluded that heterosexual women who hold traditional values about what it means to be a woman tend to hold more prejudice toward lesbians than their heterosexual female counterparts. 
Haddock and Zanna (1998) studied sexual prejudice in terms of individual differences. Specifically, they examined the relation between right-wing authoritarianism (Altemeyer, 1988) and the propensity to be prejudiced toward gays and lesbians. Individuals high in right-wing authoritarianism are described as extremely self-righteous persons who strongly uphold traditional values and norms and who willingly submit to perceived legitimate authorities maintaining these values and norms. Persons high in right-wing authoritarianism aggress against those who threaten them.

Haddock and Zanna (1998) espoused a multi-component model of attitude in which attitudes are conceived as evaluations derived from cognitive, affective, and behavioral information. In this model, cognitive information consists of stereotypic and symbolic beliefs. Stereotypic beliefs are characteristics attributed to typical members of a target group. Symbolic beliefs are described as the idea that target groups (e.g., outgroups) either violate or uphold desired values or customs of the in-group. The affective component of the model focuses on the emotions elicited by members of target groups.

In a series of studies, Haddock and Zanna (1998) found that individuals high on right-wing authoritarianism held significantly more negative attitudes toward homosexual people than individuals who were low on right-wing authoritarianism. These attitudes were best predicted by participants' symbolic beliefs that gays and lesbians threaten their traditional values and by participants' negative affective information. It was interesting that stereotypic beliefs were more predictive of low authoritarianism.

Simon (1998) was also interested in the relation between attitudes toward gay men and lesbians and stereotypes of homosexuals. Noting that this relation had not 
received much empirical attention, she examined whether an individual's negative beliefs predict his or her negative attitudes toward a target group. According to Simon (1998), the stereotypes about gay men and lesbians that are found in popular culture are quite similar to those found in the empirical literature. Using a paradigm in which preexperimentally determined positive and negative stereotypes were rated by participants as descriptive of gay men and lesbians, Simon found that positive stereotypes were seen as less descriptive of gay men and lesbians as attitudes, as measured by the Attitudes Toward Lesbians and Gay Men (ATLG; Herek, 1988), became more negative. She noted that whereas these results support the existence of a relation between attitudes and stereotypes, they are only moderately compelling, and more research is necessary, particularly using participant samples from the broader population (e.g., beyond college students).

Saucier and Cawman (2004) examined the extent to which sexual prejudice, religious fundamentalism, social dominance orientation, and support for civil unions influenced voters' choices for governor in the state of Vermont, where civil unions had recently been granted official recognition. In line with theories of symbolic racism (e.g., McConahay \& Hough, 1976), they suggested that, in an effort to maintain superior status over a minority group, majority groups use indirect prejudicial tactics such as voting for legislation that puts minority groups at a disadvantage. Saucier and Cawman (2004) predicted, therefore, that voters high on sexual prejudice measures would vote for gubernatorial candidates who stated that they would attempt to repeal civil union legislation. Also, because of the well-established relation between religious 
fundamentalism and prejudice (Allport \& Ross, 1967; Larsen, Cate, \& Reed, 1983), they predicted that religious fundamentalism would also predict voters' choices. Their results substantiated their predictions: They found that voters' attitudes toward civil union legislation greatly influenced which candidate received their votes. Additionally, support for this legislation was related to voters' levels of sexual prejudice.

In a similar vein, Morrison, Kenny, and Harrington (2005) found that participants who endorsed more negative attitudes toward gay men and lesbians also reported higher levels of religious fundamentalism and church attendance. Additionally, their findings indicated an inverse relation between negative attitudes toward gay men and lesbians and support for the human rights of gay men and lesbians.

Herek, Widamen, and Capitanio (2005) examined the extent to which people who are heterosexual understand how AIDS is transmitted and the degree to which these beliefs are influenced by sexual prejudice. In a telephone survey administered to heterosexual men and women, they found that sexual prejudice was related to erroneous judgment about transmission. Erroneous judgments were made about both sex between men and sex between men and women.. Survey participants expressed beliefs that HIV could be transmitted even in situations in which neither partner was HIV-positive in both heterosexual and homosexual sexual encounters. Herek et al. (2005) interpreted this finding to mean that the association between male homosexuality and AIDS is so strong that the stigma operates through a connection between sexual prejudice and beliefs about transmission, even in heterosexual encounters. In other words, people high in sexual prejudice attitudes are more likely to believe that HIV is transmitted in impossible ways. 
It has been suggested that sexual prejudice is related to both anger in response to homosexuality (Van de Ven, Bornholt, \& Bailey, 1996) and traditional role beliefs (Haddock \& Zanna, 1998; Parrott, Adams, \& Zeichner, 2002). Using an experimental paradigm, Parrot and Zeichner (2005) examined the role of sexual prejudice and anger in antigay aggression. They randomly assigned heterosexual men to watch either a malemale or male-female erotic video. Dependent variables consisted of measurements of preand post-manipulation state anger, sexual prejudice, and physical aggression. Physical aggression was measured using the Response-Choice Aggression Paradigm (RCAP; Zeichner, Frey, Parrot, \& Butryn, 1999) in which participants are placed in competition with an ostensible opponent. Based on reaction time outcomes, electrical shock levels are chosen and delivered to and from the competitors (e.g., the participant and the fictitious opponent). The level of aggression is determined by the frequency and magnitude of the shocks delivered by the participant.

The results showed that, for participants who competed against a gay male opponent after viewing male-male erotica, sexual prejudice and antigay anger were more positively associated with physical aggression than for participants who competed against a heterosexual male opponent. These results provide evidence that sexual prejudice is associated with antigay violence. One potential explanation for increases in anger among highly prejudiced participants is that they may adhere more strictly to traditional gender roles than participants who are not highly prejudiced. Similar to Haddock and Zanna's (1998) work on the relation between sexual prejudice and authoritarian personalities, more research is warranted to confirm this explanation. Another explanation for this 
finding is related to physiological responses to erotic stimuli. Past research (e.g., Lawrence, Chivers, \& Bailey, 2005; Rieger, Chivers, \& Bailey, 2005) documented differences between genital response patterns and subjective response patterns in individuals who were exposed to erotic video clips. This research suggests that physiological arousal, in addition to social attitudes, is an additional component that may be related to negative responses to homosexuality.

Bernstein (2004) took a sociological position on sexual prejudice by positing that it can be theorized in an historical context. She stated that, similar to what has been theorized about racial prejudice, individuals and organizations influence homophobia by disseminating information that hierarchically situates heterosexual people above homosexual people from a sociological standpoint. Using survey methods, she determined that group position scales explained a substantial proportion of variance in measures of homophobia.

Similar to what Bernstein (2004) suggested, much of the negativity toward homosexual people may be rooted in the pervasive beliefs of Judeo-Christian religious teachings (Brooke, 1993). Stein (2004) argued that the United States is unique in its citizens' views on homosexuality. He stated that US citizens are particularly polarized in their thoughts, in part because of an extreme dichotomization in beliefs (e.g., the rightwing Christian fundamentalist movement versus the gay and lesbian rights movement). Stein's (2004) stance is that this chasm serves to exacerbate polarization and to fuel debates on homosexuality that are not truly representative of views of the general population. Said differently, the conflicting view points of the religious right and the 
liberal left have created a divergence so severe that it has taken on a life of its own and has created the illusion that most US citizens fall into one of these extreme positions.

Although progress has been made toward understanding sexual prejudice in terms of its predictors, in terms of individual differences associated with it, and in terms of how it functions in relation to attitudes, stereotypes, and behaviors, there is much that remains unknown. Although a great deal of literature focuses on well-substantiated methods for studying other types of prejudice and attitude formations, there is a paucity of research that borrows these paradigms to examine sexual prejudice. Even sparser is the literature that specifically studies prejudice toward gay and lesbian parents. Given the rising number of children who are being raised by gays and lesbians and the extant, though meager, literature on the negative experiences of these families, this is but one area in which sexual prejudice research is clearly warranted.

\section{Measuring Prejudice}

In social cognition research, measurement techniques for prejudice are commonly categorized into two groups: implicit and explicit measures. Simply stated, implicit measures are indirect, unobtrusive techniques for collecting data, whereas explicit measures are direct techniques for obtaining information. Perhaps the most well known implicit measurement technique is the implicit association test (IAT; Greenwald et al., 1998).

The IAT was designed to assess the strength of association between a target and an attribute dimension. In a typical IAT task, participants are asked to assign stimuli to categories using response keys that have dual meanings. The latency with which 
participants are able to complete this task is the measure of interest. Greenwald et al.'s (1998) IAT consisted of asking participants first to categorize names as typical of Black people or White people. Then, participants were asked to categorize a series of clearly valenced words as pleasant or unpleasant. Finally, these tasks were combined so that, for some trials, a Black name was paired with a pleasantly valenced word, and for other trials, a Black name was paired with an unpleasantly valenced word. The response latency results of this study indicated that individuals had a more difficult time (i.e., responded more slowly) associating Black names with pleasantly valenced words.

The Affect Misattribution Procedure (AMP; Payne et al., 2005) is another example of an implicit measure. Based on established priming techniques, the AMP presents participants with a series of paired stimuli; the first stimulus, or prime, is an attitude object designed to evoke an affective reaction, and the second stimulus is an ambiguous symbol. Participants are asked to avoid making judgments about the prime; instead, they are instructed to rate the pleasantness of the ambiguous stimulus. Essentially, the AMP measures the affective transfer from the prime to the ambiguous stimulus. Similar to other implicit measures, the AMP is useful for assessing socially sensitive constructs because individuals are unaware that these constructs are being measured.

Implicit measures are not synonymous with implicit attitudes (Fazio \& Olson, 2003). That is, an implicit measure of a construct such as an attitude does not imply that the attitude itself is implicit, or that an individual is unaware of the attitude. The "implicit" in implicit measures simply refers to the fact that an individual is unaware that 
the attitude is being measured. The utility of implicit measures, then, is that they measure constructs that are not readily accessible via other methods (Hoffman et al., 2005).

Conversely, explicit measures are methods of estimating constructs via direct inquiry. Examples of explicit measures are ratings scales, questionnaires, and interviews. While explicit measures are usually easily administered and often possess sound psychometric properties, it is important to note that issues such as awareness, honesty, social desirability, and other response sets must be considered when interpreting the results of data from these methods of measurement.

\section{Relations between Implicit and Explicit Measures}

There has been considerable interest in the relation between implicit and explicit measures of the same construct. In theory, psychometrically sound instruments designed to measure the same construct should be positively correlated. The fundamental difference, however, between implicit and explicit measures - that implicit measures are unobtrusive, thereby making individuals unaware of the construct that is being measured - suggests that, at least in some cases, implicit and explicit measures should not be related.

Using Fazio's (1990) model to explain this concept, the magnitude of relation between implicit and explicit measures varies as a function of motivation and ability to control a response. Thus, differences in motivation and opportunity to select responses deliberately should lead to differences in correlations between measures. For instance, the lack of motivation or opportunity to select responses deliberately should produce low correlations between implicit and explicit measures. 
The construct under study must also be considered when examining the relations between implicit and explicit measures. When topics of interest are not socially sensitive, correlations between measures tend to be high, whereas socially sensitive topics tend to produce low correlations. An example of the variability of correlations due to social sensitivity was documented by Franco and Maass (1999) who found that the relation between implicit and explicit measures depended on whether outgroups were normatively protected. They predicted that explicit measures would be correlated with each other but not with implicit measures when the target group was not normatively protected. The results supported this prediction. When the target group was normatively protected (Jews), explicit measures correlated with each other but not with the implicit measure. In contrast, when the target group was not normatively protected. (Islamic Fundamentalists), explicit and implicit measures were significantly correlated.

Hoffman et al. (2005) suggested other possible explanations for why correlations between implicit and explicit measures tend to vary across studies. One potential reason is social desirability. Essentially, when individuals are motivated to respond in what is perceived as a socially appropriate manner, explicit measures will not be related to implicit measures which are unbiased by motivational influences. This hypothesis is consistent with Fazio's (1990) model. Another potential reason for the lack of relation between implicit and explicit measures is that implicit measures may tap representations that are not available for explicit report. Yet another reason for the lack of correlation is that implicit measures may tap old, automatically activated representations, as opposed to newly acquired ones. 
To better understand the relation between implicit and explicit measures, Hofmann et al. (2005) conducted a meta-analysis of several studies. The results indicated that correlations between implicit and explicit measures increased as a function of the spontaneity of responses. Hoffman et al. (2005) suggested that quick responses represented more automatically activated representations, whereas deliberated responses were more likely to represent information retrieved from long term memory. Therefore, when persons are not motivated to work to retrieve or deliberate over such information, explicit measures will be related to implicit measures.

More recently, Payne et al. (2008) examined the relation between implicit and explicit measures as a function of the similarity in task demands of each measure. That is, they investigated whether implicit and explicit measures became more strongly correlated as the tasks that participants were asked to engage in became more similar to each other. In a series of studies, they manipulated the AMP in multiple ways. In one study, they changed the metric of the AMP to a continuous 4-point scale so that it would correspond to the metric of the explicit measure they used. In another study, they asked participants to rate the prime (a photograph) rather than the target (an ambiguous symbol). Yet in another study, they varied the AMP task such that it became a task that used words rather than photographs, therefore more similar to the structure of an explicit measure that requires reading words. In essence the findings most relevant to the present study were that the relation between implicit and explicit measures became stronger as their structural similarity increased. Payne et al. (2008) offered these results as an explanation 
for the relatively low correlations between implicit and explicit measures that are found in the extant literature.

In addition to the relation between these measures, researchers have been increasingly interested in how well implicit and explicit measures predict behaviors. Karpinski and Hilton (2001) found no relation between food preferences demonstrated on an IAT and subsequent food choices. Similarly, Brochu and Morrison (2007) found that implicit attitudes toward overweight targets as measured by an IAT did not predict participants' willingness to interact with the targets. Other researchers, however, have reported significant relations between the IAT and overt behavior. For example, Greenwald and Farnham (2000) found a significant relation between self-esteem as measured by the IAT and behavioral reactions to success or failure. Asendorpf, Banse, and Mucke (2002) predicted interactions with strangers based on IAT measures of shyness. Turning to the use of implicit measures of prejudice, Dovidio et al. (2002) investigated White participants' perceptions of interracial interactions. They found that explicit measures predicted deliberative behaviors, whereas implicit measures predicted spontaneous behaviors.

Jellison, McConnell, and Gabriel (2004) predicted similar results with attitudes and behaviors directed at gay and heterosexual men. They found that implicit measures predicted ingroup preferences for gay and heterosexual men. Also, implicit and explicit measures were positively correlated in this study. The authors suggested that one potential reason for this relation was the nature of the design; only ingroup attitudes were assessed, and therefore concerns about social desirability were probably low. 


\section{Prejudice and Personality}

There has been longstanding interest in the role of personality in prejudice (Graziano et al., 2007; Reynolds, Turner, Haslam, \& Ryan, 2001). In general, the approach used to examine the relation between personality and prejudice has taken one of two routes: a focus on individual differences or a focus on intergroup relations. As noted by Crandall and Eshleman (2003), however, the individual differences approach has essentially been dismissed in recent years. The few studies that have addressed prejudice as a personality trait (Haddock \& Zanna, 1998; Parrott et al., 2002; Reynolds et al., 2001) have concentrated on individual difference variables such as right-wing authoritarianism (e.g., Altemeyer, 1988) and social dominance orientation. Similarly, a recent metaanalysis revealed that these constructs strongly predicted prejudice (Sibley \& Duckitt, 2009). Further, this meta-analysis indicated that prejudice was predicted by low Agreeableness, one of the Big Five personality factors commonly defined in terms of prosocial motivation, or the desire to engage in behavior that benefits others (Graziano \& Eisenberg, 1997). Similar findings were reported by Ekehammar and Akrami (2007) who found that Agreeableness predicted prejudiced attitudes.

Several studies have linked Agreeableness to overt behavior. Cuperman and Ickes (2009) examined the role of Big Five dimensions of personality, including Agreeableness, on interaction behaviors between dyads who were strangers, finding that initial interactions with others were generally more pleasant when at least one person in the dyad was an agreeable individual. Rothbart, Ellis, Rueda, and Posner (2003) examined Agreeableness as it relates to personality development, specifically, 
temperament. Agreeableness has also been studied in relation to effortful control (JensenCampbell, Rosselli, Workman, Santisi, Rios, \& Bojan, 2002; Kieras, Tobin, Graziano, \& Rothbart, 2005). Tobin, Graziano, Vanman, and Tassinary (2000) examined how Agreeableness influences emotional experience and expression. Agreeableness has also been studied in relation to competitiveness and cooperation (Graziano, Hair, \& Finch, 1997); interpersonal conflict (Graziano, Jensen-Campbell, \& Hair, 1996); and social desirability (Graziano \& Tobin, 2002). Of particular relevance to the present research, Agreeableness has been linked to attitudes toward diversity (Riemann, Grubich, Hempel, Mergel, \& Richter, 1993; Strauss, Connerley, \& Ammermann, 2003) and prejudice (Graziano et al., 2007).

One program of research that has explored the relation between prejudice and Agreeableness was conducted by Graziano and colleagues (2007). As a dimension of personality, Agreeableness encompasses tendencies such as being kind, considerate, cooperative, or likeable. In terms of daily social behaviors, Agreeableness is demonstrated by working to maintain good relations. Based on Crandall et al.'s (2002) assertion that prejudice expression was related to social norms, Graziano et al. (2007) theorized that the expression of prejudice was linked to Agreeableness, or the desire to maintain smooth relations with others. According to Graziano et al. (2007), an individual's decision to express prejudice is related to (a) whether the person holds a given prejudice and (b) whether the situation dictates the expression of prejudiced behavior. Linking this argument to Agreeableness, Graziano et al. posited that individuals 
high in Agreeableness would respond to prejudice-invoking stimuli according to the perceived normative appropriateness of prejudice expression.

Graziano et al. (2007) conducted a series of studies to examine the relation between Agreeableness and prejudice. One of their central hypotheses was that persons high in Agreeableness would actively work to suppress socially undesirable prejudices. One study involved the replication of some of Crandall et al.'s (2002) results concerning the social acceptability of several categories of prejudice. Participants were asked to rate either the social acceptability or their personal feelings about 105 social groups. Using Agreeableness, condition (social acceptability vs. personal feelings) and sex as predictors, the results indicated that Agreeableness was not related to normative beliefs. Agreeableness was related to personal feelings; persons high in Agreeableness reported fewer negative personal endorsements than did persons low in Agreeableness.

Particularly relevant to the present study, a separate regression conducted on traditional targets of prejudice, including people who are homosexual, revealed that persons low in Agreeableness were not only more negative in general than persons high in Agreeableness, but they also directed their negativity to traditional social outgroups such as gays and lesbians.

Another study in this line of research is pertinent to the present study. In Study 3, Graziano et al. (2007) employed a paradigm designed to measure prejudice against overweight individuals. Given a contrived situation involving an activity with a partner labeled as similar to them, individuals were given the option of abandoning a similar, overweight partner in favor of a dissimilar, unknown partner. It was hypothesized that, 
for persons high in Agreeableness, similarity would be enough reason to stay with their overweight partner despite any negative evaluations. Conversely, for persons low in Agreeableness, it was predicted that partner similarity would not overcome negative evaluations. Therefore, persons low in Agreeableness would abandon their overweight partners.

The analyses demonstrated that the only instances of partner abandonment occurred in the overweight partner condition. Of further interest, the only individuals who abandoned their overweight partners were men low in Agreeableness. According to Graziano et al. (2007), these data are indicative of blatant and selective discrimination against overweight individuals by men.

Taken together, the results of this line of research have two important implications for the present study. First, these results suggest that Agreeableness is likely to be a significant predictor of the expression of prejudice. Second, these data suggest that Agreeableness may moderate the relation between implicit measures of prejudice and prejudice behaviors.

Another indication of the potential role of Agreeableness in the current study is based on the recent work of Graziano and Tobin (2009) who suggested that Agreeableness is important to understanding interpersonal processes in that it may play a part in motivating behaviors that include prejudice suppression. They proposed a theoretical model in which Agreeableness activates an evolutionary fight-flight response in individuals such that persons high in Agreeableness would suppress negative attitudes toward traditional target outgroups. Similar to the findings of Graziano et al. (2007) that 
were previously discussed, this model suggests that Agreeableness plays a significant role in prejudice processes.

\section{Motivation to Control Prejudice}

There have been dramatic changes in self-reported attitudes about prejudice toward various outgroups over the past 50 years (Plant \& Devine, 1998). Prevailing social norms about the acceptability of expressing negative attitudes toward outgroups have changed and the notion of political correctness has greatly influenced interpersonal interactions. In light of these changes, researchers have tackled a new research question: Do these changes in self-reported attitudes reflect a sincere departure from prejudiced attitudes, or do they merely reflect an increased social pressure to suppress these attitudes? To begin to answer this question, new avenues of research have been generated to examine (a) whether changing social norms account for diminishing selfreports of prejudice; and (b) how and why some individuals respond differently to normative pressures to suppress prejudice whereas others do not (e.g., Dunton \& Fazio, 1997; Plant \& Devine, 1998).

In 1989, Devine stated that little was known about whether individuals can control the use of stereotypes across settings (e.g., work, school). Further, the contexts in which people have to manage the use of stereotypes are varied and the motivation to control their use varies from personal reasons to normative, or self-presentation, reasons. Devine (1989) argued that both the nature of the target group and the origins of the motivation to control the use of stereotypes toward the target group deserved consideration in the attempt to explain this phenomenon. 
A body of research suggests that stereotyping some groups is socially acceptable, whereas stereotyping other groups, publicly or privately, is not socially acceptable (Crandall et al., 2002). These differences, according to Devine (1989), could have important implications for the source of motivation to control stereotypes. Two such sources have been identified in the literature. Internal motivation to suppress prejudice has been conceived as resulting from personal, internalized standards. External motivation to suppress prejudice is conceived as resulting from pressure to comply with social norms.

Until recently, relatively few attempts have been made to assess internal and external sources of motivation to respond without prejudice. Dunton and Fazio (1997) developed a scale to measure the motivation to control prejudiced reactions toward people who are Black. Although this scale failed to produce statistically distinct internal and external motivation factors, it provided the foundation for future research in this area. Following this research, Plant and Devine (1998) set out to develop more psychometrically sound measures of internal and external motivation to respond without prejudice. Their major intent was to assess why individuals were motivated to respond without prejudice.

Plant and Devine (1998) addressed the issue of measuring motivation to respond without prejudice by developing the Internal Motivation to Respond without Prejudice Scale (IMS) and the External Motivation to Respond without Prejudice Scale (EMS). Similar to Devine (1989), they posited that the trend in self-reported attitudes about prejudice was a function of individuals' responses to the wave of political correctness 
that had swept the United States. In other words, people's changes in self-reported attitudes were only intended to create socially desirable impressions and were not indicative of true attitude changes. Both scales were found to have sound reliability with Cronbach alphas ranging from .76 to .85 and convergent and discriminant validity with other self-report measures of prejudice and social evaluation. Two distinct factors internal and external motivation - emerged to explain individuals' motivations to avoid prejudiced responses. Correlations between the IMS and EMS scales were small and negative.

Building on previous research, Devine et al. (2002) emphasized that people's efforts to control prejudiced reactions are conscious decisions. Possessing motivation to overcome these reactions, however, does not guarantee it will happen across situations. In this series of studies, Devine et al. (2002) collected implicit and explicit measures of racial bias and hypothesized that the motivation to control prejudice would moderate the relation between these scores. Implicit measures consisted of a sequential priming task in Study 1, an implicit association test (IAT) in Studies 2 and 3, and a cognitive busyness task in Study 3. The explicit measure for all studies consisted of a paper-pencil measure of attitudes toward people who are Black.

Using Plant and Devine's (1998) Internal and External Motivation to Control Prejudice Scales (IMS, EMS), they found that (a) all participants with high IMS reported positive attitudes toward people who are Black; (b) participants with high IMS and low EMS demonstrated lower levels of bias on the implicit measures than did high IMS high EMS persons; and (c) that low internal motivation levels predicted higher levels of 
prejudice on the explicit measure. These results suggested that persons who have high IMS and high EMS are more likely to transgress their internalized standards than persons with high IMS and low EMS.

Amodio, Harmon-Jones, and Devine (2003) extended this program of research by examining IMS and EMS as moderators on a physiological index of affective racial bias. They used a startle probe latency measure of eye blinks, which has been demonstrated to be responsive to affective responses (Lang, Bradley, \& Culthbert, 1990), as the physiological measure. Positive affect inhibits startle reactions, whereas negative affect amplifies startle reactions. The startle probe procedure involved measuring automatic eye blink responses induced by a short blast of white light. The probes were administered while participants viewed pictures of persons who are Black and White.

The researchers found that high IMS low EMS participants demonstrated lower levels of automatic bias than high IMS high EMS participants. Consistent with past research (e.g., Devine et al., 2002), the results suggest that individuals high in internal levels of motivation are able to regulate their responses more readily than others because their beliefs are internalized and thus more automatic. According to Amodio et al. (2003) these results may be interpreted to mean that some people who have low levels of prejudice sometimes spontaneously respond in a negative way. More specifically, some people who have high internal and external motivations to avoid prejudiced responses seem to be more prone to actions that conflict with their non-prejudiced beliefs than people who have high internal and low external motivations. These results suggest that both IMS and EMS factors should be carefully considered in future research. 
Crandall and Eshleman (2003) proposed a different framework in which to view the expression of prejudice. According to these researchers, most conceptualizations of prejudice expression are two factor theories. The first factor is genuine prejudice affective, primary beliefs that are negative and have motivational force. The second factor is the motivation to control genuine prejudice.

Crandall and Eshleman (2003) offered the justification-suppression model of prejudice. In this model, various factors (e.g., social, cultural, cognitive) lead to genuine prejudice, a powerful negative reaction to prejudice-evoking stimuli. Other forces such as social norms and personal beliefs work to suppress these negative reactions. A third factor, justification, allows for the expression of negative reactions when a person perceives it is acceptable. Therefore, prejudice that is normally suppressed can be expressed without guilt or shame. Crandall and Eshleman (2003) argued that genuine prejudice almost always undergoes the suppression and justification processes before it is acted upon and before they are internalized into a person's belief system. Using this model to conceptualize results of previous studies, when suppression of prejudice does not occur, the relation between genuine and reported prejudice is strong; conversely, when suppression is high and there is no justification for expressing genuine prejudice, the correspondence between genuine and reported prejudice is low.

Noting that traditional measures of racist attitudes have shown a downward trend of racial prejudice, Ziegert and Hanges (2005) determined a need to assess racism with measures that define it in more modern terms. They designed a study that compared traditional and modern racism scales. Additionally, they included an implicit attitude 
measure and a measure of the motivation to control prejudice. Similar to Devine et al. (2002), they hypothesized that the motivation to control prejudice would moderate the relations between implicit and explicit measures. Further, they anticipated that the correspondence would be stronger for traditional measures than for modern measures of racial attitudes. Their results supported these hypotheses and demonstrated that the motivation to control prejudice moderates the relation between implicit and explicit measures.

More recently, programs of research in the area of motivation to control prejudice have focused on individual differences, intergroup interactions, and self-regulation processes as they relate to the motivation to control prejudice. Devine, Brodish, and Vance (2005) wrote extensively on this program of research and presented a model of self-regulatory processes in interracial interactions. One important feature of this model is the inclusion of outcome expectancies, or people's expectancies that outcomes of their non-prejudiced responses will be positive or negative. Another important feature included in the model is that it is based on the assumption that people adopt one of two sets of standards in a given situation: other-imposed standards alone, or other-imposed standards and self-imposed standards.

Devine et al. (2005) developed this model because of the lack of research that examined these issues. They contended that the motivation to control prejudice significantly affects the extent to which individuals are concerned with appearing prejudiced. According to Devine and her colleagues, this model integrates much of the previously discussed literature on the motivation to control prejudice. They suggested 
that by taking into consideration both internal and external sources of motivation and attempting to find the reasons behind the motivation, much richer information about prejudice and its underlying causes can be better understood.

Further work on motivation by Plant and Devine (2009) focused not on the outcome itself (e.g., suppression of prejudice) but on the efforts put forth toward that outcome. Along the same lines as their work on internal and external motivation sources, Plant and Devine (2009) reasoned that some people would attempt to eliminate prejudice all together, while other people would put forth efforts to hide their prejudice from those who would disapprove of it. In a series of studies, they set out to examine the role of effort in the motivation to control prejudice by providing Caucasian participants with an opportunity to "learn" to act in a non-prejudiced way before having a scheduled interaction with an African-American person. In addition to being told about the program that could help them avoid seeming prejudiced, one-half of the participants were told that prejudiced behaviors would likely be detectable in the upcoming interaction while the other half of the participants were told that the prejudiced behaviors would likely go undetected. The findings demonstrated that persons who were high in EMS and low in IMS spent more time on the program in the detectable condition. That is, participants who were externally, but not internally, motivated to control prejudice spent more time on the program when they believed their behaviors would be detectable. Persons high in IMS spent considerable time on the program regardless of the detection condition, suggesting that they truly wanted to be non-prejudiced. Persons low in EMS spent little time on the program regardless of condition, and persons high in IMS, but low on EMS, 
also spent little time on the program. The authors reasoned that these participants may have believed that they were not prejudiced and therefore perceived little need for learning how to control it.

In subsequent studies in this series, Plant and Devine (2009) used the same paradigm as described above but first administered an IAT task and shared participants' results with them. Most of the findings were consistent with the aforementioned findings. One particularly interesting finding was that when participants who were high in IMS and low in EMS were shown their prejudiced IAT responses, they showed considerable interest in the program. This finding contradicts the findings from the first study in which high IMS-Low EMS individuals showed little interest in the program. The authors surmised from this finding that IMS is primary to EMS and that these individuals truly do possess the intention of avoiding prejudice. Also interesting was the finding that Low IMS-High EMS participants were not interested in decreasing undetectable prejudice, even when it was explained to them that spending time on the program would likely facilitate the upcoming interaction with the African-American person. This finding suggests that individuals with this profile are truly uninterested in being unprejudiced and that what is more important for them is not to be perceived that way.

In another line of research on the relation of motivation to control prejudice expression, Legault, Green-Demers, Grant, and Chung (2007) conceptualized motives through the lens of self-determination theory. Self-determination theory posits that as motives become more internalized or self-determined, the likelihood of acting in a manner that is consistent with these motives increases. Across three studies, they found 
that individuals whose motives to suppress prejudice were self-determined were more likely to actually suppress prejudice behavior than individuals whose motives to suppress prejudice were not self-determined. Based on these findings, Legault, Green-Demers, and Eadie (2009) further examined the motivation to control prejudice in the context of automatic responses to prejudicial stimuli. They hypothesized that individuals who rehearse prejudice regulation because it is a personally important goal have automatically activated suppression mechanisms. Their results confirmed their hypotheses. Participants who were self-determined were able to inhibit automatically activated stereotypes before using them to make negative evaluations. These findings contrast with some previous theories (i.e., Devine, 1989) about the motivation to suppress prejudice and offer directions for future research that attempts to understand prejudice processes more fully.

Taken together, the recent research related to the motivation to control prejudice suggests that it remains a complex mechanism that will require additional study to understand completely. What is clear is that the source of motivation plays a key role in determining attitudinal and behavioral outcomes of automatically activated stereotypes.

The Present Study

The goal of the current study is to glean new information on sexual prejudice and to determine the extent to which teachers have implicit and explicit prejudicial attitudes and behaviors toward gay and lesbian parents. To accomplish this goal, a two-phase study was conducted. In the first phase, participants were asked to complete implicit and explicit measures of sexual prejudice as well as personality measures. In the second phase, participants were asked to complete a brief personality measure before they were 
assigned to complete an interview task with a fictitious parent. In the second phase, participants were randomly assigned to one of four conditions: similar heterosexual parent, dissimilar heterosexual parent, similar homosexual parent, and dissimilar homosexual parent. In the similar heterosexual parent condition, participants had an interview partner who was heterosexual and similar to the participant in terms of personality. In the dissimilar heterosexual parent condition, participants had a parent who was heterosexual and dissimilar to the participant in terms of personality. In the similar homosexual parent condition, participants had a parent who was homosexual and similar to the participant in terms of personality. Finally, in the dissimilar homosexual parent condition, participants had a parent who was homosexual and dissimilar to the participant in terms of personality. Following assignment of interview partner, participants were given the opportunity to change partners because of an ostensible experimenter error, based on the Graziano et al. (2007) paradigm. They were also asked to complete a social distance measure to assess prejudice behavior further.

Based on the literature, seven hypotheses were tested. First, I expected that participant scores on the implicit measure (AMP) would be higher for homosexual primes than for heterosexual primes. That is, prime-target pairs with homosexual primes would receive significantly more "unpleasant" responses than prime-target pairs with heterosexual primes. Further, it was predicted that participants would report more prejudice toward gay male parents than they would toward lesbian parents. Second, I expected that implicit measures of sexual prejudice would be correlated with explicit measures of sexual prejudice. Third, I predicted that participants' Agreeableness would 
be negatively correlated with explicit measures of prejudice. Fourth, I predicted that the implicit measure of prejudice would be related to prejudice behavior. Fifth, I predicted that teachers' Agreeableness would predict prejudice behaviors. Finally, I expected that the interaction between Agreeableness and implicit prejudice would predict prejudice behaviors. Specifically, I predicted that individuals low in Agreeableness and high in implicit prejudice would demonstrate the greatest prejudice behavior, that individuals low in Agreeableness and high in implicit prejudice would not differ significantly from individuals high in Agreeableness and high in implicit prejudice, and that individuals high in Agreeableness and low in implicit prejudice would demonstrate the least prejudice behaviors.

In addition to testing these hypotheses, I also conducted some exploratory analyses on these data. Based on the literature, it was unclear whether and how Agreeableness, motivation to control prejudice, suppression of prejudice, and implicit prejudice would interact as predictors of prejudice behavior. Thus, my exploratory analyses focused on describing the effects related to these interactions. 


\section{CHAPTER III \\ RESEARCH DESIGN}

\section{Overview}

Conceptually, the overall design consisted of a 2 (parent: heterosexual vs. homosexual) x 2 (similarity: similar vs. dissimilar parent) $x 2$ (sex: male vs. female participant) x 2 (Agreeableness: high vs. low) factorial design. Parent, similarity, sex, and Agreeableness were between-subjects variables, and the study consisted of two phases.

The first phase of the study consisted of recruiting students from a Midwestern university for participation in several mass testing sessions. Efforts were made to recruit pre-service teachers in this sample. During this portion of the study, data were collected in the form of questionnaires and a modified version of the Affect Misattribution Procedure (AMP; Payne et al., 2005; Patel, Pryor, Monroe, \& Reeder, 2008; Patel, Pryor, Reeder, \& Monroe, 2007). Following mass testing, participants were recruited by telephone and email for the second phase of the study that consisted of an experimental manipulation designed to measure prejudicial behavior and attitudes. At the conclusion of Phase 2, participants received $\$ 5$ for participation. Additionally, if participants were enrolled in a psychology course at the time of participation, they received extra credit commensurate with the amount of time committed to be in the study. Participants received separate extra credit for Phase 1 and Phase 2 participation. Two phases were 
employed to minimize the chances that participants would realize the true intent of the study.

Participants

Phase 1. Participants were recruited via classroom visits during which researchers described the study broadly and the benefits of participating in it, including extra credit in a psychology course. Students were also recruited via the Psychology Department subject pool at a Midwestern university. A total of 562 (126 male and 436) pre-service teachers or students enrolled in psychology courses participated in Phase 1. Their ages ranged from 18 to $57(M=19.90, S D=3.48)$. Due to missing data, some analyses included fewer participants than the total number of participants in the study.

Table 1 presents the participants' age, sex, and ethnic/racial background, and Table 2 presents the participants' college major. Four participants reported that they read Chinese and therefore were excluded from the analyses. Ten participants did not report race. Seven participants did not report their college major. Of the 553 participants who reported their sexual orientation, 535 identified themselves as heterosexual, 11 identified themselves as bisexual, and 6 identified themselves as homosexual. One individual responded by marking "Other." To examine the possibility that the inclusion of nonheterosexual participants influenced the pattern of results, all analyses were rerun with self-reported heterosexuals only. In all cases the pattern of results did not change. Table $\mathrm{C} 1$ presents correlations for all Phase 1 predictors. 
Table 1

Race/Ethnicity and Sex of Phase 1 Participants

\begin{tabular}{|c|c|c|c|c|c|c|}
\hline \multirow[b]{2}{*}{ Race/Ethnicity } & \multicolumn{2}{|c|}{ Male } & \multicolumn{2}{|c|}{ Female } & \multicolumn{2}{|c|}{ Total } \\
\hline & $n$ & $\%$ & $n$ & $\%$ & $n$ & $\%$ \\
\hline $\begin{array}{l}\text { African- } \\
\text { American }\end{array}$ & 3 & 2.5 & 18 & 4.2 & 21 & 3.8 \\
\hline $\begin{array}{l}\text { American } \\
\text { Indian/Alask } \\
\text { an Native }\end{array}$ & 0 & 0.0 & 1 & 0.2 & 1 & 0.2 \\
\hline Asian/Pacific & & & & & & \\
\hline Islander & 3 & 2.5 & 9 & 2.1 & 12 & 2.2 \\
\hline Caucasian & 108 & 90 & 390 & 90.3 & 498 & 90.2 \\
\hline Hispanic/Latino & 5 & 4.2 & 11 & 2.5 & 16 & 2.9 \\
\hline Other & 1 & 0.8 & 3 & 0.7 & 4 & 0.7 \\
\hline Totals & 120 & 100.0 & 432 & 100.0 & 552 & 100.0 \\
\hline
\end{tabular}

Table 2

Participants by Sex and Major for Phase 1

\begin{tabular}{|c|c|c|c|c|c|c|}
\hline \multirow[b]{2}{*}{ Major } & \multicolumn{2}{|c|}{ Male } & \multicolumn{2}{|c|}{ Female } & \multicolumn{2}{|c|}{ Total } \\
\hline & $n$ & $\%$ & $n$ & $\%$ & $n$ & $\%$ \\
\hline Education & 50 & 40.7 & 216 & 50.0 & 266 & $\overline{47.9}$ \\
\hline Psychology & 15 & 12.2 & 55 & 12.7 & 70 & 12.6 \\
\hline Other & 57 & 46.3 & 138 & 31.9 & 195 & 35.1 \\
\hline Undeclared & 1 & 0.8 & 23 & 5.3 & 24 & 4.3 \\
\hline Totals & 123 & 100.0 & 432 & 100.0 & 555 & 100.0 \\
\hline
\end{tabular}

Phase 2. Of the 562 individuals who participated in the first phase of the study, $372(66.20 \%)$ agreed to be invited back for additional studies. Of these individuals, 203 (47 men and 156 women) participated in Phase 2. Their ages ranged from 18 to $57(M=$ $19.70, S D=4.57)$. Of the 201 participants who reported their sexual orientation, 194 
identified themselves as heterosexual, 4 identified themselves as bisexual, and 2 identified themselves as homosexual. One individual responded by marking "Other." Three participants did not report race. Table 3 presents the participants' age, sex, and ethnic/racial background, and Table 4 presents the participants' college major.

Table 3

Race/Ethnicity and Sex for Phase 2 Participants

\begin{tabular}{|c|c|c|c|c|c|c|}
\hline \multirow[b]{2}{*}{ Race/Ethnicity } & \multicolumn{2}{|c|}{ Male } & \multicolumn{2}{|c|}{ Female } & \multicolumn{2}{|c|}{ Total } \\
\hline & $n$ & $\%$ & $n$ & $\%$ & $\bar{n}$ & $\%$ \\
\hline $\begin{array}{l}\text { African- } \\
\text { American }\end{array}$ & 0 & 0.0 & 8 & 5.1 & 8 & 4.0 \\
\hline $\begin{array}{l}\text { American } \\
\text { Indian/Alaska } \\
\text { n Native } \\
\text { Asian/Pacific }\end{array}$ & 0 & 0.0 & 1 & 0.6 & 1 & 0.5 \\
\hline $\begin{array}{l}\text { Aslan/Pacific } \\
\text { Islander }\end{array}$ & 1 & 2.3 & 4 & 2.6 & 5 & 2.5 \\
\hline Caucasian & 41 & 93.3 & 136 & 87.2 & 177 & 88.5 \\
\hline Hispanic/Latino & 1 & 2.3 & 6 & 3.8 & 7 & 3.5 \\
\hline Other & 1 & 2.3 & 1 & 0.6 & 2 & 1.0 \\
\hline Totals & 44 & 100.0 & 156 & 100.0 & 200 & 100.0 \\
\hline
\end{tabular}

Table 4

Participants by Sex and Major for Phase 2

\begin{tabular}{lrrrrrrrr}
\hline & \multicolumn{2}{c}{ Male } & & \multicolumn{2}{c}{ Female } & & \multicolumn{2}{c}{ Total } \\
\cline { 2 - 5 } \cline { 8 - 9 } Major & $n$ & $\%$ & & $n$ & $\%$ & & $n$ & $\%$ \\
\hline Education & 25 & 55.6 & & 67 & 43.2 & & 92 & 46.0 \\
Psychology & 5 & 11.1 & & 23 & 14.8 & & 28 & 14.0 \\
Other & 15 & 33.3 & & 59 & 38.1 & & 74 & 37.0 \\
Undeclared & 0 & 0.0 & & 6 & 3.9 & & 6 & 3.0 \\
Totals & 45 & 100.0 & & 155 & 100.0 & & 200 & 100.0 \\
\hline
\end{tabular}


Independent samples t-tests were conducted to determine whether differences existed between individuals who participated in Phase 1 only and individuals who participated in both Phase 1 and Phase 2. Table 5 shows that the analyses revealed no evidence of significant differences between these groups on Phase 1 measures.

Table 5

Means and Standard Deviations of Phase 1 Variables by Participation in Phase 1 Only or Phase 1 and Phase 2

\begin{tabular}{|c|c|c|c|c|c|c|c|c|}
\hline \multirow[b]{2}{*}{ Prime Type } & \multicolumn{3}{|c|}{ Phase 1} & \multicolumn{5}{|c|}{ Phase 1 and Phase 2} \\
\hline & $n$ & Mean & $\mathrm{SD}$ & $n$ & Mean & $\mathrm{SD}$ & $\begin{array}{c}t \\
\text { value }\end{array}$ & $\begin{array}{c}p \\
\text { value } \\
\end{array}$ \\
\hline Gay all & 354 & 1.50 & 0.21 & 202 & 1.48 & 0.21 & -1.27 & .20 \\
\hline Gay kissing & 354 & 1.68 & 0.28 & 202 & 1.64 & 0.27 & -1.47 & .14 \\
\hline Gay families & 354 & 1.32 & 0.26 & 202 & 1.31 & 0.26 & -0.51 & .61 \\
\hline Lesbian all & 354 & 1.00 & 1.00 & 202 & 1.45 & 0.20 & -0.74 & .46 \\
\hline $\begin{array}{l}\text { Lesbian } \\
\text { kissing }\end{array}$ & 354 & 1.57 & 0.31 & 202 & 1.56 & 0.30 & -0.10 & .92 \\
\hline $\begin{array}{l}\text { Lesbian } \\
\quad \text { families }\end{array}$ & 354 & 1.35 & 0.24 & 202 & 1.33 & 0.24 & -1.07 & .29 \\
\hline $\begin{array}{l}\text { Heterosexual } \\
\text { all }\end{array}$ & 354 & 1.26 & 0.21 & 202 & 1.27 & 0.21 & 0.70 & .49 \\
\hline $\begin{array}{l}\text { Heterosexual } \\
\text { kissing }\end{array}$ & 354 & 1.25 & 0.20 & 202 & 1.27 & 0.21 & 1.08 & .28 \\
\hline $\begin{array}{l}\text { Heterosexual } \\
\text { families }\end{array}$ & 354 & 1.26 & 0.25 & 202 & 1.27 & 0.24 & 0.27 & .79 \\
\hline Neutral & 354 & 1.49 & 0.31 & 202 & 1.53 & 0.30 & 1.41 & .16 \\
\hline $\begin{array}{l}\text { External } \\
\text { motivation }\end{array}$ & 350 & 5.17 & 1.96 & 197 & 5.06 & 1.87 & -0.63 & .53 \\
\hline $\begin{array}{l}\text { Internal } \\
\text { motivation }\end{array}$ & 350 & 6.73 & 1.95 & 197 & 6.88 & 1.98 & 0.84 & .40 \\
\hline Suppression & 354 & 5.42 & 1.49 & 202 & 5.42 & 1.42 & -0.01 & 1.00 \\
\hline MHNS-G & 353 & 34.49 & 1.00 & 202 & 33.94 & 1.00 & -0.60 & .55 \\
\hline MHNS-L & 351 & 32.91 & 1.00 & 202 & 32.49 & 1.00 & -0.47 & .64 \\
\hline Agreeableness & 354 & 3.97 & 0.59 & 202 & 3.94 & 0.59 & -0.41 & .68 \\
\hline
\end{tabular}




\section{Stimulus Materials}

Implicit measure of prejudice. The Affect Misattribution Procedure (AMP; Payne et. al., 2005) is an example of an implicit association test (IAT) that is designed to measure implicit attitudes. The IAT has been used in social cognition research to measure unobtrusively constructs ranging from self-esteem to stereotypes (Fazio \& Olson, 2003). For the present study, the AMP was modified to measure implicit attitudes toward gay and lesbian parents, consistent with previous time modifications by Pryor and colleagues (Patel et al., 2007; 2008). The procedure involved rating a series of stimuli displayed using an overhead computer projector. The stimuli consisted of a series of 84 pairs of photographs (primes) and ambiguous symbols (targets). The photographs showed people involved in two types of activities: couples kissing and families with children (36 each). Of the photographs of couples kissing, there were photographs of gay male couples kissing, lesbian couples kissing, and heterosexual couples kissing (12 each). To control for potential racial prejudice, all persons in all photographs were Caucasian. Photographs were matched on background (e.g., setting, activity) and number of children in the photograph, and they were piloted to determine the saliency of the family composition (i.e., how obvious it was that the parents are homosexual or heterosexual couples). Additionally, there were 12 neutral primes that consisted of an image of a gray square. Internal consistency, as measured by Cronbach's alpha, for the photographs used for the AMP are presented in Table 6. 
Table 6

Cronbach's Alpha for AMP Photographs by Person and Activity

\begin{tabular}{lc}
\hline Prime Type & Cronbach's Alpha \\
\hline Gay Kissing & .83 \\
Gay Families & .75 \\
Lesbian Kissing & .86 \\
Lesbian Families & .76 \\
Heterosexual Kissing & .70 \\
Heterosexual Families & .81 \\
Neutral & .85 \\
All primes combined & .86 \\
\hline
\end{tabular}

Each prime was paired with a target figure represented by a Chinese pictograph. A unique pictograph was used for each prime. To control for order effects, participants were randomly assigned to one of two presentation orders of the pairs. Using an adapted version of the Payne et al. (2007) paradigm, the prime was presented for $1 \mathrm{~s}$, followed by a blank screen for $1 \mathrm{~s}$. Then, the target pictograph appeared for $1 \mathrm{~s}$, followed by a blank screen that appeared for $5 \mathrm{~s}$. During that time, participants responded to the target pictograph by marking "Pleasant" or "Unpleasant" on a response sheet that was provided. At the end of the 5-s time period, an audible cue instructed participants that the next pair of stimuli was about to appear. The cue consisted of a computerized sound byte that said the number of the pair about to be rated (i.e., one, two, three).

Explicit measure of prejudice. Similar to explicit measures of other targets of prejudice (e.g., racial/ethnic minorities, women), the content of scales designed to 
measure prejudice have changed over the past 40 years to reflect more modern forms of prejudice expression (McConahay \& Hough, 1976; Walls, 2008). Consistent with changes in cultural beliefs about prejudice, researchers have found that attitudes toward outgroups have shifted from traditional hostility to more subtle types of prejudice expression (e.g., public policy). Therefore, scales have emerged that have been shown to tap into more modern attitudes toward targeted groups. For this study, explicit attitudes toward gay and lesbian parents were measured using the Modern Homo-negativity Scale (MHNS; Morrison \& Morrison, 2002), a scale designed to assess modern attitudes toward gay men and lesbians. There are separate scales for gay men (MHNS-G) and for lesbians (MHNS-L). Each scale has 12 items, and therefore scores can range from 12 to 60 , with higher scores indicating more prejudice. Internal consistency of this scale, as measured by Cronbach's alpha, was .89 for the MHNS-G and .90 for the MHNS-L with this sample.

Motivation to respond without prejudice. The extent to which individuals expressed prejudice was measured using the original and an adapted version of the Internal and External Motivation to Respond without Prejudice Scale (Plant \& Devine, 1998). The authors reported reliability estimates for the Internal and External scales that range between .76 and .85 . Additionally, they reported correlations between the Internal and External scales that ranged between -.14 and -.15 , demonstrating that the scale is tapping distinct and independent sources of motivation. The authors also reported that the scales also have good convergent and discriminant validity with other prejudice measures 
such as the Motivation to Control Prejudiced Reactions Scale (Dunton \& Fazio, 1997) and the Modern Racism Scale (MRS; McConahay, Hardee, \& Batts, 1981).

Because this scale was developed to assess prejudice toward Black people, an adapted version of the scale was also used to assess prejudice toward homosexual people. Consistent with previous research, the scale consistency of the Internal and External Scales, as measured by Cronbach's alpha, were .85 and .74 , respectively, for Black people, and .89 and .80 , respectively, for homosexual people.

Suppression of prejudice. The Suppression of Prejudice Scale (Crandall et al., 2003) was developed to serve as a broader measure of prejudice suppression. Specifically, the scale assesses individual differences in the internal motivation to suppress prejudice, or the desire to appear non-prejudiced. The scale was negatively correlated with the Modern Racism Scale (McConahay et al., 1981) and was positively correlated with Dunton \& Fazio's (1997) Concern scale of the Motivation to Control Prejudiced Reactions in previous research. In this study, the internal consistency of the Suppression of Prejudice Scale, as measured by Cronbach's alpha, was .73.

Personality. The Big Five Inventory (BFI; John \& Srivastava, 1999) was administered to assess personality. More specifically, the BFI provided Agreeableness scores for each participant. In this study, the BFI was administered twice. During Phase 1 , it was administered as part of large screening sessions. During Phase 2, it was administered as part of the deception; participants were told that their scores on a personality measure would determine which parent they would interview. The correlation between administrations of Agreeableness was .73, $p<.001$. Internal consistency of 
Agreeableness scores for both administrations, as measured by Cronbach's alpha, was 77. Agreeableness scores from Phase 1 will be used in our analyses.

In addition to these measures, participants responded to questions regarding the number of gay men and lesbians they knew. These data are provided in Tables 7 and 8 .

Table 7

Number of Known Gay Men and Lesbians by Phase 1 Participants $(N=562)$

\begin{tabular}{|c|c|c|c|c|c|c|c|c|}
\hline \multirow[b]{2}{*}{ Frequency } & \multicolumn{4}{|c|}{ Gay Men } & \multicolumn{4}{|c|}{ Lesbians } \\
\hline & 0 & $1-3$ & $4-6$ & $\geq 7$ & 0 & $1-3$ & $4-6$ & $\geq 7$ \\
\hline $\begin{array}{c}\text { Immediate } \\
\text { family } \\
\text { member }\end{array}$ & 527 & 27 & 1 & 0 & 529 & 20 & 5 & 0 \\
\hline $\begin{array}{l}\text { Extended family } \\
\text { member }\end{array}$ & 440 & 100 & 4 & 10 & 476 & 64 & 2 & 11 \\
\hline Close friend & 324 & 197 & 24 & 10 & 415 & 111 & 19 & 7 \\
\hline Other & 183 & 269 & 74 & 23 & 274 & 224 & 35 & 13 \\
\hline
\end{tabular}


Table 8

Number of Known Gay Men and Lesbians by Phase 2 Participants $(N=203)$

\begin{tabular}{|c|c|c|c|c|c|c|c|c|}
\hline \multirow[b]{2}{*}{ Frequency } & \multicolumn{4}{|c|}{ Gay men } & \multicolumn{4}{|c|}{ Lesbians } \\
\hline & 0 & $1-3$ & $4-6$ & $\geq 7$ & 0 & $1-3$ & $4-6$ & $\geq 7$ \\
\hline $\begin{array}{l}\text { Immediate } \\
\text { family } \\
\text { member }\end{array}$ & 189 & 10 & 1 & 0 & 192 & $\overline{5}$ & 2 & 0 \\
\hline $\begin{array}{c}\text { Extended } \\
\text { family } \\
\text { member }\end{array}$ & 149 & 48 & 2 & 2 & 169 & 26 & 2 & 2 \\
\hline Close friend & 106 & 80 & 9 & 5 & 148 & 41 & 6 & 3 \\
\hline Other & 64 & 94 & 30 & 10 & 94 & 85 & 10 & 7 \\
\hline
\end{tabular}

Behavioral measures. For the second phase of the study, participants were told that they would participate in a brief activity in which they would act as interviewers. They were told that the purpose of the study was to examine how the similarity of an interviewer's personality to an interviewee's personality affected the amount and quality of information gleaned from the interview. Further, they were told that for this study, the primary interest of the experimenter was family interview processes and that a group of parents has been recruited to participate as interviewees. These instructions created the prospect of future interaction with the ostensible partner. The behavioral measure of prejudice was participants' decisions to change partners or remain with the one assigned. A behavioroid questionnaire (e.g., Aronson \& Carlsmith, 1963) designed to measure participant beliefs about how they would behave in a given situation was also 
administered to assess prejudicial reactions to partners, namely the social distance measure.

\section{Procedure}

Phase 1

The Affect Misattribution Procedure (AMP) and questionnaires were administered during mass testing sessions. Participants arrived at a classroom equipped with a computer connected to a digital projector. They sat at desks and were given packets containing AMP response sheets and questionnaires. The AMP was administered first, followed by the questionnaires. For the AMP, participants were told that they would see pairs of pictures flashed one after the other - a real-life photograph followed by a Chinese character. They were told that the photograph was a signal that the Chinese character would soon appear and that they should do nothing with it. Their job, the participants were told, was to judge the visual pleasantness of the Chinese character. They were instructed to respond to the pictograph as quickly as possible by marking "Pleasant" or "Unpleasant" on the response provided. Participants were told that an audio cue stating the slide number they were rating would alert them to prepare for each new pair of stimuli. Participants responded to each prime-target pair once for a total of 84 trials. The AMP administration lasted approximately 11 minutes.

After the AMP, participants completed the questionnaire portion of the study. At the conclusion of each session, participants were debriefed, thanked for their participation, and given extra credit slips if they were enrolled in a psychology course. Additionally, participants were told that they were eligible for participation in future 
studies, at least one of which offered monetary compensation. They were asked to sign a consent form stating whether they agreed to be contacted for future research studies.

\section{Phase 2}

Before participants arrived, each was randomly assigned to either a similar or dissimilar parent condition. Between 1 and 4 participants signed up for each session which lasted no more than half an hour. Experimenters led participants to separate rooms where the purpose of the study and the activity to be completed was explained. After filling out consent forms, participants were told that they would fill out a brief personality questionnaire that would be scored and compared to participating parents' scores (i.e., the interviewees) and then matched with either a similar or dissimilar parent for a brief structured interview activity. Participants filled out the questionnaire and waited for the experimenter to collect it. They were instructed to wait in the room while their information was being matched to a similar or dissimilar parent who was in the waiting room. After approximately 10 minutes, the experimenter returned to the room with a file folder. One half of participants were told that they had been matched with similar parents, whereas the other half of participants was told that they had been matched with dissimilar parents. All participants were instructed to review the file that contained demographic information about the interviewee's family.

Each file folder contained a photograph of the family on the inner left-hand side and a sheet of paper with demographic information on the inner right-hand side. This information consisted of names and ages of the parents and children. As part of the 
experimental manipulation, one half of the parents interviewed were part of families with heterosexual parents, and the other half were part of families with gay male parents. To control for potential racial prejudice, all families were Caucasian.

The experimenter left the participant with the file folder for about 2 minutes ostensibly to get the parent from the waiting room. Upon returning to the room, the experimenter explained that a mistake had been made and that participants were supposed to make their own decision regarding whether to do the activity with a similar or dissimilar parent. Participants were told to choose between the similar/dissimilar parent, with whom they had already been matched, and a similar/dissimilar parent who was also participating in the study. Participants were assured that there was no penalty for switching and that the experiment would take no longer than normal if they decided to switch interview partners. They were encouraged to make their decision quickly. Once the decision was made, participants were instructed to complete a social distance questionnaire based on attraction-based impression formation research (Snyder \& Haugen, 1994; Stangor, 2000). Referring to the parent whose information they were provided, participants were asked to rate the extent to which they looked forward to meeting that parent, would introduce him to family, and would enjoy spending time with him. These items were presented on a scale anchored by 1 (strongly disagree) and 5 (strongly agree). They were averaged to form a single composite measure of prejudice. The internal reliability of the social distance questionnaire, as measured by Cronbach's alpha, was 0.82 . Refer to Appendix A for the social distance items. In addition to the social distance questionnaire, data were collected on participants' decisions to switch to 
an unknown interviewee or to stay with the interviewee whose photograph and family compositions they viewed. After this decision was recorded and participants completed the social distance questionnaire, participants were debriefed using a funnel format and thanked for their participation. Participants were paid $\$ 5$ cash and given extra credit if they were currently enrolled in a psychology course.

In line with ethical guidelines put forth by the American Psychological Association, participants gave informed consent and were apprised of their right to withdraw from the study at any time without penalty. Additionally, participants were fully debriefed after the study. The data are confidential and are kept in a secure location. This study was approved by the Institutional Review Board at the university at which the research was conducted. 


\section{CHAPTER IV}

\section{ANALYSIS OF THE DATA \\ Preliminary Analyses}

\section{Analysis of Undergraduate Major}

The overarching purpose of this study was to examine teacher attitudes toward gay and lesbian parents. As such, an effort was made to recruit pre-service teachers as participants. My Phase 1 sample contained $48.2 \%$ education majors. I conducted a series

of analyses to ascertain whether differences existed between the responses of participants who were education majors and participants who were not education majors. First, I conducted a two-way, repeated measures MANOVA to examine differences in AMP responses. The dependent variable was ratings of AMP stimuli. The within-subjects factors were activity portrayed in AMP photographs with two levels (activity: couples kissing and couples in families) and sexual orientation of individuals portrayed in photographs with three levels (sexual orientation: gay male couples, lesbian couples, and heterosexual couples). The between-subjects factor was college major (education vs. noneducation major). Planned pairwise comparisons were also conducted using Bonferroni corrections for multiple comparisons.

Based on this analysis, there was no evidence that the three-way interaction between activity, sexual orientation, and major was significant, Wilks's $\Lambda=0.99, F(2$, $547)=1.56, p=.21$, partial $\eta^{2}=.006$. Similarly, there was no evidence that the between- 
subjects effect of major was significant, $F(1,54)=0.02, p=.89$. The results of the MANOVA indicated a significant main effect for activity, (Wilks's $\Lambda=.63, F[1,548]=$ 324.33, $p<.001$ ) and a significant main effect for sexual orientation, (Wilks's $\Lambda=.62$, $F[2,547]=168.47, p<.001)$; these effects, however, were qualified by significant twoway interactions.

There was a significant two-way interaction between major and sexual orientation, Wilks's $\Lambda=.99, F(2,547)=3.95, p=.02$, partial $\eta^{2}=.014$. Education majors rated prime-target pairs with gay male photographs $(M=1.48, S D=0.20)$ as significantly less pleasant than prime-target pairs with heterosexual photographs $(M=$ $1.27, S D=0.21), t(547)=10.79, p<.001$. Similarly, non-education majors rated primetarget pairs with gay male photographs as significantly less pleasant than prime-target pairs with heterosexual photographs $(M=1.25, S D=0.20), t(547)=14.44, p<.001$.

Education majors rated lesbian prime-target pairs $(M=1.46, S D=0.18)$ as significantly less pleasant than heterosexual photographs, $t(547)=11.18, p<.001$. Similarly, non-education majors rated prime-target pairs with lesbian photographs as significantly less pleasant than heterosexual photographs, $t(547)=12.5, p<.001$.

There was no evidence of a significant difference between education majors' ratings of prime-target pairs with gay male photographs and prime-target pairs with lesbian photographs, $t(547)=1.33, p=.59$. A different pattern emerged for noneducation majors who rated prime-target pairs with photographs of gay males $(M=1.51$, $S D=0.22$ ) as significantly less pleasant than prime-target pairs with photographs of lesbians $(M=1.45, S D=0.20), t(547)=5.00, p<.001$. 
As shown in Figure 1, there was also a significant two-way interaction between activity and sexual orientation, Wilks's $\Lambda=.44, F(2,547)=354.07, p<.001$, partial $\eta^{2}=$ .564. Prime-target pairs with gay males kissing $(M=1.67, S D=0.28)$ were rated as significantly less pleasant than prime-target pairs with lesbians kissing $(M=1.57, S D=$ $0.30), t(547)=7.69, p<.001$. Similarly, prime-target pairs with gay males kissing were rated as significantly less pleasant than prime-target pairs with heterosexuals kissing $(M=$ $1.26, S D=0.20), t(547)=25.75, p<.001$. Finally, prime-target pairs with lesbians kissing were rated as significantly less pleasant than prime-target pairs with heterosexuals kissing, $t(547)=19.5, p<.001$.

Prime-target pairs with lesbians portrayed in families $(M=1.34, S D=0.24)$ were rated as significantly less pleasant than prime-target pairs with gay males portrayed in families $(M=1.32, S D=0.26), t(547)=-3.13, p=.01$. Prime-target pairs with gay males portrayed in families were rated as significantly less pleasant than prime-target pairs with heterosexuals portrayed in families $(M=1.27, S D=0.25), \mathrm{t}(547)=4.08, p<.001$.

Finally, prime-target pairs with lesbians portrayed in families were rated as significantly less pleasant than prime-target pairs with heterosexuals portrayed in families, $t(547)=$ $6.50, p<.001$. 


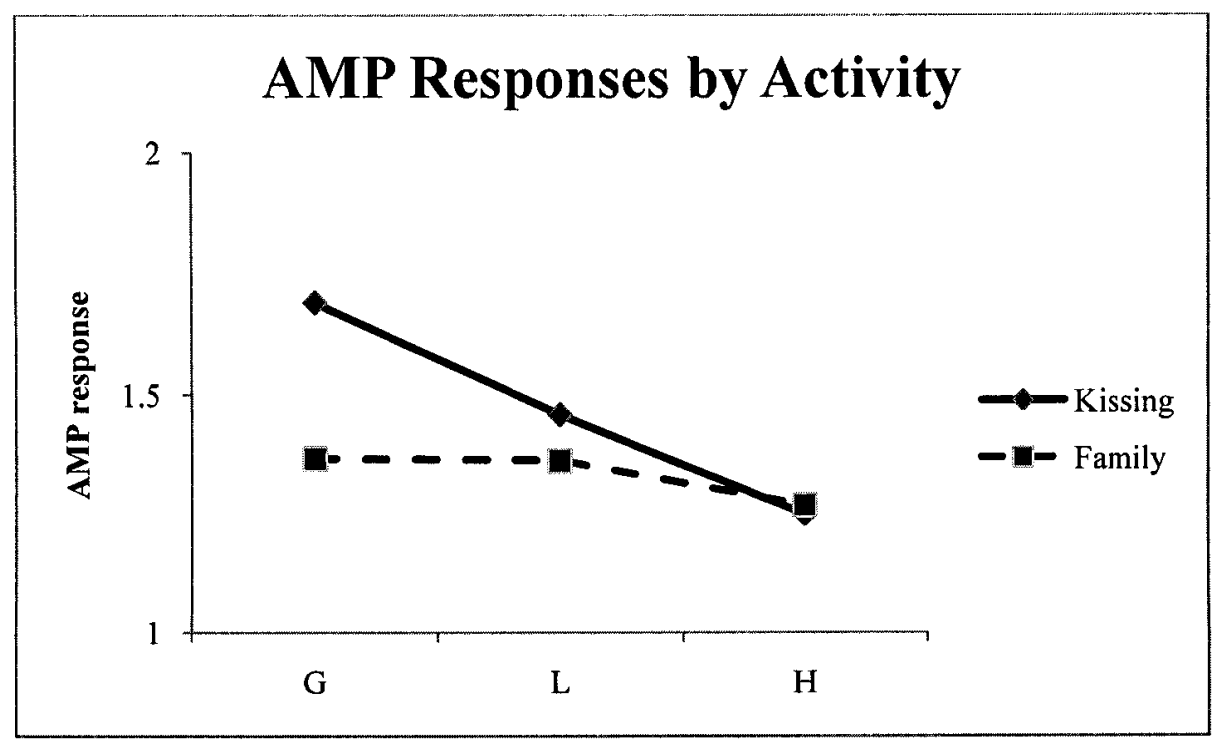

Figure 1. AMP responses to photographs of gay men, lesbians, and heterosexuals by activity.

As shown in Figure 2, there was a significant two-way interaction between activity and major, Wilks's $\Lambda=.99, F(1,548)=4.55, p=.03$, partial $\eta^{2}=.008$.

Education majors rated prime-target pairs with couples kissing $(M=1.51, S D=0.17)$, $t(548)=14.07, p<.001$ as significantly more unpleasant than couples in families $(M=$ $1.30, S D=0.20$ ). Similarly, non-education majors rated prime-target pairs with couples kissing $(M=1.49, S D=0.16)$ as significantly less pleasant than couples in families $(M=$ $1.32, S D=0.20), t(548)=11.07, p<.001$. Thus, both education and non-education majors rated the pairs with couples kissing as less pleasant than those with couples in families. The significant interaction indicates that the difference in ratings between these targets (i.e., couples kissing and couples in families) is greater for education majors than 
it is for non-majors; however, this difference is small enough that it is not likely to be meaningful.

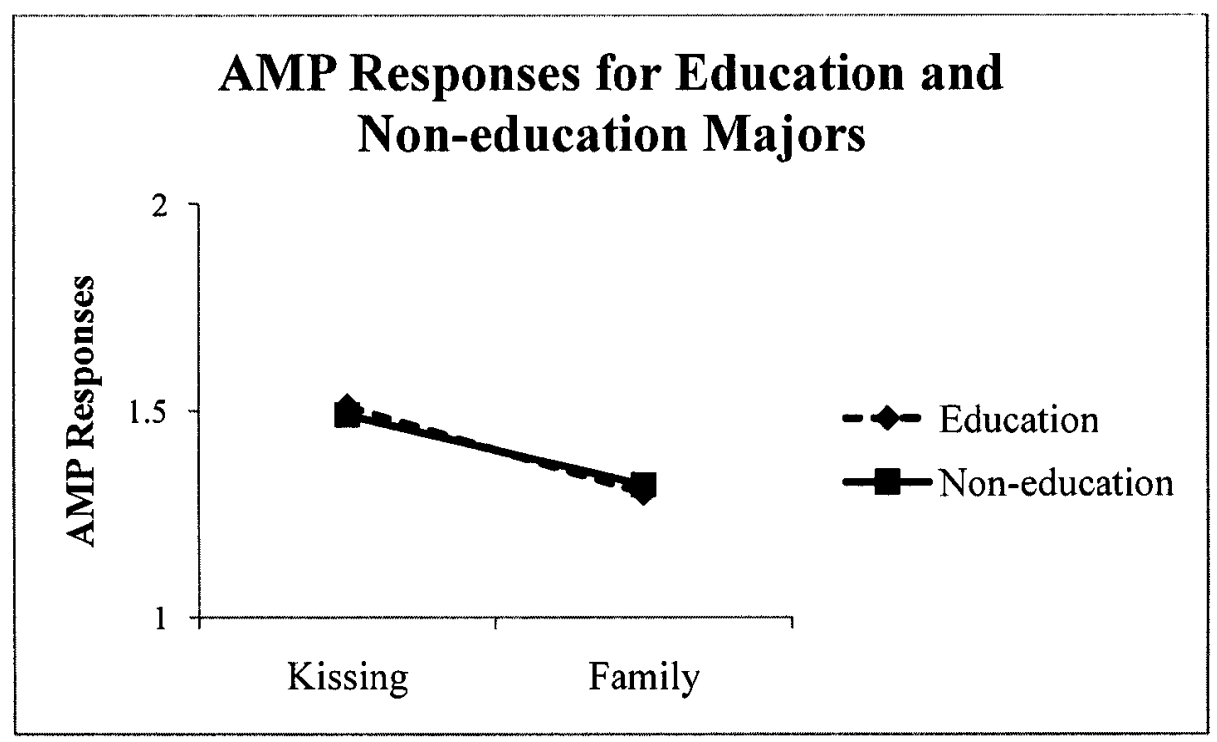

Figure 2. AMP responses to photographs of couples kissing or in families.

To further investigate whether participant responses varied based on whether they were education majors, I conducted a one-way MANOVA on the following measures: MHNS-G, MHNS-L, both versions of the External and Internal MRWP, Suppression of Prejudice, Agreeableness, and the social distance outcome measure. Table 9 presents the means and standard deviations. The MANOVA showed no evidence of a significant main effect for major, Wilks's $\Lambda=.99, F(8,529)=0.84, p=.570$. 
Taken together, the lack of evidence of a main effect for college major and the inconsequential amount of variance accounted for by the two-way (sexual orientation $\mathrm{X}$ major interaction) and three-way (activity $\mathrm{X}$ sexual orientation $\mathrm{X}$ major) interactions in the ANOVA, as measured by partial $\eta^{2}$ of .015 and .010 , and the findings from the MANOVA indicate that there are only trivial differences between education and noneducation majors. Therefore, education and non-education majors were combined for all further analyses. 
Table 9

Means and Standard Deviations of Education and Non-education Majors for Agreeableness, MHNS-G, MHNS-L, Internal and External MRWP Scales, Suppression of Prejudice, and Social Distance

\begin{tabular}{|c|c|c|c|c|c|c|}
\hline \multirow[b]{2}{*}{ Measure } & \multicolumn{3}{|c|}{ Education Majors } & \multicolumn{3}{|c|}{ Non-Education Majors } \\
\hline & $n$ & Mean & SD & $n$ & Mean & $\mathrm{SD}$ \\
\hline Agreeableness & 263 & 3.99 & 0.62 & 286 & 3.92 & 0.57 \\
\hline MHNS-G & 262 & 33.70 & 10.23 & 286 & 34.72 & 10.64 \\
\hline MHNS-L & 261 & 32.31 & 10.11 & 285 & 33.11 & 10.42 \\
\hline $\begin{array}{l}\text { External MRWI } \\
\text { black }\end{array}$ & 263 & 5.69 & 1.74 & 286 & 5.47 & 1.90 \\
\hline $\begin{array}{l}\text { Internal MRWP } \\
\text { black }\end{array}$ & 263 & 7.28 & 1.79 & 286 & 7.18 & 1.70 \\
\hline $\begin{array}{c}\text { External MRWF } \\
\text { homosexual }\end{array}$ & 255 & 5.18 & 1.85 & 286 & 5.06 & 1.99 \\
\hline $\begin{array}{c}\text { Internal MRWP } \\
\text { homosexual }\end{array}$ & 255 & 6.89 & 1.92 & 286 & 6.69 & 1.98 \\
\hline $\begin{array}{l}\text { Suppression of } \\
\text { prejudice }\end{array}$ & 263 & 5.56 & 1.44 & 286 & 5.30 & 1.46 \\
\hline Social distance & 92 & 3.71 & 0.56 & 108 & 3.77 & 0.62 \\
\hline
\end{tabular}




\section{AMP Order Effect}

Each participant responded to one of two different AMP orders. A three-way, mixed-design ANOVA was conducted to investigate potential order effects. The dependent variable was participant ratings of AMP stimuli. The within-subjects factors were activity portrayed in AMP photographs with two levels (couples kissing and couples in families) and sexual orientation with three levels (gay male couples, lesbian couples, and heterosexual couples). The between-subjects factor was order (forward and reverse order).

There was a significant three-way interaction between activity, sexual orientation, and order, Wilks's $\Lambda=.99, F(2,553)=3.27, p=.04$, partial $\eta^{2}=.01$. Follow up analyses revealed that, when prime-target pairs consisted of couples kissing, participants who viewed Order 1 rated prime-target pairs with gay men $(M=1.66, S D=0.28)$ as significantly more unpleasant than prime-target pairs with lesbians $(M=1.55, S D=0.30)$, $t(553)=6.06, p<.001$. Similarly, they rated prime-target pairs with gay men as significantly more unpleasant than prime-target pairs of heterosexuals $(M=1.28, S D=$ $0.21), t(553)=17.09, p<.001$. Participants who viewed Order 1 rated prime-target pairs of lesbians as significantly less pleasant than heterosexuals, $t(553)=12.71, p<.001$.

When prime-target pairs consisted of photographs of couples in families, participants who viewed Order 1 rated prime-target pairs with lesbians $(M=1.36, S D=$ $0.24)$ as significantly more unpleasant than prime-target pairs with gay men $(M=1.31$, $S D=0.26), t(553)=-4.80, p<.001$. Similarly, they rated prime-target pairs of lesbian families as significantly less pleasant than prime-target pairs of heterosexuals, $(M=1.29$, 
$S D=0.25), t(553)=4.13, p<.001$. There was no evidence of a significant difference between ratings for prime-target pairs with gay men and prime-target pairs with heterosexuals, $t(553)=1.06, p=.88$, for participants who viewed Order 1 .

When prime-target pairs consisted of photographs of couples kissing, participants who viewed Order 2 rated prime-target pairs of gay men $(M=1.68, S D=0.28)$ as significantly less pleasant than prime-target pairs of lesbians $(M=1.59, S D=0.30), \mathrm{t}(553)$ $=4.80, \mathrm{p}<.001$. They rated prime-target pairs of gay men as significantly less pleasant that heterosexuals $(M=1.23, S D=0.20), t(553)=18.92, \mathrm{p}<.001$. They rated primetarget pairs of lesbians as significantly less pleasant than prime-target pairs of heterosexuals, $t(553)=15.56, p<.001$.

When prime-target pairs consisted of photographs of couples in families, participants who viewed Order 2 rated prime-target pairs of gay men $(M=1.33, S D=$ $0.26)$ as significantly less pleasant than prime-target pairs of heterosexuals $(M=1.23, S D$ $=0.24), t(553)=5.16, p<.001$. They rated prime-target pairs of lesbians $(M=1.32, S D=$ 0.24 ) as significantly less pleasant than prime-target pairs of heterosexuals, $t(553)=5.41$, $p<.001$. There was no evidence of a significant difference in ratings for prime-target pairs of gay men and prime-target pairs of lesbians, $t(553)=0.64, p=1.00$, for participants who viewed Order 2.

The amount of variance accounted for by the significant two-way (sexual orientation $\mathrm{X}$ order) and three-way (activity $\mathrm{X}$ sexual orientation $\mathrm{X}$ order) interactions were $1.6 \%$ and $1.2 \%$, respectively. These amounts are trivial and, when coupled with the absence of evidence of a significant main effect for order, suggest that it is not necessary 
to consider order effects in further analyses. Thus, we collapsed across order in all subsequent analyses.

Stimulus Photograph Effects

In Phase 2, participants were randomly assigned to respond to either a family with gay male parents or a family with heterosexual parents. There were two photographs used in each condition. Independent samples t-tests were conducted to compare responses on the social distance measure between the two photographs in the gay male parent condition and to compare responses on the social distance measure between the two photographs in the heterosexual parent condition. The means and standard deviations are presented in Table 10. There was no evidence of a significant difference between the two photographs of heterosexual parents, $t(93)=1.71, p=.09$, or the two photographs of gay male parents, $t(106)=-1.01, p=.32$. Therefore, the data were collapsed across photographs within each condition for future analyses. 
Table 10

Means and Standard Deviations for Social Distance across Photographs and Sexual Orientation of Parents

\begin{tabular}{lcccc} 
Parents sexual orientation & & $\mathrm{n}$ & Mean & SD \\
\hline & Photograph 1 & 54 & 3.84 & 0.63 \\
Gay male & Photograph 2 & 54 & 3.95 & 0.51 \\
& & & & \\
& Photograph 1 & 46 & 3.68 & 0.55 \\
Heterosexual & & & & \\
& Photograph 2 & 49 & 3.48 & 0.55 \\
\hline
\end{tabular}

Chi-square tests were used to compare participants' decisions to stay with or abandon their interview partners. Table 11 shows the observed frequencies for each condition. There was no evidence that participant responses significantly varied across photographs in the gay male parent condition, $\chi^{2}(1,108)=0.34, p=.56$. Similarly, there was no evidence that participant responses significantly varied across photographs in the heterosexual parent condition, $\chi^{2}(1,95)=1.08, p=.30$. Despite the lack of significant findings of the chi-square tests that suggests that there were no differences between the two photographs with gay male parents or between the two photographs with heterosexual parents, the assertion that there truly are no differences is tentative. As 
Table 11 demonstrates, only four of 203 participants chose to abandon their partners. Because of the low frequencies in each cell, the analyses are not meaningful.

Table 11

Partner Abandonment Decisions across Sexual Orientation and Photograph Viewed

Decision to abandon partner

\begin{tabular}{lcccc} 
Parent sexual orientation & & Yes & No & Total \\
\hline & Photograph 1 & 2 & 52 & 54 \\
Gay male & Photograph 2 & 1 & 53 & 54 \\
& Photograph 1 & 1 & 45 & 46 \\
Heterosexual & Photograph 2 & 0 & 49 & 49 \\
& & & & \\
& & 4 & 199 & 203 \\
\hline
\end{tabular}

Similarity of Interviewee

As part of the experimental manipulation, participants were randomly assigned to one of two conditions related to the perceived similarity of the ostensible interviewee. Participants were either told that they had a personality that was similar or dissimilar to the parent they would interview. Although I did not make specific hypotheses about the effect of this manipulation, I wanted to investigate whether there were any differences 
associated with it. Thus, a 2 (similarity) $\times 2$ (sexual orientation of interviewee) $\times 2$ (participant sex) ANOVA was conducted with social distance as the dependent variable and perceived similarity, sexual orientation of the parent interviewee, and participants' sex as between-subjects variables. Tables 12 and 13 present the means and standard deviations.

Based on the ANOVA findings, there was no evidence that the 3-way interaction between sexual orientation of interviewee (gay male or heterosexual male parents), similarity, and participant sex was significant, $F(1,195)=1.58, p=.21$. There was a significant main effect for sexual orientation of the interviewee, $F(1,195)=4.67, p=.03$; however, it was qualified by a significant Sexual orientation of interviewee X Participant sex interaction, $F(1,195)=4.56, p=.03$, partial $\eta^{2}=.02$, and a Similarity X Participant sex interaction, $F(1,195)=14.12, p<.001$, partial $\eta^{2}=.07$. Follow-up $t$ tests on the Interviewee X Participant sex interaction revealed that female participants rated gay male interviewees $(M=3.97, S D=0.55)$ significantly more positively than they rated heterosexual male interviewees $(M=3.57, S D=0.54), t(154)=-4.54, p<.001$. There was no evidence that male participants rated gay male parents $(M=3.61, S D=0.58)$ significantly differently from heterosexual parents $(M=3.60, S D=0.62), t(45)=-0.06, p$ $=.95$. Follow up $t$ tests on the Similarity X Participant sex interaction revealed that male participants rated interviewees more positively when they were perceived as more dissimilar $(M=3.79, S D=0.64)$ to them than when they were perceived as more similar to them $(M=3.44, S D=0.51), t(45)=2.10, p=.04$. In contrast, female participants rated interviewees significantly more positively when they were perceived as $\operatorname{similar}(M=$ 
$3.95, S D=0.53)$ to them than when they were perceived as dissimilar to them $(M=3.63$, $S D=0.58), t(154)=-3.62, p<.001$.

There was no evidence of a significant main effect for similarity, $F(1,195)=$ $0.10, p=.75$, or participant sex, $F(1,195)=3.08, p=.08$. Finally, there was no evidence of a significant interaction between sexual orientation of interviewee and similarity, $F(1$, $195)=.75, p=.19$. Based on the lack of evidence for a significant main effect for similarity or for the three-way (Similarity $\mathrm{x}$ Sexual orientation of interviewee $\mathrm{x}$ Participant sex) interaction, we collapsed the data across the similarity conditions for all subsequent analyses. 
Table 12

Means and Standard Deviations on Social Distance by Sex and Parent Interviewee Sexual Orientation in Similar Condition

\begin{tabular}{lllll} 
Sexual orientation & & $n$ & Mean & SD \\
\hline \multirow{2}{*}{ Gay male } & Men & 11 & 3.31 & 0.55 \\
& & & & \\
& Women & 45 & 4.11 & 0.55 \\
& Men & 14 & 3.54 & 0.48 \\
Heterosexual & & & & \\
& Women & 34 & 3.73 & 0.43 \\
& Men & 25 & 3.44 & 0.51 \\
Total & Women & 79 & 3.95 & 0.53 \\
& & & & \\
\hline
\end{tabular}


Table 13

Means and Standard Deviations on Social Distance by Sex and Parent Interviewee Sexual Orientation in Dissimilar Condition

\begin{tabular}{lllll} 
Sexual orientation & & $n$ & Mean & SD \\
\hline & Men & 11 & 3.91 & 0.47 \\
Gay male & & & & \\
& Women & 41 & 3.81 & 0.51 \\
& Men & 11 & 3.68 & 0.78 \\
Heterosexual & Women & 36 & 3.42 & 0.58 \\
& & & & \\
& Men & 22 & 3.61 & 0.58 \\
Total & Women & 77 & 3.63 & 0.58 \\
& & & & \\
\hline
\end{tabular}

\section{Hypotheses Testing}

Hypothesis 1a: Participant Scores on the Implicit Measure Will be Higher for Homosexual Primes Than For Heterosexual Primes

I predicted that AMP ratings would be higher for prime-target pairs with homosexual primes than for prime-target pairs with heterosexual primes. That is, I hypothesized that targets paired with photographs of homosexual persons would receive significantly more "unpleasant" responses than targets paired with photographs of heterosexual persons. A dependent t-test was conducted to investigate this hypothesis. The paired variables were participant ratings of all heterosexual AMP stimuli and 
participant ratings of all homosexual AMP stimuli. Table 14 presents AMP means in descending order from least to most pleasant. Overall, the findings supported this hypothesis: Prime-target pairs with homosexual photographs $(M=1.47, S D=0.18)$ were rated as significantly more unpleasant than prime-target pairs with heterosexual photographs $(M=1.26, S D=0.21), t(555)=-18.45, p<.001$. 
Table 14

Means for AMP Responses in Descending Order

\begin{tabular}{llcc} 
Type of AMP prime & Participant sex & Mean & SD \\
\hline Gay males kissing & Men & 1.72 & 0.29 \\
Gay males kissing & Women & 1.65 & 0.27 \\
Lesbians kissing & Women & 1.65 & 0.27 \\
Gay families & Men & 1.46 & 0.28 \\
Lesbian families & Men & 1.40 & 0.26 \\
Lesbian families & Women & 1.33 & 0.23 \\
Heterosexual families & Men & 1.28 & 0.24 \\
Gay families & Women & 1.28 & 0.24 \\
Lesbians kissing & Men & 1.27 & 0.22 \\
Heterosexual families & Women & 1.26 & 0.25 \\
Heterosexuals kissing & Women & 1.26 & 0.20 \\
Heterosexuals kissing & Men & 1.24 & 0.22 \\
\hline
\end{tabular}

Hypothesis 1b: Participants Will Report More Prejudice toward Gale Male Parents Than They Will toward Lesbian Parents

I hypothesized that participants would rate AMP targets that were paired with photographs of gay men more negatively than AMP targets that were paired with 
photographs of lesbians. A dependent t-test was conducted with the paired variables being all gay male AMP stimuli and all lesbian AMP stimuli. The findings supported our hypothesis: Prime-target pairs with gay male photographs $(M=1.49, S D=0.21)$ were rated significantly more unpleasant than prime-target pairs with lesbian photographs $(M=$ $1.45, S D=0.19), t(555)=4.77, p<.001$.

To further analyze and understand participant responses across each type of AMP stimuli, a two-way, repeated measures MANOVA was also conducted to investigate this hypothesis. Planned pairwise comparisons were also conducted using Bonferroni corrections for multiple comparisons. Table 15 presents the means and standard deviations. The dependent variable was participant ratings of AMP stimuli. The withinsubjects factors were activity portrayed in AMP photographs with two levels (couples kissing and couples in families) and sexual orientation with three levels (gay male couples, lesbian couples, and heterosexual couples). The between-subjects variable was participant sex. 
Table 15

Means and Standard Deviations for AMP Responses by Type of Prime

\begin{tabular}{|c|c|c|c|c|}
\hline Type of AMP prime & & $n$ & Mean & SD \\
\hline \multirow{3}{*}{ Gay men kissing } & Men & 123 & 1.72 & 0.29 \\
\hline & Women & 433 & 1.65 & 0.27 \\
\hline & Total & 556 & 1.67 & 0.28 \\
\hline \multirow{3}{*}{ Gay families } & Men & 123 & 1.46 & 0.28 \\
\hline & Women & 433 & 1.28 & 0.24 \\
\hline & Total & 556 & 1.32 & 0.26 \\
\hline \multirow{3}{*}{ Lesbians kissing } & Men & 123 & 1.27 & 0.22 \\
\hline & Women & 433 & 1.65 & 0.27 \\
\hline & Total & 556 & 1.57 & 0.30 \\
\hline \multirow{3}{*}{ Lesbian families } & Men & 123 & 1.40 & 0.26 \\
\hline & Women & 433 & 1.33 & 0.23 \\
\hline & Total & 556 & 1.34 & 0.24 \\
\hline \multirow{3}{*}{ Heterosexuals kissing } & Men & 123 & 1.24 & 0.22 \\
\hline & Women & 433 & 1.26 & 0.20 \\
\hline & Total & 556 & 1.26 & 0.20 \\
\hline \multirow{3}{*}{ Heterosexual families } & Men & 123 & 1.28 & 0.24 \\
\hline & Women & 433 & 1.26 & 0.25 \\
\hline & Total & 556 & 1.27 & 0.25 \\
\hline
\end{tabular}


There was a significant three-way interaction between sexual orientation, participant sex, and activity, Wilks's $\Lambda=.73, F(2,553)=100.33, p<.001$, partial $\eta^{2}=$ .27. Refer to Figure 3 for an illustration of this interaction. Follow up analyses revealed that, for prime-target pairs that consisted of photographs of couples kissing, male participants rated gay men $(M=1.73, S D=0.29)$ as significantly more unpleasant than lesbians $(M=1.27, S D=0.22), t(553)=19.87, p<.001$. Similarly, they rated gay men as significantly more unpleasant than heterosexuals $(M=1.24, S D=0.22), t(553)=14.18, p$ $<.001$. There was no evidence of a significant difference between ratings for lesbians and heterosexuals, $t(553)=0.81, p=1.00$.

Follow-up analyses also revealed that female participants who viewed primetarget pairs that consisted of photographs of couples kissing rated gay men $(M=1.65, S D$ $=0.27)$ as significantly more unpleasant than heterosexuals $(M=1.26, S D=0.20), t(553)$ $=21.72, p<.001$. Similarly, they rated lesbians $(M=1.65, S D=0.27)$ as significantly more unpleasant than heterosexuals, $t(553)=24.31, p<.001$. There was no evidence of a significant difference between female participants' ratings for gay men and their ratings for lesbians, $t(553)=0.17, p=1.00$.

For prime-target pairs that consisted of photographs of couples in families, male participants rated gay men $(M=1.46, S D=0.28)$ as significantly more unpleasant than lesbians $(M=1.40, S D=0.26), t(553)=3.63, p=.001$. Similarly, they rated gay men as significantly more unpleasant than heterosexuals $(M=1.28, S D=0.24), t(553)=6.85, p$ $<.001$. Finally, male participants rated lesbians as significantly more unpleasant than heterosexuals, $t(553)=5.08, p<.001$. 
Female participants rated lesbians $(M=1.33, S D=0.23)$, as significantly more unpleasant than gay men $(M=1.28, S D=0.24), t(553)=-5.75, p<.001$. They also rated lesbians as significantly more unpleasant than heterosexuals, $(M=1.26, S D=0.25)$, $t(553)=4.92, p<.001$ There was no evidence of a significant difference between female participants' ratings for gay men and their ratings for heterosexuals, $t(553)=1.29, p=.63$. 


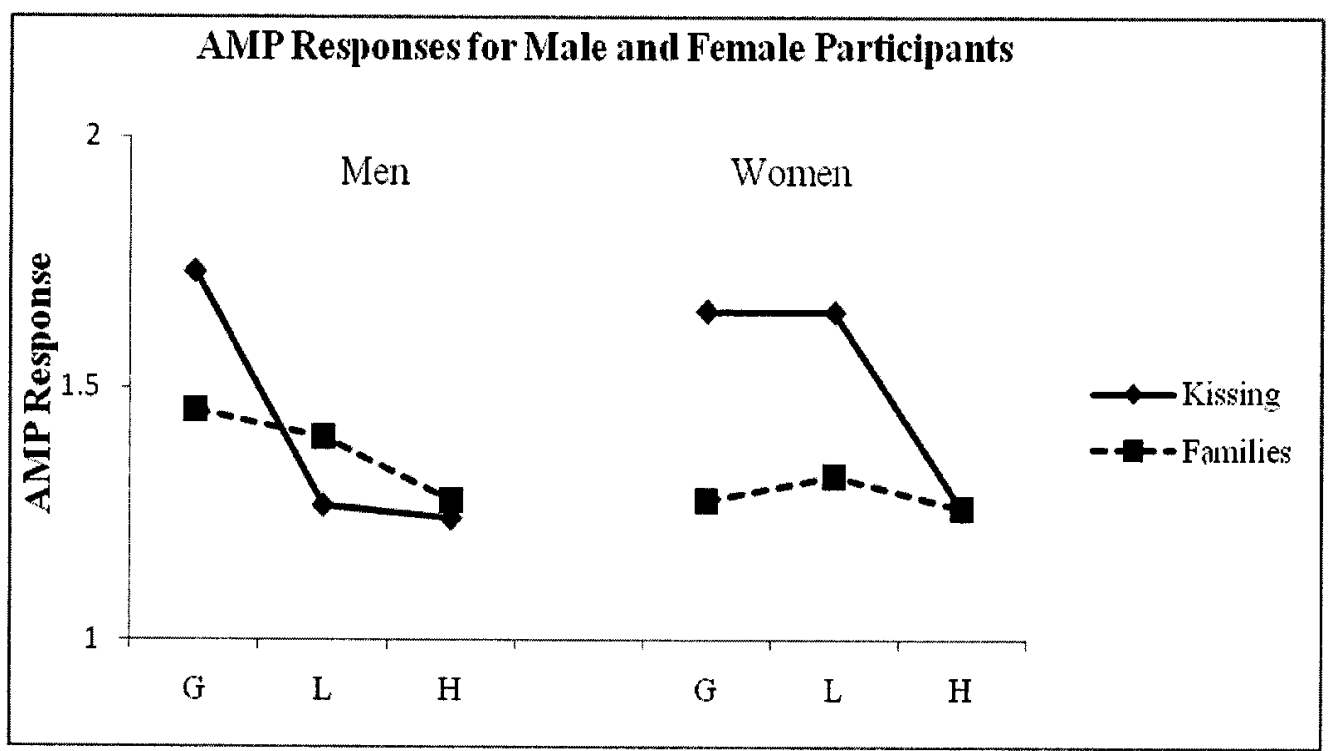

Figure 3. AMP responses of male and female participants.

\section{Hypothesis 1 Summary}

In general, AMP ratings were more negative for prime-target pairs with homosexual primes than for prime-target pairs with heterosexual primes. With two exceptions, targets that were paired with photographs of homosexual persons (gay male or lesbian couples), regardless of whether they were shown kissing or in families, received significantly more "unpleasant" responses than targets that were paired with photographs of heterosexual couples engaged in either activity. One exception occurred for male participants' ratings of lesbian couples kissing: Men's ratings of these targets did not vary significantly from their ratings of heterosexual couples kissing. Moreover, men rated prime-target pairs that contained photographs of lesbians kissing as more pleasant than all prime-target combinations except targets paired with photographs of 
heterosexual couples kissing or in families. The other exception occurred for female participants' ratings of gay male couples in families: Women's ratings of gay male couples and heterosexual couples did not vary significantly from one another.

Hypothesis2: Implicit Measures of Sexual Prejudice Will be Correlated with Explicit Measures of Sexual Prejudice

I predicted that implicit and explicit measures of prejudice would be related. Specifically, I predicted that AMP responses would be correlated with the Modern Homo-negativity Scales for Gay Men and Lesbians (MHNS-G and MHNS-L). Table 16 shows the means and standard deviations of both MHNS scales for male and female participants. Table 17 presents the intercorrelations for these variables. A correlation matrix that presents all possible intercorrelations can be found in Table C1.

Table 16

Means and Standard Deviations for MHNS Scales

\begin{tabular}{lllll} 
Variable & & $n$ & Mean & SD \\
\hline & Men & 124 & 38.82 & 10.64 \\
MHNS-G & Women & 431 & 32.98 & 10.03 \\
& Total & 555 & 34.29 & 10.45 \\
& Men & 123 & 35.57 & 9.49 \\
MHNS-L & Women & 430 & 31.95 & 10.32 \\
& Total & 553 & 32.76 & 10.25 \\
\hline
\end{tabular}


Table 17

Intercorrelations for AMP Responses and MHNS Scales

$\begin{array}{lll}\text { Measure } & \text { MHNS-G MHNS-L }\end{array}$

1) AMP all gay men $(n=556)$

$.51 * *$

$.47 *$

2) AMP gay men kissing $(n=556)$

$.39 * *$

$.38^{* *}$

3) AMP gay men families

$(n=556)$

$.42 * *$

$.36^{* *}$

4) AMP all lesbians

$(n=556)$

$.25^{* *}$

$.27 * *$

5) AMP lesbians kissing

$(n=556)$

.04

$.09 *$

6) AMP lesbian families

$(n=556)$

$.35 * *$

$.33^{* *}$

7) AMP all heterosexual

$(n=556)$

$-.12 * *$

$-.12 * *$

8) AMP heterosexuals kissing

$(n=556)$

$-.10^{*}$

$-.12 * *$

9) AMP heterosexual families

$(n=556)$

$-.11 *$

$-.11 *$

${ }^{*} p<.05 .{ }^{* *} p<.01$ 
Gay male couples. The correlations between the MHNS-G and AMP ratings for targets paired with photographs of gay male couples kissing, gay male couples in families, and the combination of all photographs that portrayed gay male couples were all significant, $r(551)=.39, p>.001 ; r(551)=.42, p>.001 ; r(551)=.51, p>.001$, respectively. A similar pattern emerged for correlations between the MHNS-L and AMP ratings, $r(549)=$ $.38, p>.001 ; r(549)=.36, p>.001 ; r(549)=.47, p>.001$, respectively.

Lesbian couples. The correlation between the MHNS-L and AMP ratings for targets paired with photographs of lesbian couples kissing, lesbian couples portrayed in families, and the combination of all photographs that portrayed lesbian couples were all significant, $r(549)=.09, p=.04 ; r(549)=.33, p<.001 ; r(549)=.27, p<.001$, respectively.

The correlations between the MHNS-G and AMP ratings for lesbians showed a similar pattern for lesbian couples in families, $r(551)=.35, p<.001$, and for the combination of all photographs of lesbian couples, $r(551)=.25, p<.001)$; however, there was no evidence of a significant relation for lesbian couples kissing, $r(551)=.05, N S$.

Heterosexual couples. All correlations between both MHNS scales and AMP ratings for targets paired with photographs of heterosexual couples were significant and in the opposite direction. The correlations between the MHNS-G and prime-target pairs that contained photographs of heterosexual couples portrayed kissing, in families, and combined, were $r(551)=.-10, p=.02 ; r(551)=-.11, p=.01 ; r(551)=-.12, p=.01$, respectively. The correlations between the MHNS-L and the same prime-target pairs were $r(549)=-.12, p=.01 ; r(549)=-.11, p=.01$; and $r(549)=.12, p=.004$, respectively. 


\section{Hypothesis 2 Summary}

As expected, there was a general pattern of significant relations between my implicit and explicit measures. Participant ratings of AMP stimuli for all gay male couples, regardless of activity, were positively correlated with both versions of the Modern Homo-negativity Scale (MHNS-G and MHNS-L). Similar findings were present for heterosexual couples; AMP ratings and the explicit measures, however, were inversely related. For lesbian couples, AMP ratings followed a pattern similar to ratings for gay male couples with one exception: There was no evidence of a relation between scores on the MHNS-G and responses to AMP targets paired with lesbian couples kissing.

Hypothesis 3: Participants' Agreeableness Will Be Negatively Correlated with Explicit Measures of Prejudice

I predicted that participants' Agreeableness would be negatively correlated with explicit measures of prejudice. My analysis supported this hypothesis: Agreeableness was negatively correlated with the MHNS-G and the MHNS-L, $r(553)=-.10, p=.02, r(551)$ $=-.12, p=.01$, respectively.

Hypothesis 3 Summary

To summarize, my prediction that Agreeableness and the MHNS scales would be negatively correlated was supported. 
Hypothesis 4: AMP Scores Will be Related to Prejudice Behavior

I predicted that AMP scores would be related to prejudice behavior. To test this hypothesis, I defined prejudice behavior as (1) switching, and (2) responses on the social distance measure. These outcome measures were examined separately.

Switching behavior. As shown in Table $\mathrm{Cl}$, a point-biserial correlation analysis revealed no evidence of a relation between switching behavior and AMP ratings; correlation coefficients ranged from -.04 to .12 and none reached significance. Of the 203 participants in Phase 2, only four made the decision to abandon their partners. Therefore, the analysis of relations between AMP ratings and switching behavior is not meaningful. Based on these results, the remaining analyses for prejudice behavioral outcomes focused on responses to the social distance measure.

Social distance. As shown in Table C1, the correlation between AMP ratings for targets paired with photographs of gay male couples kissing and social distance was negative and significant, $r(201)=-.19, p=.01$. The correlation between AMP ratings for targets paired with photographs of all gay male couples, regardless of activity, and social distance was negative and significant, $r(201)=-.17, p=.02$. There was no evidence that any other AMP scores were related to the social distance measure.

\section{Hypothesis 4 Summary}

I expected significant relations between AMP ratings and prejudice behavior, as measured by the social distance questionnaire, and participant switching behavior, our behavioroid measure of prejudice. Only correlations between social distance and (1) AMP ratings of targets paired with photographs of gay couples kissing and (2) AMP 
ratings of targets paired with photographs of all gay male couples were significant. The relations were inverse ones, indicating that as AMP ratings became more unpleasant, ratings of interviewees in Phase 2 became less positive.

\section{Hypothesis 5: Teachers' Agreeableness Will Predict Prejudice Behaviors}

To examine the hypothesis that Agreeableness is related to more negative evaluations of parents who are homosexual relative to parents who are heterosexual, I conducted a cross-product multiple regression analysis. When Agreeableness, sexual orientation of interviewee, and the Agreeableness x Sexual orientation of interviewee cross product were included in the regression, there was no evidence that the interaction was significant, $\beta=-.10, t(198)=-0.99, p=.32$. When examining the model in which only Agreeableness and sexual orientation of interviewee condition were entered as predictors, sexual orientation of interviewee emerged as a significant predictor of social distance, $\beta=.27, t(199)=4.03, p<.001$, such that participants responded more favorably on the social distance measure to parents who are homosexual $(M=3.89, S D=0.57)$ than to those who are heterosexual $(M=3.58, S D=0.56)$. There was no evidence that Agreeableness was a significant predictor of social distance, $\beta=.10, t(199)=1.48, p=$ .14. Results from this regression analysis are presented in Table 18. 
Table 18

Multiple Regression Analyses of Agreeableness and Sexual Orientation of Interviewee Predicting Social Distance $(N=203)$

\begin{tabular}{|c|c|c|c|c|}
\hline Variable & & $B$ & $S E B$ & $\beta$ \\
\hline \multicolumn{5}{|l|}{ Step } \\
\hline & Agreeableness & .10 & .07 & .10 \\
\hline & $\begin{array}{l}\text { Sexual orientation of } \\
\text { interviewee }\end{array}$ & .32 & .08 & $.27^{*}$ \\
\hline \multicolumn{5}{|l|}{ Step 2} \\
\hline & Agreeableness & .17 & .10 & .17 \\
\hline & $\begin{array}{l}\text { Sexual orientation of } \\
\text { interviewee }\end{array}$ & .33 & .08 & $.28^{*}$ \\
\hline & Interaction model & -.13 & .13 & -.10 \\
\hline
\end{tabular}

Note. $R^{2}=.08$ for Step $1 ; \Delta R^{2}=.01(n s)$ for Step 2 .

$* p<.01$

Hypothesis 6: The interaction between Agreeableness and Implicit Prejudice Will Predict Prejudice Behaviors

I predicted that the interaction between Agreeableness and implicit prejudice, as measured by the AMP, would predict prejudice behaviors. Specifically, I predicted that individuals low in Agreeableness and high in implicit prejudice would demonstrate the greatest prejudice behavior, individuals low in Agreeableness and high in implicit prejudice would not differ significantly from individuals high in Agreeableness and high in implicit prejudice, and individuals high in Agreeableness and low in implicit prejudice 
would demonstrate the least prejudice behaviors. I examined these relations using responses to all photographs of gay men combined as the implicit measure of prejudice. Similar analyses were conducted using difference scores (e.g., AMP responses to all prime-target pairs with photographs of gay men minus AMP responses to all prime-target pairs with photographs of heterosexual people) for various combinations of AMP responses. Results of these analyses are presented in Appendix B.

I examined this hypothesis by conducting a cross-product multiple regression. When Agreeableness, implicit prejudice, sexual orientation of interviewee, all two way interactions terms, and the three way interaction term were included in the regression, there was no evidence that the three-way interaction term predicted prejudice, $\beta=-.02, t$ $(193)=-0.16, p=.88$.

After removing the three-way interaction term, the Sexual orientation of interviewee $\mathrm{x}$ Implicit prejudice interaction was significant, $\beta=-.21, t(194)=-2.13, p=$ .03 , as shown in Table 19. A follow-up analysis of simple slopes revealed that the implicit measure was a significant predictor of prejudice when sexual orientation of interviewee was homosexual, $\beta=-.32, t(196)=-3.56, p<.001$; there was no evidence, however, that the implicit measure predicted prejudice when sexual orientation of interviewee was heterosexual, $\beta=-.02, t(196)=-0.19, p=.85$. As shown in Figure 4, AMP scores became more unpleasant as participants reported lower ratings of social distance when sexual orientation of interviewee was homosexual. 
Table 19

Multiple Regression Analyses of Agreeableness, Implicit Measure, Sexual Orientation of Interviewee, and Social Distance $(N=201)$

\begin{tabular}{|c|c|c|c|c|}
\hline Variable & & $B$ & $S E B$ & $\beta$ \\
\hline \multicolumn{5}{|l|}{ Step 1} \\
\hline & Agreeableness & 0.11 & 0.07 & .12 \\
\hline & Implicit measure & -0.52 & 0.19 & -.19 \\
\hline & Sexual orientation & 0.32 & 0.08 & $.28 * *$ \\
\hline \multicolumn{5}{|l|}{ Step 2} \\
\hline & Agreeableness & 0.17 & 0.10 & .17 \\
\hline & Implicit measure & -0.06 & 0.28 & -.02 \\
\hline & Sexual orientation & 0.32 & 0.08 & $.27 * *$ \\
\hline & Agreeableness X implicit & & & \\
\hline & measure & -0.14 & 0.33 & -.03 \\
\hline & Agreeableness $\mathrm{X}$ sexual & & & \\
\hline & orientation & -0.11 & 0.13 & -.08 \\
\hline & $\begin{array}{l}\text { Implicit measure X sexual } \\
\text { orientation }\end{array}$ & -0.80 & 0.38 & $-.21 *$ \\
\hline
\end{tabular}

Step 3

\begin{tabular}{llll} 
Agreeableness & 0.17 & 0.10 & 0.17 \\
Implicit measure & -0.07 & 0.28 & -.02 \\
$\begin{array}{l}\text { Sexual orientation } \\
\text { Agreeableness X implicit } \\
\quad \text { measure }\end{array}$ & 0.32 & 0.08 & $.27^{* *}$ \\
$\begin{array}{l}\text { Agreeableness X sexual } \\
\quad \text { orientation }\end{array}$ & -0.08 & 0.50 & -.02 \\
$\begin{array}{l}\text { Implicit measure X sexual } \\
\quad \text { orientation }\end{array}$ & -0.11 & 0.13 & -.08 \\
$\begin{array}{l}\text { Agreeableness X implicit } \\
\quad \text { measure X sexual } \\
\text { orientation }\end{array}$ & -0.80 & 0.38 & $-.21^{*}$ \\
\hline
\end{tabular}

Note. $R^{2}=.11$ for Step $1 ; \Delta R^{2}=.03(n s)$ for Step $2 . \Delta R^{2}<.001(n s)$ for Step 3.

${ }^{*} p<.05 . ; * p<.01$. 


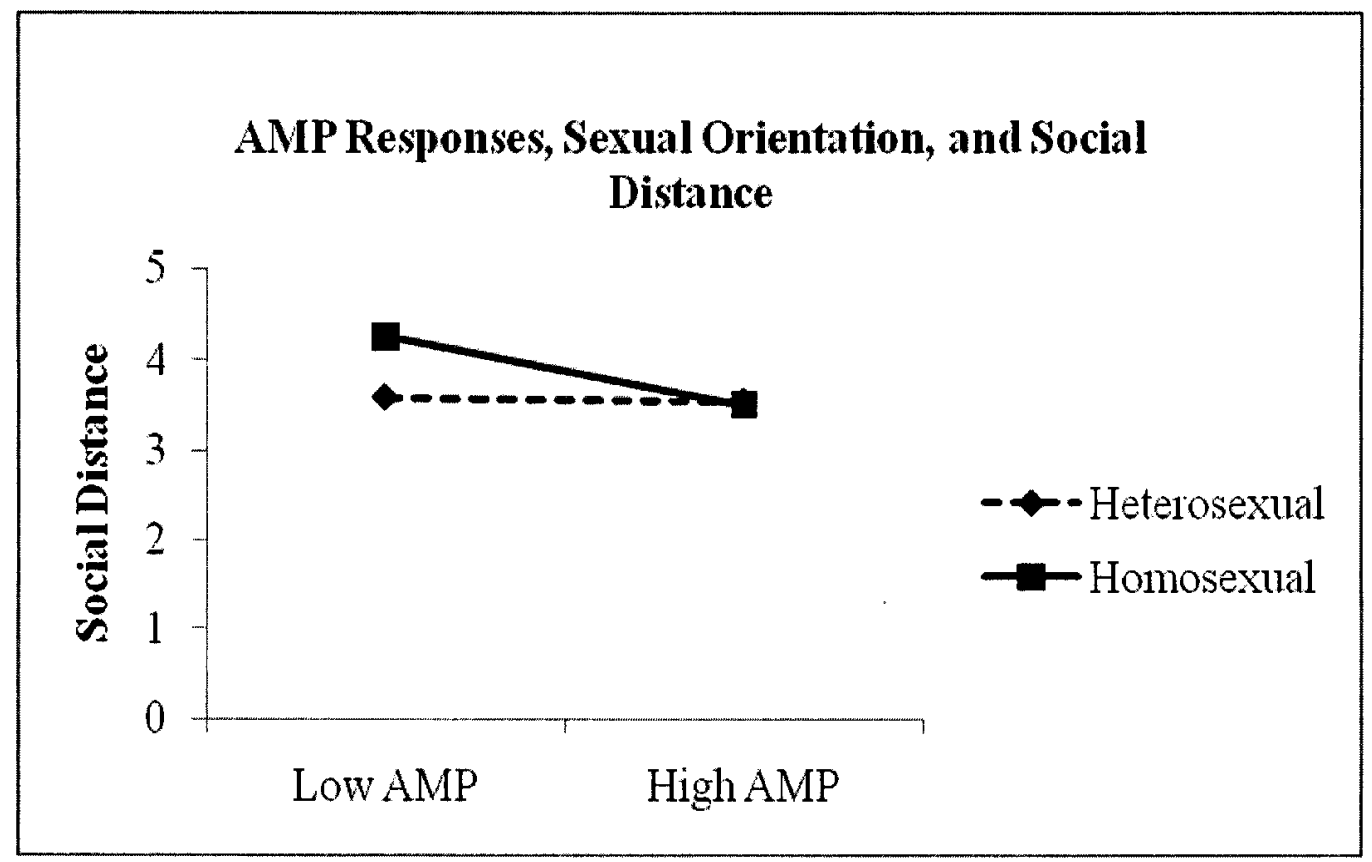

Figure 4. The interaction of AMP responses and sexual orientation of interviewee as a predictor of social distance.

In addition to the significant two-way interaction, Agreeableness emerged as a marginally significant predictor of prejudice, $\beta=.12, t(196)=1.71, p=.09$, such that participants high in Agreeableness reported more favorable ratings on the social distance measure regardless of their implicit prejudice score or sexual orientation of interviewee.

Although Agreeableness was a marginally significant predictor of prejudice and although the relation between implicit and explicit measures of prejudice was in the expected direction, my hypothesis that Agreeableness would moderate this relation was not supported.

I also examined this hypothesis by substituting other combinations of AMP slides as the implicit measure. As Table B7 demonstrates, similar patterns emerged for AMP 
combinations that included prime-target pairs with photographs of gay men. There was no evidence of similar patterns when we substituted other combinations of AMP stimuli.

\section{Exploratory Analyses}

In addition to testing our hypotheses, I also conducted some exploratory analyses on these data. Based on the literature, it was unclear whether and how Agreeableness, motivation to control prejudice, suppression of prejudice, and implicit prejudice would interact as predictors of prejudice behavior. Thus, my exploratory analyses focused on describing the effects related to these interactions. Unless otherwise noted, I examined these relations using responses to all photographs of gay men combined as the implicit measure of prejudice. Appendix B contains all the regression tables for these analyses. Motivation to Control Prejudice

I was interested in the relations between implicit prejudice, explicit prejudice, and motivation to control prejudice. Prior research (Payne et al., 2005) provided some evidence that internal motivation to control prejudice moderates the relation between implicit and explicit measures of prejudice but no evidence of a similar relation for external motivation to control prejudice. To inspect these relations in the current study, I first examined internal motivation to control prejudice, and then I examined external motivation to control prejudice. I used AMP responses to all photographs of gay men combined as the implicit measure of prejudice. The outcome variables were the MHNS-G and the MHNS-L.

Internal motivation and $M H N S-G$. When implicit prejudice, internal motivation to control prejudice, and the Implicit x Internal motivation cross product were included in a 
cross product multiple regression, there was no evidence that the interaction was significant, $\beta=-.02, t(541)=-0.53, p=.60$. As shown in Table 20, implicit prejudice and motivation emerged as significant predictors of explicit prejudice, $\beta=.32, t(542)=$ $8.75, p=<.001$, and $\beta=-.44, t(542)=-12.16, p=<.001$, respectively. A similar pattern emerged when I substituted the MHNS-L as my criterion variable. Also, when other AMP scores were substituted into this regression model, the results were similar.

\section{Table 20}

Multiple Regression Analyses of AMP Gay All, Internal Motivation, and Explicit Measures $(N=545)$

\begin{tabular}{llccc}
\hline Variable & & $B$ & $S E B$ & $\beta$ \\
\hline Step 1 & & & & \\
& Implicit prejudice & 15.67 & 1.79 & $.32^{*}$ \\
& Motivation & -2.36 & 0.19 & $-.44^{*}$ \\
& & & & \\
Step 2 & & 15.59 & 1.80 & $.32^{*}$ \\
& Implicit prejudice & -2.34 & 0.20 & $-.44^{*}$ \\
& Motivation & -0.40 & 0.76 & -.02 \\
\hline & Implicit prejudice x motivation & & & \\
\hline
\end{tabular}

Note. $R^{2}=.42$ for Step $1 ; \Delta R^{2}<.001$ for Step $2(n s)$.

${ }^{*} p<.01$ 
External motivation and MHNS-G. Implicit prejudice, external motivation, and the Implicit x External motivation cross product were included in a cross product regression analysis. As shown in Table 21, the implicit prejudice by external motivation interaction was a significant predictor of the MHNS-G measure, $\beta=-.13, t(541)=-3.52$, $p<.001$. A follow-up analysis of simple slopes revealed that the implicit measure was a significant predictor of explicit prejudice when external motivation was high, $\beta=.34, t$ $(541)=6.31, p<.001$, and when external motivation was low, $\beta=.57, t(541)=12.48$, $p<.001$. Figure 5 shows that AMP scores became more unpleasant as scores on MHNS-G increased for participants who were low in external motivation. For participants high in external motivation, AMP scores also became more unpleasant as scores on the MHNS-G increased, but the strength of the relation was not as strong as it was for participants low in external motivation, as demonstrated by the relative slopes. A similar pattern emerged when I substituted the MHNS-L as the criterion variable. Refer to Appendix B for results of these regression analyses when other AMP scores were substituted into the model. 


\section{Table 21}

Multiple Regression Analyses of AMP Gay All, External Motivation, and Explicit Measures $(N=545)$

\begin{tabular}{llccc}
\hline Variable & & $B$ & $S E B$ & $\beta$ \\
\hline Step 1 & & & & \\
& Implicit prejudice & 23.35 & 1.81 & $.47^{*}$ \\
& Motivation & -1.01 & .20 & $-.19^{*}$ \\
Step 2 & & & & \\
& & & & \\
& Implicit prejudice & 22.40 & 1.81 & $.46^{*}$ \\
& Motivation & -.97 & .20 & $-.18^{*}$ \\
& Implicit prejudice x motivation & -3.01 & 0.85 & $-.13^{*}$ \\
\hline
\end{tabular}

Note. $R^{2}=.29$ for Step $1 ; \Delta R^{2}=.02$ for Step $2(p \mathrm{~s}<.01)$.

${ }^{*} p<.01$ 


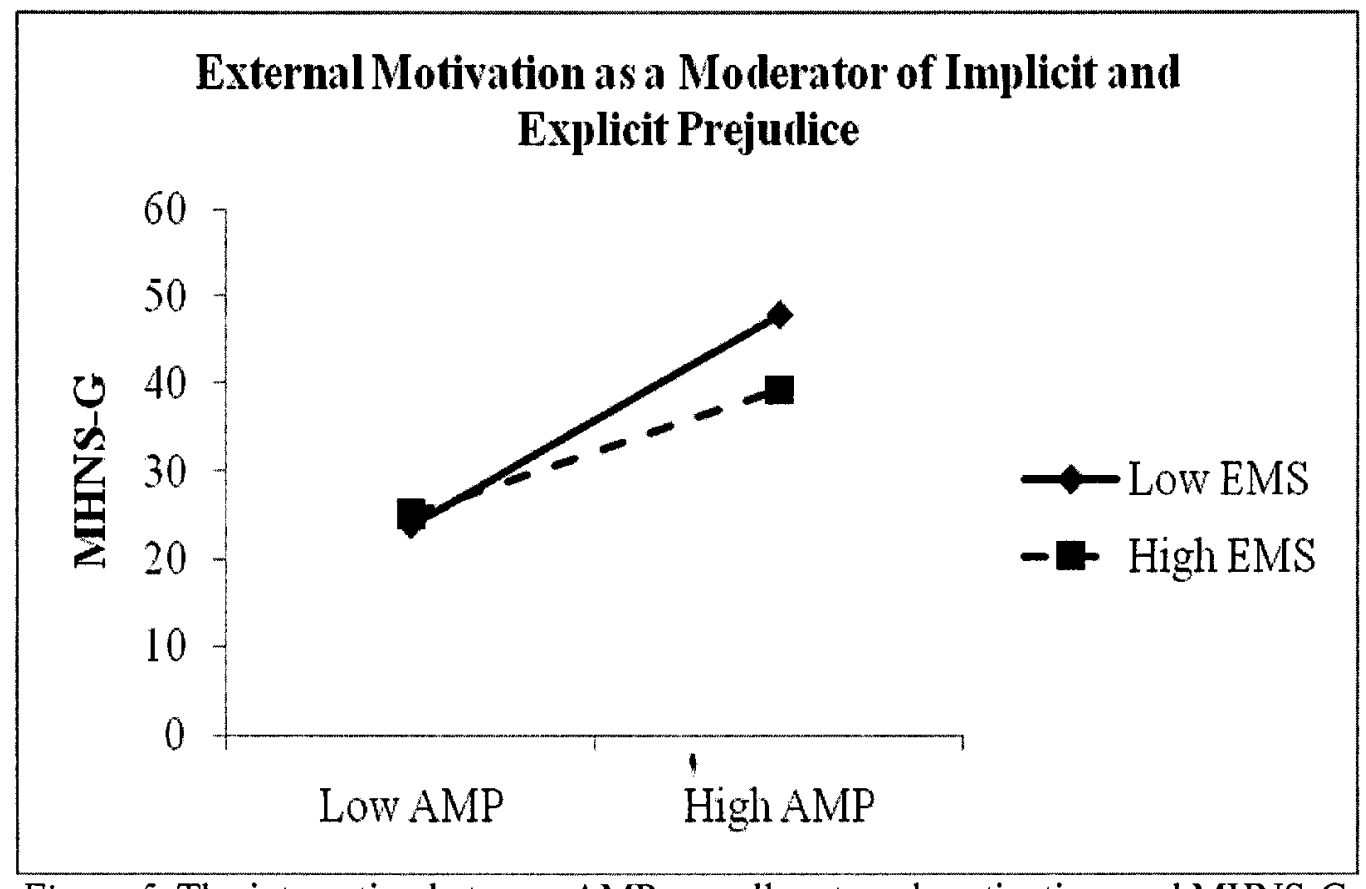

Figure 5. The interaction between AMP gay all, external motivation, and MHNS-G.

\section{Suppression of Prejudice}

Using the MHNS-G as the criterion variable, I examined the relations between implicit prejudice and suppression of prejudice using cross-product multiple regression. As shown in Table 22, when implicit prejudice, suppression, and the implicit prejudice by suppression cross product were included in the regression, there was no evidence that the interaction was significant, $\beta=-.01, t(547)=-.29, p=.77$. When only implicit prejudice and suppression were entered as predictors, both emerged as significant predictors of MHNS-G, $\beta=.49, t(549)=13.22, p<.001$, and $\beta=-.13, t(549)=-3.56, p<.001$, respectively. A similar pattern emerged when I substituted the MHNS-L as the criterion variable. Refer to Appendix B for results of these regression analyses. 
Table 22

Multiple Regression Analyses of AMP Gay All, Suppression of Prejudice, and Explicit Measures $(N=553)$

\begin{tabular}{llll}
\hline Variable & $B$ & $S E B$ & $\beta$ \\
\hline
\end{tabular}

Step 1

Implicit prejudice

Suppression
23.99

$-.94$

23.97

$-.93$

$-.32$
1.81

.26

Step 2

Implicit prejudice

Suppression

Implicit prejudice $\mathrm{x}$ suppression
$.49^{*}$

$-.13^{*}$

Note. $R^{2}=.28$ for Step $1 ; \Delta R^{2}<.001(n s)$ for Step 2 .

$* p<.01$

When other AMP scores were used in this regression model, similar patterns emerged with one exception: AMP responses that included photographs of lesbian couples kissing with the MHNS-G as the criterion variable. Implicit prejudice, suppression, and the Implicit by Suppression interaction were included in the regression. As demonstrated in Table 23, suppression emerged as a significant predictor of MHNS$\mathrm{G}, \beta=-.23, t(549)=-5.56, p<.001$, and implicit prejudice emerged as a marginally significant predictor of MHNS-G, $\beta=.08, t(549)=1.90, p=.06$. These effects were qualified, however, by a significant implicit prejudice by suppression interaction, $\beta=.13$, 
$t(549)=3.04, p=.002$. A follow-up simple slopes analysis revealed that the implicit measure was a significant predictor of explicit prejudice when suppression was high, $\beta=.20, t(549)=3.41, p=.001$. There was no evidence that the implicit measure was a significant predictor of explicit prejudice when suppression was low, $\beta=-.04, t(549)=$ $-0.74, p=.46$. Figure 6 demonstrates that, for participants who were high suppressors, AMP scores became more unpleasant as participants reported more explicit prejudice.

Table 23

Multiple Regression Analyses of AMP Lesbians Kissing, Suppression of Prejudice, and MHNS-G $(N=553)$

\begin{tabular}{llll} 
Variable & $B$ & $S E B$ & $\beta$ \\
\hline
\end{tabular}

Step 1

$\begin{array}{lrrr}\text { Implicit prejudice } & 2.55 & 1.45 & .07 \\ \text { Suppression } & -1.67 & 0.30 & -.23^{*}\end{array}$

Step 2

\begin{tabular}{lccc} 
Implicit prejudice & 2.72 & 1.44 & .08 \\
$\begin{array}{l}\text { Suppression } \\
\begin{array}{l}\text { Implicit prejudice x } \\
\text { suppression }\end{array}\end{array}$ & -1.65 & 0.30 & $-.23^{*}$ \\
\hline
\end{tabular}

Note. $R^{2}=.06$ for Step $1 ; \Delta R^{2}<=.02, p=.002$ for Step 2 .

$* p<.01$ 


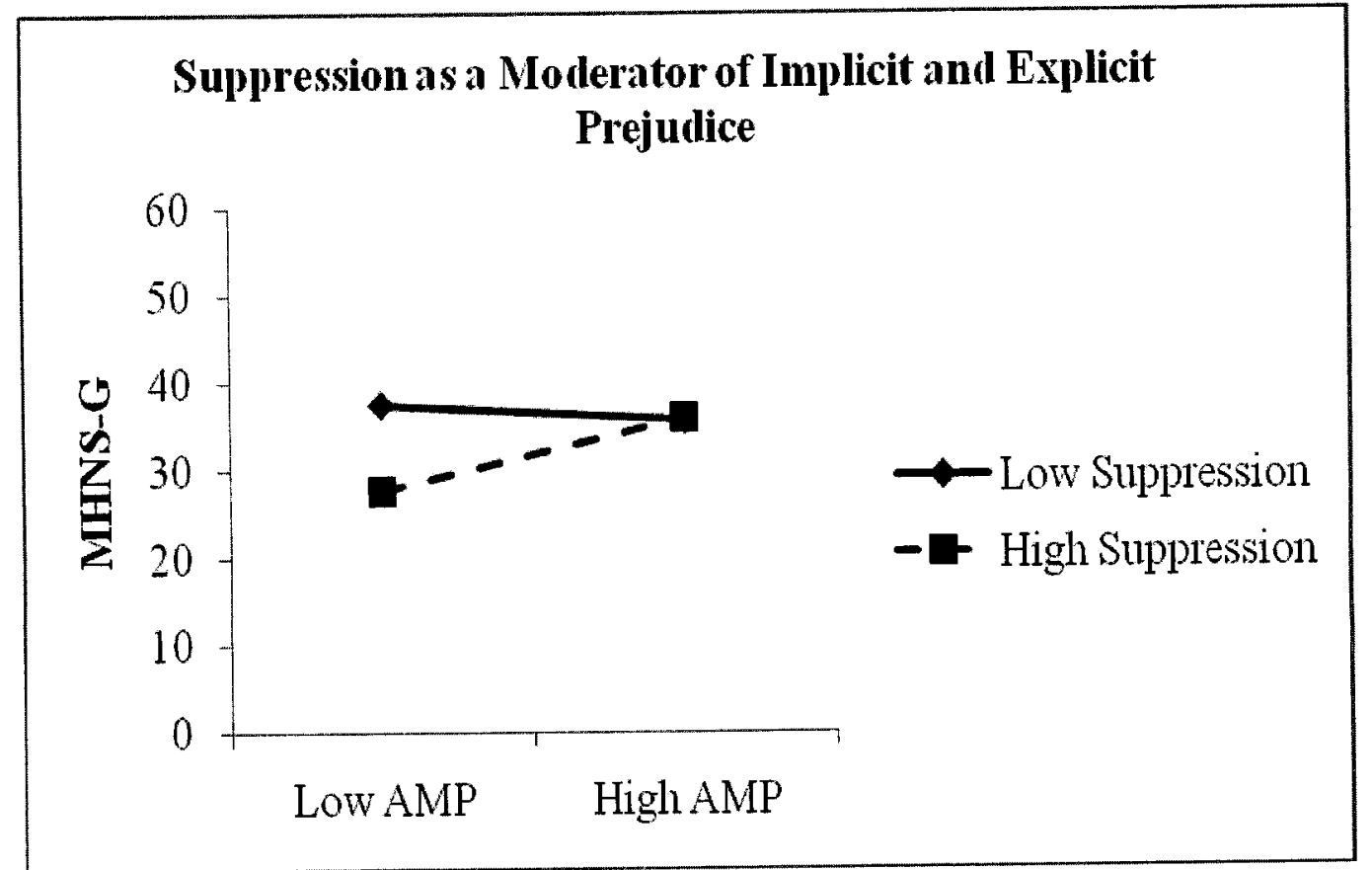

Figure 6. Interaction of AMP lesbians kissing and suppression of prejudice predicting MHNS-G.

Agreeableness

I included Agreeableness as a predictor in the model to explore its relation to internal and external motivation to respond without prejudice and suppression of prejudice. Similar to previous analyses, I began by using AMP responses to photographs of all gay men combined. I used the MHNS-G, MHNS-L, and social distance as criterion variables.

Internal motivation and MHNS scales. When I entered Agreeableness, the implicit measure, internal motivation, all two-way interactions, and the Agreeableness by AMP by Internal motivation interaction into a cross-products multiple regression analysis, there was no evidence of a significant three-way interaction, $\beta=.02, t(537)=0.50, p=.62$. As 
shown in Table 24, when the three-way interaction term was removed, there was no evidence of any significant two-way interaction; when all interactions were removed, however, a main effect for the implicit measure and internal motivation emerged as significant, $\beta=.31, t(541)=8.54, p<.001$, and $\beta=-.46 t(541)=-11.97, p<.001$, respectively. 
Table 24

Multiple Regression Analyses of Agreeableness, AMP Gay All, Internal Motivation, and MHNS-G $(N=545)$

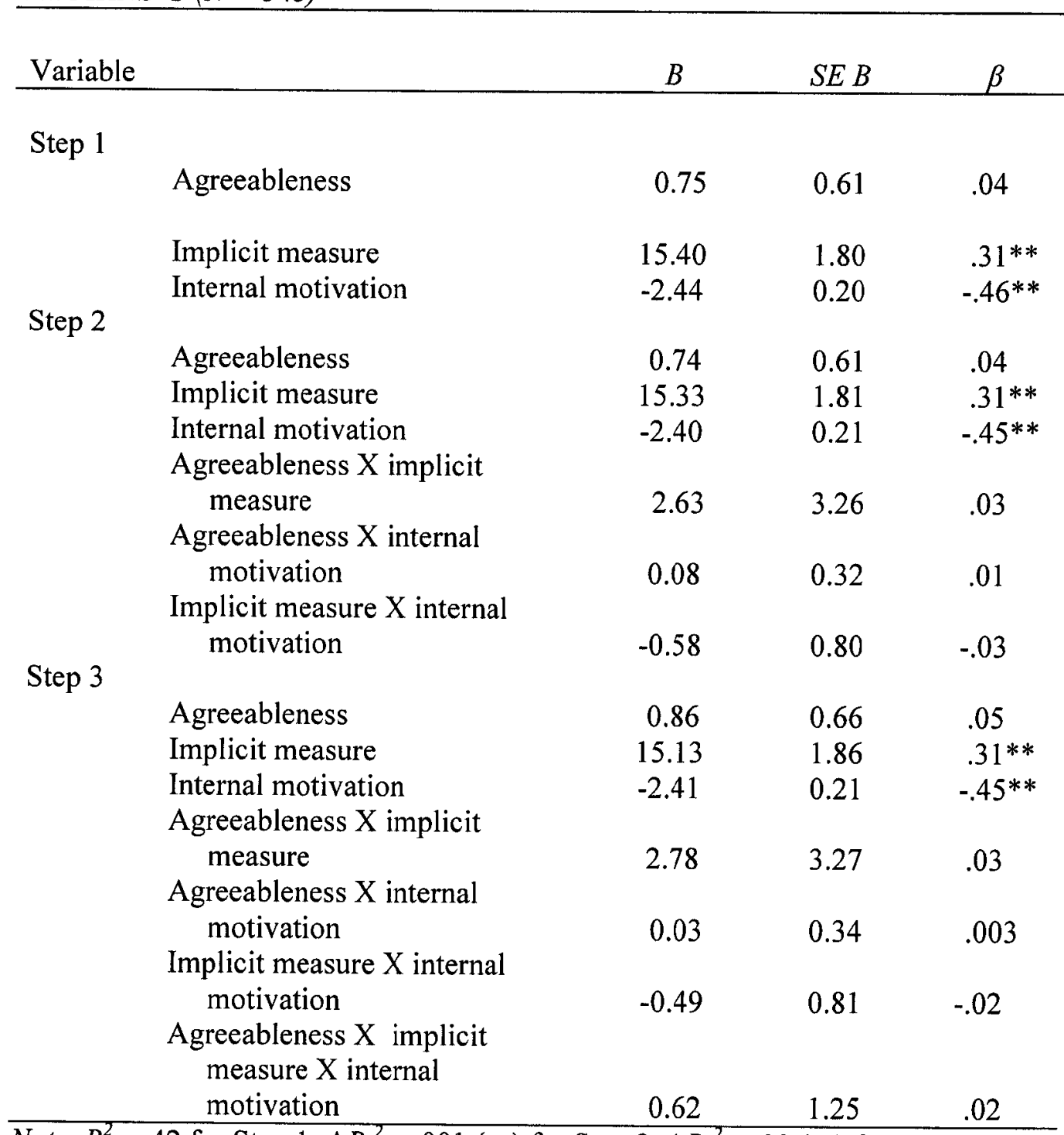

Note. $R^{2}=.42$ for Step $1 ; \Delta R^{2}=.001(n s)$ for Step $2 . \Delta R^{2}<.00(n s)$ for Step 3 .

${ }^{*} p<.05 .{ }^{* *} p<.01$. 
In contrast to the previous finding, when AMP responses to photographs of gay men in families were substituted as the implicit measure, a significant Agreeableness by Implicit measure by Internal motivation interaction emerged, $\beta=.12, t(537)=3.05$, $p=.002$. See Table 25 for the results of this analysis. A follow-up simple slopes analysis indicated that the implicit measure predicted MHNS-G for all combinations of scores on Agreeableness and internal motivation. That is, the implicit measure predicted explicit prejudice for individuals with high scores on both Agreeableness and internal motivation, $\beta=.21, t(537)=2.96, p=.003$; individuals with low scores on Agreeableness and high scores on internal motivation, $\beta=.23, t(537)=2.72, p=.01$; individuals with high scores on Agreeableness and low scores on internal motivation, $\beta=.27, t(537)=3.50, p<.001$; and for individuals with low scores on both Agreeableness and internal motivation, $\beta=$ $.21, t(537)=3.86, p<.001$. Figure 7 demonstrates the three-way interaction. The same pattern emerged when I substituted MHNS-L as my criterion variable; however, the implicit measure predicted MHNS-L only for individuals whose scores were high on Agreeableness and high on internal motivation, $\beta=.25, t(535)=3.49, p=.001$, or for individuals whose scores were low on Agreeableness and low on internal motivation, $\beta=$ $.21, t(537)=3.86, p<.001$. 
Table 25

Multiple Regression Analyses of Agreeableness, AMP Gay Families, Internal Motivation, and MHNS-G $(N=544)$

Variable

$B$

SE B

$\beta$

Step 1

Step 2

Agreeableness

1.10

0.62

.06

Implicit measure

9.05

1.47

0.20

$.23 * *$

Internal motivation

$-2.74$

$-.51 * *$

Agreeableness

1.11

0.63

.06

Implicit measure

8.98

Internal motivation

$-2.73$

1.50

0.21

$.22 * *$

Agreeableness X implicit

measure

0.72

2.67

$-.51 * *$

Agreeableness X internal

motivation

0.03

0.32

.01

Implicit Measure X internal motivation

$-0.15$

0.68

.003

Step 3

Agreeableness

Implicit measure

Internal motivation

1.71

8.92

$-2.72$

0.65

1.49

0.21

Agreeableness X implicit

measure

2.19

2.69

.03

Agreeableness X internal

motivation

$-0.13$

0.32

$-.02$

Implicit Measure $\mathrm{X}$ internal

motivation

0.03

0.68

.002

Agreeableness $\mathrm{X}$ implicit measure $X$ internal motivation

3.24

1.06 $.12^{* *}$

Note. $R^{2}=.39$ for Step $1 ; \Delta R^{2}<.001(n s)$ for Step $2 . \Delta R^{2}=.01(p<.01)$ for Step 3.

${ }^{*} p<.05 ;{ }^{* *} p<.01$. 


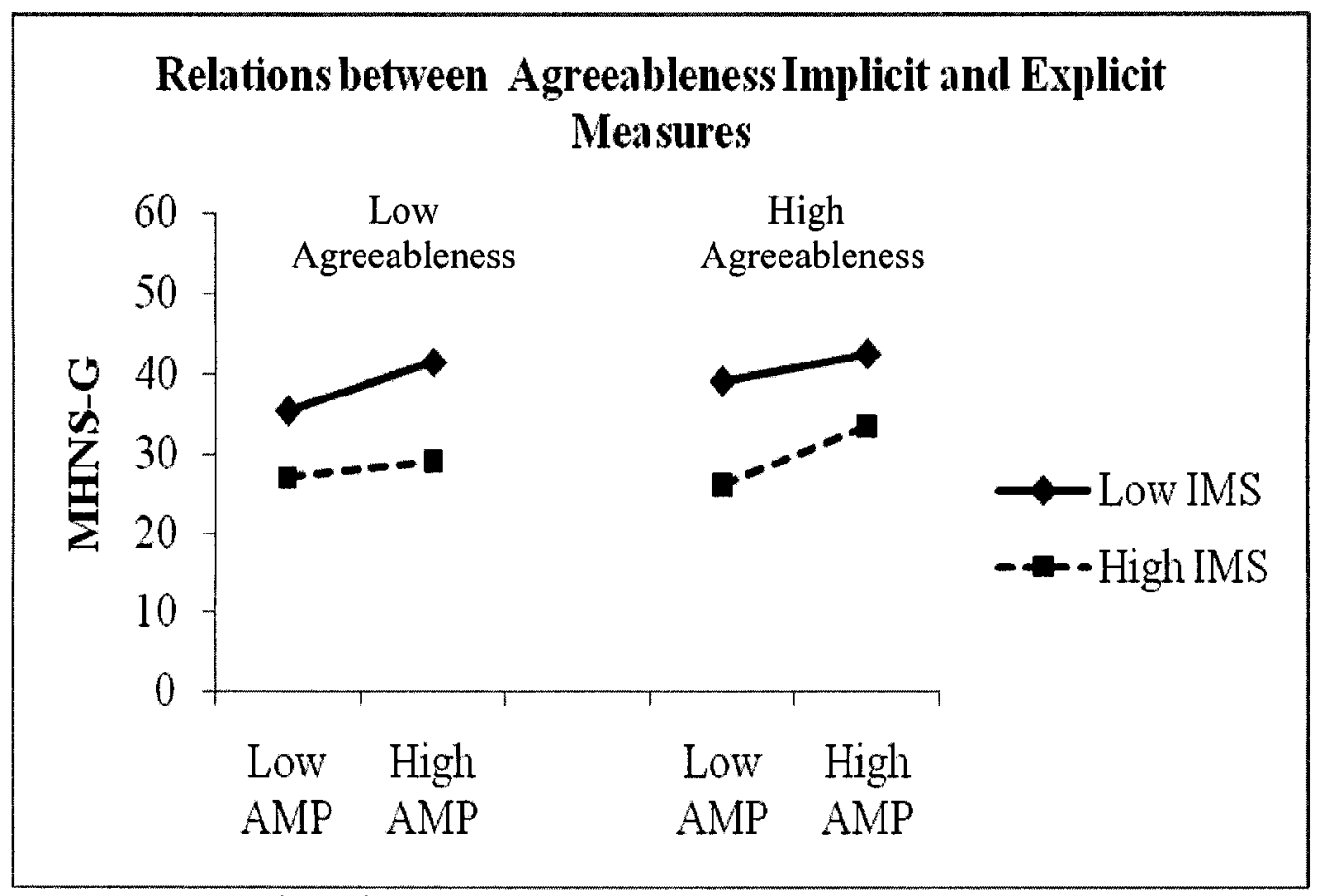

Figure 7. Interaction of agreeableness, amp gay families, and internal motivation as a predictor of MHNS-G.

Internal motivation and social distance. Using social distance as the criterion variable, I examined the relations between Agreeableness, implicit prejudice, and internal motivation using cross-product multiple regression. When Agreeableness, implicit prejudice, internal motivation, all two-way interactions, and the Agreeableness by Implicit by Internal motivation interaction were included in the regression, the three-way interaction emerged as significant, $\beta=-.19, t(188)=-2.37, p=.02$. The results are presented in Table 26. As demonstrated in Figure 8, a follow-up analysis of simple slopes revealed that the implicit measure predicted social distance only for participants with both low Agreeableness scores and low internal motivation scores, $\beta=-.18, t(197)=-$ 
$2.48, p=.01$. For these individuals, as AMP responses became more unpleasant, social distance scores became more positive. A similar pattern emerged when AMP responses to heterosexual families were substituted for the implicit measure. 
Table 26

Multiple Regression Analyses of Agreeableness, AMP Gay All, Internal Motivation, and Social Distance $(N=196)$

\begin{tabular}{|c|c|c|c|c|}
\hline Variable & & $B$ & $S E B$ & $\beta$ \\
\hline \multicolumn{5}{|l|}{ Step 1} \\
\hline & Agreeableness & 0.07 & 0.07 & .07 \\
\hline & Implicit measure & -0.35 & 0.21 & -.13 \\
\hline & Internal motivation & 0.04 & 0.02 & .12 \\
\hline \multicolumn{5}{|l|}{ Step 2} \\
\hline & Agreeableness & 0.07 & 0.07 & .08 \\
\hline & Implicit measure & -0.31 & 0.21 & -.11 \\
\hline & Internal motivation & 0.03 & 0.03 & -.03 \\
\hline & Agreeableness X implicit & & & \\
\hline & measure & -0.14 & 0.38 & -.03 \\
\hline & $\begin{array}{l}\text { Agreeableness } X \text { internal } \\
\text { motivation }\end{array}$ & 0.03 & 0.04 & .07 \\
\hline & $\begin{array}{l}\text { Implicit measure } \mathrm{X} \text { internal } \\
\text { motivation }\end{array}$ & 0.12 & 0.10 & .09 \\
\hline \multicolumn{5}{|l|}{ Step 3} \\
\hline & Agreeableness & 0.02 & 0.09 & .02 \\
\hline & Implicit measure & -0.15 & 0.22 & -.06 \\
\hline & Internal motivation & 0.05 & 0.03 & .17 \\
\hline & Agreeableness X implicit & & & \\
\hline & measure & -0.19 & 0.37 & -.04 \\
\hline & Agreeableness X internal & & & \\
\hline & motivation & 0.06 & 0.04 & .12 \\
\hline & $\begin{array}{l}\text { Implicit measure } \mathrm{X} \text { internal } \\
\text { motivation }\end{array}$ & 0.09 & 0.10 & .08 \\
\hline & $\begin{array}{l}\text { Agreeableness } X \text { implicit } \\
\text { measure } X \text { internal } \\
\text { motivation }\end{array}$ & -0.34 & 0.15 & $-0.19^{*}$ \\
\hline
\end{tabular}

Note. $R^{2}=.05$ for Step $1 ; \Delta R^{2}=.02(n s)$ for Step $2 . \Delta R^{2}=.03(p=.02)$ for Step 3 .

${ }^{*} p<.05 .{ }^{* *} p<.01$. 


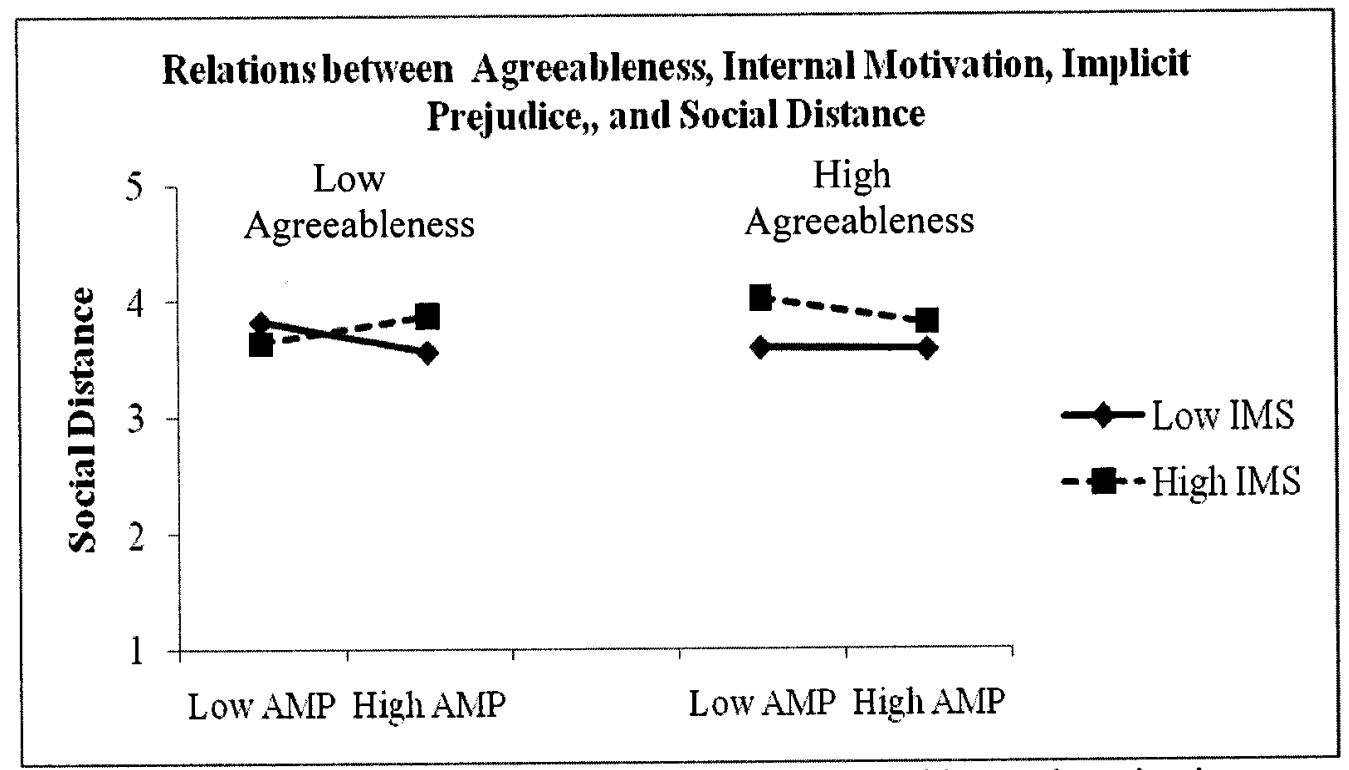

Figure 8. Interaction of Agreeableness, AMP gay all, and internal motivation as a predictor of social distance.

Although a significant three-way interaction emerged when I substituted AMP responses to photographs of lesbians in families as the implicit measure, $\beta=-.19, t$ $(188)=-2.45, p=.02$, the simple slopes analysis revealed a different pattern of results. As shown in Figure 9, the implicit measure was a significant predictor of social distance only for individuals low in Agreeableness and high in internal motivation, $\beta=.33, t$ $(188)=1.98, p=.05$. 


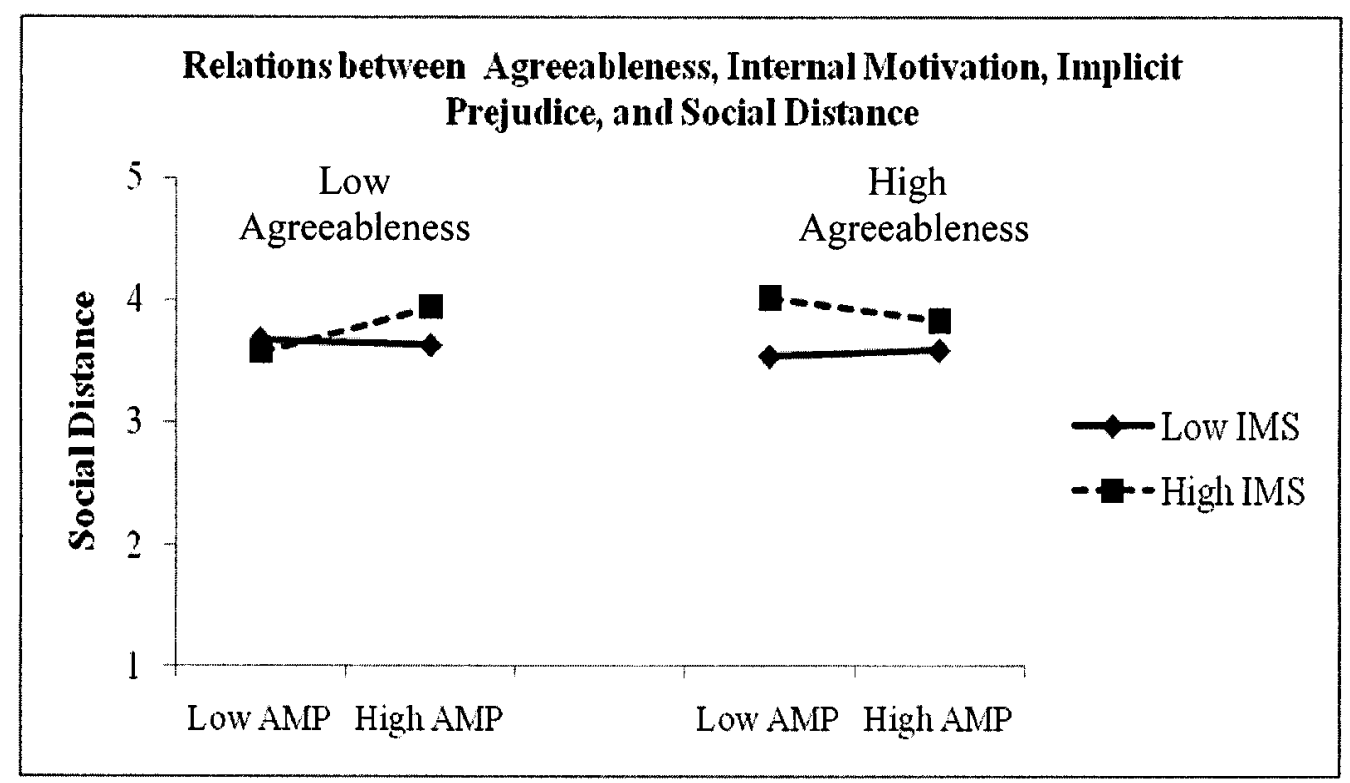

Figure 9. Interaction of agreeableness, AMP lesbian families, and internal motivation as a predictor of social distance.

External motivation and MHNS scales. When I entered Agreeableness, the implicit measure, external motivation, all two-way interactions, and the Agreeableness by AMP by External motivation interaction into a cross-products multiple regression analysis, there was no evidence of a significant three-way interaction, $\beta=.05, t(535)=$ $1.23, p=.22$. As shown in Table 27, when the three-way interaction term was removed, the Implicit by External motivation interaction emerged as significant, $\beta=-.11, t(535)=$ $-2.85, p=.01$. A follow-up simple slopes analysis indicated that the implicit measure predicted MHNS-G for individuals whose scores were low on external motivation, $\beta=$ $.34, t(541)=6.31, p<.001$, and it predicted MHNS-G for individuals whose scores were high on external motivation, $\beta=.57, t(541)=12.48, p<.001$. Figure 10 shows this interaction. 
Table 27

Multiple Regression Analyses of Agreeableness, AMP Gay All, External Motivation, and MHNS-G $(N=543)$

\begin{tabular}{|c|c|c|c|c|}
\hline Variable & & $B$ & $S E B$ & $\beta$ \\
\hline \multicolumn{5}{|l|}{ Step 1} \\
\hline & Agreeableness & -1.22 & 0.66 & -.71 \\
\hline & Implicit measure & 20.59 & 1.83 & $.43^{* *}$ \\
\hline & External motivation & -0.87 & 0.21 & $-.16^{* *}$ \\
\hline \multicolumn{5}{|l|}{ Step 2} \\
\hline & Agreeableness & -1.08 & 0.66 & -.06 \\
\hline & Implicit measure & 19.88 & 1.85 & $.41 * *$ \\
\hline & External motivation & -0.87 & 0.21 & $-.16^{* *}$ \\
\hline & $\begin{array}{l}\text { Agreeableness X implicit } \\
\text { measure }\end{array}$ & 4.60 & 3.23 & .06 \\
\hline & Agreeableness X external & & & \\
\hline & motivation & -0.05 & 0.32 & -.01 \\
\hline & $\begin{array}{l}\text { Implicit measure X external } \\
\text { motivation }\end{array}$ & -2.24 & 0.89 & $-.11^{*}$ \\
\hline \multicolumn{5}{|l|}{ Step 3} \\
\hline & Agreeableness & -0.95 & 0.66 & -.06 \\
\hline & Implicit measure & 19.42 & 1.89 & $0.40 * *$ \\
\hline & External motivation & -0.85 & 0.21 & $-.16 * *$ \\
\hline & Agreeableness X implicit & & & \\
\hline & measure & 5.25 & 3.27 & .06 \\
\hline & $\begin{array}{l}\text { Agreeableness } \mathrm{X} \text { external } \\
\text { motivation }\end{array}$ & -0.08 & 0.32 & -.01 \\
\hline & $\begin{array}{l}\text { Implicit measure } \mathrm{X} \text { external } \\
\text { motivation }\end{array}$ & -2.59 & 0.89 & $-.11 *$ \\
\hline & $\begin{array}{l}\text { Agreeableness X implicit } \\
\text { measure X external } \\
\text { motivation }\end{array}$ & 1.73 & 1.41 & .05 \\
\hline
\end{tabular}




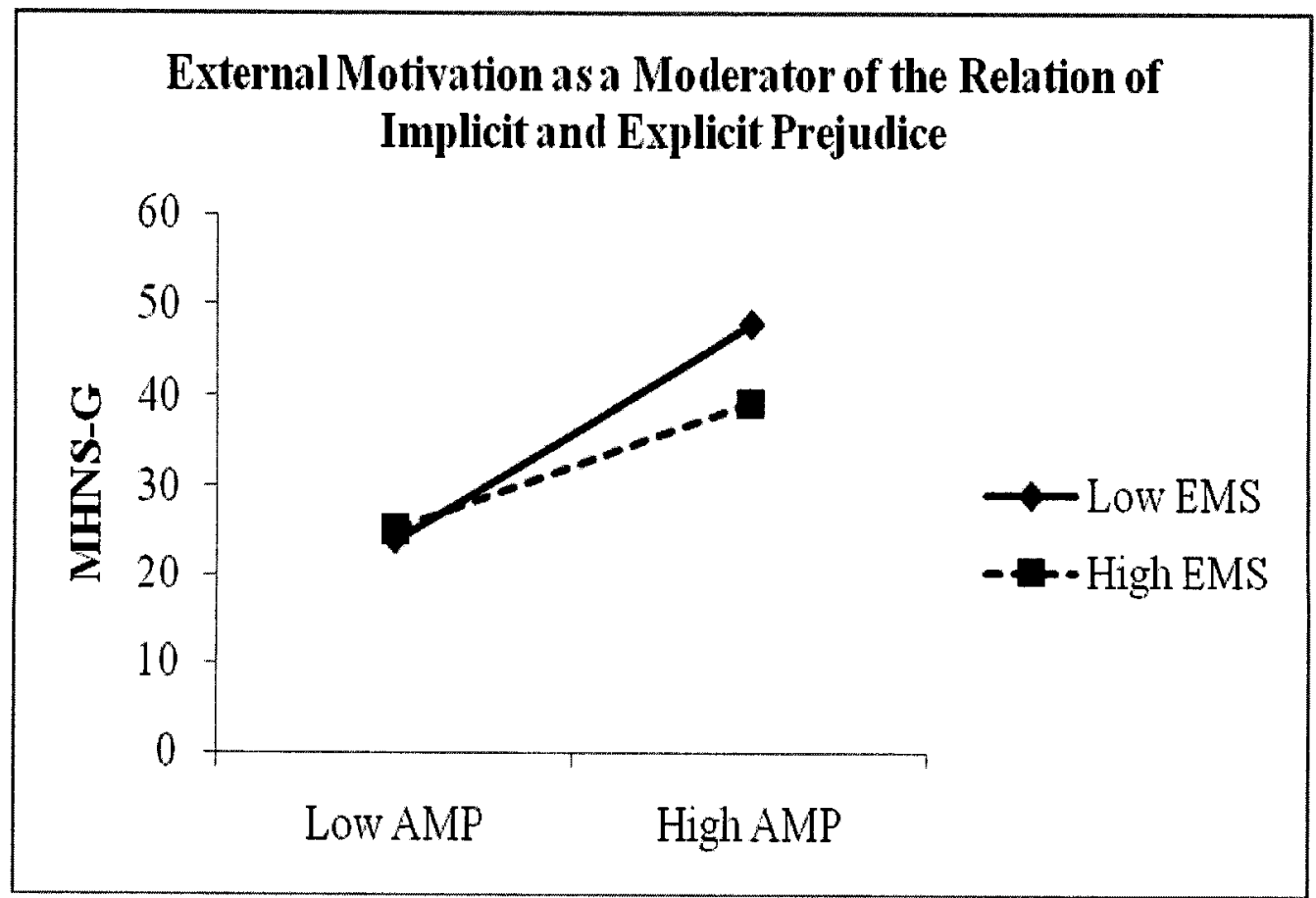

Figure 10. Interaction of AMP gay all and external motivation as a predictor of MHNS-G.

When I substituted AMP responses to photographs of gay men in families into the same regression analysis, the Agreeableness by Implicit measure by External motivation interaction emerged as a significant predictor of MHNS-G, $\beta=.10, t(537)=2.50, p=.01$. Refer to Table 28 for the results of this analysis. Follow-up simple slopes analyses revealed that the implicit measure predicted MHNS-G for individuals whose scores were high on Agreeableness and high on external motivation, $\beta=.26, t(537)=3.72, p<.001$; high on Agreeableness and low on external motivation, $\beta=.52, t(537)=6.47, p<.001$; and for individuals whose scores were low on Agreeableness and high on external motivation, $\beta=.19, t(537)=2.01, p=.05$, and low on Agreeableness and low on external 
motivation, $\beta=.46, t(537)=7.09, p<.001$. That is, the implicit measure predicted MHNS-G for all combinations of Agreeableness scores and external motivation scores.

Figure 11 presents the relations between these variables. A similar pattern emerged when AMP responses to photographs of all lesbians combined were substituted into the same regression analysis; however, there was no evidence that the implicit measure predicted the explicit measure for participants low in Agreeableness and high in external motivation, $\beta=.07, t(537)=0.73, p=.46$. The same pattern emerged when MHNS-L was substituted as the criterion variable. 
Table 28

Multiple Regression Analyses of Agreeableness, AMP Gay Families, External Motivation, and MHNS-G $(N=545)$

\begin{tabular}{|c|c|c|c|c|}
\hline Variable & & $B$ & $S E B$ & $\beta$ \\
\hline \multicolumn{5}{|l|}{ Step 1} \\
\hline & Agreeableness & -0.70 & 0.69 & -.04 \\
\hline \multirow{6}{*}{ Step 2} & Implicit measure & 15.02 & 1.57 & $.37^{* *}$ \\
\hline & External motivation & -1.04 & 0.22 & $-.19 * *$ \\
\hline & Agreeableness & -0.60 & 0.68 & -.03 \\
\hline & Implicit measure & 14.28 & 1.57 & $.36^{* *}$ \\
\hline & External motivation & -1.001 & 0.22 & $-.18^{* *}$ \\
\hline & Agreeableness X implicit & & & \\
\hline \multirow{16}{*}{ Step 3} & measure & 2.20 & 2.77 & .03 \\
\hline & Agreeableness X external & & & \\
\hline & motivation & 0.26 & 0.33 & .03 \\
\hline & $\begin{array}{l}\text { Implicit measure } \mathrm{X} \text { external } \\
\text { motivation }\end{array}$ & -2.81 & 0.79 & $-.14 * *$ \\
\hline & & & & \\
\hline & Agreeableness & -0.43 & 0.68 & -.02 \\
\hline & Implicit measure & 14.07 & 1.56 & $.35 * *$ \\
\hline & External motivation & -0.98 & 0.22 & $-.18 * *$ \\
\hline & Agreeableness X implicit & & & \\
\hline & measure & 2.96 & 2.77 & .04 \\
\hline & Agreeableness X external & & & \\
\hline & motivation & 0.23 & 0.33 & .03 \\
\hline & Implicit Measure X external & & & \\
\hline & motivation & -2.76 & 0.79 & $-.14^{* *}$ \\
\hline & $\begin{array}{c}\text { Agreeableness } X \text { implicit } \\
\text { measure } X \text { external }\end{array}$ & & & \\
\hline & motivation & 2.81 & 1.12 & $.10^{*}$ \\
\hline
\end{tabular}




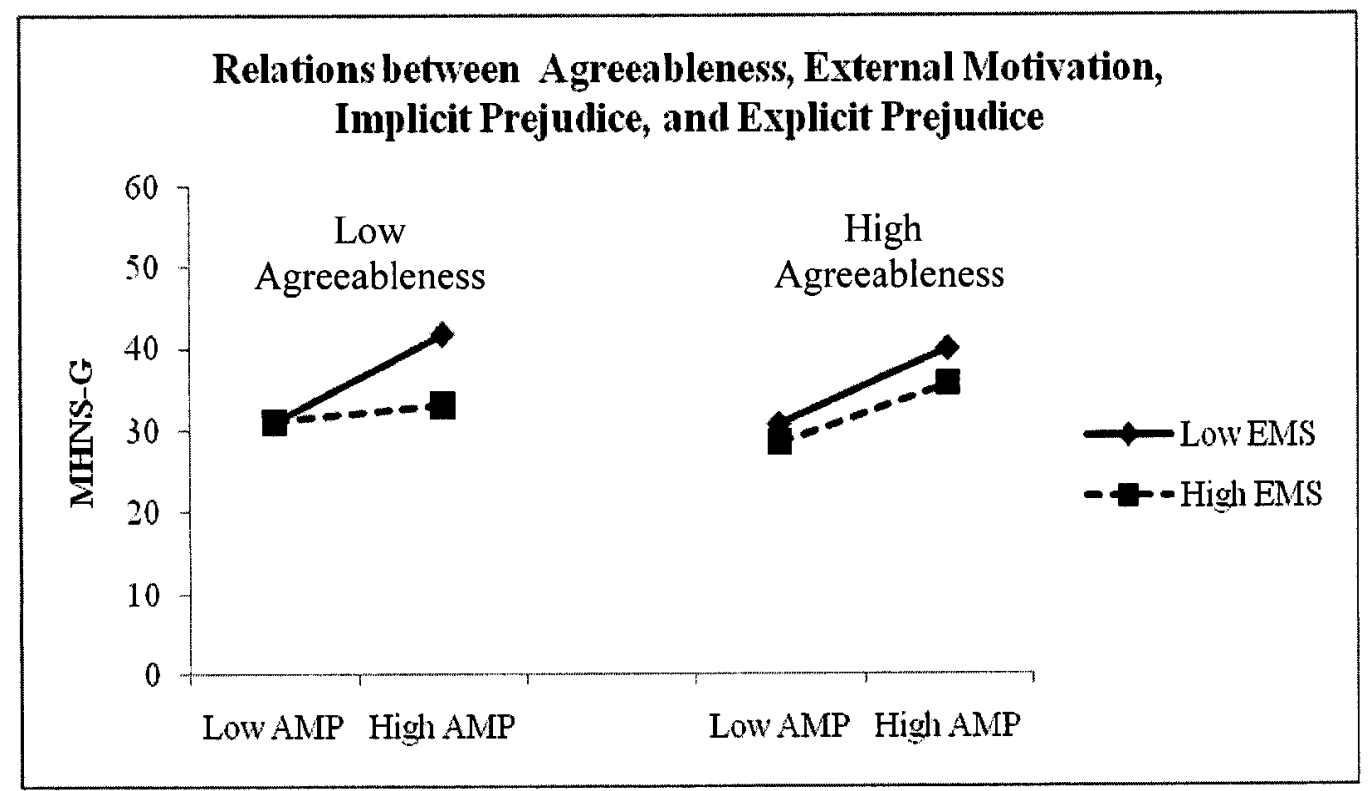

Figure 11. Three-way interaction for agreeableness, AMP gay families, and external motivation.

External motivation and social distance. When I entered Agreeableness, the implicit measure, external motivation, all two-way interactions, and the Agreeableness by AMP by External motivation interaction into a cross-products multiple regression analysis, the three-way interaction emerged as significant, $\beta=-.22, t(188)=-3.10$, $p=.002$. Table 29 shows the results of the analysis. A follow-up simple slopes analysis indicated that the implicit measure predicted social distance only for individuals whose scores were low on Agreeableness and low on external motivation, $\beta=-.38, t(188)=-$ $2.50, p=.01$. Figure 12 shows this interaction. 
Table 29

Multiple Regression Analyses of Agreeableness, AMP Heterosexual Families, External Motivation, and Social Distance $(N=196)$

Variable

Step 1

Step 2
$B$

0.09

$-0.06$

0.01
$S E B$

0.07

0.17

0.02

0.07

0.17

0.02

$-0.11$

0.01

$-0.03$

0.31

$-0.05$

0.04

0.09

0.09

0.11

$-0.08$

0.01

0.07

0.17

0.02

0.14

0.30

$-0.05$

0.04

$-.11$

motivation
mplicit measure $\mathrm{X}$ external

motivation

$0.12 \quad 0.09$

$-0.44$

motivation

0.14

.09

$-.03$

.02

Agreeableness $\mathrm{X}$ implicit

$-.05$

External motivation

Note. $R^{2}=.01$ for Step $1 ; \Delta R^{2}=.02(n s)$ for Step $2 . \Delta R^{2}=.05(p<.001)$ for Step 3 .

${ }^{*} p<.05 .{ }^{* *} p<.01$. 


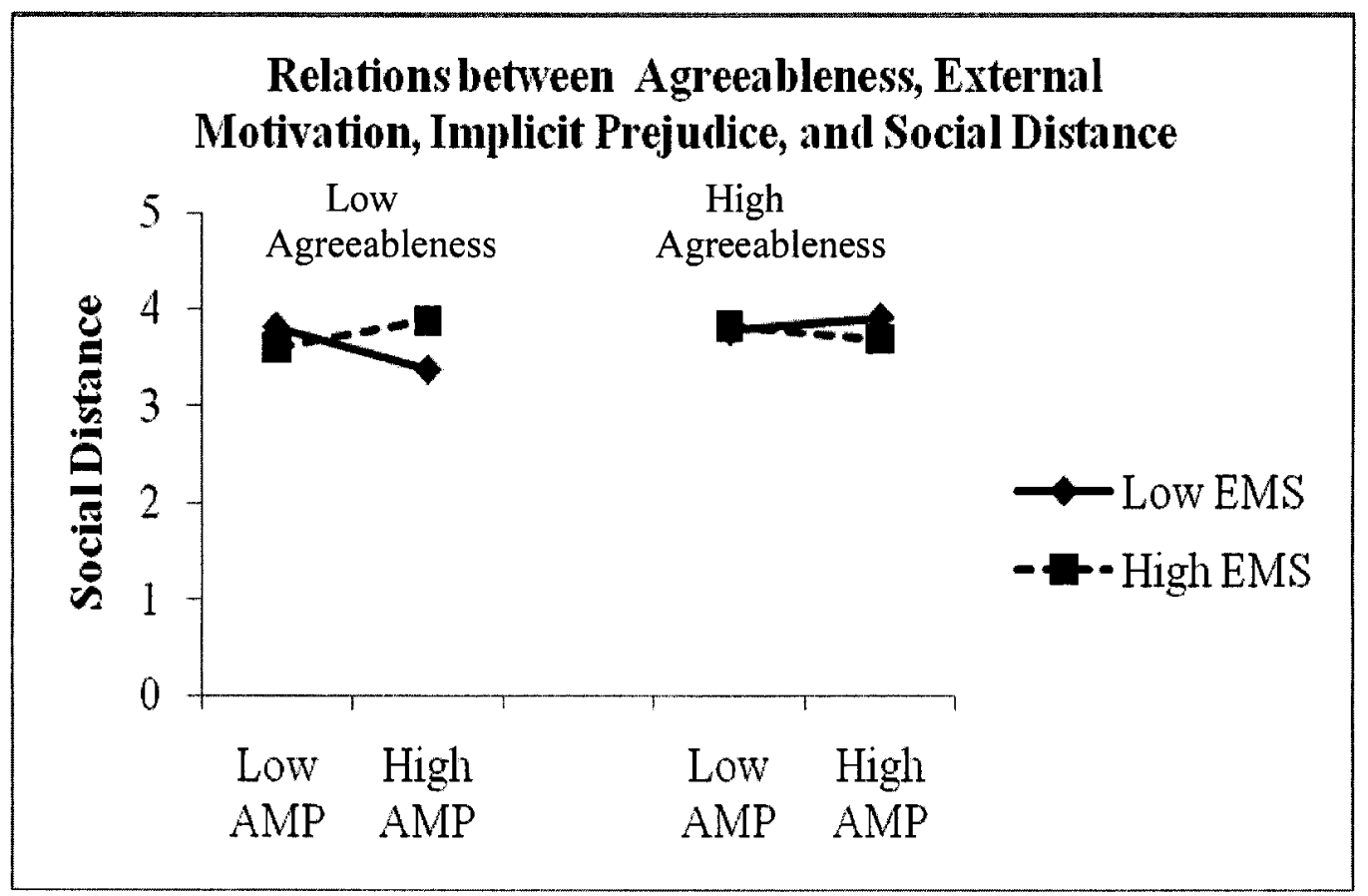

Figure 12. Three-way interaction of agreeableness, AMP heterosexual families, and external motivation predicting social distance.

Suppression of prejudice and MHNS scales. When I entered Agreeableness, the implicit measure, suppression, all two-way interactions, and the Agreeableness by AMP by Suppression interaction into a cross-products multiple regression analysis with MHNS-G as the criterion variable, there was no evidence that the three-way interaction was significant, $\beta=.01, t(545)=0.20, p=.84$. Similarly, when I removed the three-way interaction from the analysis, there was no evidence that any of the two-way interactions were significant. Table 30 demonstrates that when all interactions were removed from the analysis, there was a significant main effect for the implicit measure, $\beta=.49, t$ $(549)=13.27, p<.001$, indicating that as AMP scores became more unpleasant, MHNS- 
$\mathrm{G}$ scores increased. Also, there was a main effect for suppression, $\beta=-.12, t(549)=$ -

$2.95, p=.003$, indicating that as suppression scores decreased, MHNS-G scores increased.

That is, low suppressors endorsed more negative attitudes on the MHNS-G.

Table 30

Multiple Regression Analyses of Agreeableness, AMP Gay All, Suppression of Prejudice, and MHNS-G $(N=553)$

Variable

$B$

$S E B$

$\beta$

Step 1

Step 2

Agreeableness

Implicit measure

Suppression

Agreeableness

Implicit measure

Suppression

Agreeableness X implicit measure

Agreeableness X suppression

Implicit measure $\mathrm{X}$ suppression

Step 3

\section{Agreeableness}

Implicit measure

Suppression

Agreeableness X implicit measure

Agreeableness X suppression

Implicit measure $X$ suppression

Agreeableness $X$ implicit measure $X$ suppression $\begin{array}{lll}-0.87 & 0.68 & -.05\end{array}$

$24.08 \quad 1.81 \quad .49^{* *}$

$\begin{array}{lll}-0.82 & 0.28 & -.12 * *\end{array}$

$-0.56$

0.70

1.82

0.28

$-.03$

23.81

$-0.86$

3.45

0.42

$\begin{array}{lll}0.71 & 0.42 \quad .07\end{array}$

$-0.36$

1.19

$-.01$

$-0.53$

23.70

$-0.86$

0.72

1.90

0.28

$-.03$

3.45

3.51

0.43

.04

0.70

.07

$-0.32$

1.21

$-.01$

0.36

1.75

.01

Note. $R^{2}=.28$ for Step $1 ; \Delta R^{2}=.004(n s)$ for Step $2 . \Delta R^{2}<.001$ (ns) for Step 3 .

${ }^{*} p<.05 .{ }^{* *} p<.01$. 
When I substituted other AMP responses as our implicit measure, a similar pattern emerged with one exception: AMP responses to photographs of lesbians kissing. When I entered this variable into same regression analysis, the Agreeableness by Implicit measure by Suppression interaction emerged as significant, $\beta=.11, t(545)=\quad-2.46$, $p=.01$. Refer to Table 31 for these results. 
Table 31

Multiple Regression Analyses of Agreeableness, AMP Lesbians Kissing, Suppression of Prejudice, and MHNS-G $(N=553)$

\begin{tabular}{|c|c|c|c|c|}
\hline Variable & & $B$ & $S E B$ & $\beta$ \\
\hline \multicolumn{5}{|l|}{ Step 1} \\
\hline & Agreeableness & -0.67 & 0.79 & -.04 \\
\hline & Implicit measure & 2.70 & 1.46 & .08 \\
\hline & Suppression & -1.59 & 0.31 & $-.22 * *$ \\
\hline \multicolumn{5}{|l|}{ Step 2} \\
\hline & Agreeableness & -0.52 & 0.80 & -.03 \\
\hline & Implicit measure & 2.61 & 1.45 & .08 \\
\hline & Suppression & -1.50 & 0.31 & $-.21 * *$ \\
\hline & Agreeableness $\mathrm{X}$ implicit & & & \\
\hline & measure & -3.34 & 2.50 & -.06 \\
\hline & $\begin{array}{l}\text { Agreeableness } X \text { suppression } \\
\text { Implicit measure } X\end{array}$ & 0.94 & 0.46 & $.09 *$ \\
\hline & suppression & 3.33 & 1.004 & $.15^{* *}$ \\
\hline \multicolumn{5}{|l|}{ Step 3} \\
\hline & Agreeableness & -0.57 & 0.80 & -.03 \\
\hline & Implicit measure & 1.56 & 1.51 & .05 \\
\hline & Suppression & -1.53 & 0.31 & $-.21 * *$ \\
\hline & Agreeableness X implicit & & & \\
\hline & measure & -1.80 & 2.56 & -.03 \\
\hline & Agreeableness X suppression & 0.74 & 0.46 & .07 \\
\hline & Implicit measure $X$ & & & \\
\hline & suppression & 3.48 & 1.001 & $.15^{* *}$ \\
\hline & Agreeableness X implicit & & & \\
\hline & measure $X$ suppression & 3.50 & 1.42 & $.11^{*}$ \\
\hline
\end{tabular}

Step 3.

${ }^{*} p<.05 .{ }^{* *} p<.01$.

A follow-up simple slopes analysis indicated that the implicit measure predicted MHNS-G for individuals whose scores were high on Agreeableness and low or high on 
external motivation, $\beta=-.22, t(545)=-2.48, p=.01, \beta=.25, t(545)=3.32, p=.001$, respectively. That is, the implicit measure predicted MHNS-G for people high in Agreeableness regardless of whether or not they were low or high on the suppression scale. Further, as Figure 13 demonstrates, there was a negative relation for the implicit and explicit measure for low suppressors, whereas there was a positive relation for the implicit and explicit measure for high suppressors. It appears that high suppressors may have worked harder than low suppressors to suppress negative attitudes on the explicit measure. This pattern did not emerge when MHNS-L was substituted as the criterion variable.

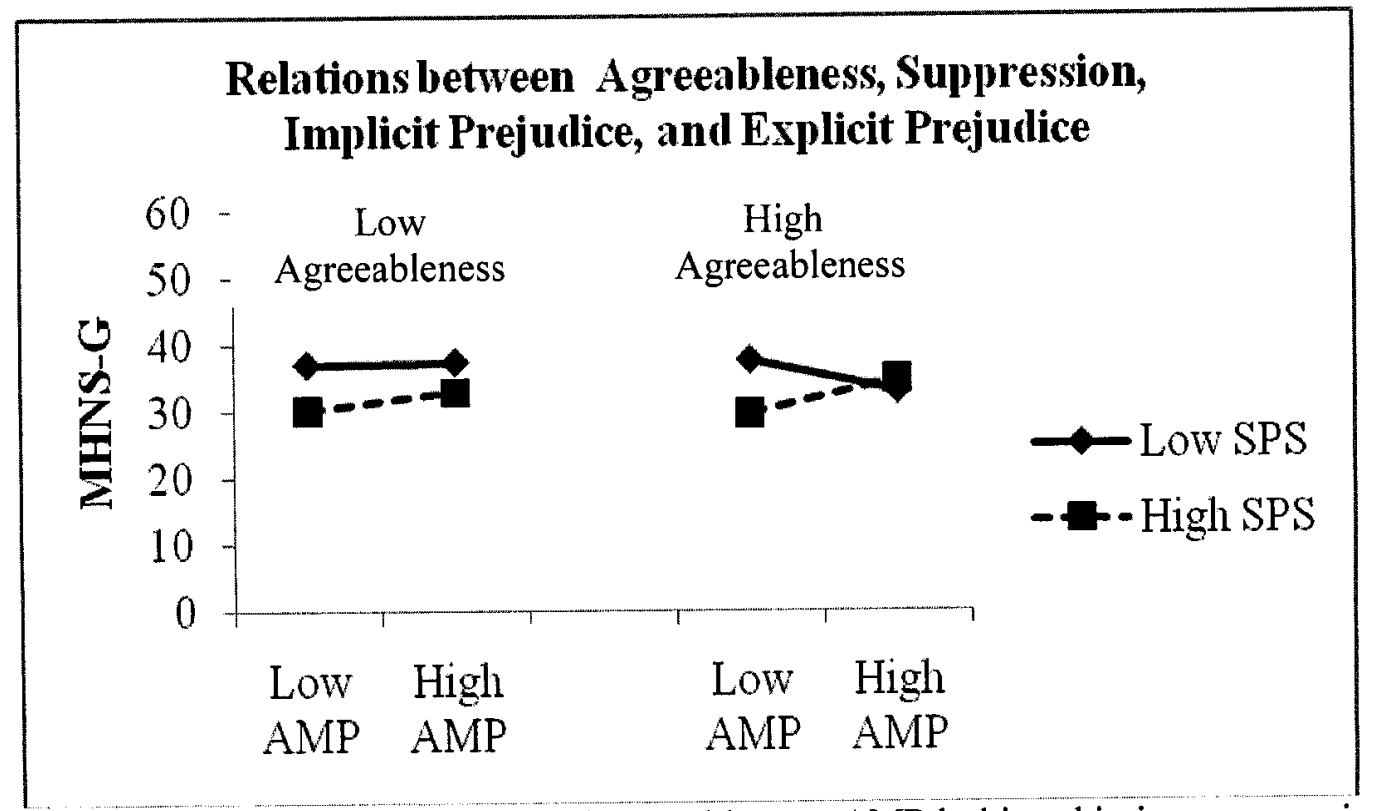

Figure 13. Three-way interaction of agreeableness, AMP lesbians kissing, suppression, and MHNS-G. 
Suppression of prejudice and social distance. Using social distance as the criterion variable, I examined the relations between Agreeableness, implicit prejudice, and suppression of prejudice using cross-product multiple regression. When Agreeableness, implicit prejudice, suppression, all two-way interactions, and the Agreeableness by Implicit by Suppression interaction were included in the regression, there was no evidence that the interaction was significant, $\beta=-.001, t(193)=-0.02, p=$ 99. As shown in Table 32, when the three-way interaction term was removed, there was no evidence that any of the two-way interactions were significant. When all interactions were removed from the regression analysis, a main effect for implicit prejudice emerged as a significant predictor of social distance, $\beta=-.18, t(197)=-2.48, p=.01$. As AMP responses became more unpleasant, social distance scores became more positive. A similar pattern of results emerged when other AMP responses were entered into the analysis. 
Table 32

Multiple Regression Analyses of Agreeableness, AMP Gay All, Suppression of Prejudice, and Social Distance $(N=201)$

\begin{tabular}{|c|c|c|c|c|}
\hline Variable & & $B$ & $S E B$ & $\beta$ \\
\hline \multicolumn{5}{|l|}{ Step 1} \\
\hline & Agreeableness & 0.10 & 0.07 & .10 \\
\hline & Implicit measure & -0.49 & 0.20 & $-.18^{*}$ \\
\hline & Suppression & -0.002 & 0.03 & -.004 \\
\hline \multicolumn{5}{|l|}{ Step 2} \\
\hline & Agreeableness & 0.12 & 0.08 & .12 \\
\hline & Implicit measure & -0.49 & 0.20 & $-0.17^{*}$ \\
\hline & Suppression & 0.001 & 0.03 & .001 \\
\hline & Agreeableness X implicit & & & \\
\hline & measure & -0.24 & 0.39 & -.05 \\
\hline & Agreeableness X suppression & 0.05 & 0.05 & .07 \\
\hline & Implicit measure $\mathrm{X}$ & & & \\
\hline & suppression & 0.11 & 0.14 & .06 \\
\hline \multicolumn{5}{|l|}{ Step 3} \\
\hline & Agreeableness & 0.12 & 0.08 & .12 \\
\hline & Implicit measure & -0.49 & 0.22 & $-.17^{*}$ \\
\hline & Suppression & 0.001 & 0.03 & .001 \\
\hline & $\begin{array}{l}\text { Agreeableness } \mathrm{X} \text { implicit } \\
\text { measure }\end{array}$ & -0.24 & 0.40 & -.05 \\
\hline & $\begin{array}{l}\text { Agreeableness } X \text { suppression } \\
\text { Implicit measure } X\end{array}$ & 0.05 & 0.05 & .07 \\
\hline & suppression & 0.11 & 0.14 & .06 \\
\hline & $\begin{array}{l}\text { Agreeableness X implicit } \\
\text { measure X suppression }\end{array}$ & -0.003 & 0.20 & -.001 \\
\hline
\end{tabular}

Note. $R^{2}=.04$ for Step $1 ; \Delta R^{2}=.01(n s)$ for Step $2 . \Delta R^{2}<.001(n s)$ for Step 3 .

${ }^{*} p<.05 .{ }^{* *} p<.01$. 


\section{Participant Sex Differences}

Although my hypotheses did not include predictions based on different response patterns for male and female participants, I conducted some supplementary analyses to further understand the data. In some cases, participant sex was already addressed in the hypothesis testing section (e.g., Hypothesis One); therefore, these hypotheses will not be revisited in this section. The remaining hypotheses for which sex of participant was not covered are discussed below.

\section{Hypothesis Two}

All gay male photographs. I predicted that implicit and explicit measures of prejudice would be related. Specifically, I predicted that AMP responses would be correlated with the Modern Homo-negativity Scales for Gay Men and Lesbians (MHNSG and MHNS-L). In hypothesis testing, I focused primarily on the relations between AMP responses to all gay photographs combined and the explicit prejudice measure for gay men. I found that the implicit measure for all slides of gay men was related to the explicit prejudice measure, MHNS-G. To examine whether sex of participant moderated this relation, I conducted a cross-products multiple regression analysis with all gay photographs, participant sex, and the all gay photographs by participant sex interaction term included. There was no evidence that the two-way interaction predicted the explicit measure, $\beta=.07, t(549)=1.01, p=.31$. A similar pattern of results was found for analyses involving photographs of gay men kissing and gay men in families. It was interesting, although unexpected, that when all gay photographs, sex of participant, and the interaction term were entered as predictors of the explicit measure of prejudice toward 
lesbians, the two-way interaction emerged as a significant predictor, $\beta=.16, t(547)=$ $2.27, p=.02$.

All lesbian photographs. Although the main hypotheses did not focus on variables related to lesbians, I conducted a series of cross product regression analyses to explore the relation between implicit measures of prejudice towards lesbians and the explicit prejudice measures. To explore whether participant sex moderated this relation, I conducted a cross-product regression analysis with all lesbian photographs, participant sex, and the two-way interaction term as predictors and the interaction emerged as a significant predictor, $\beta=.30, t(547)=3.61, p<.001$. Table 33 shows these results. A follow-up analysis of simple slopes revealed that the implicit measure was a significant predictor of explicit prejudice for female participants, $\beta=.44, t(547)=9.26, p<.001$; there was no evidence, however, that the implicit measure was a significant predictor of explicit prejudice for male participants, $\beta=.08, t(547)=0.97, p=.34$. Figure 14 shows that female participants' AMP scores became more unpleasant as their scores on MHNSL increased.

A similar pattern of results was found for the photographs of lesbians kissing; there was no evidence, however, of a similar pattern for photographs of lesbian families. It was interesting and unexpected that the interaction term of all lesbian photographs and participant sex was a significant predictor of the explicit measure of prejudice toward gay men (MHNS-G), $\beta=.24, t(549)=2.93, p=.004$. 
Table 33

Multiple Regression Analyses of Implicit Measure for All Lesbian Photographs,

Participant Sex, and the MHNS-L Explicit Measure $(N=553)$

\begin{tabular}{llrrr}
\hline Variable & & $B$ & $S E B$ & $\beta$ \\
\hline Step 1 & & & & \\
& & & & \\
& Implicit prejudice & 18.83 & 2.22 & $.36^{*}$ \\
& Participant sex & -6.43 & 1.04 & $-.26^{*}$ \\
Step 2 & & & & \\
& Implicit prejudice & 4.40 & 4.56 & .08 \\
& Participant sex & -4.93 & 1.11 & $-.20^{*}$ \\
& Implicit prejudice x participant sex & 18.78 & 5.20 & $.30^{*}$
\end{tabular}

Note. $R^{2}=.14$ for Step $1 ; \Delta R^{2}=.02, p<.001$ for Step 2 .

$* p<.01$. 


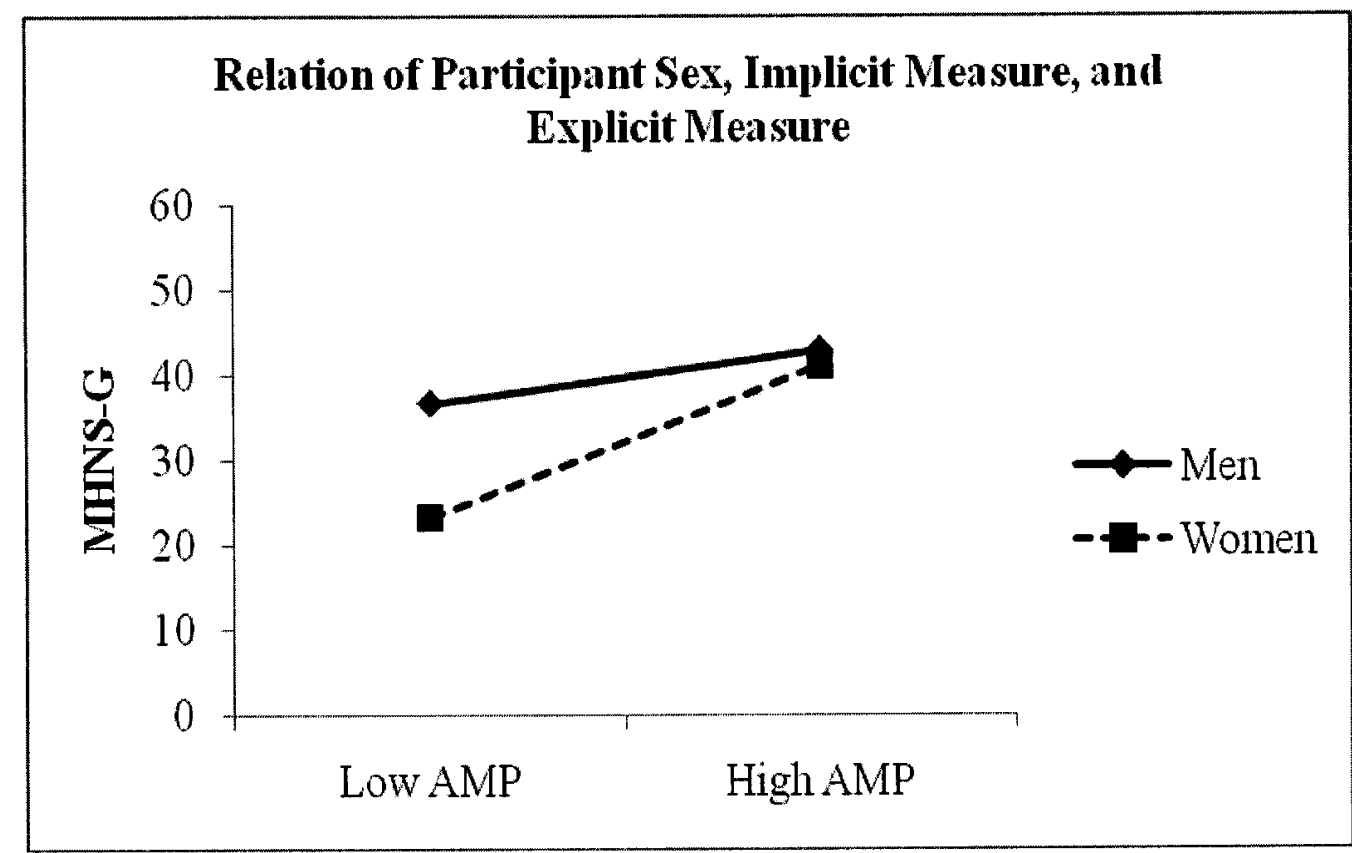

Figure 14. Interaction of AMP responses to all lesbian photographs and participant sex as predictors of MHNS-L.

\section{Hypothesis Three}

I predicted that Agreeableness would be negatively correlated with explicit measures of prejudice. To examine the effects of participant sex on the relation between Agreeableness and the MHNS-G, I entered Agreeableness, participant sex, and the Agreeableness by Participant sex interaction in a cross-product multiple regression analysis. As shown in Table 34, there was no evidence of an interaction effect, $\beta=-.01, t$ $(551)=-0.11, p=.92$. The result was similar when we substituted MHNS-L as the criterion variable, $\beta=-.06, t(549)=-0.59, p=.56$. Therefore, it was determined that participant sex did not moderate the relation between Agreeableness and explicit prejudice. 


\section{Table 34}

Multiple Regression Analyses of Agreeableness, Participant Sex, and MHNS-G $(N=555)$

\begin{tabular}{llccc}
\hline Variable & & $B$ & $S E B$ & $\beta$ \\
\hline Step 1 & & & & \\
& Agreeableness & -1.45 & 0.74 & $-.08^{*}$ \\
& Participant sex & -5.68 & 1.04 & $-.23^{*}$ \\
Step 2 & & & & \\
& Agreeableness & -1.29 & 1.70 & -.07 \\
& Participant sex & -5.68 & 1.04 & $-.23^{*}$ \\
& Agreeableness x participant sex & -0.20 & 1.89 & -.01 \\
\hline
\end{tabular}

Note. $R^{2}=.06$ for Step $1 ; \Delta R^{2}<.001(n s)$ for Step 2 .

$* p<.05$

Hypothesis Four

I predicted that AMP scores would be related to social distance. To examine participant sex as a possible moderator of this relation, I conducted a series of crossproduct regression analyses. AMP responses to photographs of all gay men combined were used as my implicit measure. Implicit prejudice, participant sex, and the implicit prejudice by participant sex interaction were entered into the model. As shown in Table 35 , there was no evidence of an interaction, $\beta=.19, t(198)=1.39, p=.17$. A similar pattern emerged when other AMP responses were substituted into the model. 
Table 35

Multiple Regression Analyses of Implicit Prejudice, Participant Sex, and Social Distance $(N=202)$

\begin{tabular}{llccc}
\hline Variable & & $B$ & $S E B$ & $\beta$ \\
\hline Step 1 & & & & \\
& Implicit prejudice & -0.42 & 0.20 & $-.15^{*}$ \\
& Participant sex & 0.15 & 0.10 & .11 \\
Step 2 & & & & \\
& Implicit prejudice & -0.87 & 0.38 & $-.31^{*}$ \\
& Participant sex & 0.13 & 0.10 & .09 \\
& Implicit prejudice x participant sex & 0.62 & 0.44 & .19 \\
\hline
\end{tabular}

Note. $R^{2}=.04$ for Step $1 ; \Delta R^{2}=.01(n s)$ for Step 2.

$* p<.05$

Hypothesis Five

I predicted that Agreeableness would predict social distance. I examined the relations between Agreeableness, sexual orientation of interviewee, participant sex and the social distance outcome measure by conducting a cross-product multiple regression analysis. When Agreeableness, sexual orientation of interviewee, participant sex, all twoway interactions, and the Agreeableness by Sexual orientation of interviewee by Participant sex cross product were included in the regression, there was no evidence that the three-way interaction or any of the two-way interactions were significant, all $\beta \mathrm{s}<$ \pm .30 , all $t s(194)< \pm 1.95$, all $p s>.05$. The results are shown in Table 36 . 
Table 36

Multiple Regression Analyses of Agreeableness, Sexual Orientation of Interviewee, Participant Sex, and Social Distance $(N=202)$

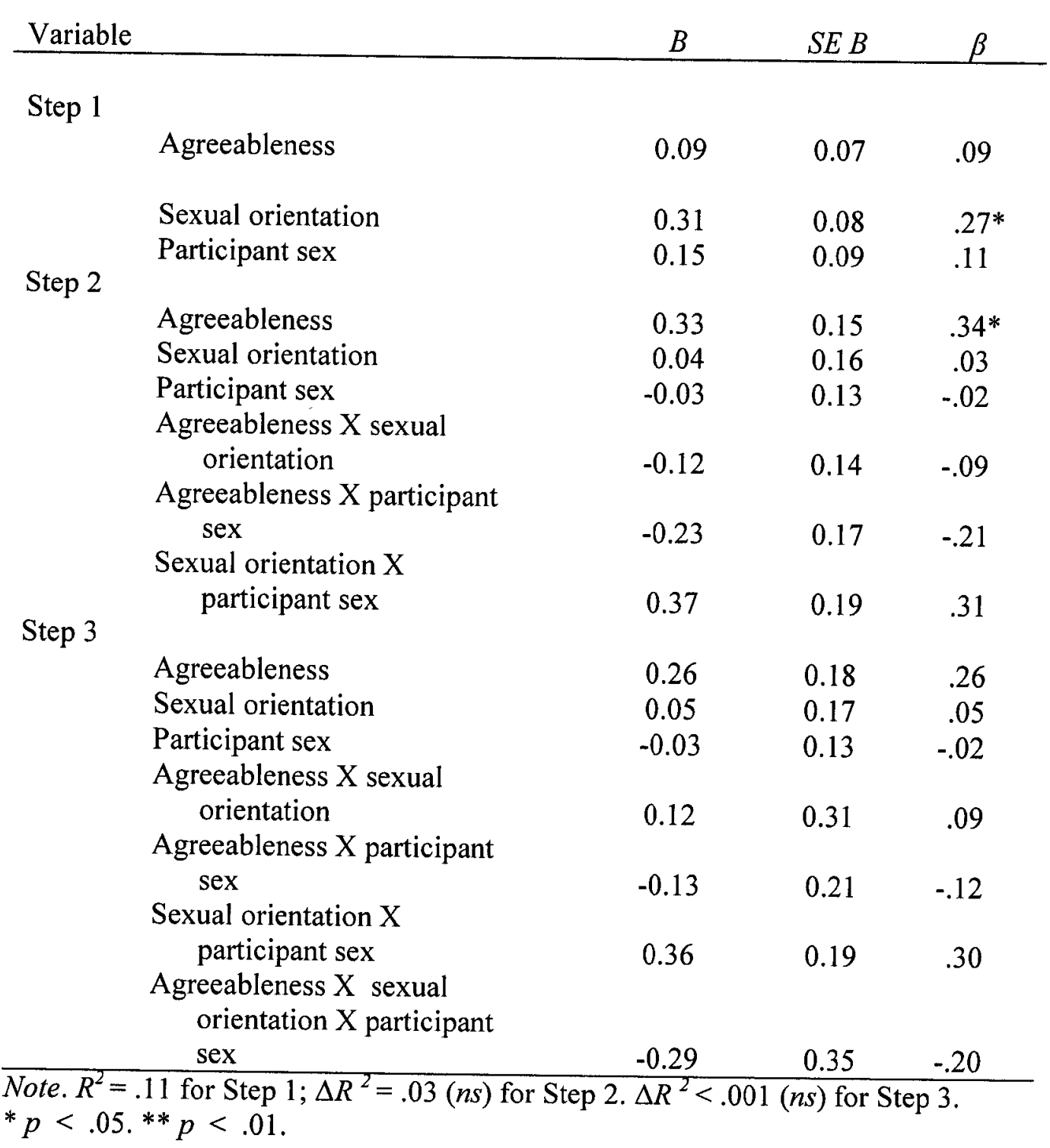


Hypothesis Six

I predicted that the interaction between Agreeableness and implicit prejudice would predict prejudice behaviors. When I entered Agreeableness, implicit prejudice, and sexual orientation of the interviewee into a cross-products regression, there was no evidence that Agreeableness was a significant predictor of social distance. Therefore, I substituted participant sex for Agreeableness to examine the relations between implicit prejudice, sexual orientation of interviewee, participant sex, and our outcome variable, social distance.

Consistent with previous analyses, I began by using AMP photographs that consisted of a combination of gay men kissing and gay men portrayed in families. As shown in Table 37, when implicit prejudice, sexual orientation of the interviewee, participant sex, all two-way interactions, and the Implicit by Sexual orientation $\mathrm{x}$ Participant sex interaction were entered into a cross-products multiple regression, there was no evidence of a significant three-way interaction, $\beta=.04, t(194)=0.20, p=.84$. When I removed the three-way interaction from the analysis, the only two-way interaction that was significant was the Implicit by Sexual orientation interaction that was previously discussed in the Results section, $\beta=-.21, t(195)=-2.11, p=.03$. There was evidence for neither a significant Sexual orientation $\mathrm{x}$ Participant sex interaction nor a significant Implicit measure by Participant sex interaction, $\beta=.23, t(195)=1.45, p=.15$, $\beta=.22, t(195)=1.70, p=.09$, respectively. Therefore, I concluded that, when AMP stimuli consisted of photographs of all gay men combined, participant sex did not moderate the relation between implicit prejudice and social distance. 
A similar pattern of results was found when I substituted AMP photographs that consisted of only gay men kissing and for AMP photographs that consisted of all photographs of gay men and lesbians combined. 
Table 37

Multiple Regression Analyses of AMP Gay All, Sexual Orientation of Interviewee, Participant Sex, and Social Distance $(N=202)$

\begin{tabular}{|c|c|c|c|c|}
\hline Variable & & $B$ & $S E B$ & $\beta$ \\
\hline \multicolumn{5}{|l|}{ Step 1} \\
\hline & Implicit prejudice & -0.44 & 0.19 & $-.16^{*}$ \\
\hline & Sexual orientation & -0.44 & 0.08 & $.27 *$ \\
\hline & Participant sex & 0.12 & 0.09 & .09 \\
\hline \multicolumn{5}{|l|}{ Step 2} \\
\hline & Implicit prejudice & -0.52 & 0.40 & -.19 \\
\hline & Sexual orientation & 0.10 & 0.16 & .09 \\
\hline & Participant sex & -0.04 & 0.13 & -.03 \\
\hline & $\begin{array}{l}\text { Implicit prejudice } X \text { sexual } \\
\text { orientation }\end{array}$ & -0.80 & 0.38 & $-.21^{*}$ \\
\hline & Implicit prejudice $\mathrm{X}$ & & & \\
\hline & participant sex & 0.72 & 0.43 & .22 \\
\hline & Sexual orientation X & & & \\
\hline & participant sex & 0.27 & 0.19 & .23 \\
\hline \multicolumn{3}{|l|}{ Step 3} & 049 & -17 \\
\hline & Sexual orientation & 0.11 & 0.17 & .09 \\
\hline & Participant sex & -0.04 & 0.13 & -.03 \\
\hline & Implicit prejudice $X$ sexual & 092 & 073 & -25 \\
\hline & $\begin{array}{l}\text { orientation } \\
\text { Implicit prejudice } \mathrm{X}\end{array}$ & & 0.12 & \\
\hline & participant sex & 0.64 & 0.60 & .19 \\
\hline & Sexual orientation $\mathrm{X}$ & & & \\
\hline & participant sex & 0.26 & 0.19 & .22 \\
\hline & $\begin{array}{r}\text { Implicit prejudice } X \text { sexual } \\
\text { orientation X participant }\end{array}$ & & & \\
\hline & $\operatorname{sex}$ & 0.17 & 0.86 & .04 \\
\hline
\end{tabular}


Similar to the findings reported above, when AMP responses to all lesbian photographs were substituted into the same multiple regression analysis, there was no evidence that the Implicit by Sexual orientation by Participant sex interaction was significant, $\beta=-.16, t(194)=-0.72, p=.47$. As shown in Table 38, however, when the three-way interaction was removed from the analysis, the Sexual orientation by Participant sex interaction emerged as significant, $\beta=.36, t(195)=2.14, p=.03$. A follow-up analysis of simple slopes revealed that sexual orientation of the interviewee predicted social distance for women, $\beta=.40, t(199)=4.23, p<.001$; there was no evidence, however, that it predicted social distance for men, $\beta=.13, t(199)=1.38, p=$ .17 . Figure 15 shows that female participants' social distance scores were more positive for homosexual interviewees than they were for heterosexual interviewees. 
Table 38

Multiple Regression Analyses of AMP Lesbian All, Sexual Orientation of Interviewee, Participant Sex, and Social Distance $(N=202)$

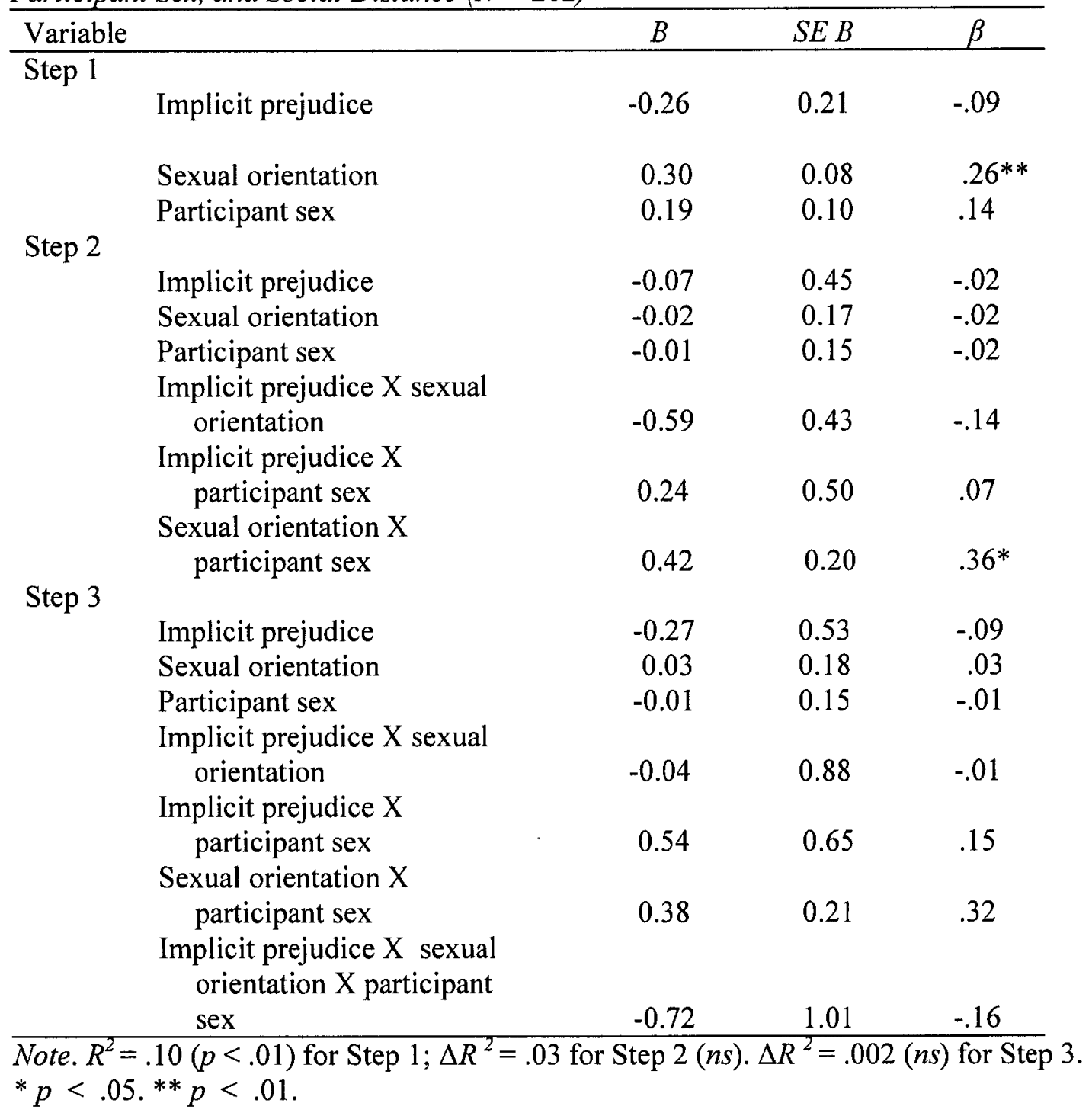




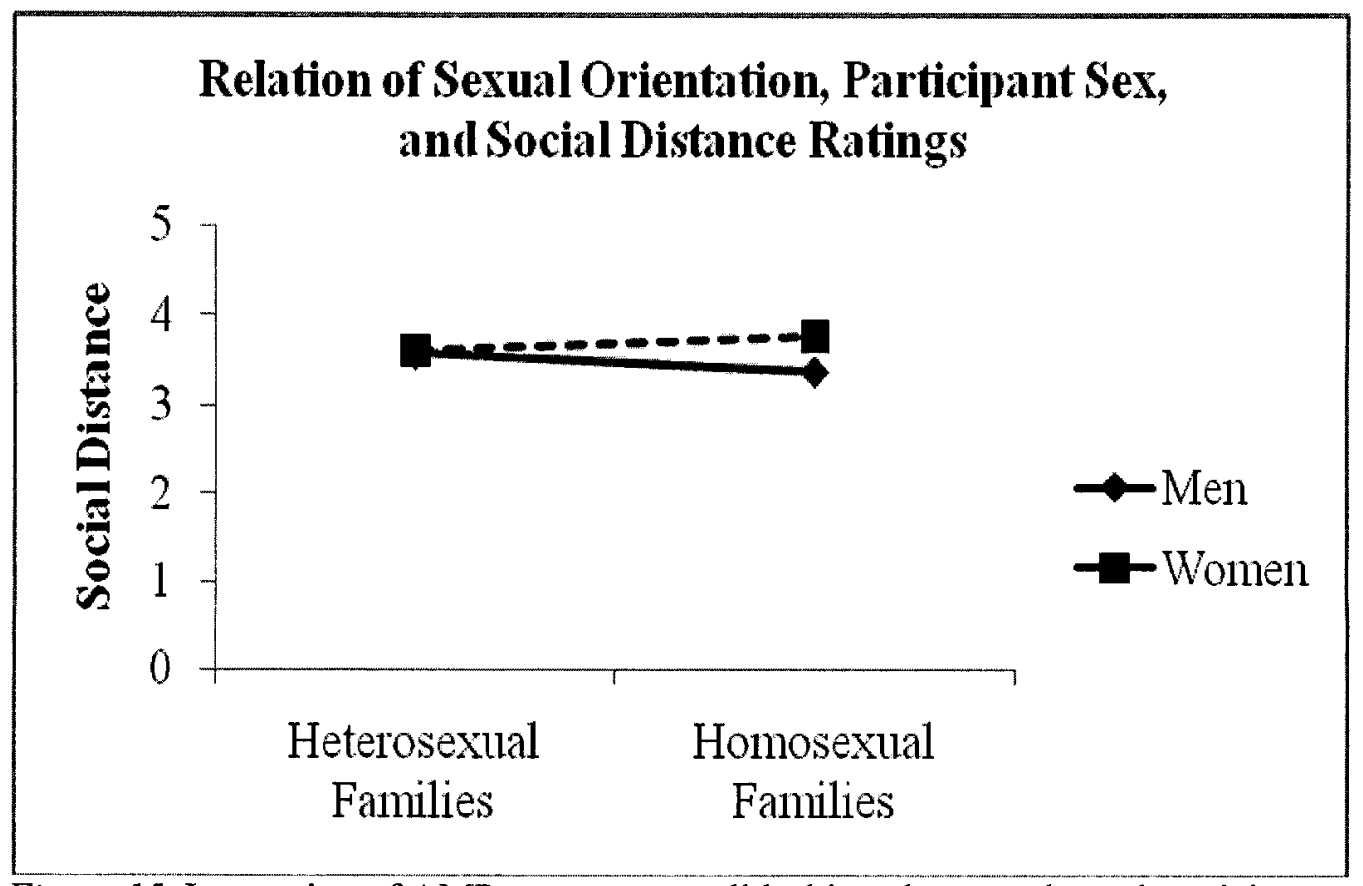

Figure 15. Interaction of AMP responses to all lesbian photographs and participant sex as predictors of social distance.

Participant Sex Differences in Exploratory Analyses

Further exploratory analyses were conducted to examine the potential influence of participant sex on the relations between implicit prejudice, explicit prejudice, motivation to control prejudice, and suppression of prejudice. Similar to previous analyses, I first examined these relations using responses to all photographs of gay men combined as the implicit measure of prejudice.

Internal Motivation to Control Prejudice

When implicit prejudice, internal motivation, participant sex, all two-way interactions, and the three-way interaction were entered into a cross-products multiple regression analysis, there was no evidence that the Implicit by Internal motivation by 
Participant sex interaction was a significant predictor of MHNS-G or MHNS-L, $\beta=.05, t$ $(537)=0.90, p=.37$, and $\beta=.03, t(535)=0.46, p=.65$, respectively. When the three-way interaction was removed from the model, the Implicit by Participant sex interaction emerged as a significant predictor of MHNS-L, $\beta=.16, t(535)=2.30, p=.02$. The relation between these variables was already examined and therefore will not be discussed in this section. See Tables 39 and 40 for the results of these regression analyses. Similar results emerged when AMP responses to photographs of all lesbians combined and to photographs of lesbians kissing. 
Table 39

Multiple Regression Analyses of AMP Gay All, Internal Motivation, Participant Sex, and $M H N S-G(N=545)$

\begin{tabular}{|c|c|c|c|c|}
\hline Variable & & $B$ & $S E B$ & $\beta$ \\
\hline \multicolumn{5}{|l|}{ Step 1} \\
\hline & Implicit prejudice & 15.42 & 1.81 & $.31 * *$ \\
\hline & Internal motivation & -2.33 & 0.20 & $-.44 * *$ \\
\hline & Participant sex & -0.80 & 0.87 & -.03 \\
\hline \multicolumn{5}{|l|}{ Step 2} \\
\hline & Implicit prejudice & 10.77 & 3.44 & $.22 * *$ \\
\hline & Internal motivation & -2.53 & 0.40 & $-.47 * *$ \\
\hline & Participant sex & -0.97 & 0.92 & -.04 \\
\hline & Implicit prejudice $\mathrm{X}$ internal & & & \\
\hline & motivation & -0.59 & 0.81 & -.03 \\
\hline & Implicit prejudice $X$ & & & \\
\hline & participant sex & 6.39 & 4.08 & .11 \\
\hline & Internal motivation $\mathrm{X}$ & & & \\
\hline & participant sex & 0.33 & 0.46 & .05 \\
\hline \multicolumn{5}{|l|}{ Step 3} \\
\hline & Implicit prejudice & 9.93 & 3.56 & $.20 * *$ \\
\hline & Internal motivation & -2.41 & 0.42 & $-.45 * *$ \\
\hline & Participant sex & -0.81 & 0.94 & -.03 \\
\hline & Implicit prejudice $X$ internal & 154 & 132 & \\
\hline & $\begin{array}{l}\text { motivation } \\
\text { Implicit prejudice } \mathrm{X}\end{array}$ & -1.54 & 1.32 & -.07 \\
\hline & participant sex & 7.16 & 4.17 & .12 \\
\hline & Internal motivation $\mathrm{X}$ & & & \\
\hline & participant sex & 0.18 & 0.49 & .03 \\
\hline & $\begin{array}{c}\text { Implicit prejudice } \mathrm{X} \text { internal } \\
\text { motivation } \mathrm{X} \text { participant }\end{array}$ & & & \\
\hline 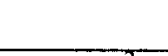 & sex & 1.50 & 1.67 & .05 \\
\hline
\end{tabular}


Table 40

Multiple Regression Analyses of AMP Gay All, Internal Motivation, Participant Sex, and MHNS-L $(N=543)$

\begin{tabular}{|c|c|c|c|c|}
\hline Variable & & $B$ & $S E B$ & $\beta$ \\
\hline \multicolumn{5}{|l|}{ Step 1} \\
\hline & Implicit prejudice & 13.34 & 1.84 & $.28^{* *}$ \\
\hline & Internal motivation & -2.36 & 0.20 & $-.45^{* *}$ \\
\hline & Participant sex & 1.17 & 0.88 & .05 \\
\hline \multicolumn{5}{|l|}{ Step 2} \\
\hline & Implicit prejudice & 6.62 & 3.48 & .14 \\
\hline & Internal motivation & -2.40 & 0.40 & $-.46 * *$ \\
\hline & Participant sex & 0.58 & 0.93 & .02 \\
\hline & $\begin{array}{l}\text { Implicit prejudice } \mathrm{X} \text { internal } \\
\text { motivation }\end{array}$ & 0.01 & 0.82 & .001 \\
\hline & $\begin{array}{c}\text { Implicit prejudice } X \\
\text { participant sex }\end{array}$ & 9.50 & 4.12 & $.16^{*}$ \\
\hline & $\begin{array}{l}\text { Internal motivation } \mathrm{X} \\
\text { participant sex }\end{array}$ & 0.06 & 0.46 & .01 \\
\hline \multicolumn{5}{|l|}{ Step 3} \\
\hline & Implicit prejudice & 6.20 & 3.60 & .13 \\
\hline & Internal motivation & -2.34 & 0.43 & $-.45 * *$ \\
\hline & Participant sex & 0.67 & 0.95 & .03 \\
\hline & $\begin{array}{l}\text { Implicit prejudice } \mathrm{X} \text { internal } \\
\text { motivation } \\
\text { Implicit prejudice } \mathrm{X}\end{array}$ & -0.48 & 1.34 & -.02 \\
\hline & participant sex & 9.88 & 4.21 & $.17^{*}$ \\
\hline & $\begin{array}{l}\text { Internal motivation } X \\
\text { participant sex } \\
\text { Implicit prejudice } X \text { internal } \\
\text { motivation } X \text { participant }\end{array}$ & -0.02 & 0.49 & -.003 \\
\hline . & $\operatorname{sex}$ & 0.77 & 1.69 & .03 \\
\hline
\end{tabular}




\section{External Motivation to Control Prejudice}

When implicit prejudice, external motivation, participant sex, all two-way interactions, and the three-way interaction were entered into a cross-products multiple regression analysis, there was no evidence that the Implicit by External motivation by Participant sex interaction was a significant predictor of MHNS-G or MHNS-L, $\beta=.05, t$ $(537)=0.77, p=.44, \beta=.01, t(535)=0.16, p=.87$, respectively. See Tables 41 and 42 for these results. A similar pattern of results was found when other AMP responses were substituted into this model with one exception. As shown in Tables 43 and 44, when the implicit measure included AMP responses to photographs of lesbians kissing, a significant Implicit by External motivation by Participant sex interaction emerged for MHNS-G and MHNS-L, $\beta=-.25, t(537)=-2.43, p=.02, \beta=.01, t(535)=0.16, p=.87$, respectively. As shown in Figure 16, a follow-up simple slopes analysis revealed that the implicit measure predicted MHNS-G for female participants with low external motivation, $\beta=.44, t(537)=5.93, p<.001$, and high motivation, $\beta=.19, t(537)=2.84, p$ $=.01$. Also, the implicit measure predicted MHNS-G for male participants with low motivation, $\beta=-.29, t(537)=-2.05, p=.04$; there was no evidence, however, that the implicit measure predicted MHNS-G for male participants with high motivation, $\beta=.05$, $t(537)=0.29, p=.77$. In contrast to the slopes for female participants who had high or low motivation, the slope for men with high motivation was negative, indicating that as explicit prejudice increased, implicit prejudice decreased. The results of this regression model were similar when MHNS-L was substituted as the outcome variable. 


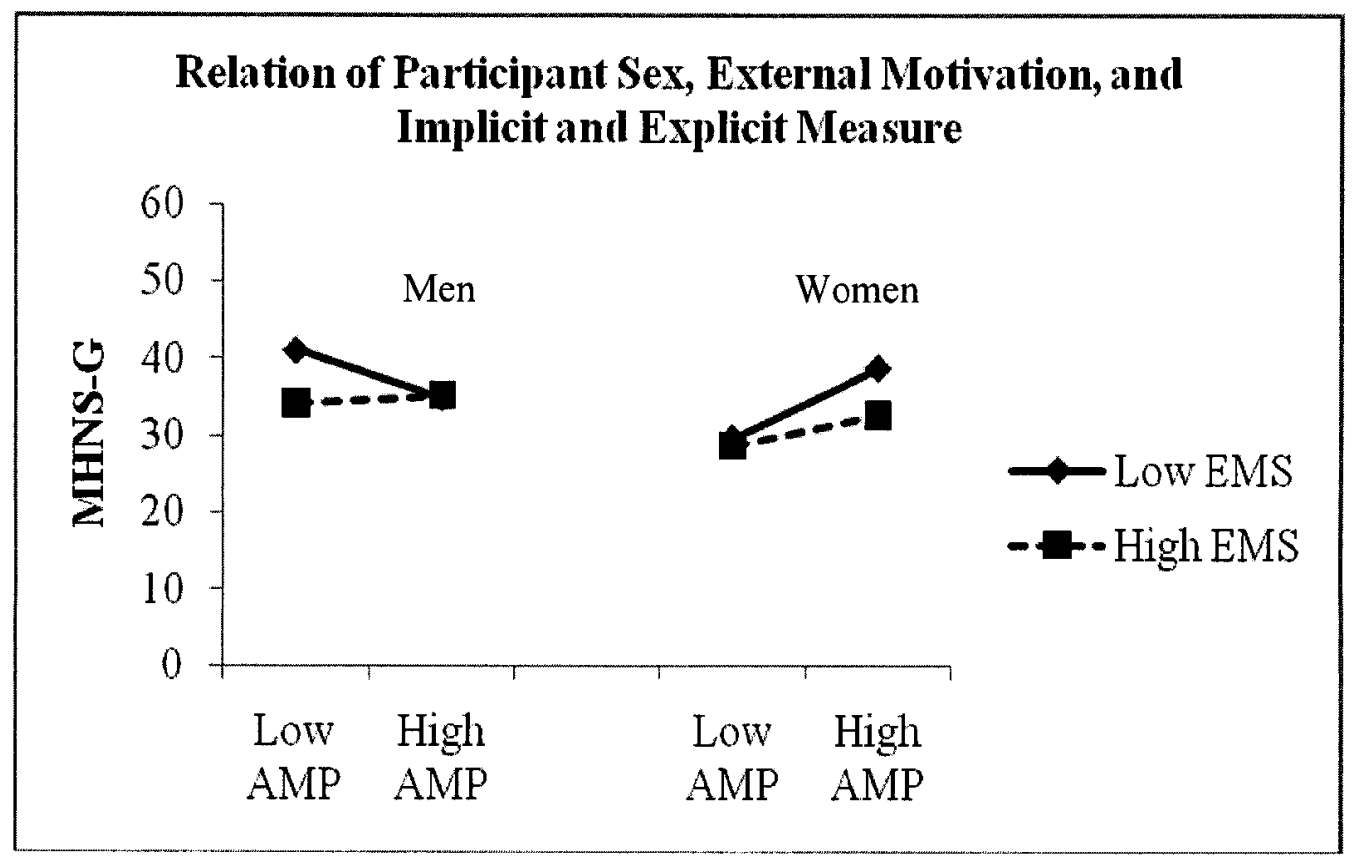

Figure 16. Interaction of participant sex, external motivation, and AMP responses to lesbians kissing as predictors of MHNS-G. 
Table 41

Multiple Regression Analyses of AMP Gay All, External Motivation, Participant Sex, and MHNS-G $(N=545)$

\begin{tabular}{|c|c|c|c|c|}
\hline Variable & & $B$ & $S E B$ & $\beta$ \\
\hline \multicolumn{5}{|l|}{ Step 1} \\
\hline & Implicit prejudice & 22.45 & 1.85 & $.46^{* *}$ \\
\hline & External motivation & -0.94 & 0.20 & $-.17 * *$ \\
\hline & Participant sex & -2.09 & 0.94 & $-.08 *$ \\
\hline \multicolumn{5}{|l|}{ Step 2} \\
\hline & Implicit prejudice & 16.57 & 3.44 & $.34 * *$ \\
\hline & External motivation & -1.08 & 0.44 & $-.22 *$ \\
\hline & Participant sex & -2.30 & 0.99 & $-.09^{*}$ \\
\hline & Implicit prejudice $\mathrm{X}$ external & -312 & 087 & $-13 * *$ \\
\hline & Implicit prejudice $\mathrm{X}$ & & & \\
\hline & participant sex & 7.01 & 4.06 & .12 \\
\hline & External motivation $\mathrm{X}$ & & & \\
\hline & participant sex & 0.23 & 0.50 & .04 \\
\hline \multicolumn{5}{|l|}{ Step 3} \\
\hline & Implicit prejudice & 15.79 & 3.59 & $.32 * *$ \\
\hline & External motivation & -1.01 & 0.45 & $-.19^{*}$ \\
\hline & Participant sex & -2.24 & 0.99 & $-.09 *$ \\
\hline & Implicit prejudice $\mathrm{X}$ external & & & \\
\hline & motivation & -4.15 & 1.60 & $-.18^{*}$ \\
\hline & Implicit prejudice $\mathrm{X}$ & & & \\
\hline & participant sex & 7.83 & 4.20 & .13 \\
\hline & External motivation $\mathrm{X}$ & & & \\
\hline & participant sex & 0.16 & 0.50 & .03 \\
\hline & $\begin{array}{l}\text { Implicit prejudice } X \text { external } \\
\text { motivation } X \text { participant }\end{array}$ & & & \\
\hline & $\operatorname{sex}$ & 1.47 & 1.90 & .05 \\
\hline
\end{tabular}


Table 42

Multiple Regression Analyses of AMP Gay All, External Motivation, Participant Sex, and MHNS-L $(N=543)$

\begin{tabular}{|c|c|c|c|c|}
\hline Variable & & $B$ & $S E B$ & $\beta$ \\
\hline \multicolumn{5}{|l|}{ Step 1} \\
\hline & Implicit prejudice & 20.45 & 1.88 & $.43 * *$ \\
\hline & External motivation & 0.93 & 0.21 & $-.18^{* *}$ \\
\hline & Participant sex & -0.15 & 0.96 & -.01 \\
\hline \multicolumn{5}{|l|}{ Step 2} \\
\hline & Implicit prejudice & 11.56 & 3.52 & $.24^{*}$ \\
\hline & External motivation & -0.87 & 0.45 & -.17 \\
\hline & Participant sex & -0.78 & 1.004 & -.03 \\
\hline & $\begin{array}{l}\text { Implicit prejudice } \mathrm{X} \text { external } \\
\text { motivation }\end{array}$ & -2.77 & 0.88 & $-.12 *$ \\
\hline & Implicit prejudice $\mathrm{X}$ & & & \\
\hline & participant sex & 11.45 & 4.14 & $.19^{*}$ \\
\hline & External motivation $\mathrm{X}$ & & & \\
\hline & participant sex & -0.03 & 0.50 & -.01 \\
\hline \multicolumn{5}{|l|}{ Step 3} \\
\hline & Implicit prejudice & 11.39 & 3.67 & $.24^{*}$ \\
\hline & External motivation & -0.86 & 0.46 & -.16 \\
\hline & Participant sex & -0.77 & 1.01 & -.03 \\
\hline & $\begin{array}{l}\text { Implicit prejudice } \mathrm{X} \text { external } \\
\text { motivation }\end{array}$ & -2.99 & 1.62 & -.13 \\
\hline & Implicit prejudice $\mathrm{X}$ & 11.62 & & \\
\hline & participant sex & & 4.29 & $.20^{*}$ \\
\hline & External motivation $\mathrm{X}$ & & & \\
\hline & participant sex & -0.05 & 0.51 & -.01 \\
\hline & $\begin{array}{l}\text { Implicit prejudice } X \text { external } \\
\text { motivation } X \text { participant }\end{array}$ & & & \\
\hline & $\operatorname{sex}$ & 0.31 & 1.93 & .01 \\
\hline
\end{tabular}

Note. $R^{2}=.24(p<.01)$ for Step $1 ; \Delta R^{2}=.02$ for Step $2(p=.002) . \Delta R^{2}<.001(n s)$ for Step 3 .

${ }^{*} p<.05{ }^{* *} p<.01$. 
Table 43

Multiple Regression Analyses of AMP Lesbians Kissing, External Motivation, Participant Sex, and MHNS-G $(N=545)$

\begin{tabular}{|c|c|c|c|c|}
\hline Variable & & $B$ & $S E B$ & $\beta$ \\
\hline \multicolumn{5}{|l|}{ Step 1} \\
\hline & Implicit prejudice & 7.82 & 1.62 & $.23 * *$ \\
\hline & External motivation & -1.28 & 0.22 & $-.24 * *$ \\
\hline & Participant sex & -7.61 & 1.19 & $-.30 * *$ \\
\hline \multicolumn{5}{|l|}{ Step 2} \\
\hline & Implicit prejudice & -6.14 & 4.00 & -.18 \\
\hline & External motivation & -2.14 & 0.53 & $-.39 * *$ \\
\hline & Participant sex & -3.34 & 1.60 & $-.13^{*}$ \\
\hline & $\begin{array}{l}\text { Implicit prejudice } \mathrm{X} \text { external } \\
\text { motivation }\end{array}$ & -1.37 & 0.81 & -.08 \\
\hline & Implicit prejudice $X$ & & & .00 \\
\hline & participant sex & 16.86 & 4.38 & $.38 * *$ \\
\hline & External motivation $X$ & & & \\
\hline & participant sex & 1.13 & 0.62 & .18 \\
\hline \multicolumn{5}{|l|}{ Step 3} \\
\hline & Implicit prejudice & -4.20 & 4.06 & -.12 \\
\hline & External motivation & -0.86 & 0.74 & -.16 \\
\hline & Participant sex & -3.89 & 1.61 & $-.16^{*}$ \\
\hline & Implicit prejudice $X$ external & & & \\
\hline & motivation & 3.12 & 2.02 & .18 \\
\hline & Implicit prejudice $X$ & & & \\
\hline & participant sex & 15.08 & 4.42 & $.34 *$ \\
\hline & External motivation $\mathrm{X}$ & & & \\
\hline & participant sex & -0.07 & 0.79 & -.01 \\
\hline & $\begin{array}{l}\text { Implicit prejudice } \mathrm{X} \text { external } \\
\text { motivation } \mathrm{X} \text { participant }\end{array}$ & & & \\
\hline & sex & -5.36 & 2.21 & $-.25^{*}$ \\
\hline
\end{tabular}


Table 44

Multiple Regression Analyses of AMP Lesbians Kissing, External Motivation, Participant Sex, and MHNS-L $(N=543)$

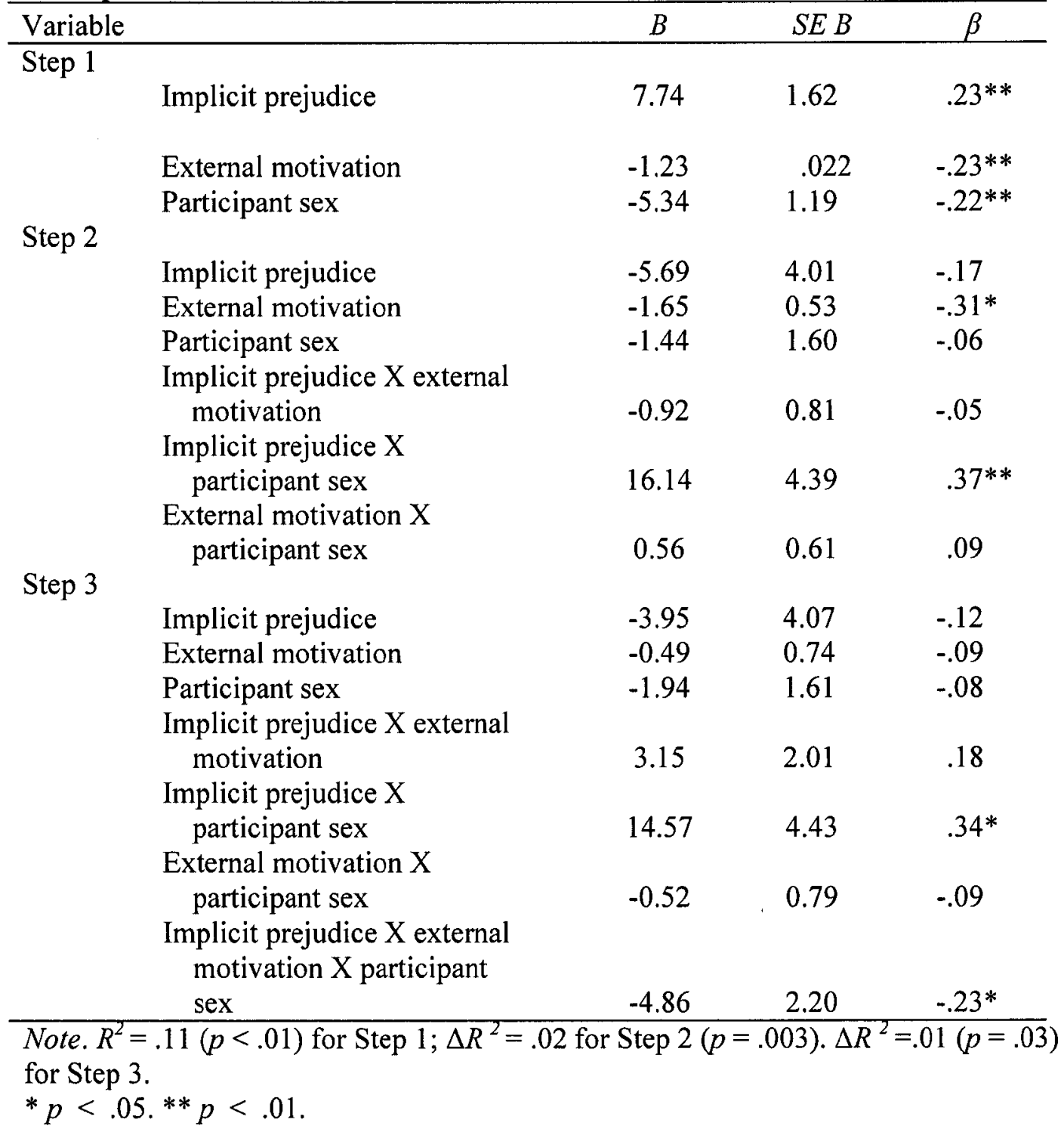




\section{Suppression of Prejudice}

When implicit prejudice, suppression of prejudice, participant sex, all two-way interactions, and the three-way interaction were entered into a cross-products multiple regression analysis, there was no evidence that the Implicit by Suppression by Participant sex interaction was a significant predictor of MHNS-G or MHNS-L, $\beta=.14, t(545)=$ $1.90, p=.06$, and $\beta=.06, t(543)=0.81, p=.42$, respectively. See Tables 45 and 46 for the results of these regression analyses. Similar results emerged when I substituted other AMP responses into the regression equation with one exception. As shown in Table 47, when AMP responses to gay men kissing were substituted into the model, the Implicit by Suppression by Participant sex interaction was a significant predictor of MHNS-G, $\beta=$ $.18, t(545)=2.36, p=.02$. A follow-up simple slopes analysis revealed that the implicit measure predicted MHNS-G for female participants with low suppression, $\beta=.33, t$ $(545)=4.81, p<.001$, and high suppression, $\beta=.40, t(545)=7.04, p<.001$. Also, the implicit measure predicted MHNS-G for male participants with low suppression, $\beta=.43$, $t(545)=4.70, p<.001$; there was no evidence, however, that the implicit measure predicted MHNS-G for male participants with high suppression, $\beta=.09, t(545)=0.76$, $p=.45$. Figure 17 demonstrates that, as AMP responses became more negative, female participants with low and high suppression scores expressed more prejudice on the explicit measure. This pattern held for male participants with low suppression but not for male participants with high suppression. 
Table 45

Multiple Regression Analyses of AMP Gay All, Suppression of Prejudice, Participant Sex, and MHNS-G $(N=553)$

\begin{tabular}{|c|c|c|c|c|}
\hline Variable & & $B$ & $S E B$ & $\beta$ \\
\hline \multicolumn{5}{|l|}{ Step 1} \\
\hline & Implicit prejudice & 23.16 & 1.85 & $.47^{* *}$ \\
\hline & Suppression & -0.80 & 0.27 & $-.11 *$ \\
\hline & Participant sex & -2.06 & 0.96 & $-.08 *$ \\
\hline \multicolumn{5}{|l|}{ Step 2} \\
\hline & Implicit prejudice & 19.49 & 3.59 & $.40^{* *}$ \\
\hline & Suppression & -0.82 & 0.59 & -.12 \\
\hline & Participant sex & -2.32 & 1.04 & -.09 \\
\hline & Implicit prejudice $\mathrm{X}$ & & & \\
\hline & suppression & -0.52 & 1.19 & -.02 \\
\hline & Implicit prejudice $\mathrm{X}$ & & & \\
\hline & participant sex & 5.17 & 4.3 & .09 \\
\hline & Suppression X participant sex & 0.02 & 0.66 & .003 \\
\hline \multicolumn{5}{|l|}{ Step 3} \\
\hline & Implicit prejudice & 16.54 & 3.90 & $.34 * *$ \\
\hline & Suppression & -0.60 & 0.60 & -.08 \\
\hline & Participant sex & -2.21 & 1.04 & $-.09 *$ \\
\hline & Implicit prejudice $X$ & & & \\
\hline & suppression & -4.27 & 2.30 & -.14 \\
\hline & Implicit prejudice $\mathrm{X}$ & & & \\
\hline & participant sex & 7.67 & 4.50 & .13 \\
\hline & Suppression X participant sex & -0.20 & 0.67 & -.02 \\
\hline & $\begin{array}{l}\text { Implicit prejudice } X \\
\text { suppression X participant }\end{array}$ & & & \\
\hline & $\operatorname{sex}$ & 5.09 & 2.68 & .14 \\
\hline
\end{tabular}

Step 3.

${ }^{*} p<.05 .{ }^{* *} p<.01$. 
Table 46

Multiple Regression Analyses of AMP Gay All, Suppression of Prejudice, Participant Sex, and MHNS-L $(N=551)$

\begin{tabular}{|c|c|c|c|c|}
\hline Variable & & $B$ & $S E B$ & $\beta$ \\
\hline \multicolumn{5}{|l|}{ Step 1} \\
\hline & Implicit prejudice & 21.28 & 1.89 & $.44 * *$ \\
\hline & Suppression & -0.87 & 0.28 & $-.12 * *$ \\
\hline & Participant sex & -0.08 & 0.98 & -.003 \\
\hline \multicolumn{5}{|l|}{ Step 2} \\
\hline & Implicit prejudice & 13.78 & 3.66 & $.29 * *$ \\
\hline & Suppression & -0.85 & 0.60 & -.12 \\
\hline & Participant sex & -0.69 & 1.05 & -.03 \\
\hline & Implicit prejudice $X$ & & & \\
\hline & suppression & -0.65 & 1.20 & -.02 \\
\hline & Implicit prejudice $\mathrm{X}$ & & & \\
\hline & participant sex & 10.57 & 4.39 & $.18^{*}$ \\
\hline & Suppression $X$ participant sex & -0.04 & 0.67 & -.004 \\
\hline \multicolumn{5}{|c|}{ gapt } \\
\hline & Implicit prejudice & 12.51 & 3.98 & $.26 * *$ \\
\hline & Suppression & -0.76 & 0.61 & -.11 \\
\hline & Participant sex & -0.64 & 1.05 & -.03 \\
\hline & Implicit prejudice $\mathrm{X}$ & & & \\
\hline & suppression & -2.28 & 2.34 & -.08 \\
\hline & Implicit prejudice $\mathrm{X}$ & & & \\
\hline & participant sex & 11.64 & 4.58 & $.20^{*}$ \\
\hline & Suppression X participant sex & -0.13 & 0.68 & -.02 \\
\hline & $\begin{array}{l}\text { Implicit prejudice } X \\
\text { suppression } X \text { participant }\end{array}$ & & & \\
\hline & sex & 2.21 & 2.73 & .06 \\
\hline
\end{tabular}

Note. $R^{2}=.23(p<.01)$ for Step $1 ; \Delta R^{2}=. .01$ for Step $2(n s) . \Delta R^{2}<.01(n s)$ for Step 3.

${ }^{*} p<.05 .{ }^{* *} p<.01$. 
Table 47

Multiple Regression Analyses of AMP Gay Men Kissing, Suppression of Prejudice, Participant Sex, and MHNS-G $(N=553)$

\begin{tabular}{|c|c|c|c|c|}
\hline Variable & & $B$ & $S E B$ & $\beta$ \\
\hline \multicolumn{5}{|l|}{ Step 1} \\
\hline & Implicit prejudice & 13.50 & 1.45 & $.36^{* *}$ \\
\hline & Suppression & -0.97 & 0.28 & $-.14 * *$ \\
\hline & Participant sex & -3.85 & 1.00 & $-.15 * *$ \\
\hline \multicolumn{5}{|l|}{ Step 2} \\
\hline & Implicit prejudice & 11.70 & 2.95 & $.31 * *$ \\
\hline & Suppression & -1.31 & 0.61 & $-.18^{*}$ \\
\hline & Participant sex & -3.68 & 1.06 & $-.15 * *$ \\
\hline & Implicit prejudice $X$ & & & \\
\hline & suppression & -0.53 & 0.98 & -.02 \\
\hline & Implicit prejudice $\mathrm{X}$ & & & \\
\hline & participant sex & 2.47 & 3.44 & .06 \\
\hline & Suppression X participant sex & 0.44 & 0.69 & .05 \\
\hline \multicolumn{5}{|l|}{ Step 3} \\
\hline & Implicit prejudice & 9.95 & 3.03 & $.26 * *$ \\
\hline & Suppression & -1.35 & 0.60 & $-.19^{*}$ \\
\hline & Participant sex & -3.37 & 1.07 & $-.13 * *$ \\
\hline & Implicit prejudice $\mathrm{X}$ & & & \\
\hline & suppression & -4.38 & 1.90 & $-.18^{*}$ \\
\hline & Implicit prejudice $X$ & & & \\
\hline & participant sex & 3.81 & 3.48 & .09 \\
\hline & Suppression X participant sex & 0.47 & 0.68 & .06 \\
\hline & $\begin{array}{l}\text { Implicit prejudice X } \\
\text { suppression X participant }\end{array}$ & & & \\
\hline & $\operatorname{sex}$ & 5.24 & 2.22 & $.18^{*}$ \\
\hline
\end{tabular}




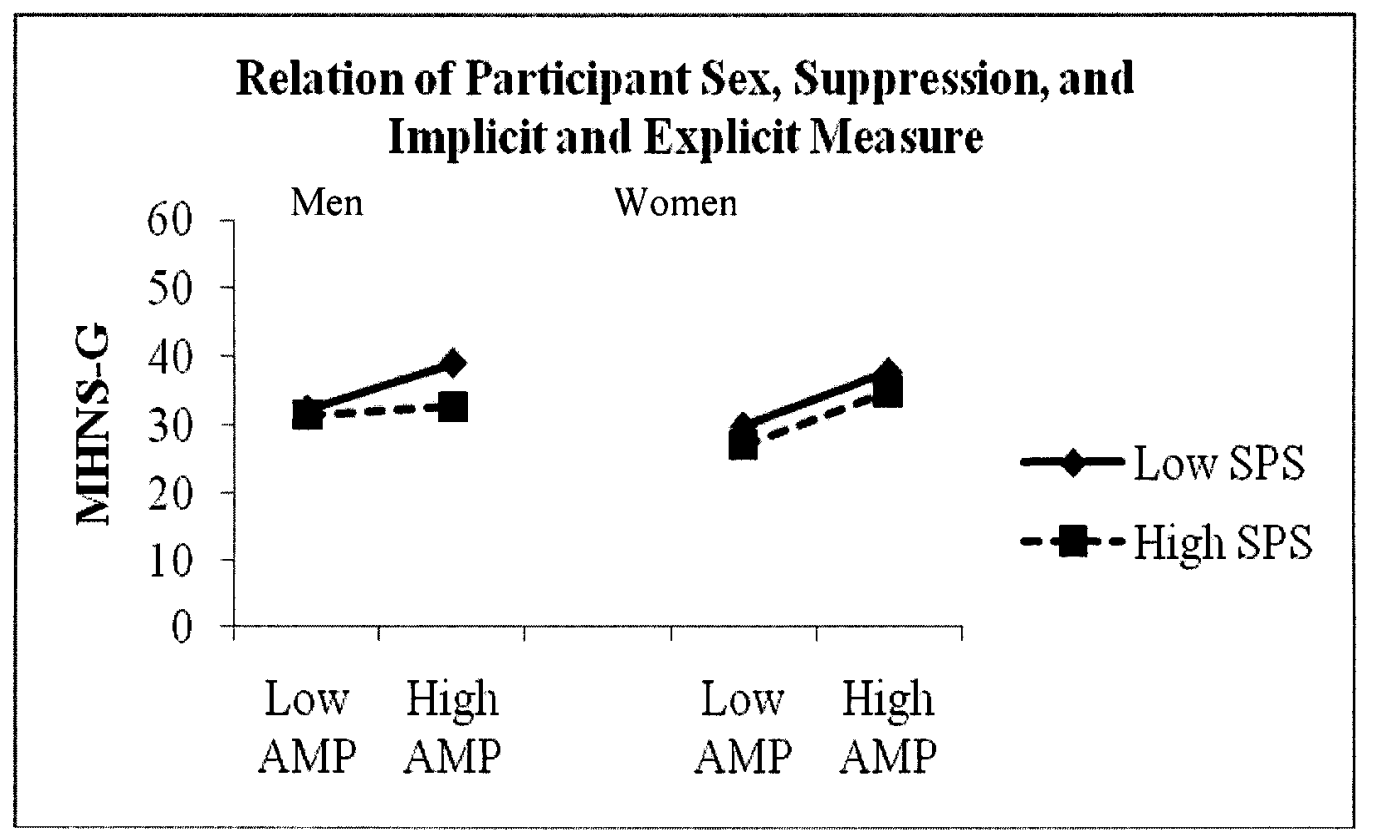

Figure 17. Interaction of AMP responses to gay kissing, suppression of prejudice, and participant sex as predictors of MHNS-G. 


\section{CHAPTER V}

\section{SUMMARY, CONCLUSIONS, AND RECOMMENDATIONS}

The present study extends the line of research examining negative attitudes toward gay men and lesbians. I employed multiple measures of prejudice that included implicit measures, explicit measures, and behavioral measures. The implicit attitudinal measure was created using the AMP paradigm (Payne et al., 2005), a method previously used to examine racial attitudes. Uniquely, in addition to using this method to study general attitudes toward gay men and lesbians, I also examined attitudes toward gay male and lesbian parents, specifically. To this end, the AMP stimuli consisted of multiple categories of persons: gay, lesbian, and heterosexual couples portrayed kissing or in family configurations. My findings were consistent with previous research that documents prejudice toward gay men and lesbians in general. Overall, I found that AMP ratings were more negative for homosexual primes than they were for heterosexual primes, an indication that people indeed hold negative attitudes toward people who are homosexual. Moreover, my findings are consistent with past research (e.g., Herek, 2000) in that people's attitudes were more negative toward gay men than they were toward lesbians. AMP targets that were paired with primes that portrayed gay men kissing were rated as more unpleasant than any other AMP prime-target pair by both male and female participants. 
It was interesting that my analysis revealed a different pattern of AMP responses for male and female participants. In contrast to the finding about men's ratings of primetarget pairs that included photographs of gay men kissing, my study found no evidence that male participants rated prime-target pairs of lesbians kissing differently than primetarget pairs with photographs of heterosexual couples kissing; however, men rated photographs of men kissing as less pleasant than photographs of lesbians kissing. Another interesting finding was that men rated prime-target pairs of lesbians kissing significantly more pleasant than prime-target pairs that included photographs of lesbians portrayed in families.

Extrapolating beyond the data, these findings may be interpreted in different ways. One explanation may lie in how men perceived and interpreted the photographs. Men may have responded to an element of sexuality as opposed to an element of homosexuality. That is, men may have rated prime photographs of lesbians kissing as pleasant because they perceived the composition of the photograph as a portrayal of two women kissing, not as lesbian women kissing. Similarly, men may have rated photographs of men kissing as unpleasant because they perceived the photographs of men kissing in a primarily sexual way and therefore reacted in a disgusted or defensive manner. Past research supports this explanation. It has been documented that men experience a range of negative reactions to gay men, including anger (Haddock \& Zanna, 1998; Van de Ven et al., 1996) and a sense of being threatened (Kite \& Whitley, 1996). Also, men who hold traditional role beliefs may hold the attitude that gay men do not fit within their definition of masculinity. This explanation is consistent with past research 
that documents that men's subjective responses to erotic stimuli are sometimes incongruent with their physiological responses to erotic stimuli (Lawrence et al., 2005; Rieger et al., 2005).

Another explanation for men's reactions to photographs of gay men kissing is derived from Devine's (1989) theory of prejudice. This theory posits that as a result of exposure to negative connotations about homosexuality - and gay men, specifically male participants in our sample experienced stereotype activation and were unable to manage their prejudice responses to photographs of gay men kissing and therefore rated them as highly unpleasant. Of course this explanation does not account for the more positive reactions to lesbians kissing.

Similar to men, it appears that women may have responded to an element of sexuality as well when they viewed the AMP stimuli. In contrast to men's ratings, however, women's ratings indicated that they found both gay male and lesbian couples kissing unpleasant relative to heterosexual couples kissing. Also, women's ratings of couples portrayed kissing varied substantially from their ratings of couples portrayed in families. Women's ratings of photographs that showed family configurations, regardless of parent sexual orientation, were substantially less unpleasant than their ratings of photographs that showed couples kissing.

It was interesting that women rated lesbians in families as significantly more unpleasant than gay men in families. One potential explanation for this finding is related to research on traditional role beliefs. Along the lines of research conducted with male participants (e.g., Haddock \& Zanna, 1998; Parrott et al., 2002) that suggest that highly 
prejudiced individuals adhere more strictly to traditional gender role beliefs than individuals who are not highly prejudiced, recent research findings suggest that women who hold traditional values, particularly related to sex and gender roles, demonstrate more anger toward lesbian women (Parrot \& Gallagher, 2008). Although I did not measure traditional values as part of this study, it is possible that they drove women's responses to photographs of lesbian couples as parents.

Another primary purpose of this research was to extend the line of research examining the relations between implicit and explicit prejudice measures. As I predicted, AMP responses for prime-target pairs that consisted of the combination of photographs of gay male couples portrayed kissing and in families were moderately positively correlated with MHNS-G, an explicit measure of prejudice toward gay men. A similar pattern was found for AMP responses to prime-target pairs that consisted of the combination of photographs of lesbians portrayed kissing and in families and the MHNS-L, an explicit measure of prejudice toward lesbians. Further, a significant negative correlation was found between AMP ratings of photographs of heterosexual couples and both the MHNS$\mathrm{G}$ and MHNS-L. In sum, it appears that measures of attitudes toward gay men and lesbians are congruent across both implicit and explicit methods of measurement: As participants' attitudes toward gay men and lesbians became more unpleasant as rated by AMP responses, their endorsements on the MHNS scale indicated increasing amounts of prejudice.

Upon further examination of the correlations between AMP responses and MHNS scores, I noted different patterns for male and female participants. Specifically, I found 
that participant sex moderated the relation between AMP responses and MHNS scores when AMP prime-target pairs consisted of the combination of photographs of lesbian couples kissing and in families and when AMP prime-target pairs consisted solely of photographs of lesbian couples kissing but not when AMP prime-target pairs consisted solely of photographs of lesbian couples in families. In both cases when participant sex moderated the relation, I found that AMP responses predicted MHNS scores for female participants but not for male participants.

My findings add to the extant literature that examines the relations between implicit and explicit measures. Presently, it is unclear whether implicit measures of prejudice generally correlate with explicit measures. Some research (e.g., Franco \& Maass, 1999) suggests that the relation between implicit and explicit measures is determined by the attitude that is being measured. Specifically, if the attitude being measured is one for which it is acceptable to harbor negative attitudes, then implicit and explicit measures of that attitude should be positively correlated because individuals are more likely to respond on the explicit measures in a way that reflects their actual feelings. In contrast, if the attitude being measured is one for which it is unacceptable to express negative attitudes, implicit and explicit measures may not be related because individuals more closely monitor their responses on the explicit measure, thereby making this measure an inaccurate reflection of their true attitudes. Along that line, Crandall et al. (2002) reported that ratings of the normative appropriateness of prejudice toward gay men and lesbian women raising children were high relative to the normative appropriateness of other social groups. Based on the results of these studies, my findings 
support the assumption that people find holding negative attitudes toward gay men and lesbians socially appropriate.

Although the results supported my prediction that implicit and explicit attitudes toward gay men and lesbians would be related, it is important to consider them in context with findings that suggest that these measures should not be related, or at least have only modest correlations. Payne et al. (2008) suggested that the relation between implicit and explicit measures may be influenced by the structure of the implicit measure employed. That is, measures that are similar in format will be more closely related than measures that are dissimilar in format. As one relevant example of an AMP modification tested by Payne et al. (2008), the scale used by participants to rate AMP targets was a Likert-type scale that was consistent with the scale for the explicit measure rather than a dichotomous rating scale (e.g., pleasant or unpleasant). They found that the correlation between measures was stronger than when the measures did not employ similarly formatted ratings scales. Because this study did not use implicit and explicit measures that were measured on similar scales, these findings contradict this possible explanation for implicit-explicit relations. Future research in this area is needed to enhance our understanding of these relations.

I was also interested in whether the implicit measure correlated with social distance scores, the measure of prejudice that was taken during the second phase of the study. As expected, there was an inverse relation between AMP ratings and social distance. Specifically, I found that AMP ratings of targets paired with photographs of gay couples kissing and AMP ratings of targets paired with photographs of all gay male 
couples were negatively correlated with social distance, indicating that as AMP ratings became more unpleasant, social distance ratings of parent interviewees declined.

As part of this study, I also focused on individual differences as they relate to sexual prejudice. Specifically, I was interested in the relations between Agreeableness, implicit and explicit measures of prejudice, and prejudice behavior. As I expected, Agreeableness was negatively correlated with our explicit measures (the MHNS scales), such that individuals low in Agreeableness reported more prejudice than individuals high in Agreeableness reported. Also, Agreeableness was a marginally significant predictor of social distance scores such that individuals high in Agreeableness rated prospective interviewees more favorably than individuals low in Agreeableness rated them. Aside from these results, my examination of the relation between Agreeableness and prejudice was not as fruitful as predicted.

Graziano et al. (2007) demonstrated that individuals low in Agreeableness held more negative attitudes toward traditional social outgroups, including homosexual people, than individuals high in Agreeableness. Further, these researchers found that Agreeableness predicted prejudiced behavior such that men who were low in Agreeableness were more likely than men who were high in Agreeableness to abandon an overweight partner in a laboratory setting. Based on these findings, I predicted that only persons who were low in Agreeableness and who held negative attitudes toward gay men would choose to abandon gay male interviewees in a similar laboratory situation. My findings did not support the prediction. Only four participants in the study made the decision to abandon their partners, thereby making statistical analyses meaningless. 
One plausible explanation for these findings is that participants may have been influenced by an element of social desirability. Especially for participants who were paired with a homosexual interview partner, the decision to stay with their partners may have been made under conditions that produced social pressure to avoid being viewed as homophobic. Also, it is possible that, despite pilot testing, the stimuli were not salient enough; that is, some participants may not have been aware that their interview partner was a gay man. Finally, it is possible that few participants decided to abandon their partners because the sample for Phase 2 included only 45 men. In the Graziano et al. (2007) study, the only participants who made the decision to abandon their partners were men low in Agreeableness.

Although, it could be argued that I was unable to replicate previous findings because the deception employed was ineffective, the debriefing process indicated that participants actually believed they would interview someone. Also, previous research using this paradigm, including the deception, found significant differences in Agreeableness between participants who decided to abandon their partners and participants who decided not to abandon their partners. Therefore, I see this explanation as less plausible.

Beyond investigating the link between implicit and explicit measures of prejudice, I was interested in exploring the relation between implicit prejudice and prejudice behavior. Previous research (e.g., Asendorpf, Banse, \& Mucke , 2002; Dovidio et al., 2002; Greenwald \& Farnham, 2000) has demonstrated that implicit measures predict prejudice behavior. As previously mentioned, during Phase 2 of this study, one of the 
measures of prejudice behavior was a social distance questionnaire. My study indicated that the interaction between AMP ratings and the sexual orientation of the interviewee predicted social distance ratings. When participants were told that they would interview a gay male parent, their AMP responses (collected during Phase 1) predicted social distance scores (during Phase 2). There was no evidence of this relation for participants who were told they would interview a heterosexual parent. Although these results were consistent with previous findings, it is important to be cautious when interpreting them. My prejudice measure was not a true measure of prejudice behavior; rather, it was behavioroid in nature (Aronson \& Carlsmith, 1963). Ideally, future research on sexual prejudice will address the link between implicit measures and actual prejudice behavior (as I attempted to do by allowing participants to switch partners).

At the outset of this study, it was unclear whether and how some of the measures would be related; therefore, I conducted a series of exploratory analyses in an effort to determine what, if any, patterns could be identified as potential avenues of future research.

Previous research (e.g., Payne et al., 2005) provided evidence that the motivation to control prejudiced reactions moderates the relation between implicit and explicit prejudice measures. Specifically, Payne et al. (2005) found that an interaction between AMP responses and internal motivation to control prejudice predicted explicit prejudice. This interaction was interpreted as evidence that, for individuals who are highly motivated to control prejudice internally, implicit and explicit measures are not related, whereas for individuals who are not motivated to control prejudice internally, implicit 
and explicit measures are positively correlated. Said differently, when people are motivated to appear non-prejudiced, their implicit measures act as true measures of their attitudes while their explicit measures are mitigated by their motivation. Therefore, there is no correspondence between implicit and explicit measures for these individuals. My results were not consistent with the results from previous research. I found no evidence that internal motivation moderated the implicit-explicit relation.

One plausible explanation for this contrast in findings lies in the type of prejudice that was measured. Payne et al. (2005) investigated racial attitudes, whereas my investigation centered on prejudice toward gay men and lesbians. Previous research (e.g., Crandall et al., 2003) suggests that it may be more acceptable to hold negative attitudes toward gay men and lesbians than toward other outgroups. If that is the case, then it is plausible that, regardless of the level of internal or external motivation to avoid being prejudiced, individuals' scores on implicit and explicit prejudice measures will correspond with each other.

Although my exploratory analyses were extensive, few of them appear to offer substantive information related to the relations among the constructs I studied. I noted the pattern of results found on the differences between men's and women's responses to AMP stimuli that included photographs of lesbians kissing. The interaction between participant sex, AMP scores, and external motivation predicted explicit prejudice scores. Upon examination of the simple slopes, the most compelling finding was for men who were low in external motivation. This slope was the only one of the four in this regression analysis that was negative, indicating that implicit scores became more pleasant as 
explicit scores became less pleasant. One interpretation of this lack of correspondence between the implicit and explicit measure is that men who were low in external motivation were more apt to express negative attitudes on the MHNS scales but, given the nature of the AMP, were unable to monitor these same feelings on the implicit measure.

There was one other finding related to participant sex differences: Sexual orientation of the parent interviewee in Phase 2 predicted social distance for female participants but not for male participants. Female participants' ratings were more positive for gay male families than they were for heterosexual families. This finding was unexpected and warrants future investigation aimed at replication.

Also, I found that male participants rated interviewees, all of whom were male, more positively when they were perceived as dissimilar in personality than when they were perceived as similar. This pattern, which was not evident for female participants, is consistent with previous research (e.g., Herek, 2000; Kite \& Whitley, 1996) suggesting that men may feel threatened by homosexuality. More specifically, men may feel threatened by being perceived as homosexual. It is important to consider how this response pattern for men may have influenced the current findings.

\section{Conclusions}

This study contributes to the research literature in several ways. First, it is an examination of prejudice toward gay men and lesbians, an outgroup that has been understudied relative to other traditional social outgroups (e.g., African-American people, Jewish people). Moreover, this study is unique in that it examined negative attitudes 
toward gay men and lesbians as parents. Although there is a body of literature on prejudice toward gay male and lesbian parents, it is largely descriptive in nature. That is, much of what is written is based on data collected via survey instruments and interviews. Also, much of what has been studied related to gay male and lesbian parents has focused on outcomes for their children rather than prejudice toward them. This study employed multiple methods of data collection aimed specifically at measuring prejudice toward this population.

A primary purpose of this study was to examine pre-service teacher attitudes toward gay and lesbian parents. To that end, I recruited as many education majors as possible to participate in this study. The final sample included $48.2 \%$ education majors. Although I did not specifically predict that differences in attitudes would exist between education majors and non-education majors, I examined group differences as part of my analyses. There was no evidence that education majors' attitudes varied from noneducation majors' attitudes, suggesting that individuals who become teachers hold attitudes that are similar to those of the general college-student population.

This research also contributes to the prejudice literature by employing previously used experimental paradigms to expand the current knowledge of prejudice mechanisms. I used the AMP paradigm as a measure of implicit prejudice and subsequently investigated the relation between AMP responses and explicit measures of prejudice. Also, I used a partner abandonment paradigm to explore Agreeableness as it relates to prejudice behavior toward gay parents. 
Finally, this study adds to the literature on teacher attitudes toward gay and lesbian parents. Although I found that pre-service teacher attitudes do not systematically vary from the attitudes of others, my findings are consistent with previous ones that suggest that prejudice toward gay and lesbian parents exists (Bliss \& Harris, 1999; Vogt \& McKenna, 1998). Moreover, and in line with group norm theory of prejudice, the positive relation between implicit and explicit attitudes that I found indicates that individuals may believe that it is acceptable to hold negative attitudes toward gay men and lesbians. Clearly, there are many implications of this finding, the first of which is for gay and lesbian parents with children who attend school. Research has shown that families struggle with whether to disclose their family constellation at school (Lindsay et al., 2006). It is also clear from past studies that the absence of a good relationship between home and school is deleterious in several ways (Pianta \& Walsh, 1996). Negative teacher attitudes are yet another factor that may serve to maintain a level of mistrust or discomfort in this important relationship between children and families.

A second implication for these findings is for school administrators. Taken together with the finding that many teachers report receiving no training related to gay and lesbian parenting issues (Bliss \& Harris, 1999; Fontaine, 1997; Uribe \& Harbeck, 1991), administrators may be called upon to develop policies and procedures related to these issues and train personnel accordingly. A third implication is for teacher educators who develop and implement curricula for pre-service teachers. Past research indicates that gay and lesbian issues may not be included in the array of diversity issues (Butler, 1994; Herek, 2005). My findings that negative attitudes toward gay men and lesbians as 
parents exists suggests that developers of higher education curriculum address these issues to provide pre-service teachers with a broader definition of diversity.

Implications for School Psychologists

The results of this study have several implications for school psychologists who are perhaps in the best position to work with teachers and families with gay and lesbian parents. It is well established that positive relationships between families and schools are important. Good home-school collaboration is related to several positive outcomes for students including academic achievement and social-emotional well being (Swap, 1992; Vickers \& Minke, 1995). Given the importance of the relationship between schools and families, my findings regarding prejudice toward gay and lesbian parents are particularly meaningful. School psychologists are perhaps in the best position to help schools establish and maintain positive home school relations. As professionals who work in schools, they are able to provide a broad range of services to teachers, students, and families. As an example, school psychologists can provide individual consultation with teachers who have students with same-sex parents. In this capacity, they can help teachers and parents collaborate with each other to ensure that students have the same learning opportunities as children with heterosexual parents. School psychologists can also provide consultation services on a larger scale. They are qualified to provide schoolwide in-service training that includes psycho-educational components that address issues related to gay and lesbian parents and disseminate findings on the positive outcomes of children raised by same-sex parents. Also, school psychologists are well versed in the implementation of school-wide positive behavior interventions that help create positive 
school climate. By including children and families with same-sex parents in these initiatives, it may enhance relations between gay and lesbian parents and the schools attended by their children.

My results are also significant for school psychology trainers. Although there has been an upward trend to infuse diversity issues into school psychology curricula, it is unclear whether the definition of diversity includes issues related to gay and lesbian parenting. Previous research shows that families led by gay men and lesbians are more visible now than in the past (McCann \& Delmonte, 2005, Kozik-Rosabal, 2000). School psychologists need to be prepared to face the challenges that may arise as a result of prejudice toward them. Similarly, university-based trainers should be aware of this training issue as it relates to pre-service teacher curriculum. Many school psychology programs are housed within departments of education. They should be aware of the opportunity to work with other educators to ensure that pre-service teachers are adequately prepared to work with families led by gay and lesbian parents.

\section{Limitations}

One limitation of this study lies in the participant sample. All participants were undergraduate students whose ages were typical for college students, and it is difficult to generalize these findings to a broader population, namely that of inservice teachers. One factor that makes it especially tenuous to expand these findings related to negative attitudes toward a broader population of teachers is school culture. Given that prejudicial attitudes may be maintained by group norms, it is possible that they are malleable. That is, it is possible that teacher attitudes toward gay and lesbian parents may depend, at least 
in part, on the school culture in which they work. Therefore, attitudes held by pre-service teachers prior to beginning their careers may not be representative of their attitudes after becoming immersed in their respective schools.

Another potential limitation is the proportion of men relative to women in this sample. Although the number of male participants was somewhat representative of the number of men in the teaching profession, these results are consistent with past research that suggests the importance of understanding sex differences in prejudicial attitudes in the general population. Given that I found significant differences between men's and women's responses to gay male couples and lesbian couples who were portrayed kissing or in families despite the low proportion of men relative to women in the sample, efforts to increase this proportion in future studies would allow greater power to detect and measure sex differences.

Another finding that is related to this limitation lies in the inability to elicit enough prejudicial responses (i.e., switching partner behaviors) in Phase 2 to make the analyses meaningful. It is possible that there were so few participants who decided to abandon their partners because the sample for Phase 2 included only 45 men. In the Graziano et al. (2007) study, the only participants who made the decision to abandon their partners were men who were low in Agreeableness. Therefore, the small proportion of men relative to women may have played another important role in the outcome of this research. It follows then that another potential limitation of this study is that it consisted primarily of implicit and explicit self-report data rather behavioral data. 


\section{Recommendations for Future Research}

The findings of the present study suggest several avenues of future research. Consistent with previous research, I found that individuals hold negative attitudes toward gay men and lesbians. Further, I found that more prejudice was expressed toward gay men than lesbians and that activity (couples kissing or couples in families) influenced prejudicial responses, with participants rating couples kissing as more unpleasant than couples in families with the exception of men's ratings of lesbians portrayed kissing. Based on these results, it appears that individuals in this sample may have responded based on a layer of perceived sexuality in the photographs. Future research that examines this component of sexual prejudice would increase our understanding of specifically what drives negative attitudes toward gay men and lesbians.

Additionally, these findings suggest that future research be directed at understanding female attitudes toward lesbian women. These results are consistent with recent findings that women differ from men in their attitudes toward lesbians. One potential explanation that has been offered is based on women's traditional role beliefs. Future research may further the understanding of the origins of these negative attitudes.

As previously indicated, my results were not consistent with previous research that employed the partner abandonment paradigm as a way to examine prejudice behavior. One possible explanation for these results is the potential role of social desirability on the part of participants. In the future, I suggest designing an experimental paradigm in which social desirability as a potential moderator is minimized. 
I also suggest further examination of the relation between implicit and explicit measures of prejudice. As researchers continue to examine this relation, it will be important to determine under what circumstances we should expect implicit and explicit prejudice measures to be positively or negatively related. In this way, we can improve our understanding of the mechanisms that drive prejudice expression.

Related to the examination of the relation of implicit and explicit measures is the examination of motivation to control prejudiced behavior as a moderator of these relations. In contrast to prior findings, I found that external motivation rather than internal motivation moderated the implicit-explicit relation. Future research should focus on systematically examining these relations with various targets.

In conclusion, this study contributed to multiple areas of literature including patterns of prejudice toward gay men and lesbians with and without children, relations among implicit and explicit prejudice measures, and the link between Agreeableness and prejudice. Further, my results serve to inform school psychologists and trainers in school psychology about the prevalence of negative attitudes toward gay and lesbian parents of children in the schools. Finally, results of this investigation serve as an impetus to teacher training programs to ensure that their curricula address diversity issues related to gay and lesbian parents, and to school administrators to develop school policy and procedure related to the issues of gay and lesbian parents. 


\section{REFERENCES}

Allport, G.W. (1954). The nature of prejudice. New York: Doubleday.

Allport, G.W., \& Ross, J.M. (1967). Personal religious orientation and prejudice. Journal of Personality and Social Psychology, 5, 432-443.

Altemeyer, B. (1988). Enemies of freedom: Understanding right-wing authoritarianism. San Francisco: Jossey-Bass.

Amodio, D.M., Harmon-Jones, E., \& Devine, P.G. (2003). Individual differences in the activation and control of affective race bias as assessed by startle eye-blink response and self-report. Journal of Personality and Social Psychology, 84, 738753.

Anderssen, N., Amlie, C., \& Ytteroy, E.A. (2002). Outcomes for children with lesbian or gay parents: A review of studies from 1978 to 2000. Scandinavian Journal of Psychology, 43, 335-351.

Asendorpf, J.B., Banse, R., \& Mucke, D. (2002). Double dissociation between implicit and explicit personality self-concept: The case of shy behavior. Journal of Personality and Social Psychology, 83, 380-393.

Bailey, J.M., Bobrow, D., Wolfe, M., \& Mikach, S. (1995). Sexual orientation of adult sons of gay fathers. Developmental Psychology, 31, 124-129.

Barron, J.M., Struckman-Johnson, C., Quevillon, R., \& Banka, S.R. (2008). Heterosexual men's attitudes toward gay men: A hierarchical model including masculinity, 
openness, and theoretical explanations. Psychology of Men and Masculinity, 9, 154-166.

Berstein, M. (2004). Paths to homophobia. Sexuality Research \& Social Policy, 1, 4155.Bigner, J. (2004). Working with gay and lesbian parents. Journal of Couple and Relationship Therapy, 3, 85-93.

Bliss, G.K., \& Harris, M.B. (1999). Teachers' views of students with gay or lesbian parents. Journal of Gay, Lesbian, and Bisexual Identity, 4, 149-171.

Bos, H.M.W., van Balen, F., van den Boom, D.C. (2007). Child adjustment and parenting in planned lesbian-parent families. American Journal of Orthopsychiatry, 77, 3848.

Brochu, P.M. \& Morrison, M.A. (2007). Implicit and explicit prejudice toward overweight and average-weight women: testing their correspondence and relation to behavioral intentions. The Journal of Social Psychology, 147, 681-706.

Brooke, S.L. (1993). The morality of homosexuality. Journal of Homosexuality, 25, 7799.

Butler, K.B. (1994). Prospective teachers' knowledge, attitudes, and behavior regarding gay men and lesbians. (ERIC Document Reproduction Service No. ED379251)

Clark, V., Kitzinger, C., \& Potter, J. (2004). 'Kids are just cruel anyway': Lesbian and gay parents' talk about homophobic bullying. British Journal of Social Psychology, 43, 531-550.

Crandall, C.S., \& Eshleman, A. (2003). A justification-suppression model of the expression and experience of prejudice. Psychological Bulletin, 129, 414-446. 
Crandall, C.S., Eshleman, A., \& O'Brien, L. (2002). Social norms and the expression and suppression of prejudice: The struggle for internalization. Journal of Personality and Social Psychology, 82, 359-378.

Cuperman, R., \& Ickes, W. (2009). Big Five predictors of behavior and perceptions in initial dyadic interactions: Personality similarity helps extraverts and introverts, but hurts "disagreeables." Journal of Personality and Social Psychology, 97, 667684.

Devine, P.G. (1989). Stereotypes and prejudice: Their automatic and controlled components. Journal of Personality and Social Psychology, 56, 5-18.

Devine, P.G., Brodish, A.B., \& Vance, S.L. (2005). The role of internal and external motivation to respond without prejudice. In J.P. Forgas, K.D. Williams, \& M. Simon (Eds.), Social Motivation: Conscious and Unconscious Processes (pp. 249273) New York: Cambridge.

Devine, P.G., Plant, E.A., Amodio, D.M., Harmon-Jones, E., \& Vance, S.L. (2002). The regulation of explicit and implicit race bias: The role of motivations to respond without prejudice. Journal of Personality and Social Psychology, 82, 835-848.

Dovidio, J.F., Kawakami, K., \& Gaertner, S.L. (2002). Implicit and explicit prejudice and interracial interaction. Journal of Personality and Social Psychology, 82, 62-68.

Dovidio, J.F., Kawakami, K., Johnson, C., Johnson, B., \& Howard, A. (1997). On the nature of prejudice: Automatic and controlled processes. Journal of Experimental Social Psychology, 33, 510-540. 
Dunton, B.C., \& Fazio, R.H. (1997). An individual difference measure of motivation to control prejudiced reactions. Personality and Social Psychology Bulletin, 23, 316326.

Ekehammar, B., \& Akrami, N. (2003). The relation between personality and prejudice: A variable- and a person-centered approach. European Journal of Personality, 17, 449-464.

Ekehammar, B. \& Akrami, N. (2007). Personality and prejudice: From Big Five personality factors to facets. Journal of Personality, 75, 899-926.

Erich, S., Kanenberg, H., Case, K., Allen, T., Bogdanos, T. (2009). An empirical analysis of factors affecting adolescent attachment in adoptive families with homosexual and straight parents. Children and Youth Services Review, 31, 398-404.

Esses, V.M., Haddock, G., \& Zanna, M.P. (1993). Values, stereotypes, and emotions as determinants of intergroup attitudes. In D.M. Mackie \& D.L. Hamilton (Eds.), Affect, cognition, and stereotyping: Interactive processes in group perception (pp. 137-166. New York: Academic Press.

Fagan, T.K. \& Wise, P.S. (2000). School psychology: Past, present and future ( $2^{\text {nd }}$ ed.). Bethesda, MD: National Association of School Psychologists.

Fazio, R.H. (1990). Multiple processes by which attitudes guide behavior: The MODE model as an integrative framework. In M.P. Zanna (Ed.), Advances in experimental social psychology (Vol. 23, pp. 75-109). New York: Academic.

Fazio, R.H., \& Olson, M.A. (2003). Implicit measures in social cognition research: Their meaning and use. Annual Review of Psychology, 54, 297-327. 
Flaks, D. K., Ficher I., Masterpasqua, F., \& Joseph, G. (1995). Lesbians choosing motherhood. A comparative study of lesbian and heterosexual parents and their children. Developmental Psychology, 31, 105-114.

Fontaine, J. (1997). The sound of silence: Public school response to the needs of gay and lesbian youth. Journal of Gay and Lesbian Social Services, 7, 101-109.

Franco, F.M., \& Maass, A. (1999). Intentional control over prejudice: When the choice of the measure matters. European Journal of Social Psychology, 29, 469-477.

Frisby, C.L., \& Reynolds, C.R. (Eds.). (2005). Comprehensive handbook of multicultural school psychology. Hoboken, NJ: Wiley \& Sons.

Gartrell, N., Deck, A., Rodas, C., Peyser, H., \& Banks, A. (2005). The national lesbian family study: 4 . Interviews with the 10-year-old children. American Journal of Orthopsychiatry, 75, 518-524.

Golombok, S., Spencer, A., \& Rutter, M. (1983). Children in lesbian and single-parent households: Psychosexual and psychiatric appraisal. Journal of Child Psychology and Psychiatry, 24, 551-572.

Golombok, S., \& Tasker, F. (1996). Do parents influence the sexual orientation of their children? Findings from a longitudinal study of lesbian families. Developmental Psychology, 32, 3-11.

Graziano, W. G., Bruce, J. W., Sheese, B. E. \& Tobin, R. M. (2007). Attraction, personality and prejudice: Liking none of the people most of the time. Journal of Personality and Social Psychology, 95, 65-582. 
Graziano, W.G. \& Eisenberg, N. (1997). Agreeableness: A dimension of personality. In R. Hogan, J. Johnson, \& S. Briggs (Eds.), Handbook of personality psychology (pp. 795-824). San Diego: Academic Press.

Graziano, W.G., Hair, E.C., \& Finch, J.F. (1997). Competitiveness mediates the link between personality and group performance. Journal of Personality and Social Psychology, 73, 1394-1408.

Graziano, W.G., Jensen-Campbell, L.A., \& Hair, E.C. (1996). Perceiving interpersonal conflict and reacting to it: The case for Agreeableness. Journal of Personality and Social Psychology, 70, 820-835.

Graziano, W.G., \& Tobin, R.M. (2002). Agreeableness: Dimension of personality or social artifact? Journal of Personality, 70, 695-728.

Graziano, W. G., \& Tobin, R. M. (2009). Agreeableness. In M. R. Leary \& R. H. Hoyle (Eds.), Handbook of individual differences in social behavior (pp. 46-61). New York: Guilford.

Green, R. (1978). Sexual identity of 37 children raised by homosexual or transsexual parents. American Journal of Psychiatry, 135, 692-697.

Greenwald, A.G., \& Farnham, S.D. (2000). Using the implicit association test to measure self-esteem and self-concept. Journal of Personality and Social Psychology, 79, $1022-1038$.

Greenwald, A.G., McGhee, D.E., \& Schwartz, J.L.K. (1998). Measuring individual differences in implicit cognition: The implicit association test. Journal of Personality and Social Psychology, 74, 1464-1480. 
Haddock, G., \& Zanna, M.P. (1998). Authoritarianism, values, and the favorability and structure of antigay attitudes. In G.M. Herek (Ed.) Stigma and sexual orientation: Understanding prejudice against lesbians, gay men, and bisexuals (pp. 82-107). Thousand Oaks, CA: Sage.

Herek, G.M. (1988). Heterosexuals' attitudes toward lesbians and gay men: A review of empirical research with the ATLG scale. In B. Greene \& G.M. Herek (Eds.), Lesbian and gay psychology: Theory, research, and clinical applications (pp. 206-228). Thousand Oaks, CA: Sage.

Herek, G.M. (1989). Hate crimes against lesbians and gay men: Issues for research and policy. American Psychologist, 44, 948-955.

Herek, G.M. (2000). The psychology of sexual prejudice. Current directions in psychological science, 9, 19-22.

Herek, G.M. (2002). Gender gaps in public opinion about lesbians and gay men. Public Opinion Quarterly, 66, 40-66.

Herek, G.M. (2005). Beyond "homophobia:" Thinking about sexual prejudice and stigma in the twenty-first century. Sexuality Research and Social Policy, 1, 6-24.

Herek, G.M. (2007). Confronting sexual stigma and prejudice: Theory and practice. Journal of Social Issues, 63, 905-925.

Herek, G.M., Gillis, J., \& Cogan, J. (1999). Psychological sequalae of hate crime victimization among lesbian, gay, and bisexual adults. Journal of Consulting and Clinical Psychology, 67, 945-951. 
Herek, G.M., Widaman, K.F., \& Capitanio, J.P. (2005). When sex equals AIDS: Symbolic stigma and heterosexual adults' inaccurate beliefs about sexual transmission of AIDS. Social Problems, 52, 15-37.

Hoffman, W., Gawronski, B., Gschwender, T., Le, H., \& Schmitt, M. A Meta-Analysis on the Correlation Between the Implicit Association Test and Explicit Self-Report Measures Personality and Social Psychology Bulletin, 31, 1369 - 1385.

Huggins, S. L. (1989). A comparative study of self-esteem of adolescent children of divorced lesbian mothers and divorced heterosexual mothers. Journal of Homosexuality, 18, 123-135.

Hughes, J.N., Hasbrouck, J.E., Serdahl, E., Heidgerken, A., \& McHaney, L. (2001). Responsive systems consultation: A preliminary evaluation of implementation and outcomes. Journal of Educational and Psychological Consultation, 12, 179201.

Human Rights Campaign. (n.d.). U.S. Census Breaks New Ground in Same-Sex Household Data. Retrieved August 13, 2005, from http://www.hrc.org.

Jellison, W.A., McConnell, A.R., \& Gabriel, S. (2004). Implicit and explicit measures of sexual orientation attitudes: Ingroup preferences and related behaviors and beliefs among gay and straight men. Personality and Social Psychology Bulletin, 30, $629-642$.

Jensen-Campbell, L.A., Rosselli, M., Workman, K.A., Santisi, M., Rios, J.D., \& Bojan, D. (2002). Agreeableness, conscientiousness, and effortful control processes. Journal of Research in Personality, 36, 476-489. 
John, O.P., \& Srivastave, S. (1999). The Big Five trait taxonomy: history, measurement, and theoretical perspectives. In L.A. Pervin \& O.P. John (Eds.), Handbook of personality: Theory and Research ( $2^{\text {nd }}$ ed., pp. 102-138). New York: Guilford.

Karpinski, A., \& Hilton, J.L. (2001). Attitudes and the implicit association test. Journal of Personality and Social Psychology, 81, 774-778.

Kieras, J.E., Tobin, R.M., Graziano, W.G., \& Rothbart, M.K. (2005). You can't always get what you want: Effortful control and children's responses to undesirable gifts. Psychological Science, 16, 391-396.

Kozik-Rosabal, G. (2000). "Well, we haven't noticed anything bad going on," said the principal. Parents speak about their gay families and schools. Education and Urban Society, 32, 368-389.

Lang, P.J., Bradley, M.M., \& Culthbert B.N. (1990). Emotion, attention, and the startle reflex. Psychological Review, 97, 377-395.

Larson, K.S., Cate, R., \& Reed, M. (1983). Anti-Black attitudes, religious orthodoxy, permissiveness, and sexual information: A study of the attitudes of heterosexuals toward homosexuality. Journal of Sex Research, 19, 105-118.

Lawrence, A.A., Latty, E.M., Chivers, M.L., \&Chivers, \& Bailey, J.M. (2005). Measurement of sexual arousal in postoperative male-to-female transsexuals using vaginal photoplethysmography. Archives of Sexual Behavior, 34, 135-145.

Legault, L., Green-Deemers, \& Eadie, A. (2007). When internalization leads to automatization: The role of self-determination in automatic stereotype suppression and implicit prejudice regulation. Motivation and Emotion, 33, 10-24. 
Legault, L., Green-Demers, I., Grant, P., \& Chung, J. (2009). On the self-regulation of implicit and explicit prejudice: A self-determination theory perspective. Personality and Social Psychology Bulletin, 33, 732-749.

Lindsay, J., Perlesz, A., Brown, R., McNair, R., de Vaus, D., \& Pitts, M. (2006). Stigma or respect: Lesbian-parented families negotiation school settings. Sociology, 40, 1059-1077.

McCann, D., \& Delmonte, H. (2005). Lesbian and gay parenting: babes in arms or babes in the woods? Sexual and Relationship Therapy, 20, 333-347.

McConahay, J.B., Hardee, B.B., \& Batts, V. (1981). Has racism declined? It depends on who's asking and what is asked. Journal of Conflict Resolution, 25, 563-579.

McConahay, J.B., \& Hough, J.C. (1976). Symbolic racism. Journal of Social Issues, 32, $23-45$.

Meyer, H.H. (2003). Prejudice, social stress, and mental health in lesbian, gay, and bisexual populations: Conceptual issues and research evidence. Psychological Bulletin, 129, 674-697.

Middleton, V.A. (2002). Increasing preservice teachers' diversity beliefs and commitment. The Urban Review, 34, 343-361.

Monteith, M.J., Sherman, J.W., \& Devine, P.J. (1998). Suppression as a stereotype control strategy. Personality and Social Psychology Review, 2, 63-82.

Morrison, T.G., Kenny, P., \& Harrington, A. (2005). Modern prejudice toward gay men and lesbian women: Assessing the viability of a measure of modern homonegative 
attitudes within an Irish context. Genetic, Social, and General Psychology Monographs, 131, 219-250.

Morrison, M. A., \& Morrison, T. G. (2002). Development and validation of a scale measuring modern prejudice toward gay men and lesbian women. Journal of Homosexuality, 43, 15-37.

Murray, P., \& McClintock, K. (2005). Children of the closet: A measurement of the anxiety and self-esteem of children raised by a non-disclosed homosexual or bisexual parent. Journal of Homosexuality, 49, 77-95.

National Center for Education Statistics. (2006, April). Characteristics of schools, districts, teachers, principals, and school libraries in the United States. Retrieved August 23, 2006, from http://nces.ed.gov/pubs2006/2006313.pdf.

Park, S.H., Glaser, J., \& Knowles, E.D. (1998). Implicit motivation to control prejudice moderates the effect of cognitive depletion on unintended discrimination. Social Cognition, 26, 401-419.

Parrott, D.J., Adams, H.E., \& Zeichner, A. (2002). Homophobia: Personality and attitudinal correlates. Personality and Individual Differences, 32, 1269-1278.

Parrot, D.J. \& Gallagher, K.E. (2008). What accounts for heterosexual women's negative emotional responses to lesbians?: Examination of traditional gender role beliefs and sexual prejudice. Sex Roles, 59, 229-239.

Parrott, D.J., \& Zeichner, A. (2005). Effects of sexual prejudice and anger on physical aggression toward gay and heterosexual men. Psychology of Men \& Masculinity, $6,3-17$. 
Patel, A. M., Pryor, J. B., Monroe, A., \& Reeder, G. D. (2008). My big fat family: The stigma-by-association effect in families. Presentation at the meetings of the Society for Personality and Social Psychology meetings, Albuquerque, NM.

Patel, A. M., Pryor, J. B., Reeder, G. D., \& Monroe, A. (2007). How implicit and explicit racial attitudes are related to a stigma-by-association effect. Presentation at the meetings of the Association for Psychological Science, Washington, DC.

Payne, B.K., Burkley, M.A., \& Stokes, M.B. (2008). Why do implicit and explicit attitude tests diverge? The role of structural fit. Journal of Personality and Social Psychology, 94, 16-31.

Payne, B.K., Cheng, C.M., Govorun, O., \& Stewart, B.D. (2005). An inkblot for attitudes: Affect misattribution as implicit measurement. Journal of Personality and Social Psychology, 89, 277-293.

Pianta, R.C., \& Walsh, D.J. (1996). High-risk children in schools: Constructing sustaining relationships. New York: Routledge \& Kegan Paul.

Plant, E.A., \& Devine, P.G. (1998). Internal and external motivation to respond without prejudice. Journal of Personality and Social Psychology, 75, 811-832.

Plant, E. A. \& Devine, P.G. (2009). The active control of prejudice: Unpacking the intentions guiding control efforts. Journal of Personality and Social Psychology, $96,640-652$.

Ray, V., \& Gregory, R. (2001). School experiences of the children of lesbian and gay parents. Family Matters, 59, 28-34. 
Reynolds, K.J., Turner, J.C., Haslam, S., \& Ryan, M. (2001). The role of personality and group factors in explaining prejudice. Journal of Experimental Social Psychology, $37,427-434$.

Rieger, G., Chivers, M.L., \& Bailey, J.M. (2005). Sexual arousal patterns of bisexual men. Psychological Science, 16, 579-584.

Riemann, R., Grubich, C., Hempel, S., Mergel, S., \& Richter, M. (1993). Personality and attitudes toward current political topics. Personality and Individual Differences, $15,313-321$.

Rivers, I., Poteat, V.P., \& Noret, N. (2008). Victimization, social support, and psychosocial functioning among children of same-sex and opposite-sex couples in the United Kingdom. Developmental Psychology, 44, 127-134.

Rothbart, M.K, Ellis, L.K., Rueda, M.R., \& Posner, M. (2003). Developing mechanisms of temperamental effortful control. Journal of Personality, 71, 1113-1143.

Saucier, D.A., \& Cawman, A.J. (2004). Civil unions in Vermont: Political attitudes, religious fundamentalism, and sexual prejudice. Journal of Homosexuality, 48, 1 18.

Schweickart, P. (1988). The challenge of diversity. ADE Bulletin, 88, 21-26.

Sears, J. (1991). Educators, homosexuality, and homosexual students: Are personal feelings related to professional beliefs? Journal of Homosexuality, 22, 29-79.

Sherif, M., \& Sherif, C.W. (1953). Groups in harmony and tension. New York: Harper.

Sibley, C.G. \& Duckit, J. (2009). Personality and prejudice: A meta-analysis and theoretical review. Personality and Social Psychology Review, 12, 248-279. 
Simon, A. (1998). The relationship between stereotypes of and attitudes toward lesbians and gays. In G.M. Herek (Ed.) Stigma and sexual orientation: Understanding prejudice against lesbians, gay men, and bisexuals (pp. 62-81). Thousand Oaks, CA: Sage.

Singer, J., \& Smith, S. (2002, April). Using intercollegiate response groups to help teacher education students bridge differences of race, class, and ethnicity. Paper presented at the American Educational Research Association Meeting, New Orleans, LA.

Snyder, M., \& Haugen, J.A. (1994). Why does behavioral confirmation occur? A functional perspective on the role of the perceiver. Journal of Experimental Social Psychology, 30, 218-246.

Son Hing, L.S., Chung-Yan, G.A., Hamilton, L.K., \& Zanna, M.P. (2008). A twodimensional model that employs explicit and implicit attitudes to characterize prejudice. Journal of Personality and Social Psychology, 94, 971-987.

Stangor, C. (2000). Volume overview. In C. Stangor (Ed.), Stereotypes and prejudice (pp. 1-16). Philadelphia: Psychology Press.

Stein, T.S. (2004). Expanding our notions of homophobia and sexual prejudice. Sexuality Research and Practice, 1, 3-5.

Strauss, J.P., Connerley, M.L., \& Ammermann, P.A. (2003). The "threat hypothesis," personality, and attitudes toward diversity. Journal of Applied Behavioral Science, 39, 32-52. 
Swap, S.M. (1992). Parent involvement and success for all children: What we know now. In S.L. Christenson \& J.C. Conoley (Eds.), Home-school collaboration: Enhancing children's academic and social competence (pp. 53-80). Silver Spring, MD: National Association of School Psychologists.

Tatto, M.T. (1996). Examining values and beliefs about teaching diverse students: Understanding the challenges for teacher education. Educational Evaluation and Policy Analysis, 18, 155-180.

Taylor, P.A. (2001, April). Good news and bad news: A comparison of teacher educators' and preservice teachers' beliefs about diversity issues. Paper presented at the Annual Meeting of the American Educational Research Association, Seattle, WA.

Tobin, R.M., Graziano, W.G., Vanman, E.J., \& Tassinary, L.G. (2000). Personality, emotional experience, and efforts to control emotions. Journal of Personality and Social Psychology, 79, 656-669.

United States Census Bureau (2000). Married-couple and unmarried-partner households: 2000. Census 2000 special reports. Retrieved August 17, 2005, from http://www.census.gov/prod/2003pubs/censr-5.pdf.

United States Department of Education (n.d.). The no child left behind act of 2001 . Retrieved August 23, 2006, from http://www.ed.gov/policy/elsec/leg/esea02/index.html. 
Uribe, V., \& Harbeck, K.M. (1991). Addressing the needs of lesbian, gay, and bisexual youth: The origins of project 10 and school-based intervention. Journal of Homosexuality, 22, 9-28.

Van de Ven, P., Bornholt, L., \& Bailey, M. (1996). Measuring cognitive, affective, and behavioral components of homophobic reaction. Archives of Sexual Behavior, 25, 155-179.

Vickers, H.S., \& Minke, K.M. (1995). Exploring parent-teacher relationships: Joining and communication to others. School Psychology Quarterly, 10, 133-150.

Vogt, W.P. (1997). Tolerance and education: Learning to live with diversity and difference. Thousand Oaks, CA: Sage.

Vogt, W.P., \& McKenna, B.J. (1998). Teachers' tolerance: Their attitudes toward political, social, and moral diversity. Paper presented at the Annual Meeting of the American Educational Research Association (San Diego, April 13-17, 1998) ED423 344 UD 032557

Wainright, J.L. \& Patterson, C.J. (2008). Peer relations among adolescents with female same-sex parents. Developmental Psychology, 44, 117-126.

Wainright, J.L., Russell, S.T., \& Patterson, C.J. (2004). Psychosocial adjustment, school outcomes, and romantic relationships of adolescents with same-sex parents. Child Development, $75,1886-1898$.

Walls, N.E. (2008). Toward a multidimensional understanding of heterosexism: The changing nature of prejudice. Journal of Homosexuality, 55, 20-70. 
Wells, J., \& Franken, M. (1987). University students' knowledge about and attitudes toward homosexuality. Journal of Humanistic Education and Development, 26, 81-95.

Zeichner, A., Frey, F.C., Parrott, D.J., \& Butryn, M. (1999). Measurement of laboratory aggression: A new response-choice paradigm. Psychological Reports, 82, 12291237.

Ziegert, J.C., \& Hanges P.J. (2005). Employment discrimination: The role of implicit attitudes, motivation, and a climate for racial bias. Journal of Applied Psychology, $90,553-562$. 
APPENDIX A

SURVEYS 
Social Distance Questionnaire

\begin{tabular}{|ccccc|}
\hline 1 & 2 & 3 & 4 & 5 \\
Not at all & Not very & Neutral & Somewhat & Very \\
\hline
\end{tabular}

1. To what extent would you like to spend time with this person?

2. To what extent would want to you introduce this person to your family?

3. To what extent would you look forward to meeting this person?

4. To what extent would you want to introduce this person to your friends?

5. To what degree would you feel comfortable spending time with this person?

6. To what degree does this person appear attractive to you?

7. To what degree does this person appear friendly to you?

\section{Demographic Information}

A. Age:

B. Sex:
a. male
b. female

C. Class level:
a. freshman
b. sophomore
c. junior
d. senior
e. graduate - master's
f. graduate - doctoral
g. other (specify:

D. Major:

E. D. Religious affiliation:
a. Protestant
b. Roman Catholic
c. Jewish
d. Other Christian 
e. Muslim

f. Buddhist

g. Hindu

h. other (specify:

i. none

F. How often do you attend religious services?

a. Never

b. 1-2 times a year

c. 3-11 times a year

d. 1-3 times a month

e. once a week or more

G. Your race/ethnic group:

a. American Indian/Alaskan

b. Asian/Pacific Islander

c. Black/African American

d. Hispanic/Latino

e. White, Non-Hispanic

f. other (specify:

H. What is your nationality?

a. U.S. Citizen

b. other (specify:

I. Are you currently employed?

a. No

b. Yes, I have an on-campus, part-time job. d. Yes, I have an off-campus, part-time job.

c. Yes, I have an on-campus, full-time job. e. Yes, I have an off-campus, full-time job.

J. How many gay, lesbian, or bisexual people do you know in the following categories?

\begin{tabular}{|l|l|l|}
\hline Categories & Number of Males & Number of Females \\
\hline $\begin{array}{l}\text { Immediate family (brothers, } \\
\text { sisters, parents, } \\
\text { grandparents, or children) }\end{array}$ & & \\
\hline $\begin{array}{l}\text { Other family (aunts, uncles, } \\
\text { or cousins) }\end{array}$ & & \\
\hline Close friends & & \\
\hline $\begin{array}{l}\text { Other people you know } \\
\text { personally }\end{array}$ & & \\
\hline
\end{tabular}


K. Which sexual orientation most closely describes you?

a. Heterosexual

b. Homosexual

c. Bisexual

d. Other (specify: 
APPENDIX B

REGRESSION TABLES 

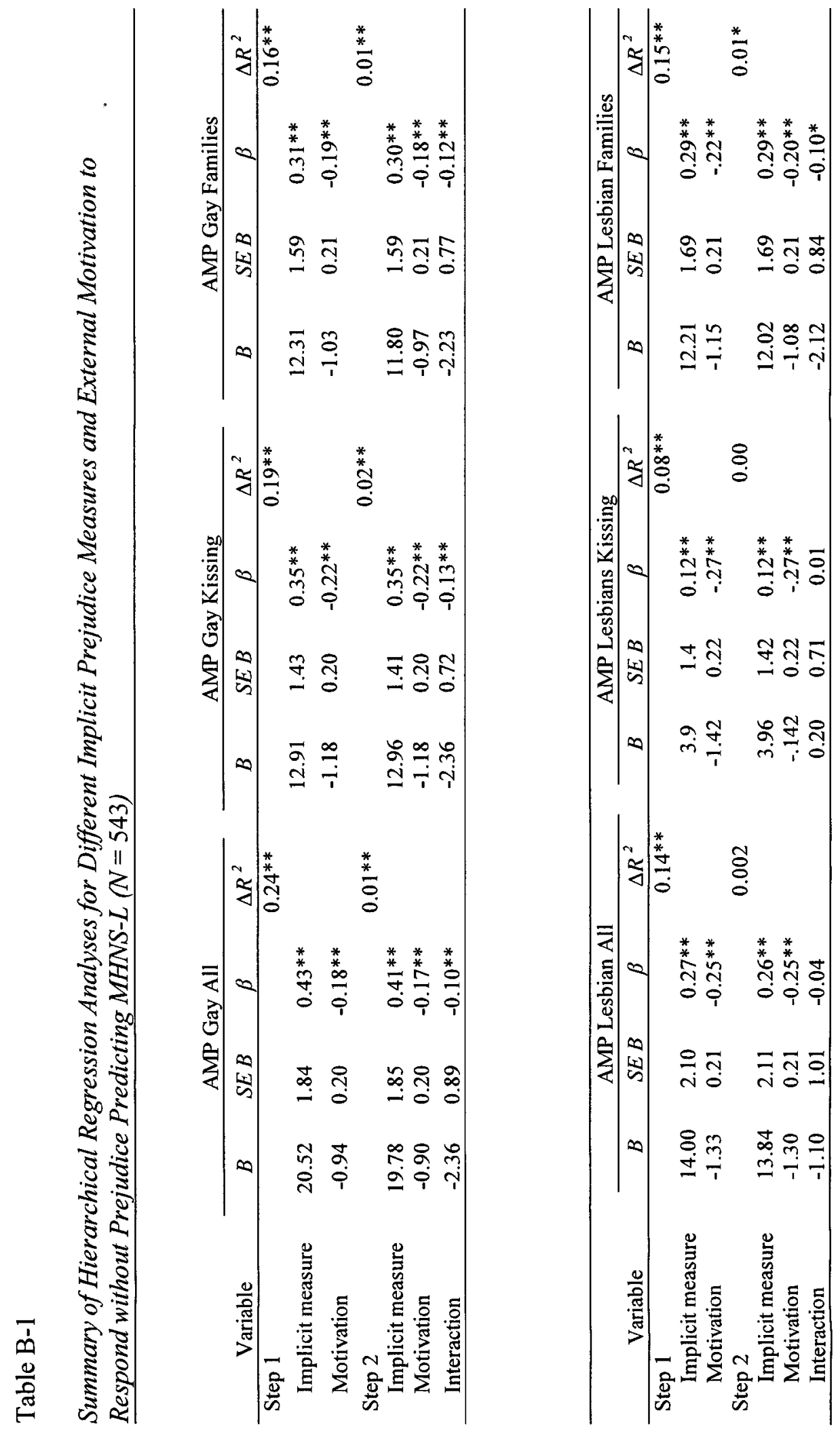


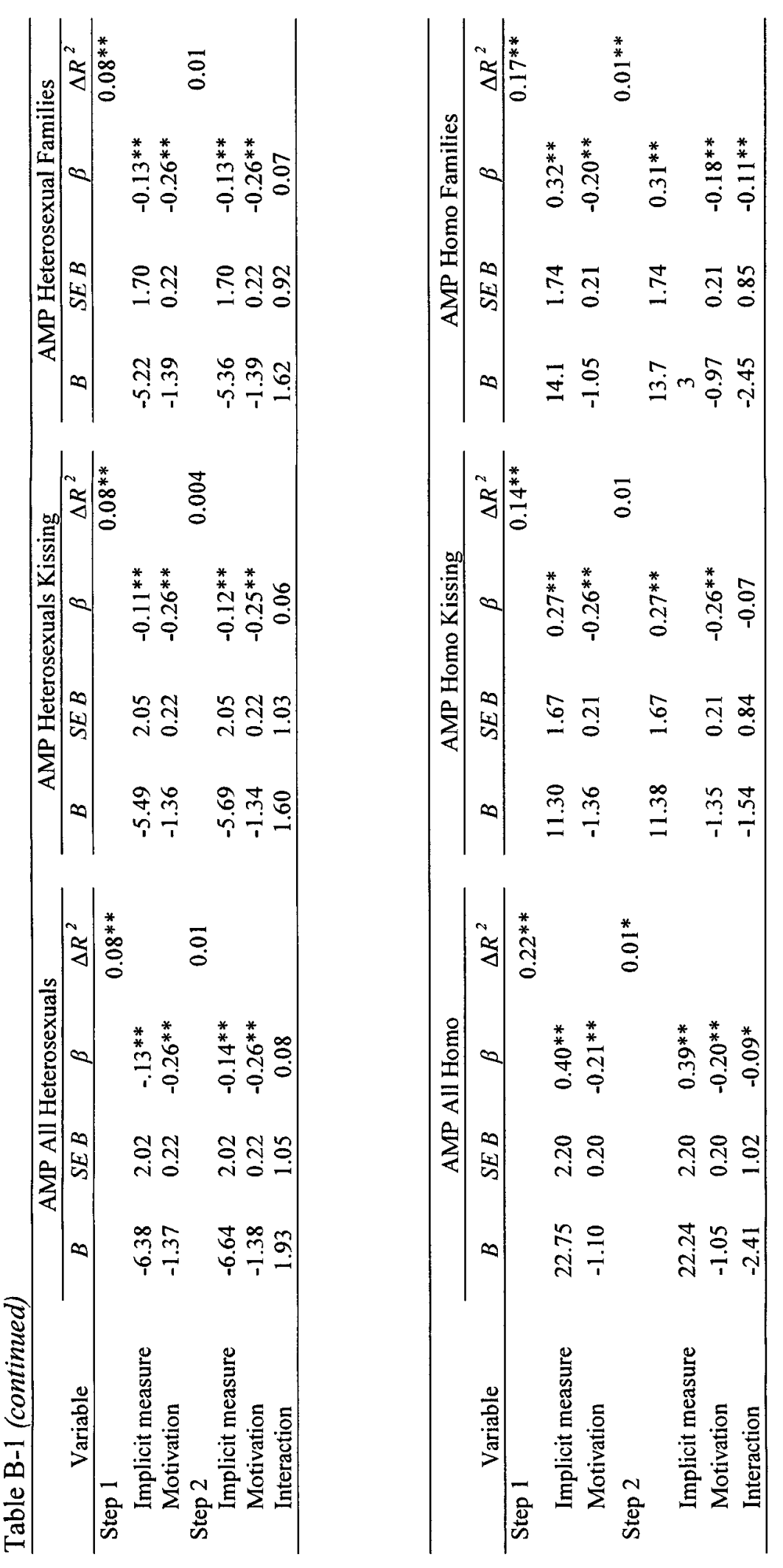



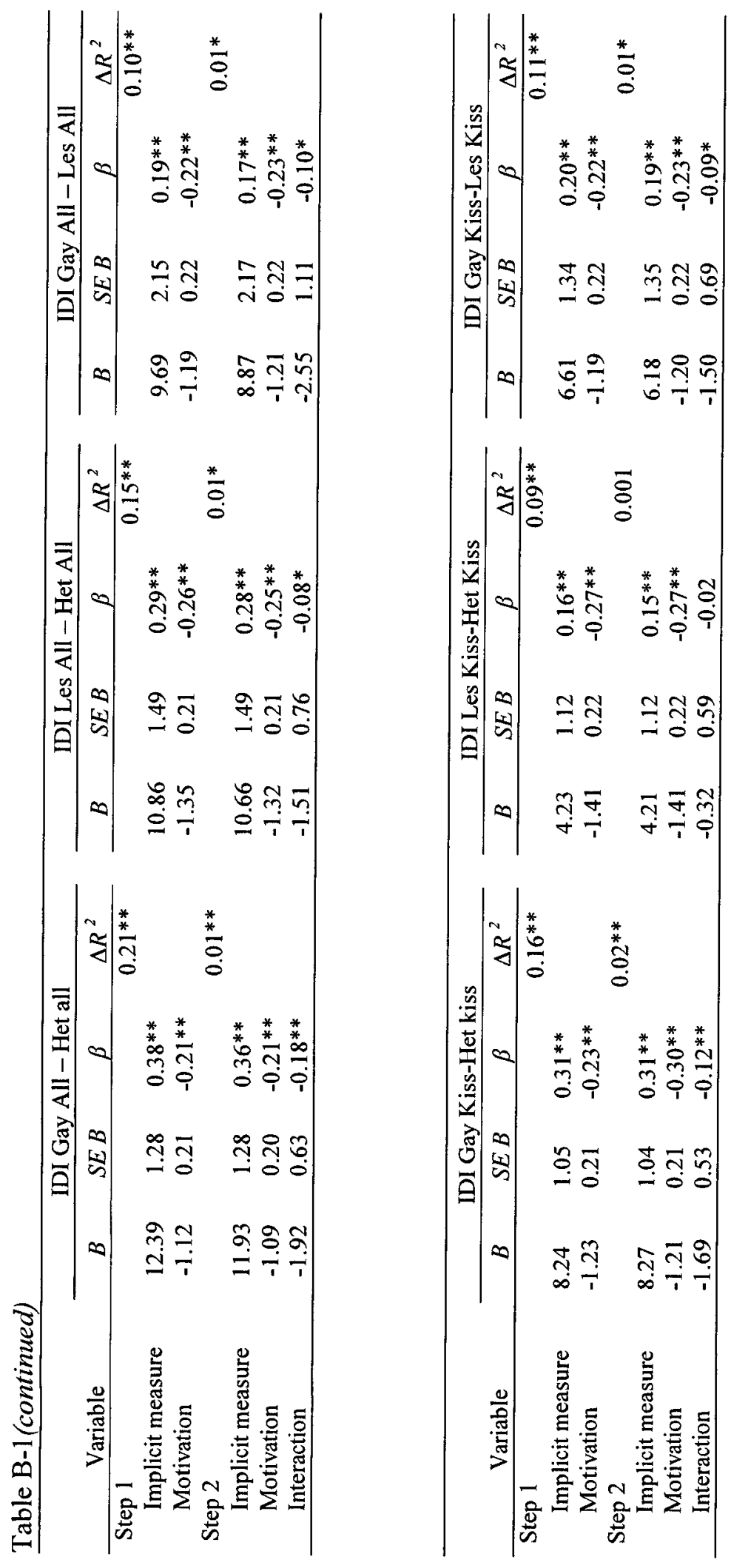

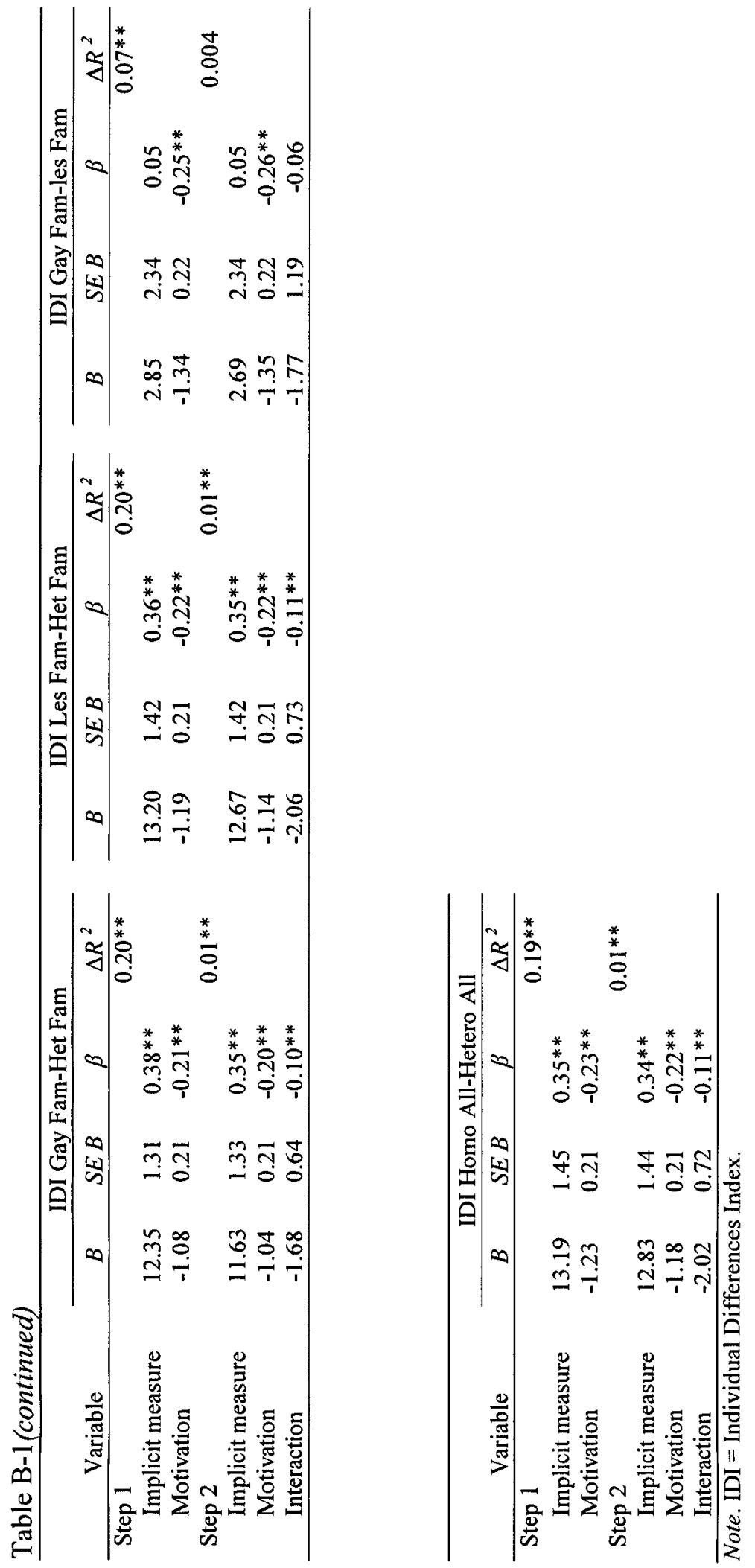

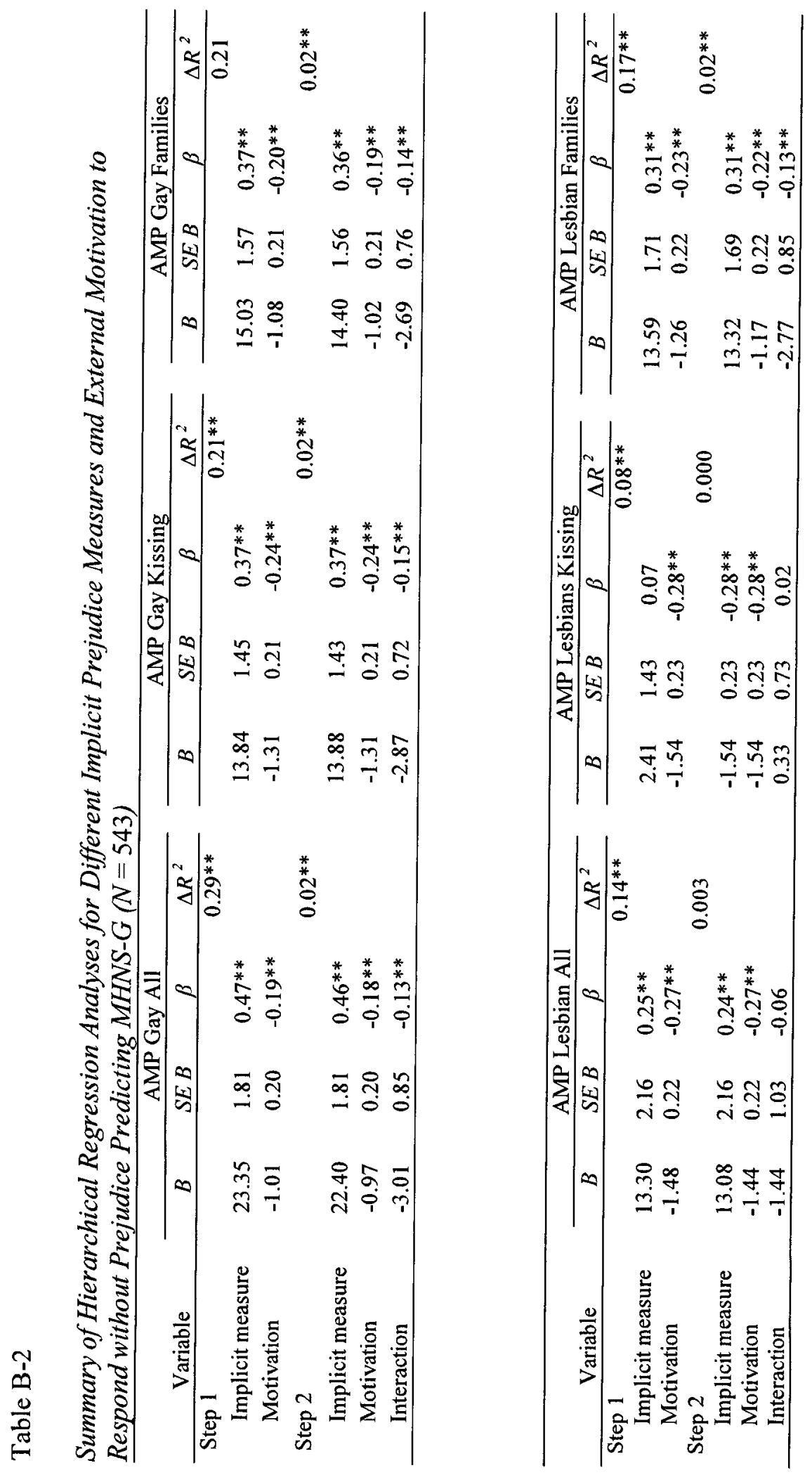


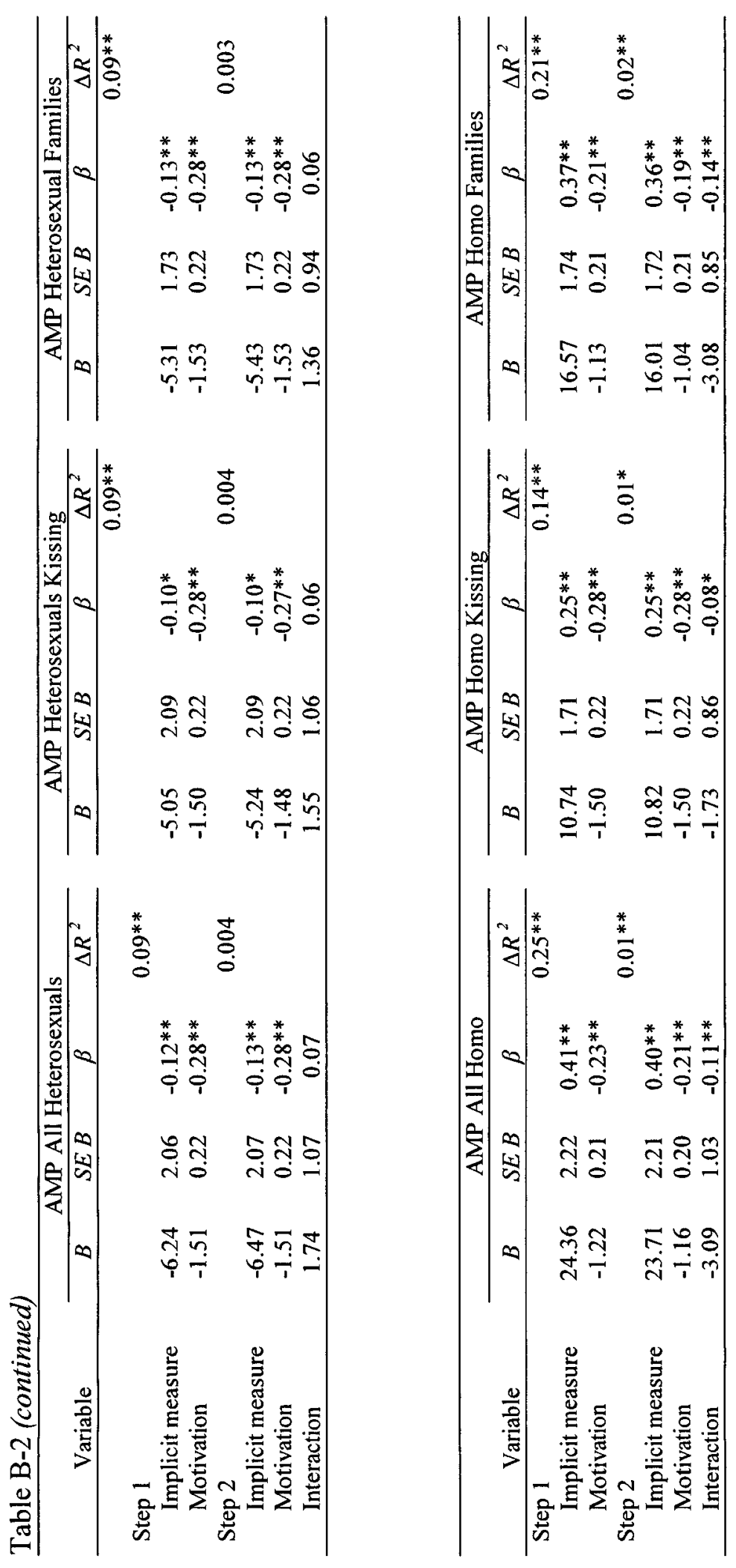



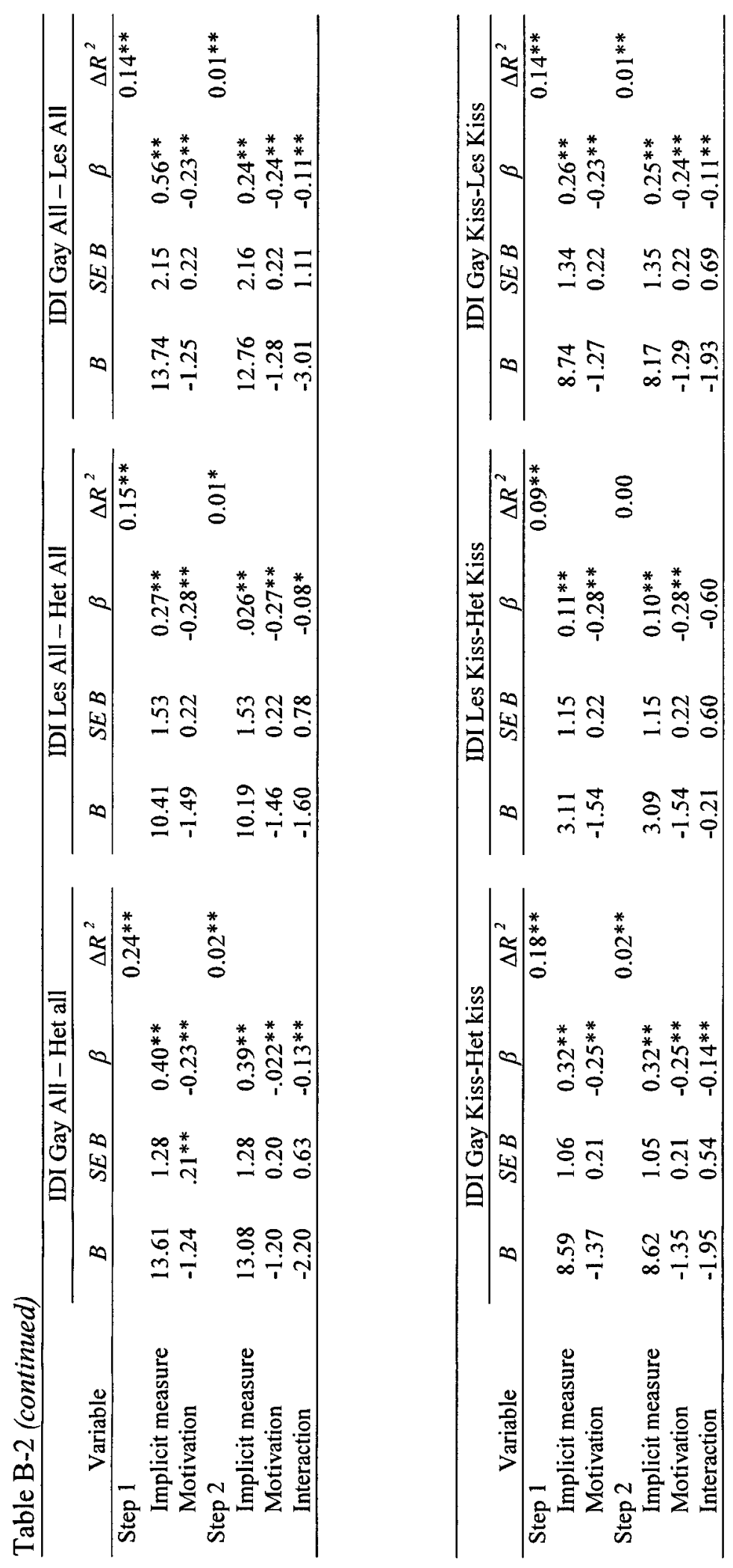

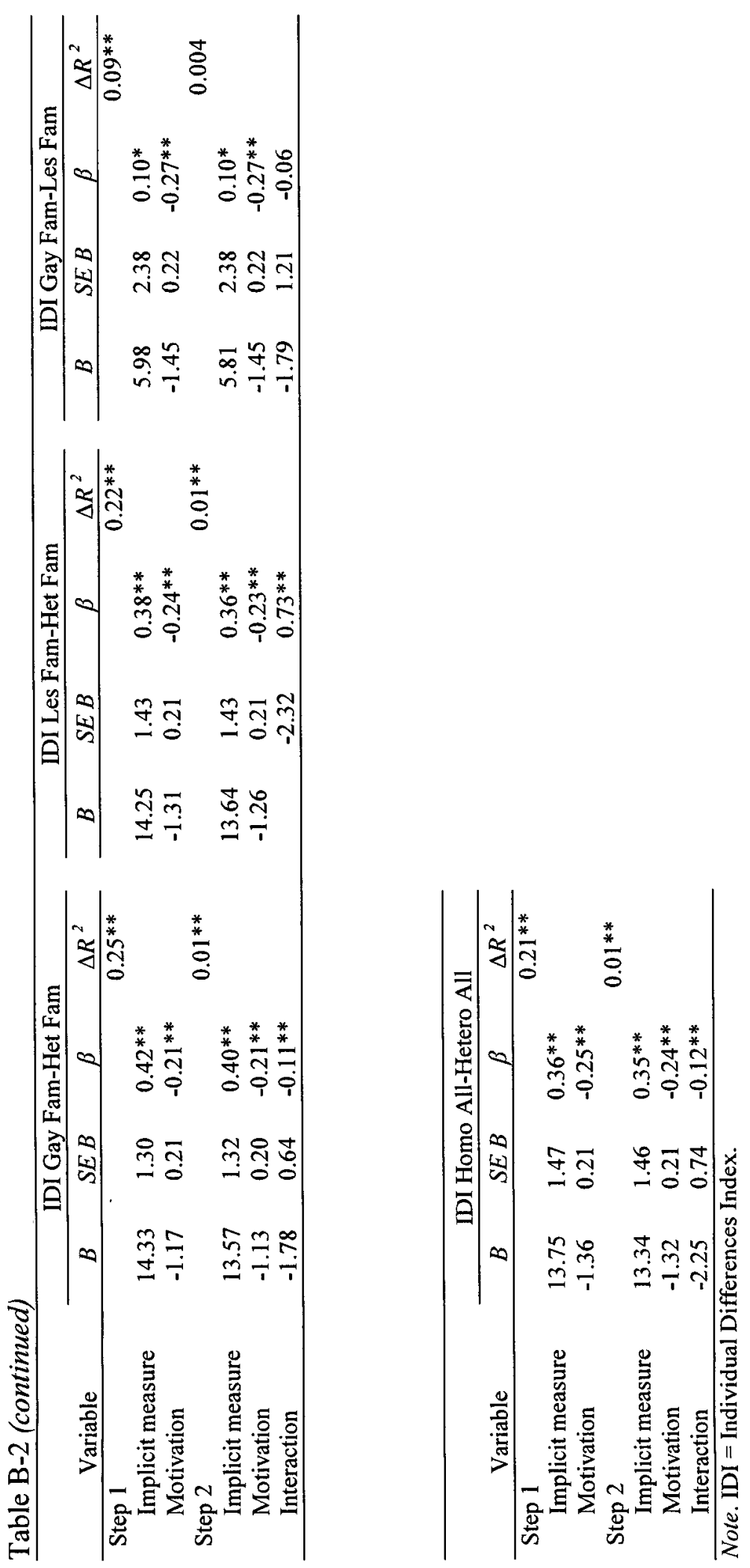

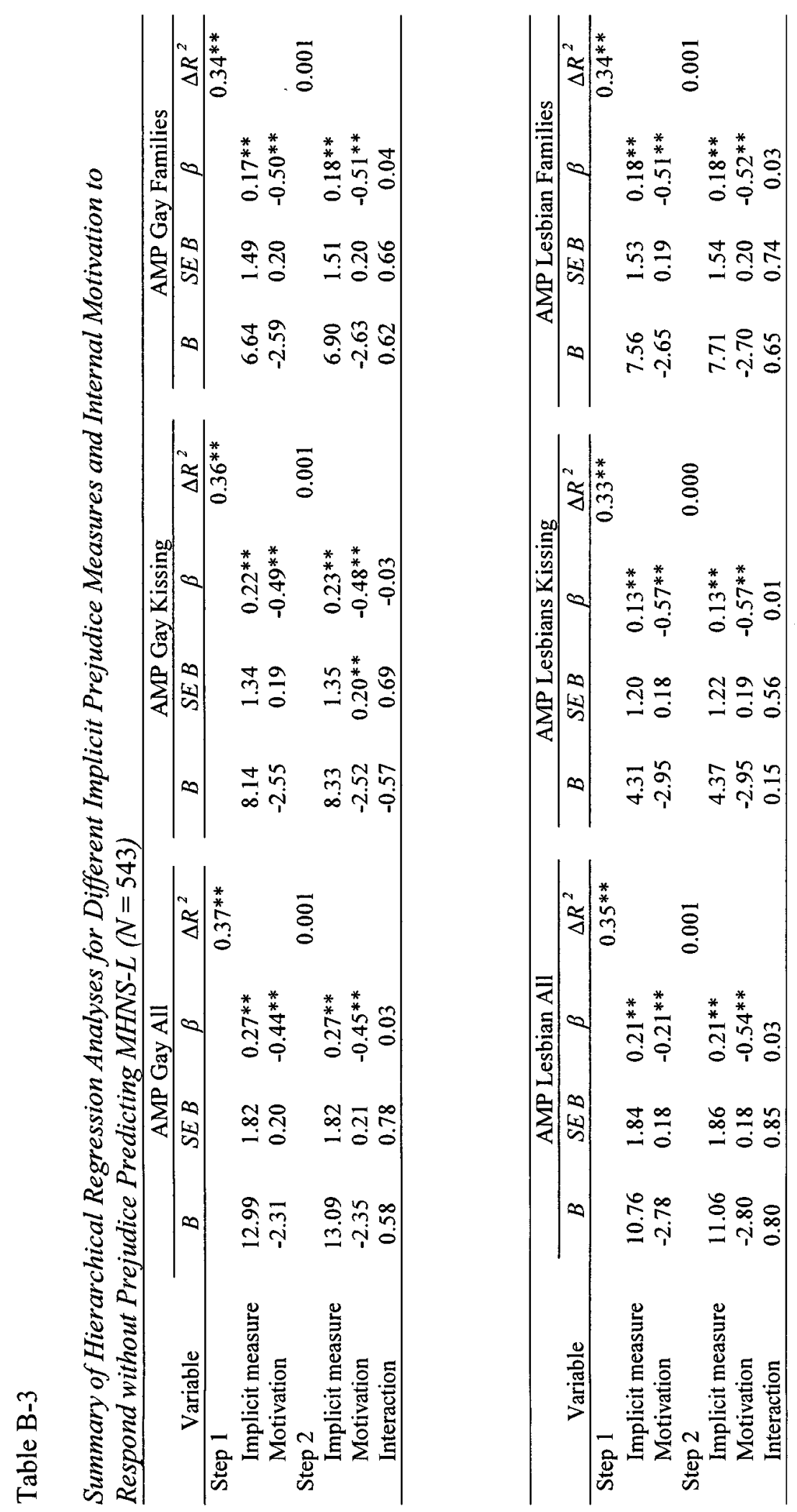

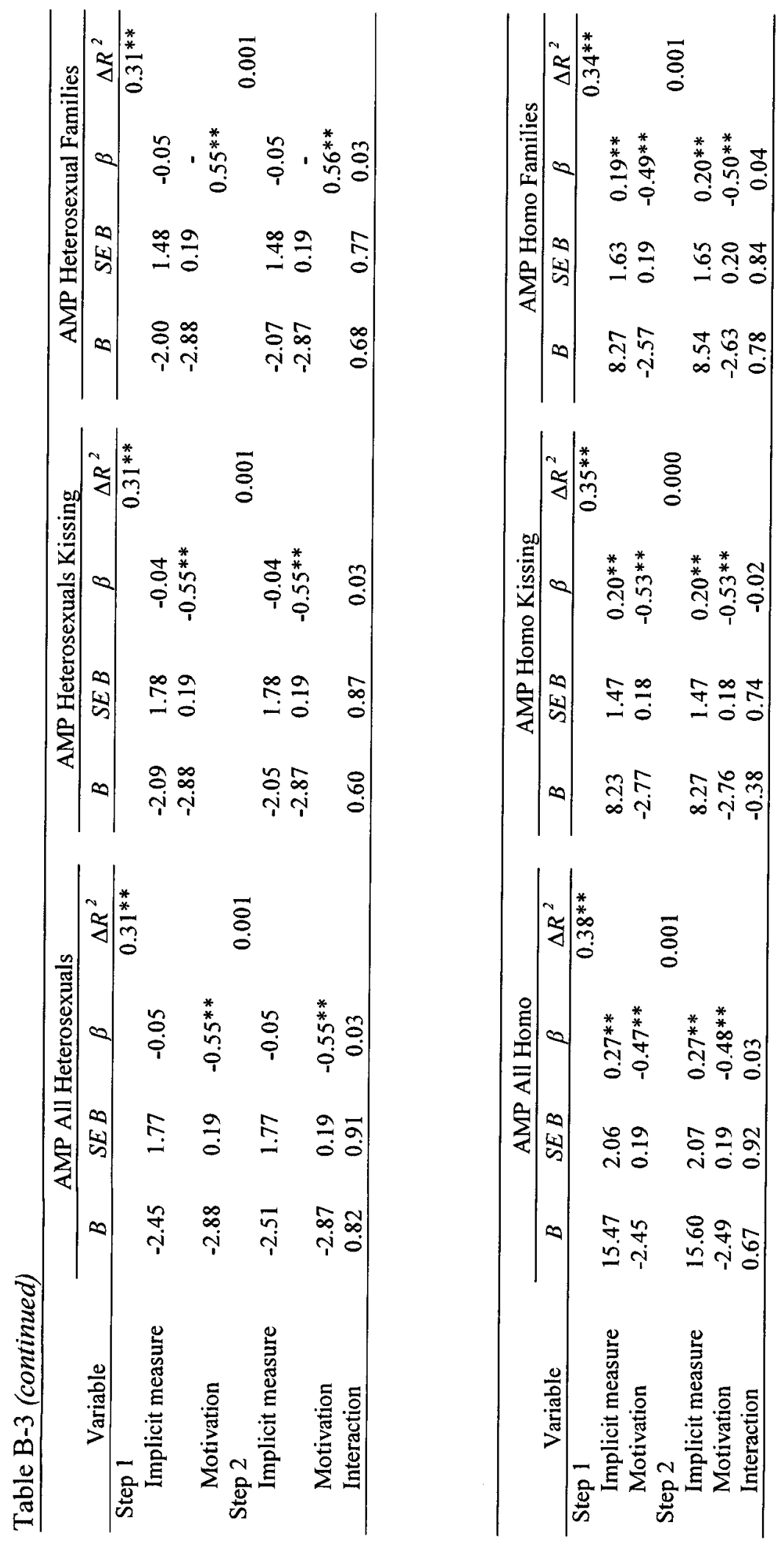

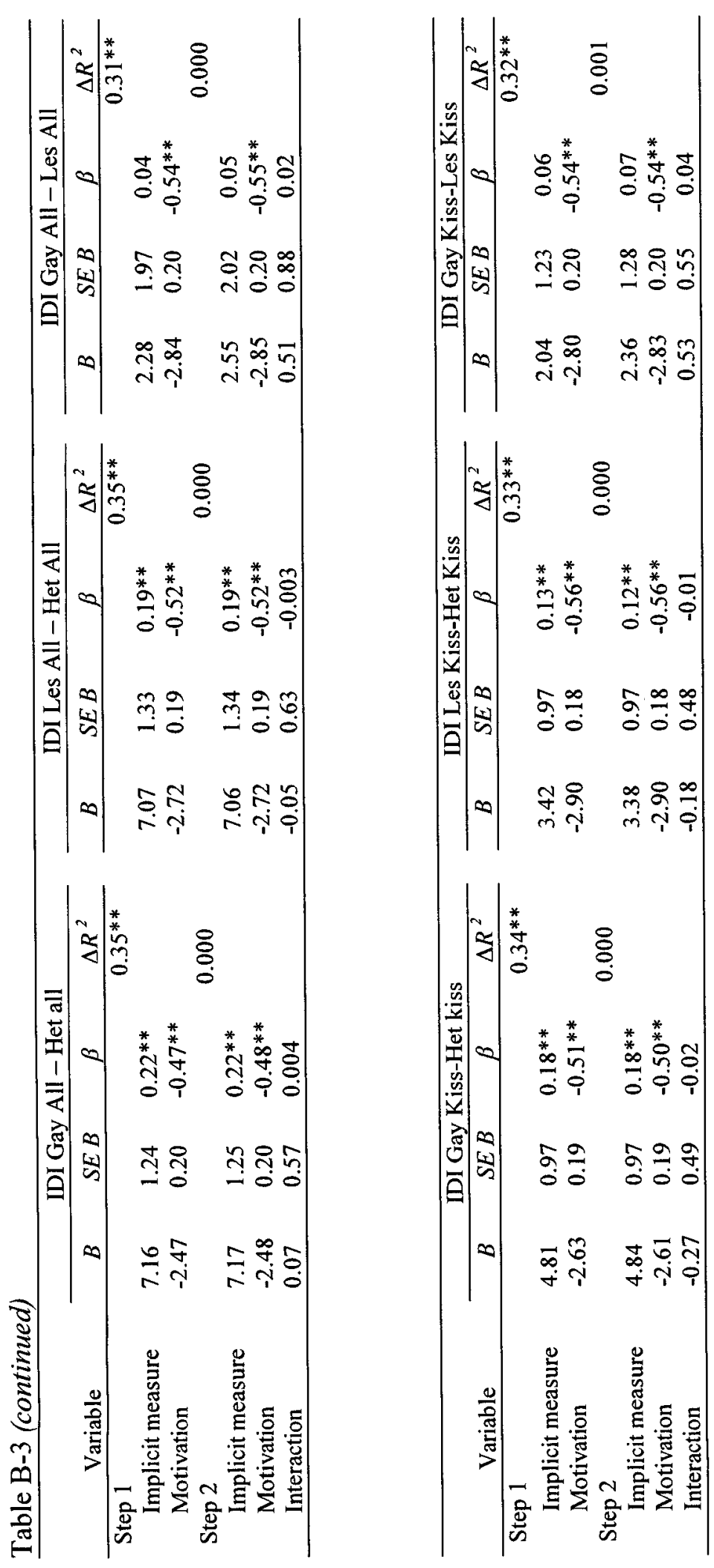

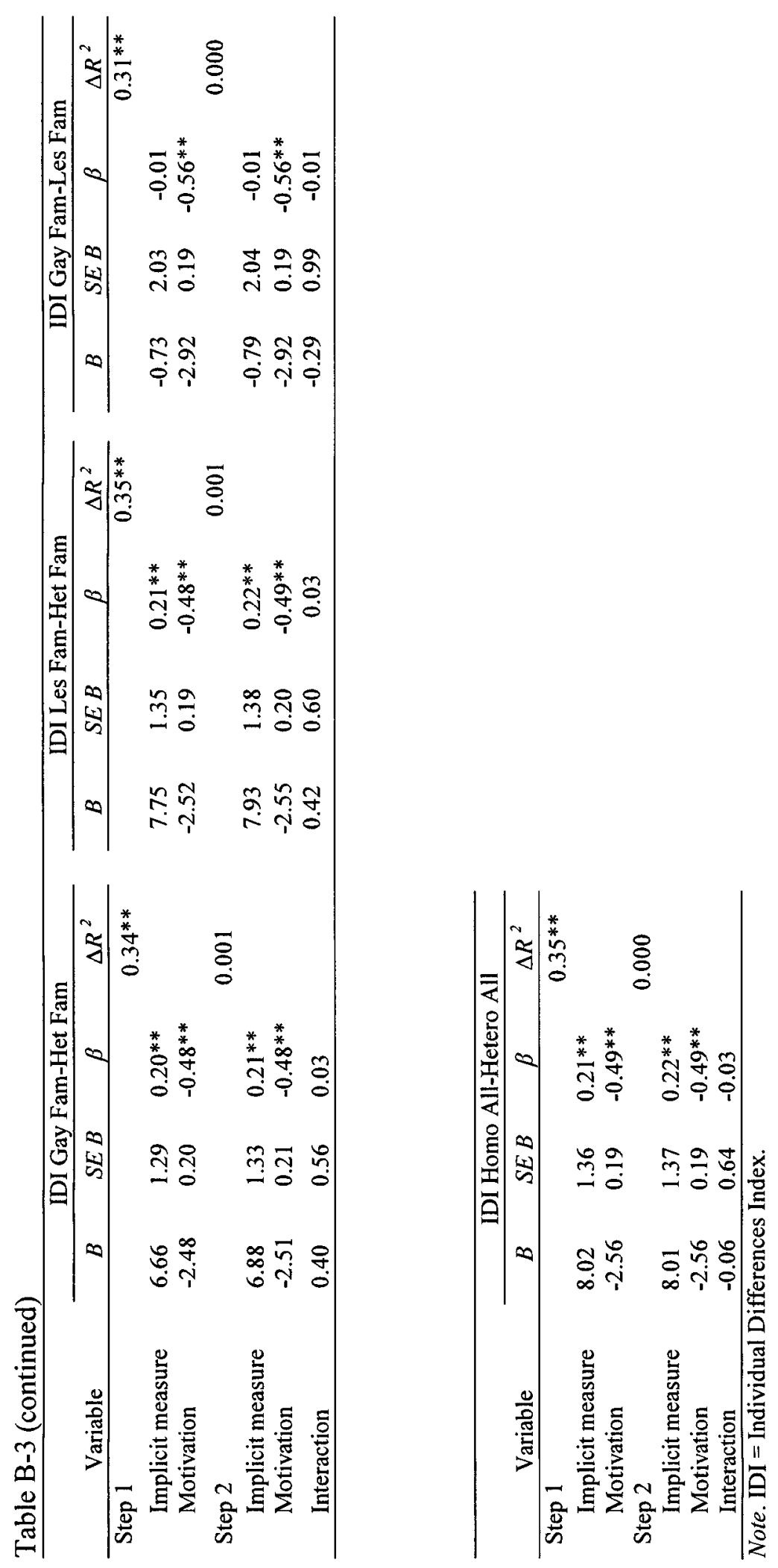

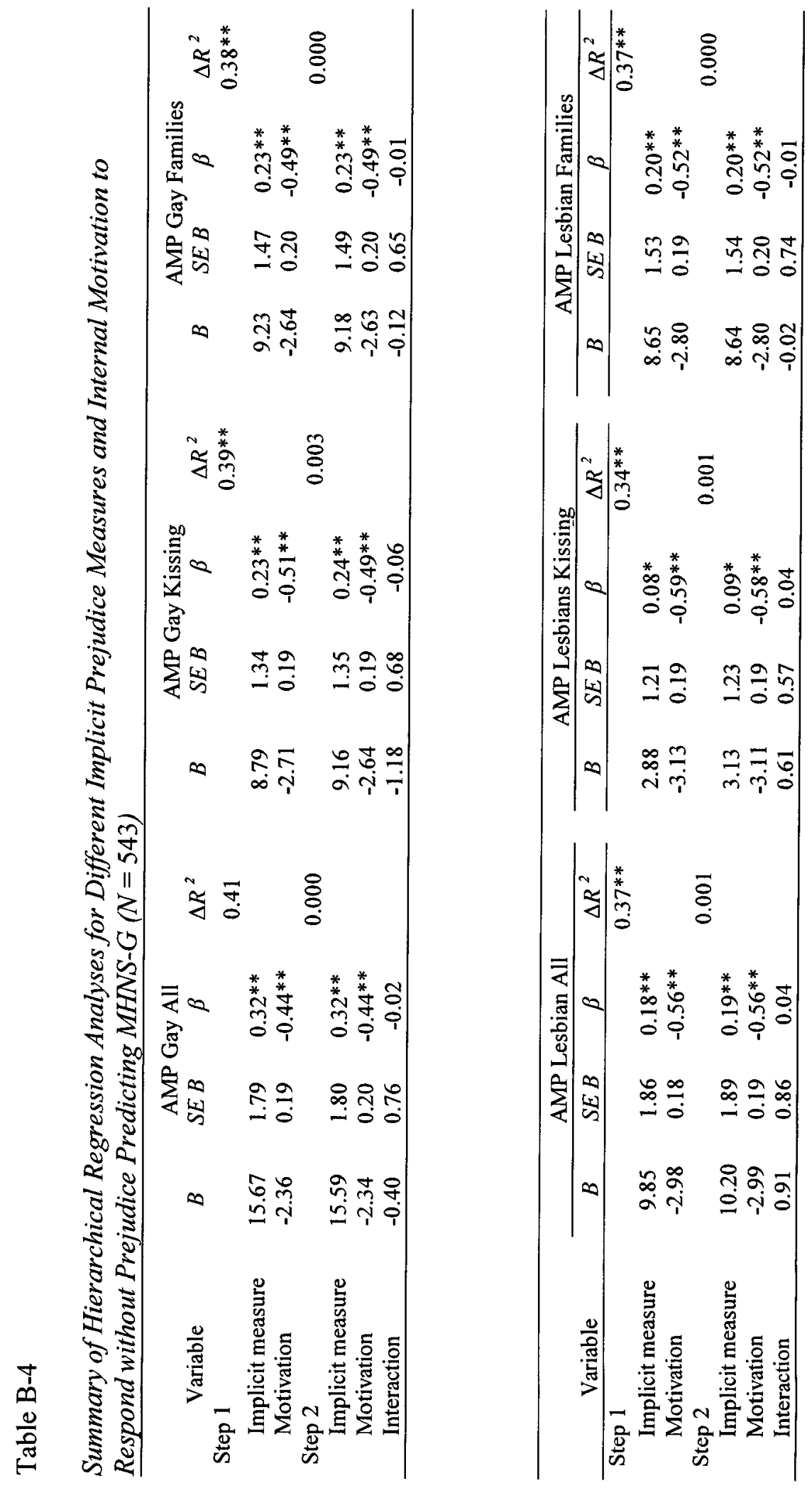


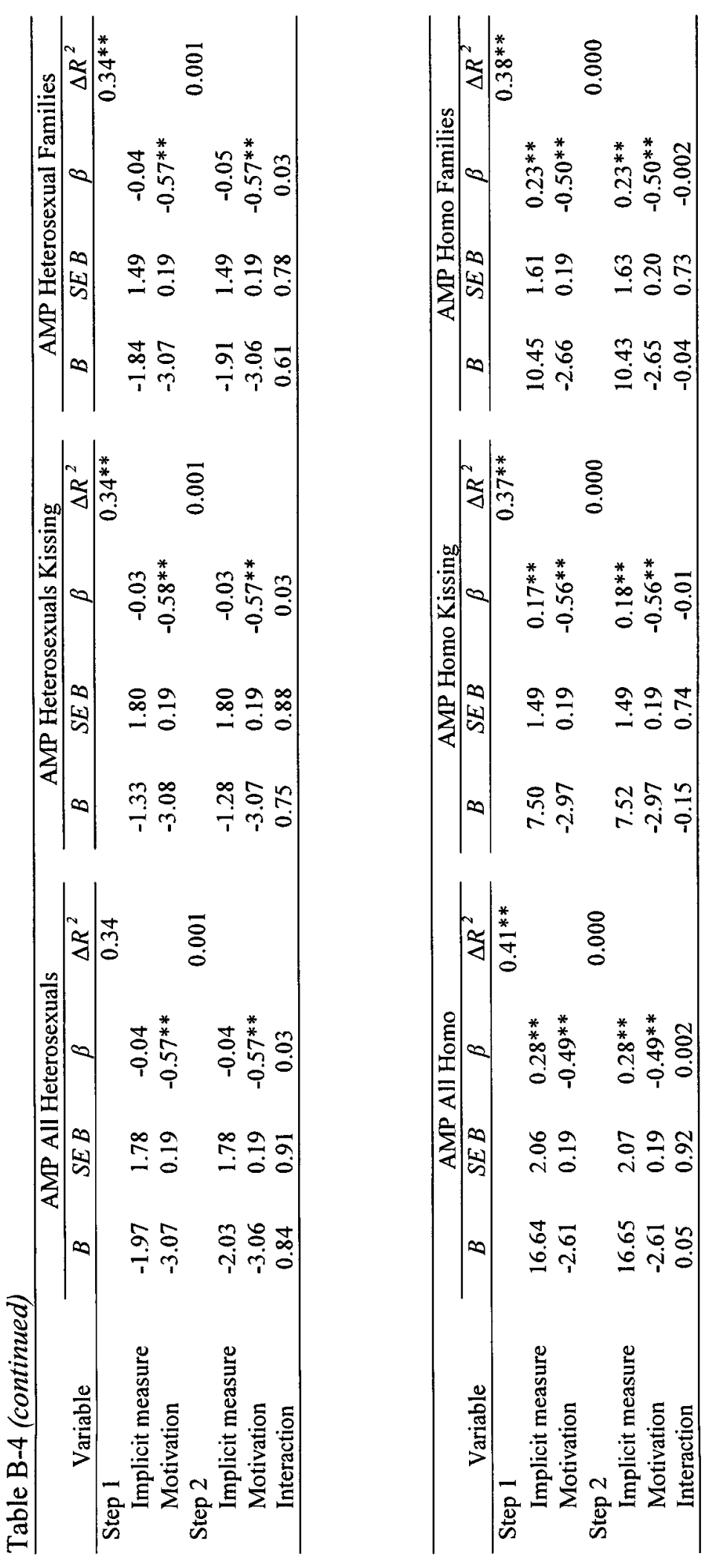



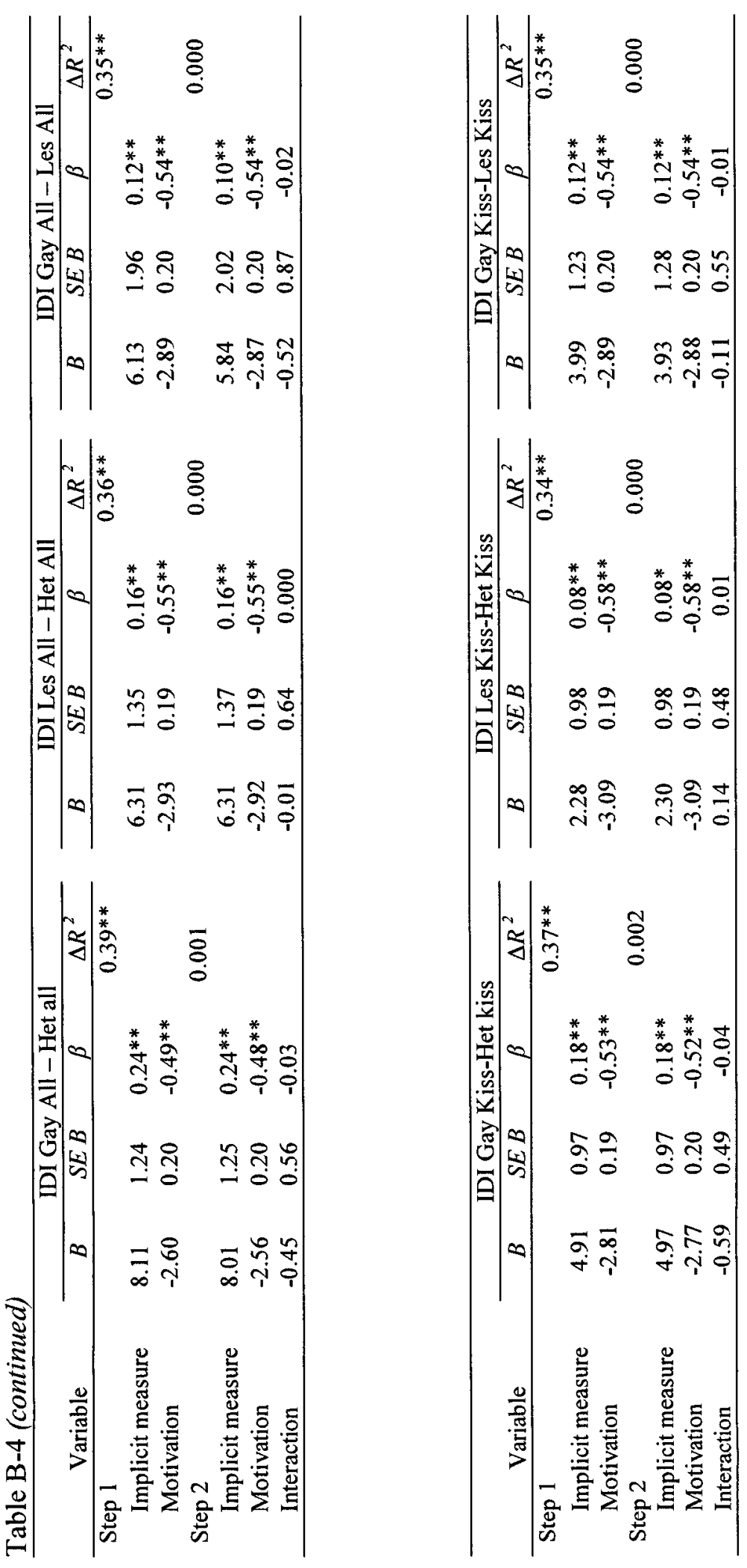

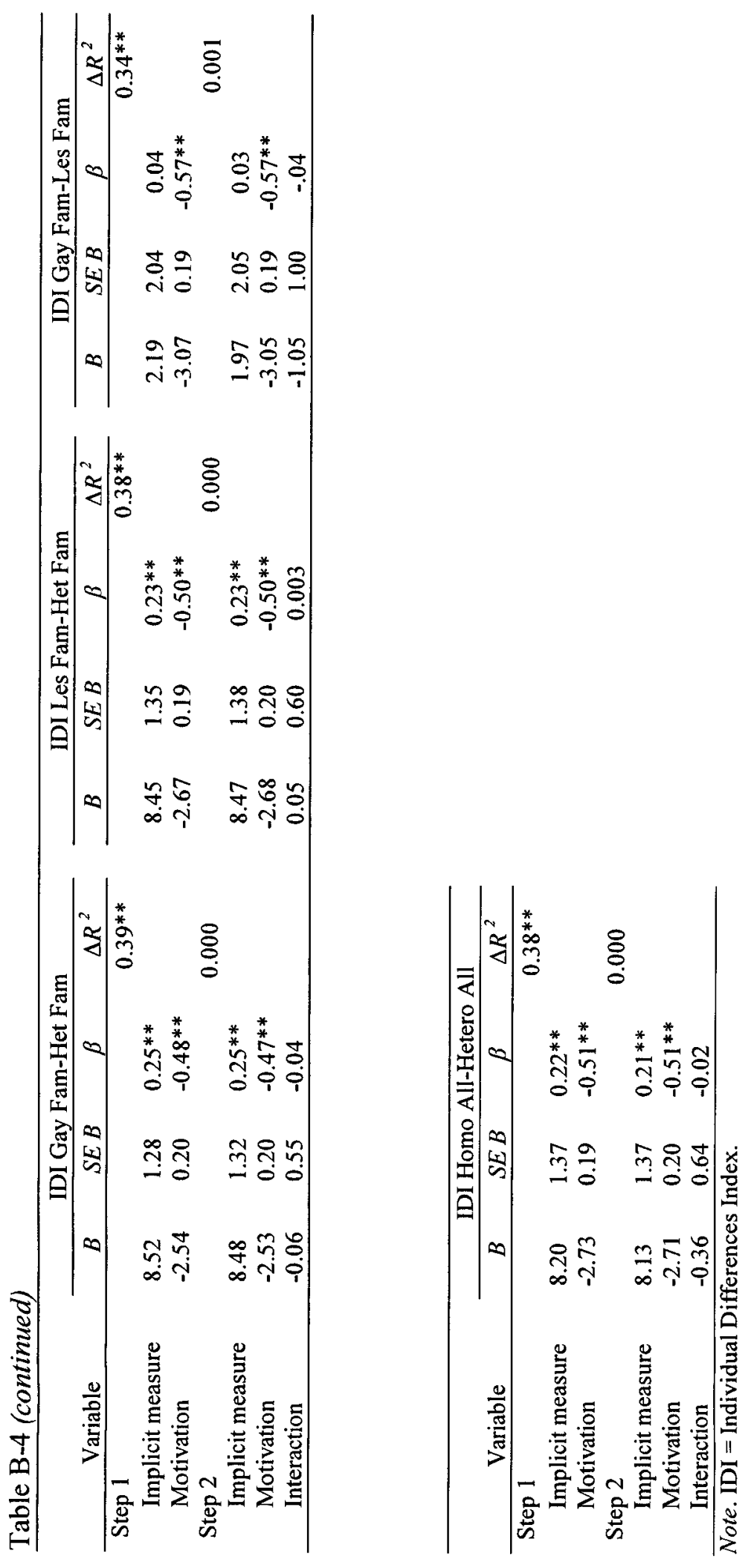

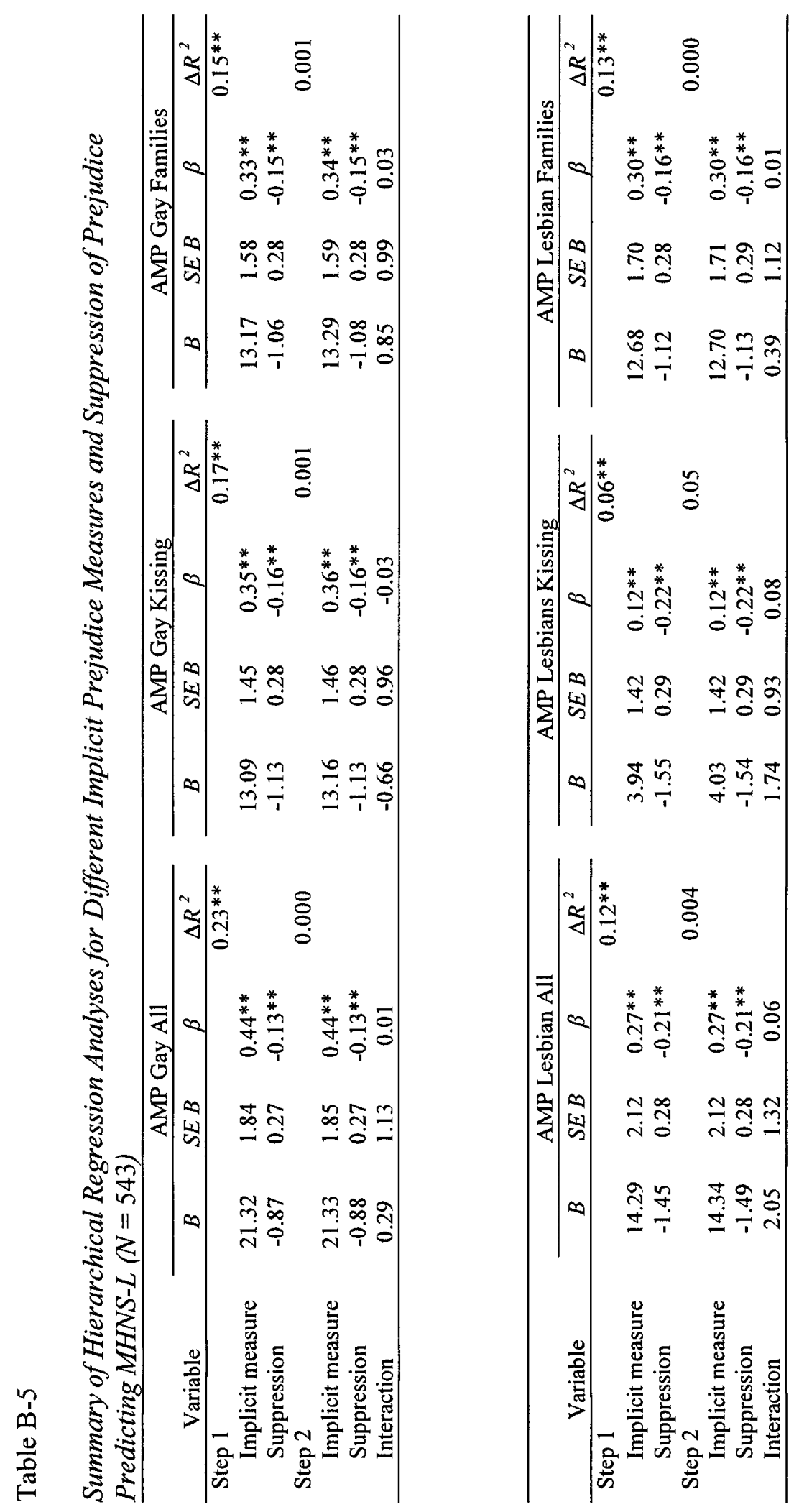

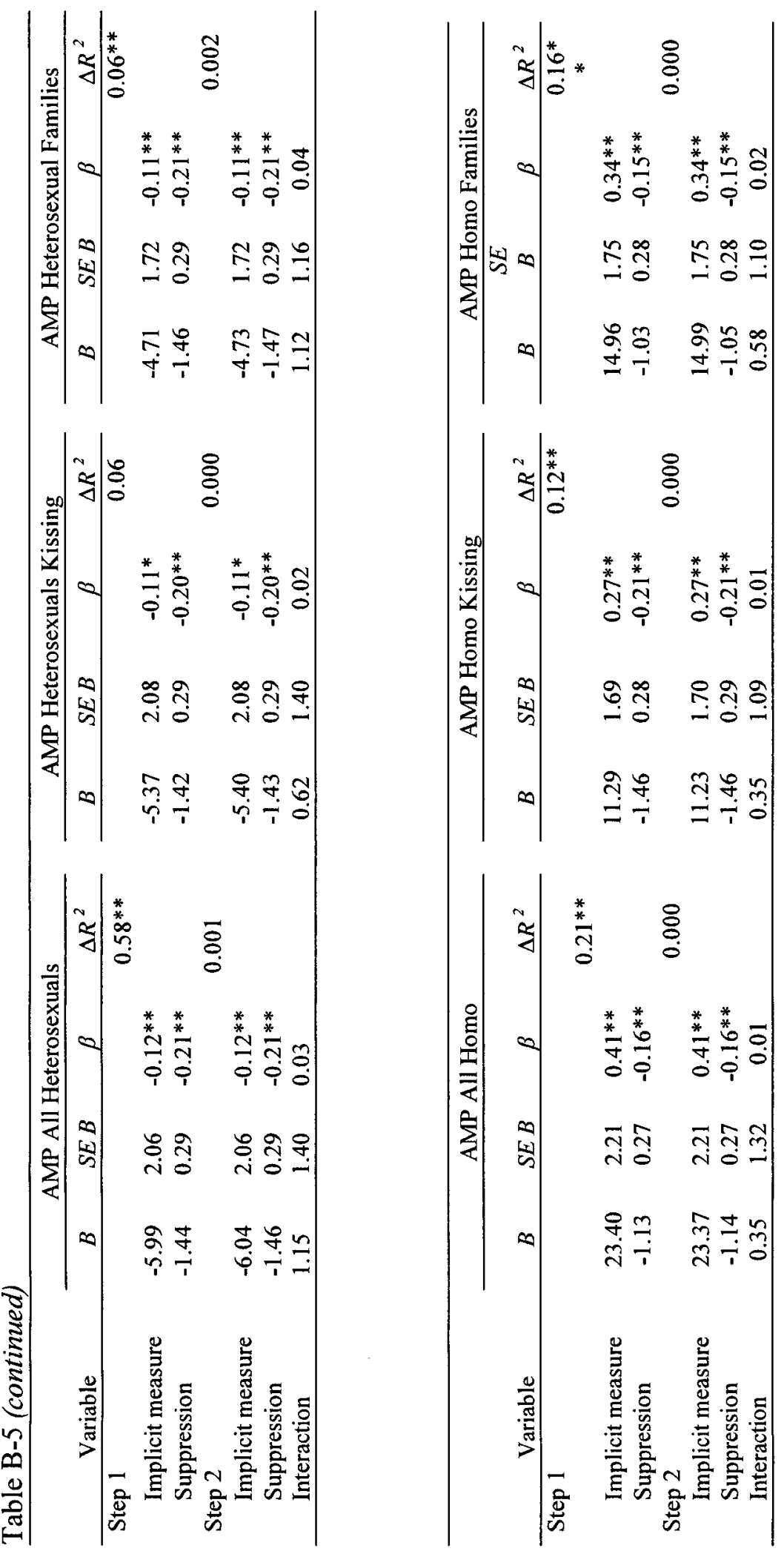

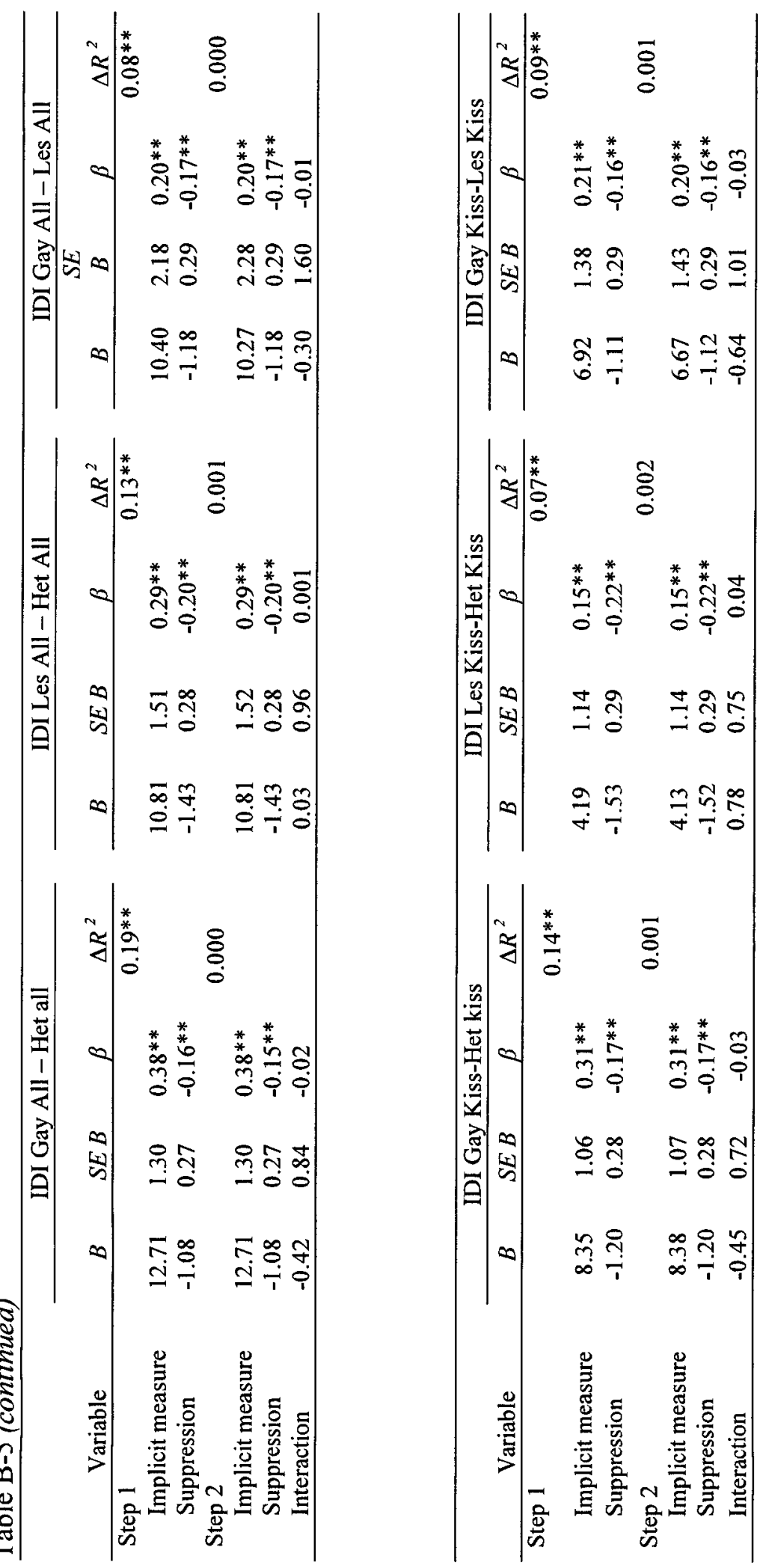

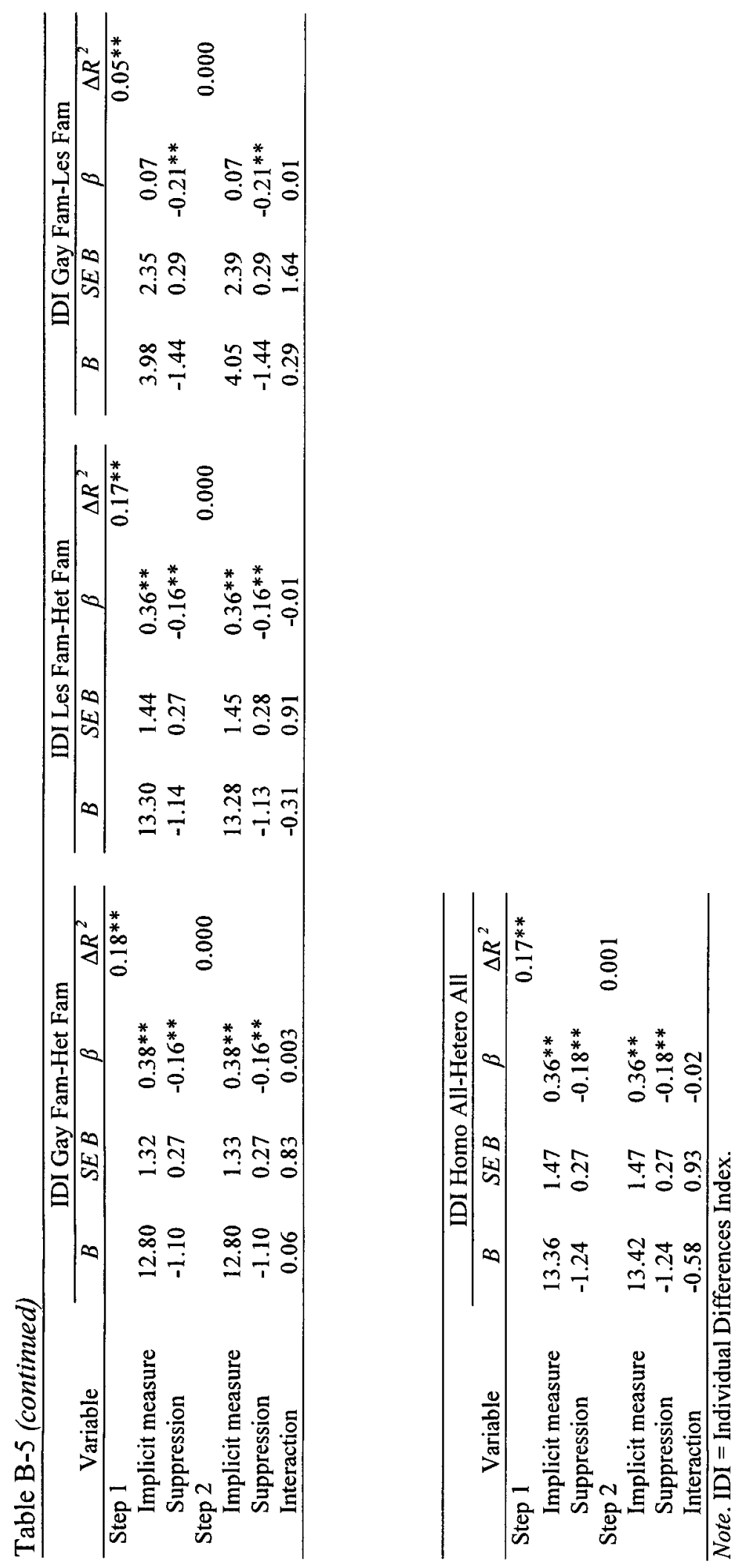

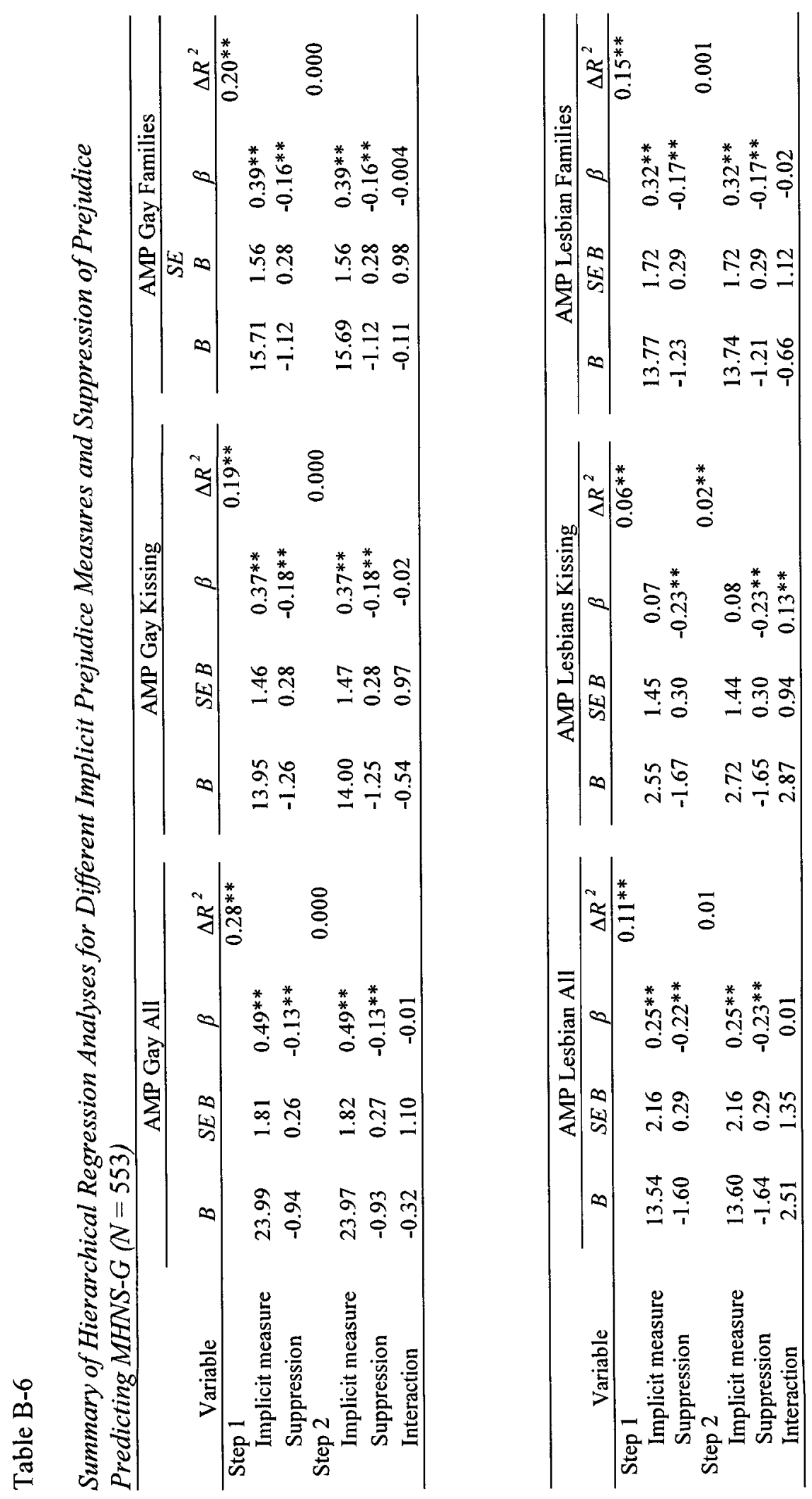

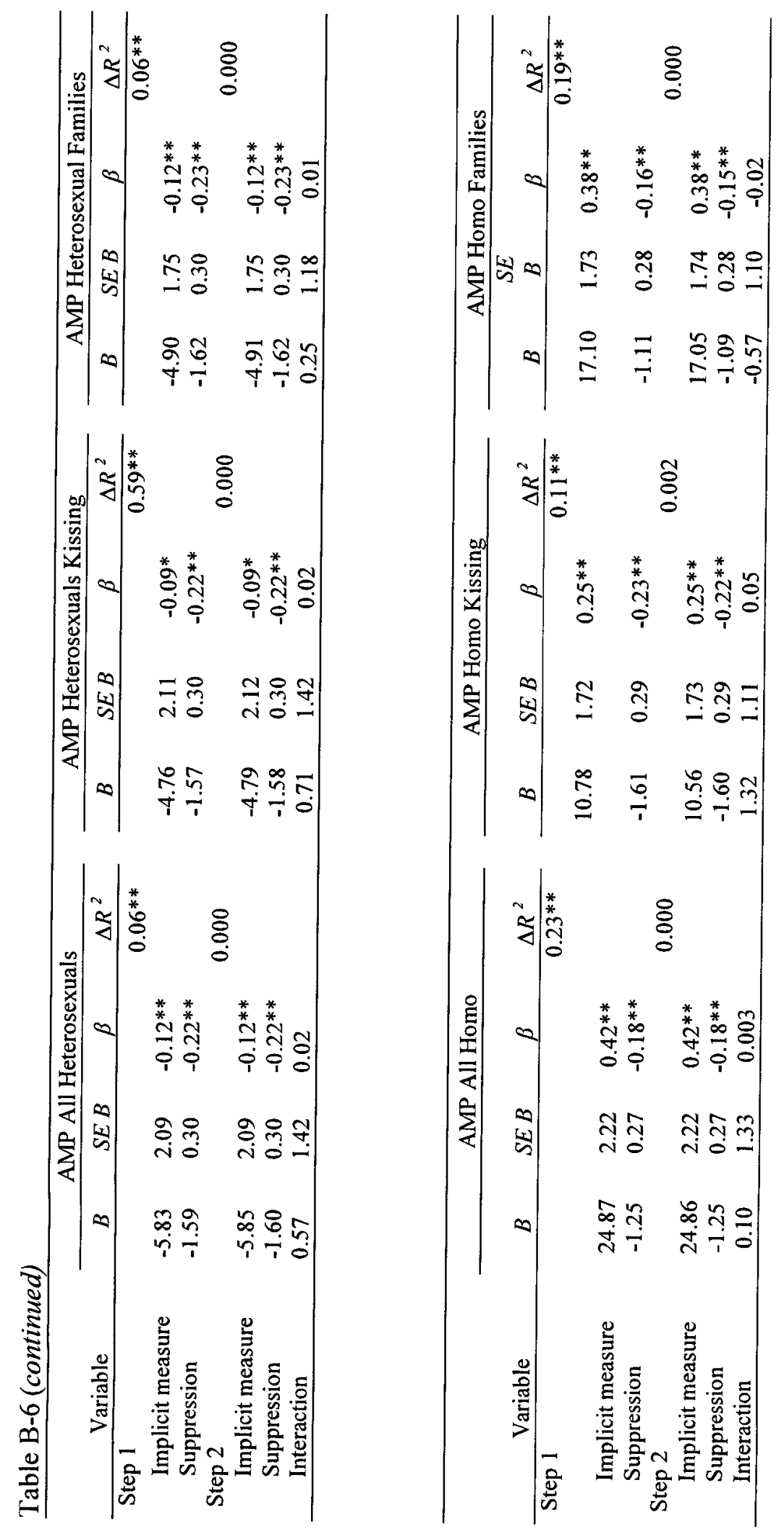

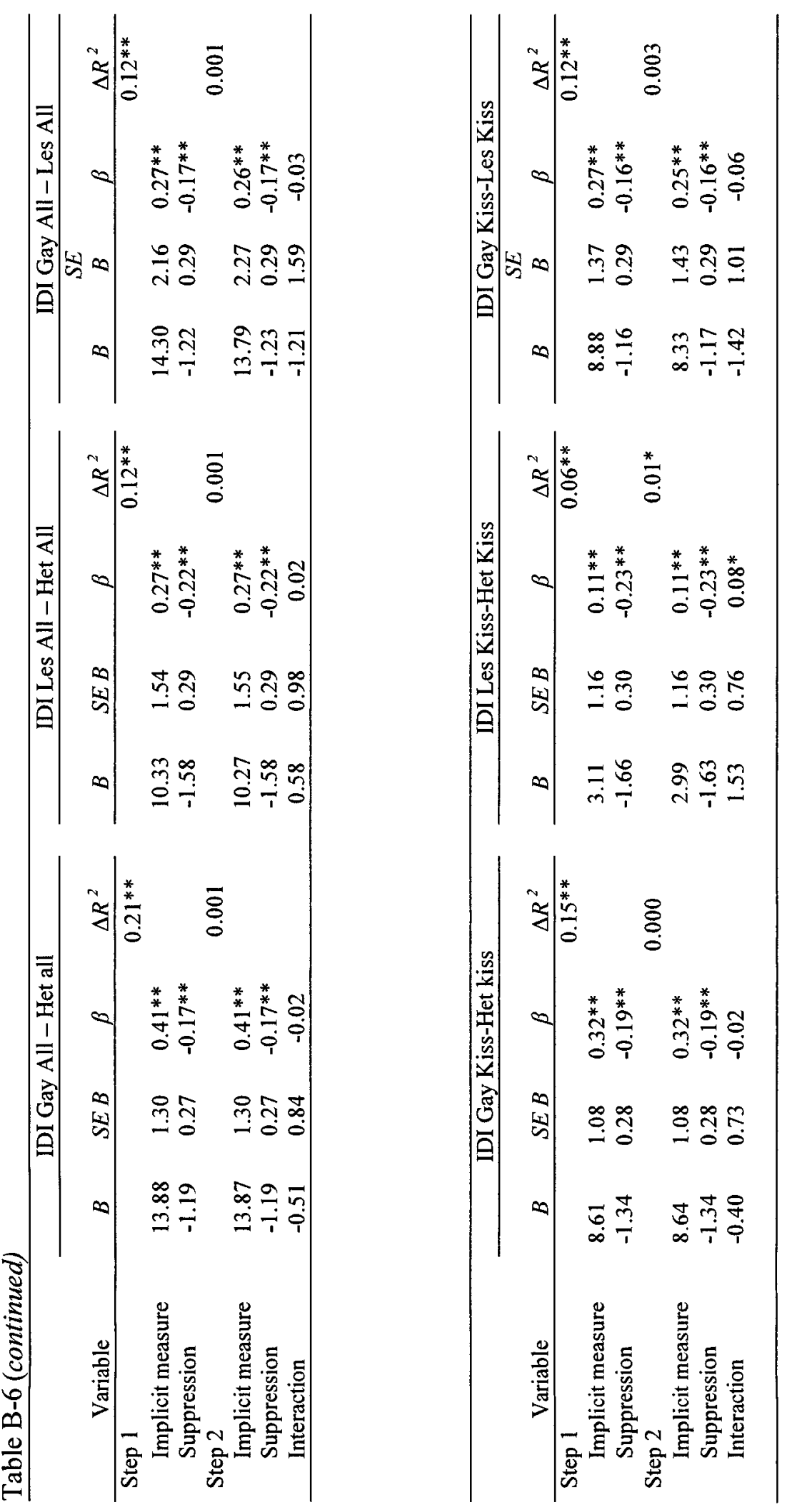

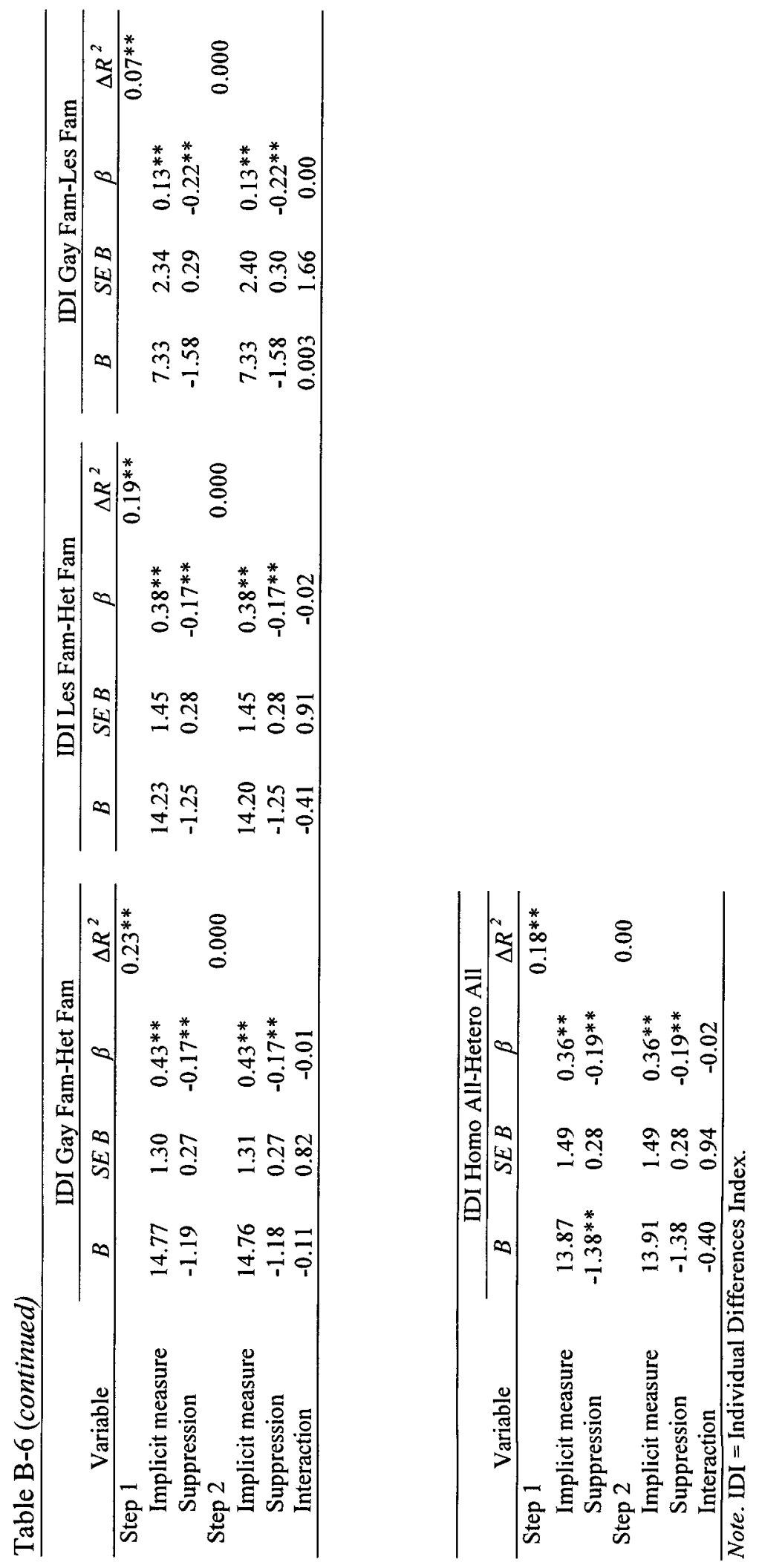

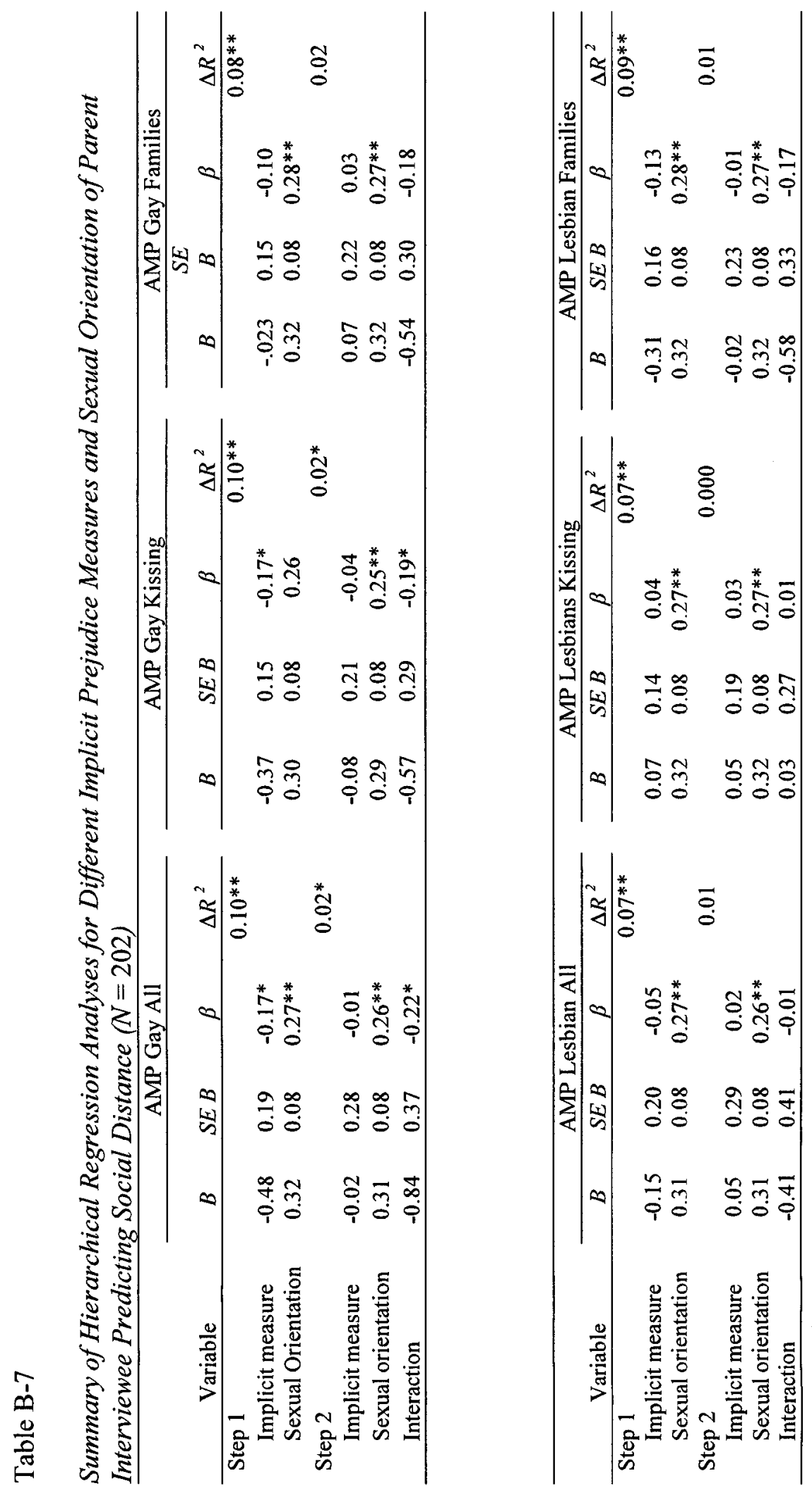


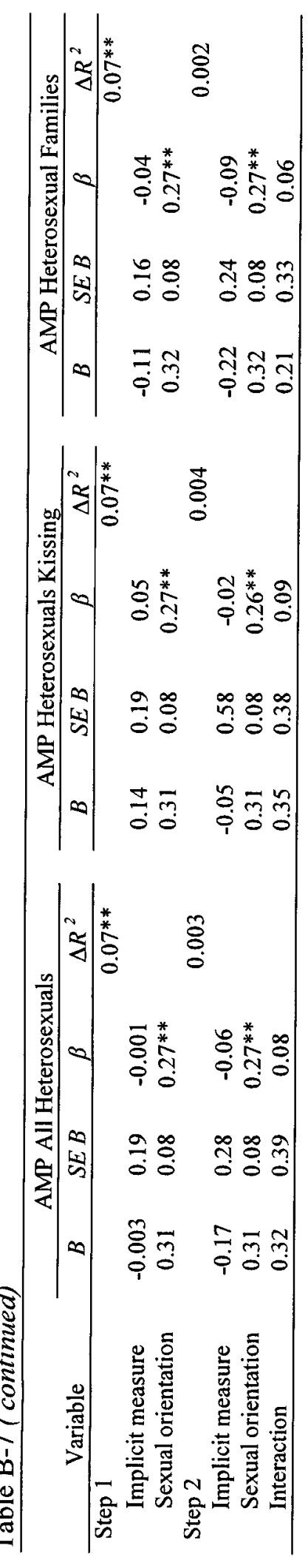

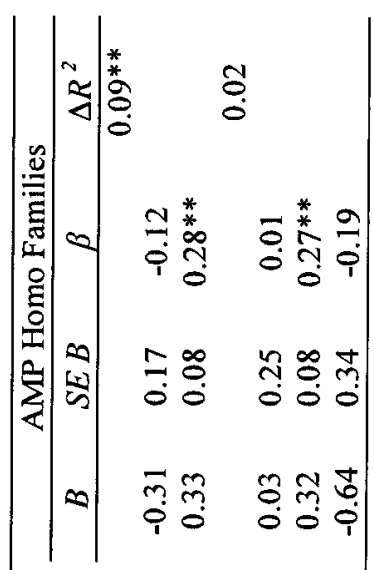

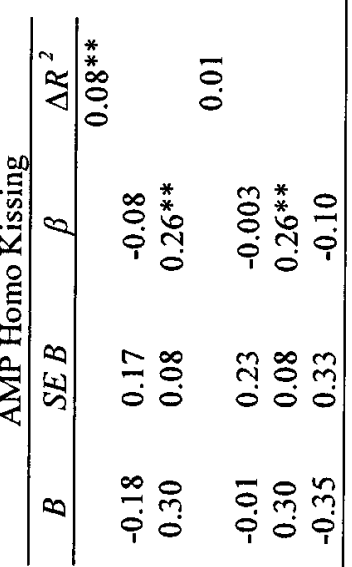

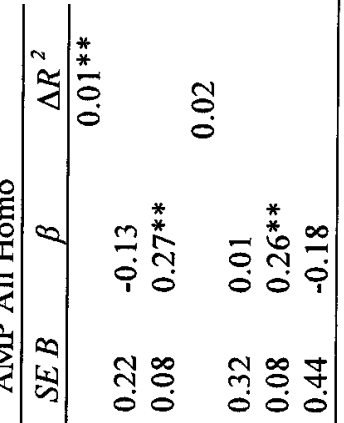

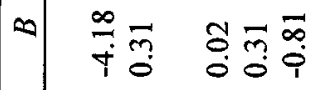

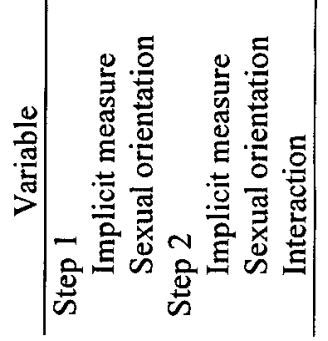



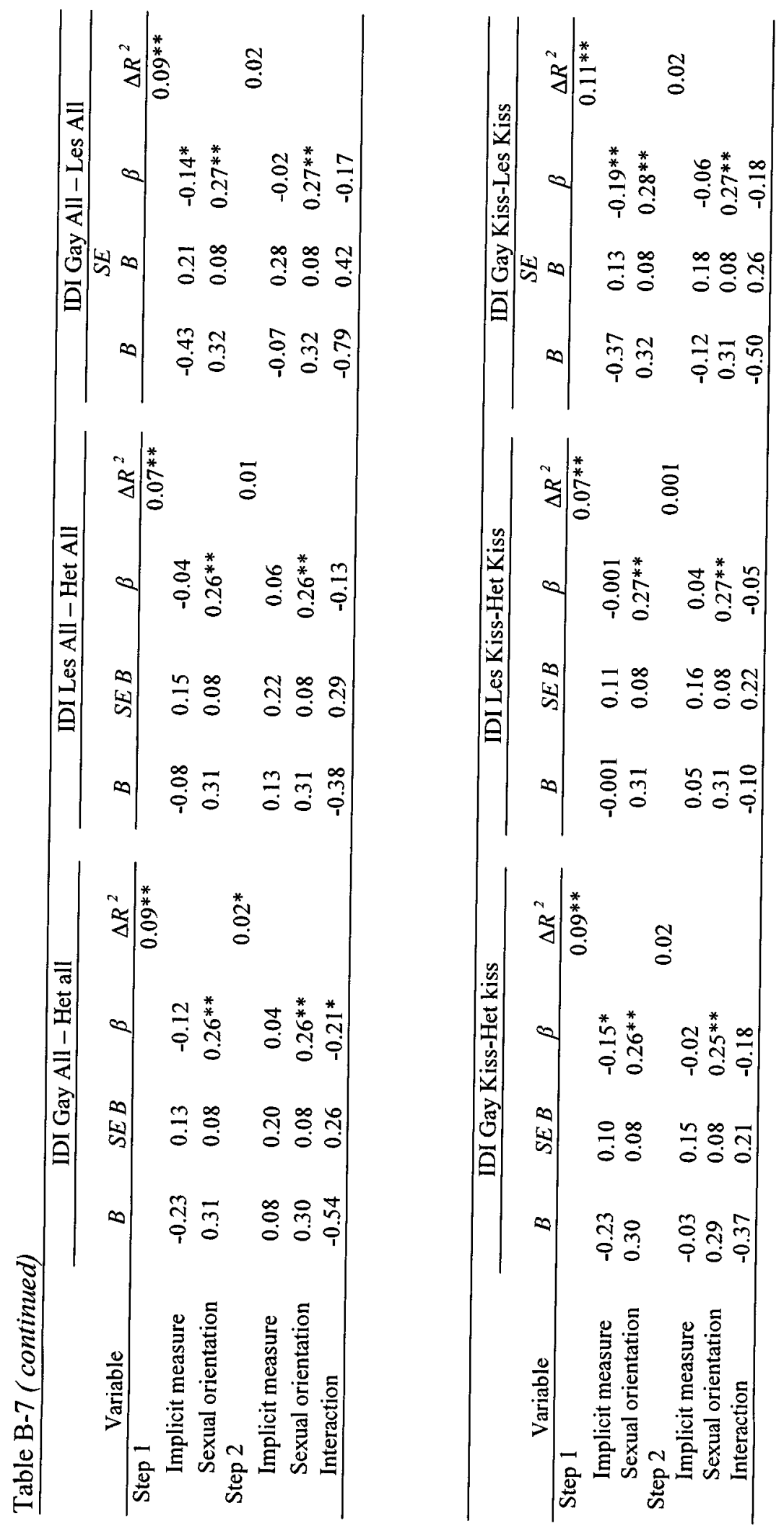

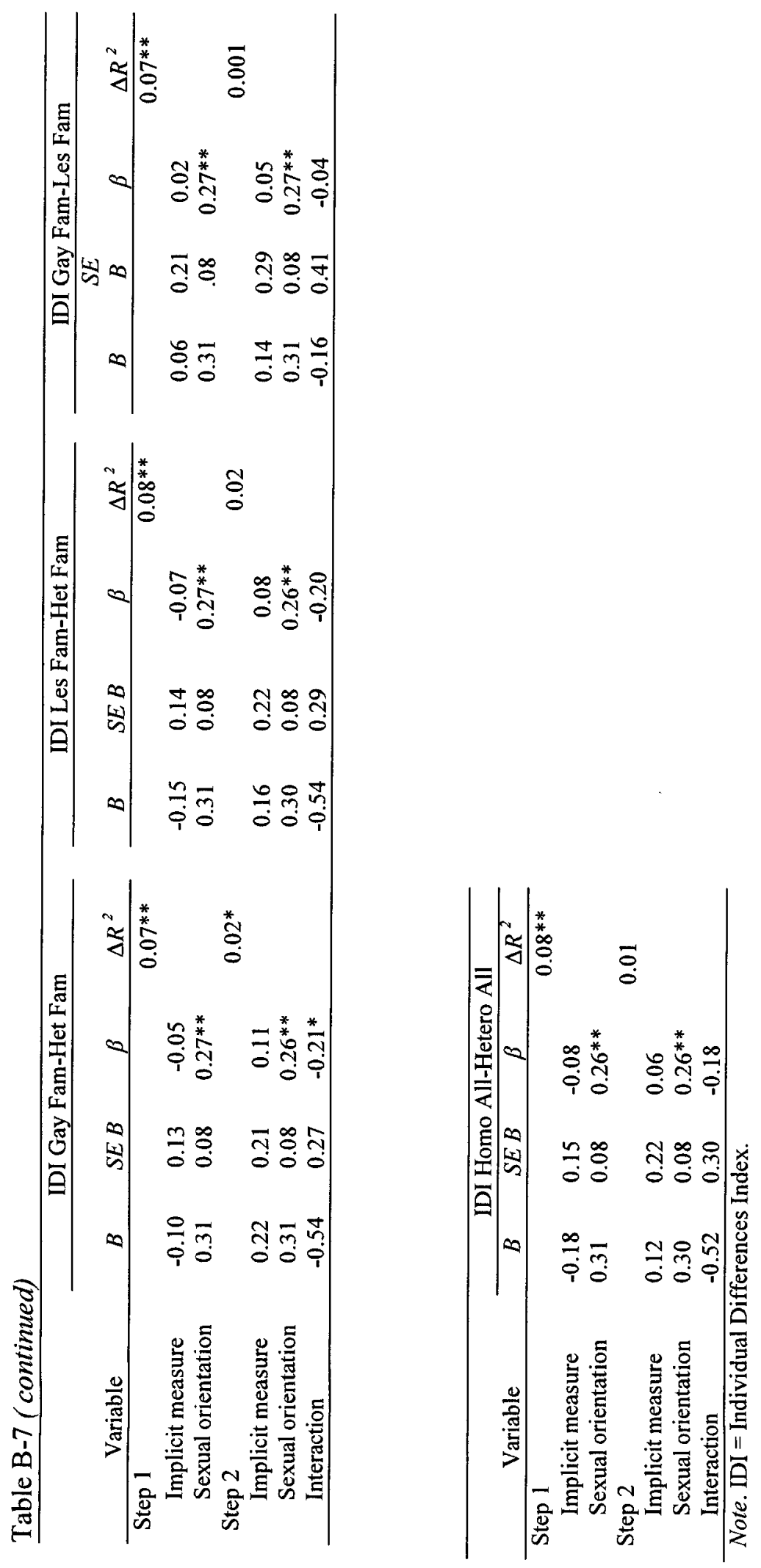


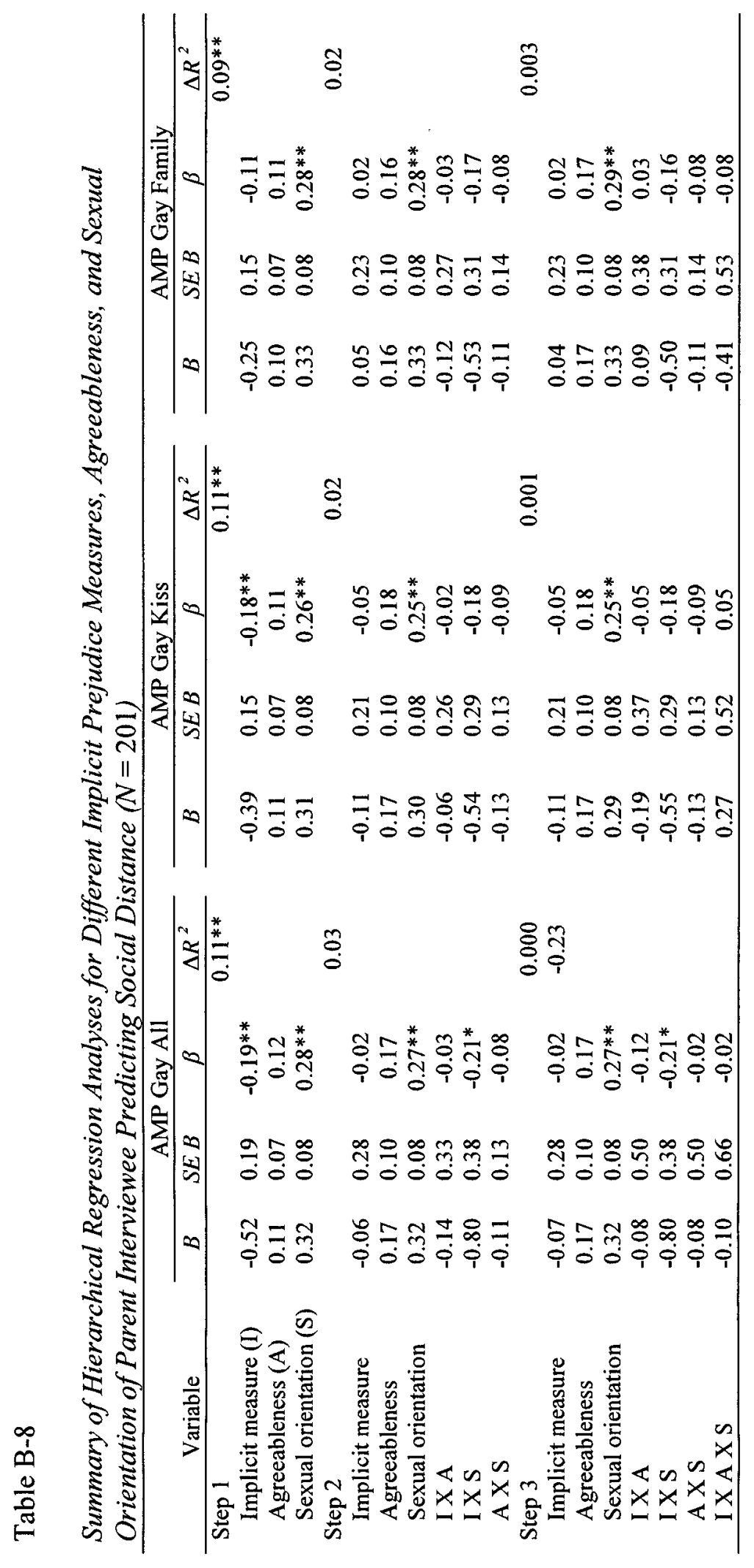




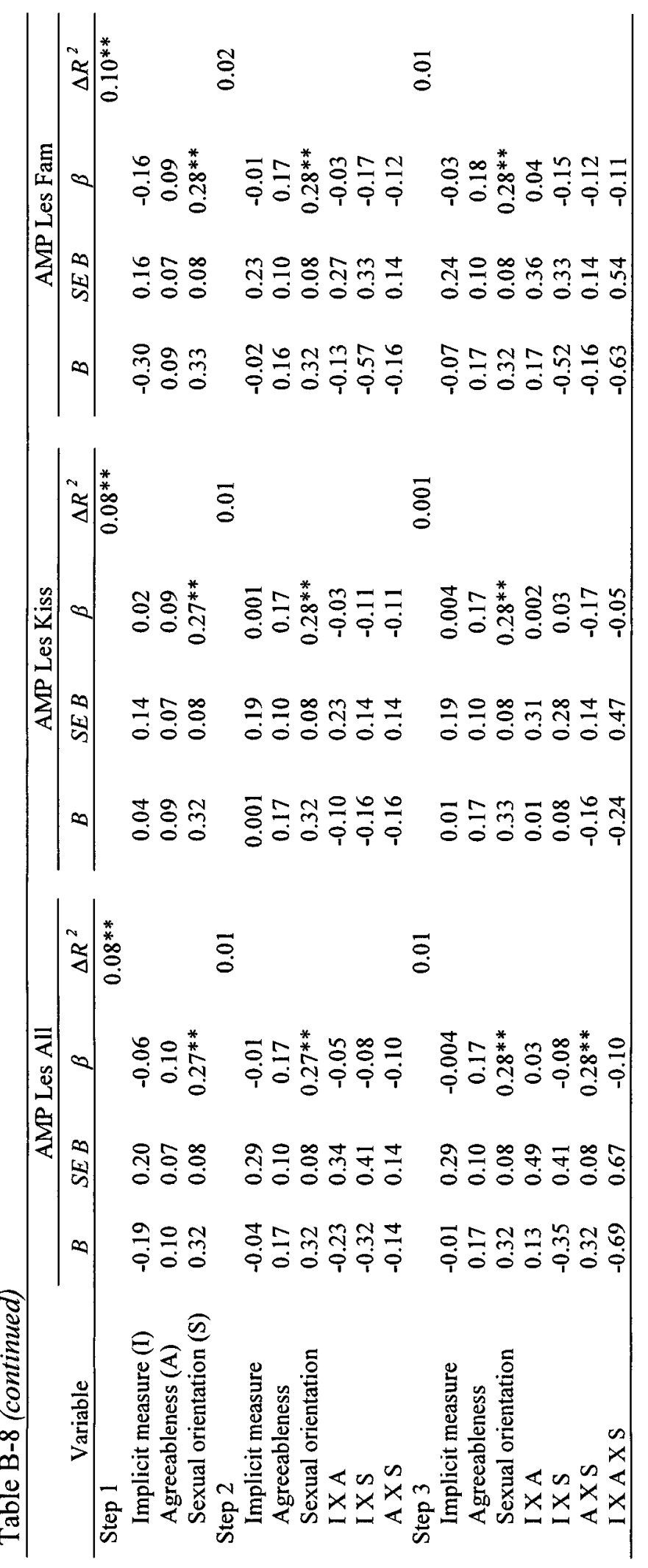




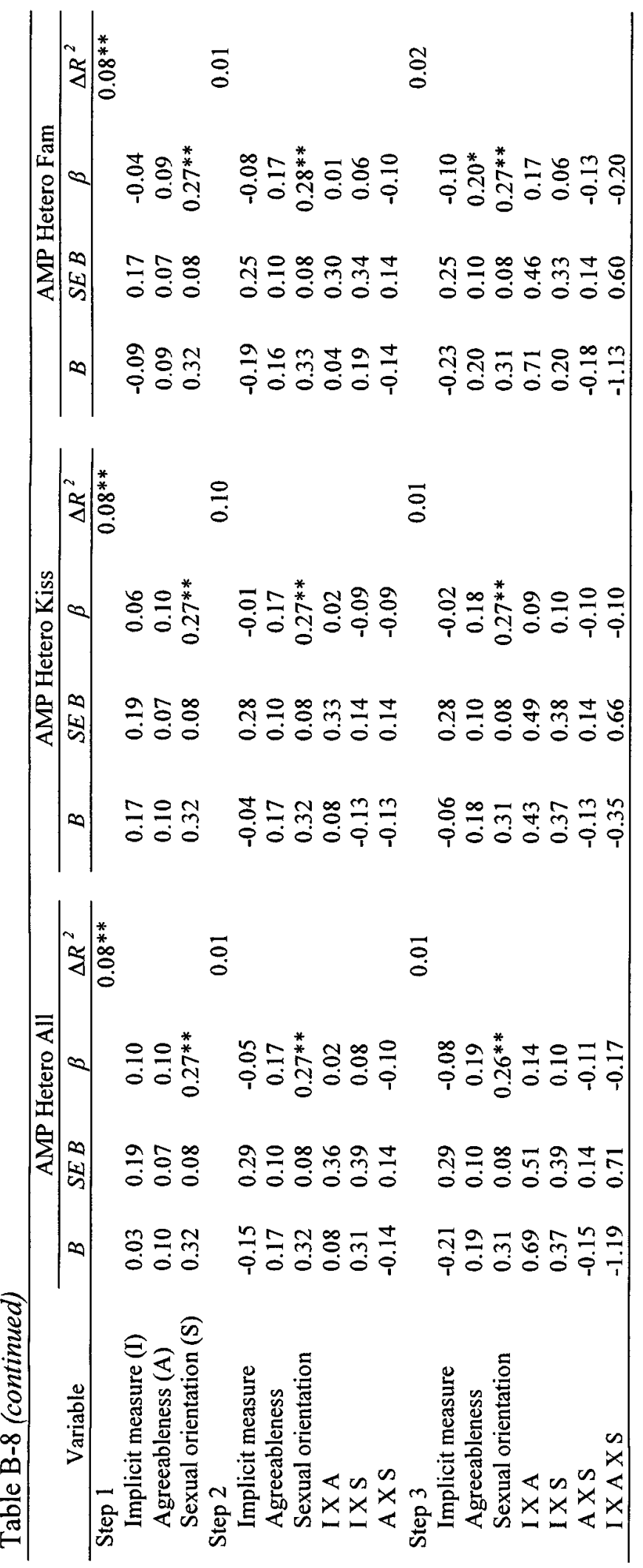




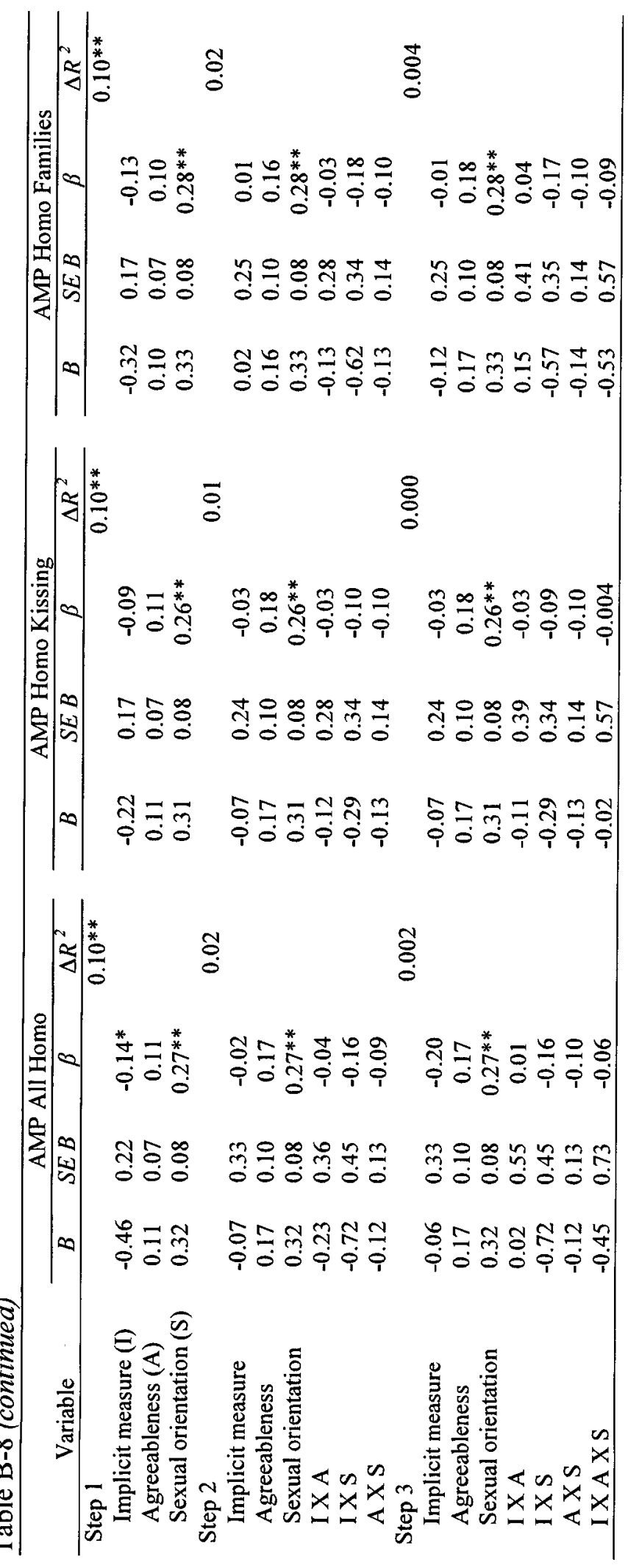




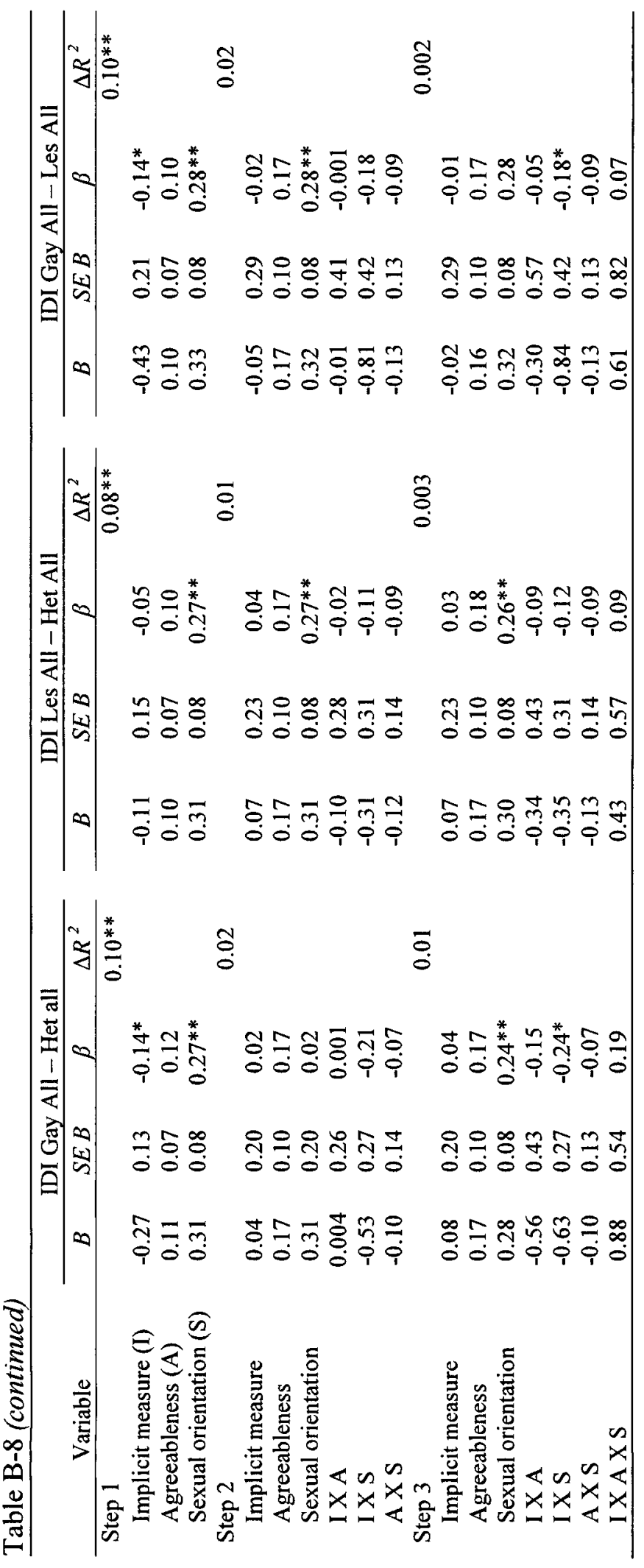




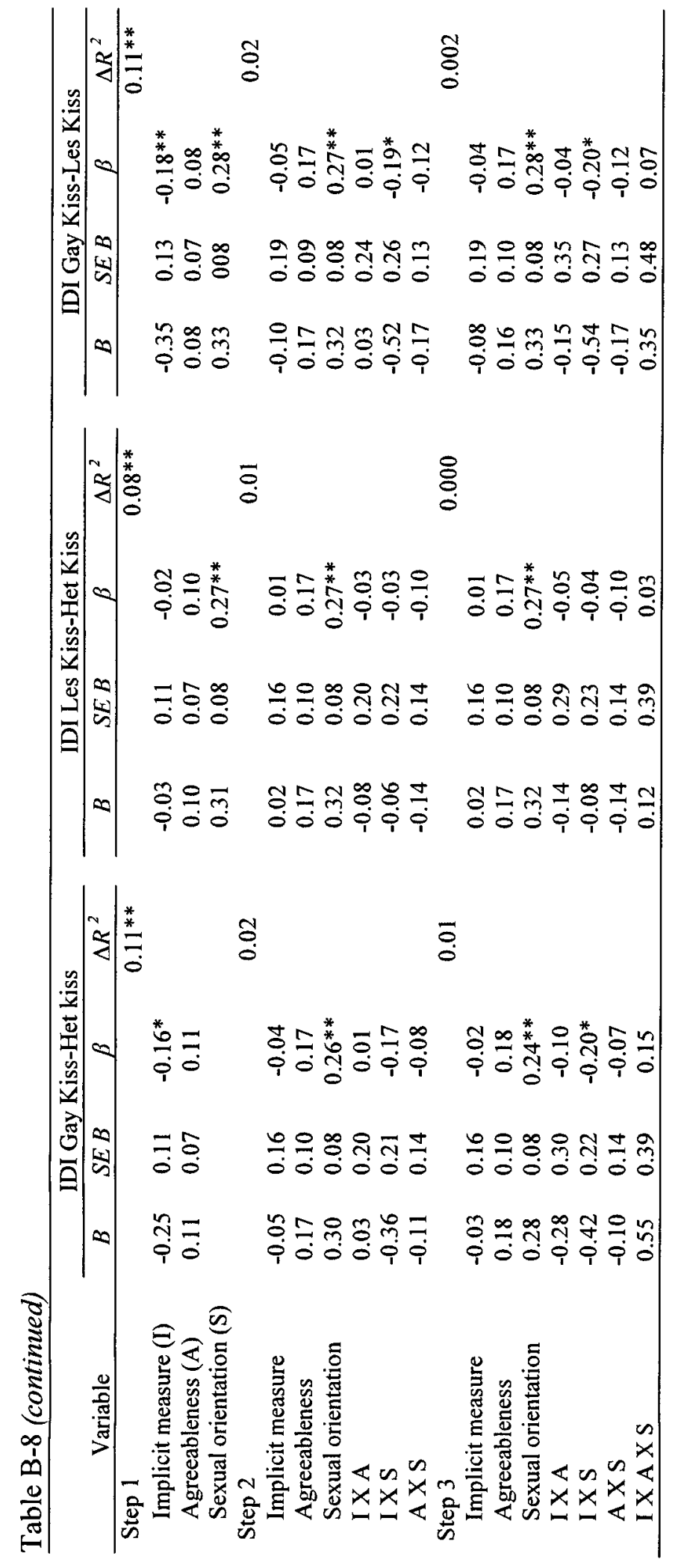




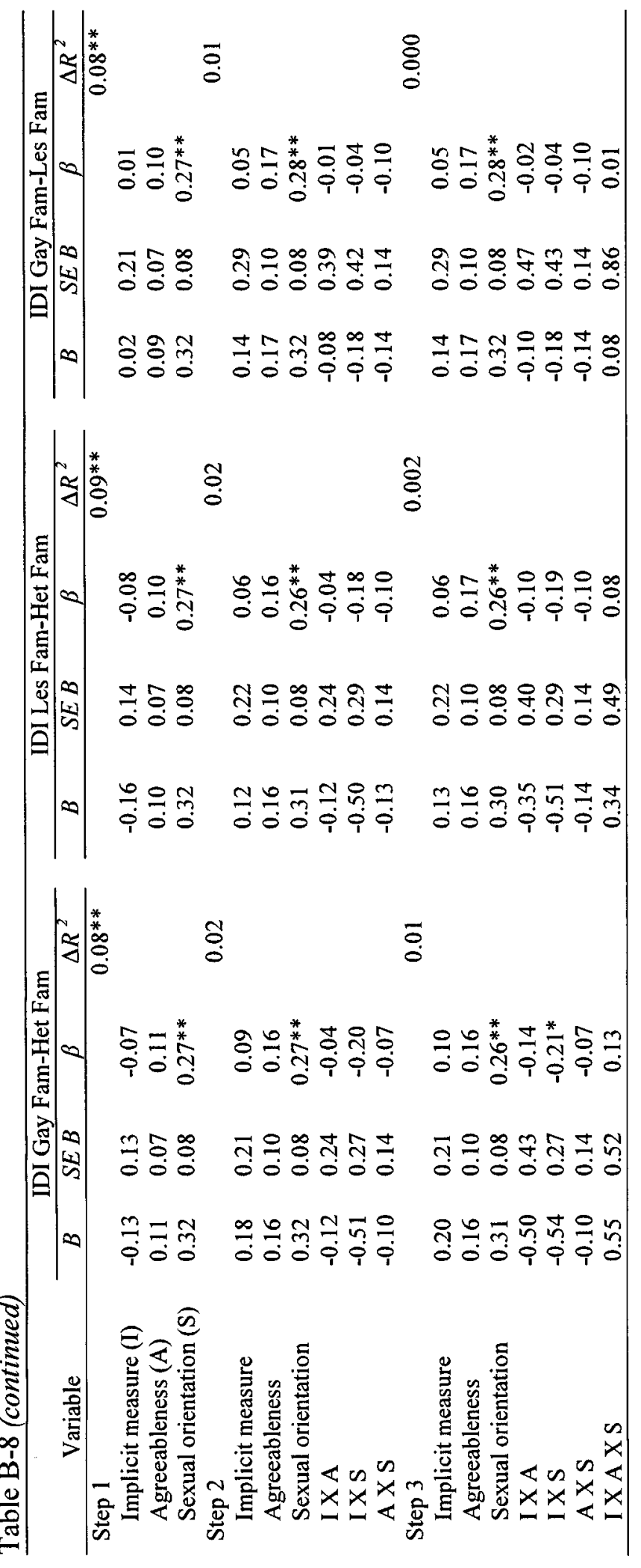




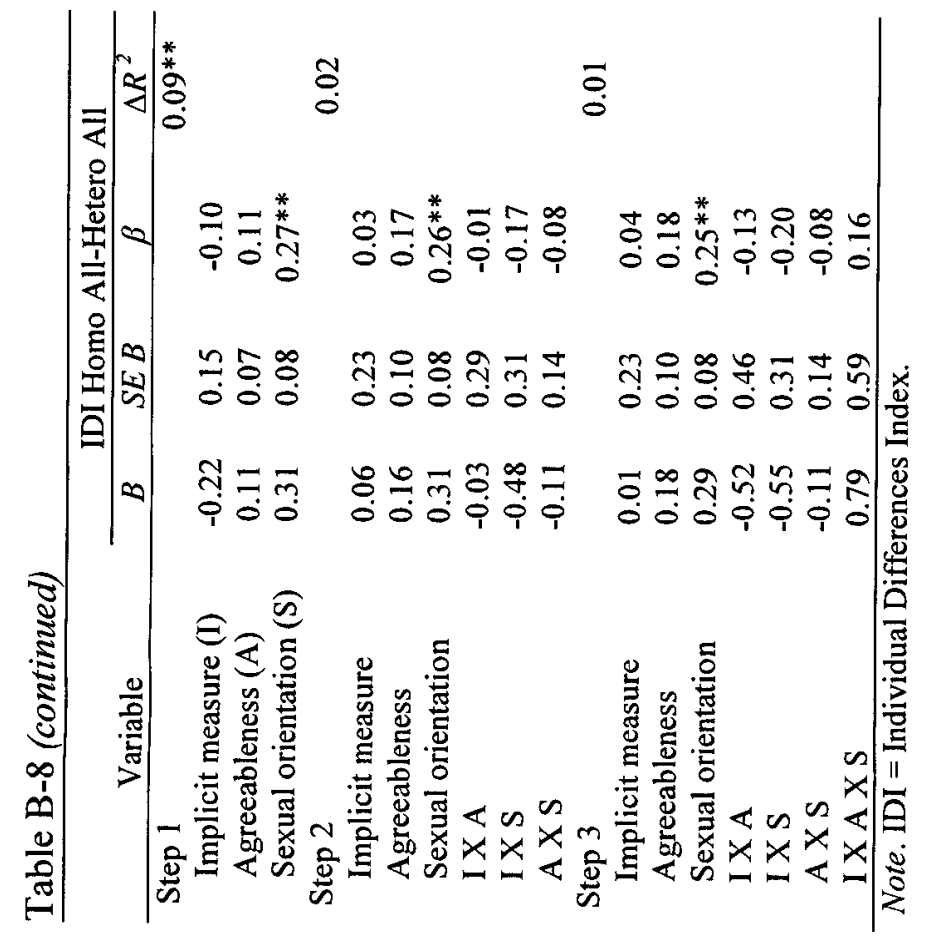




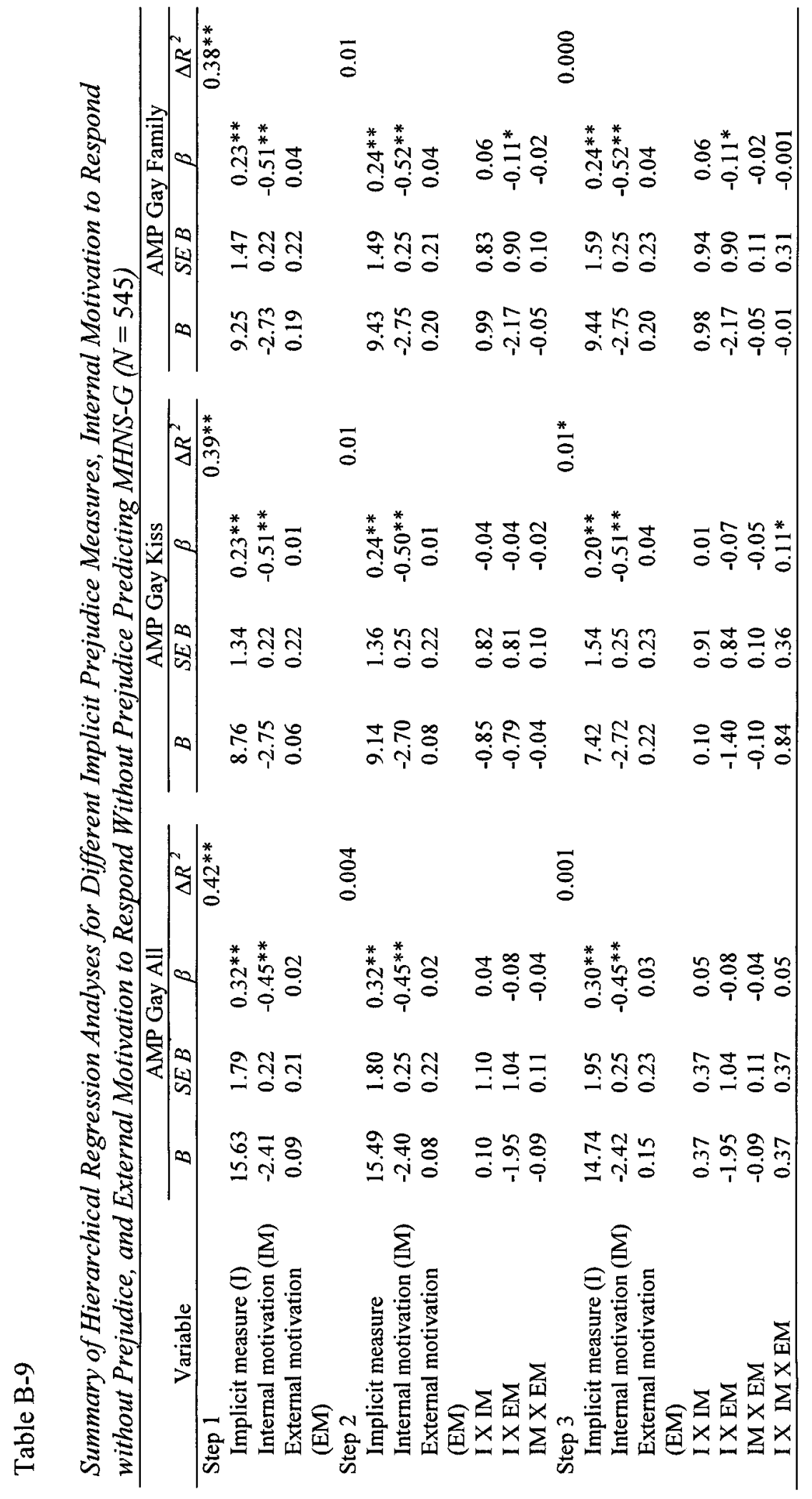




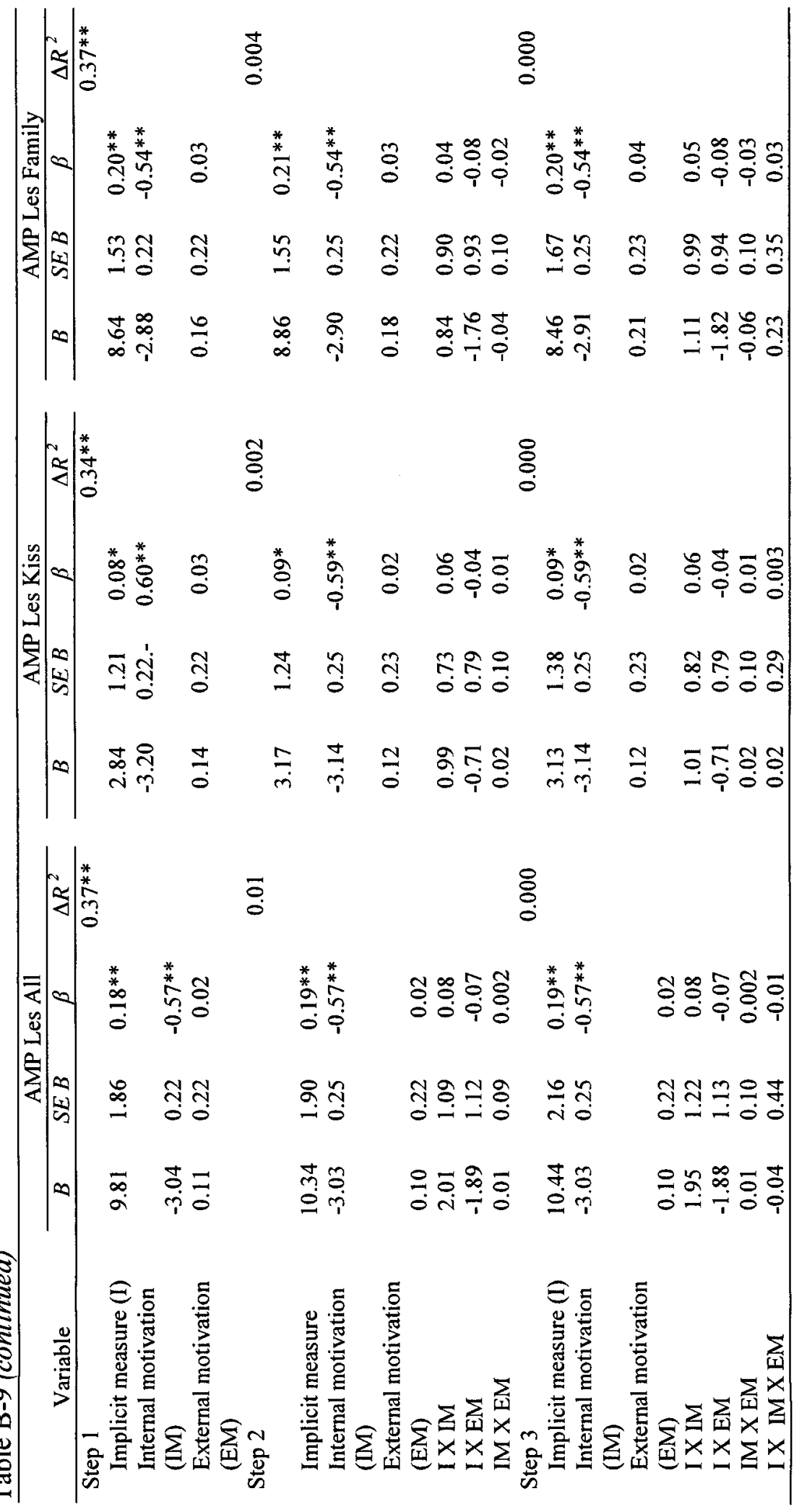




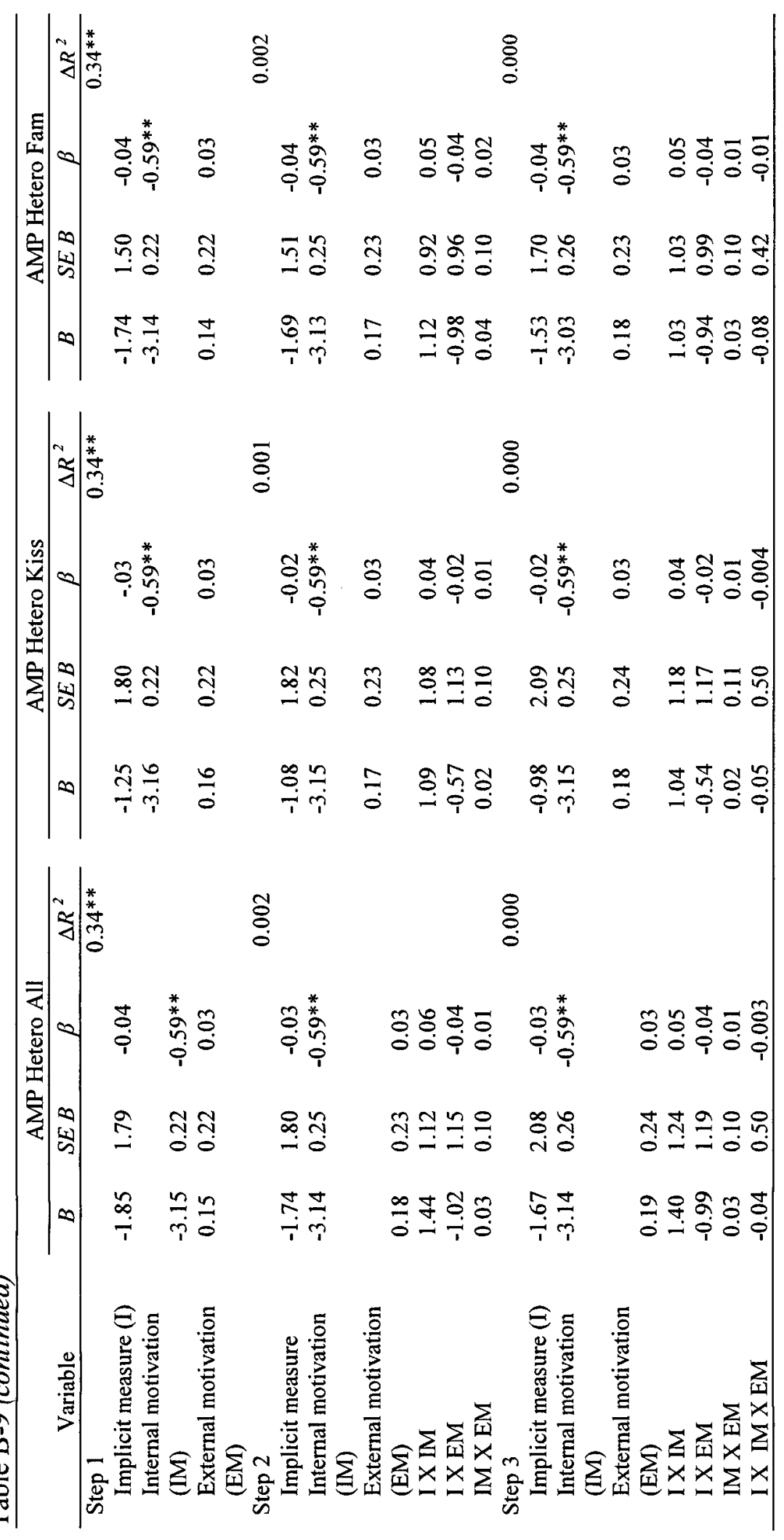




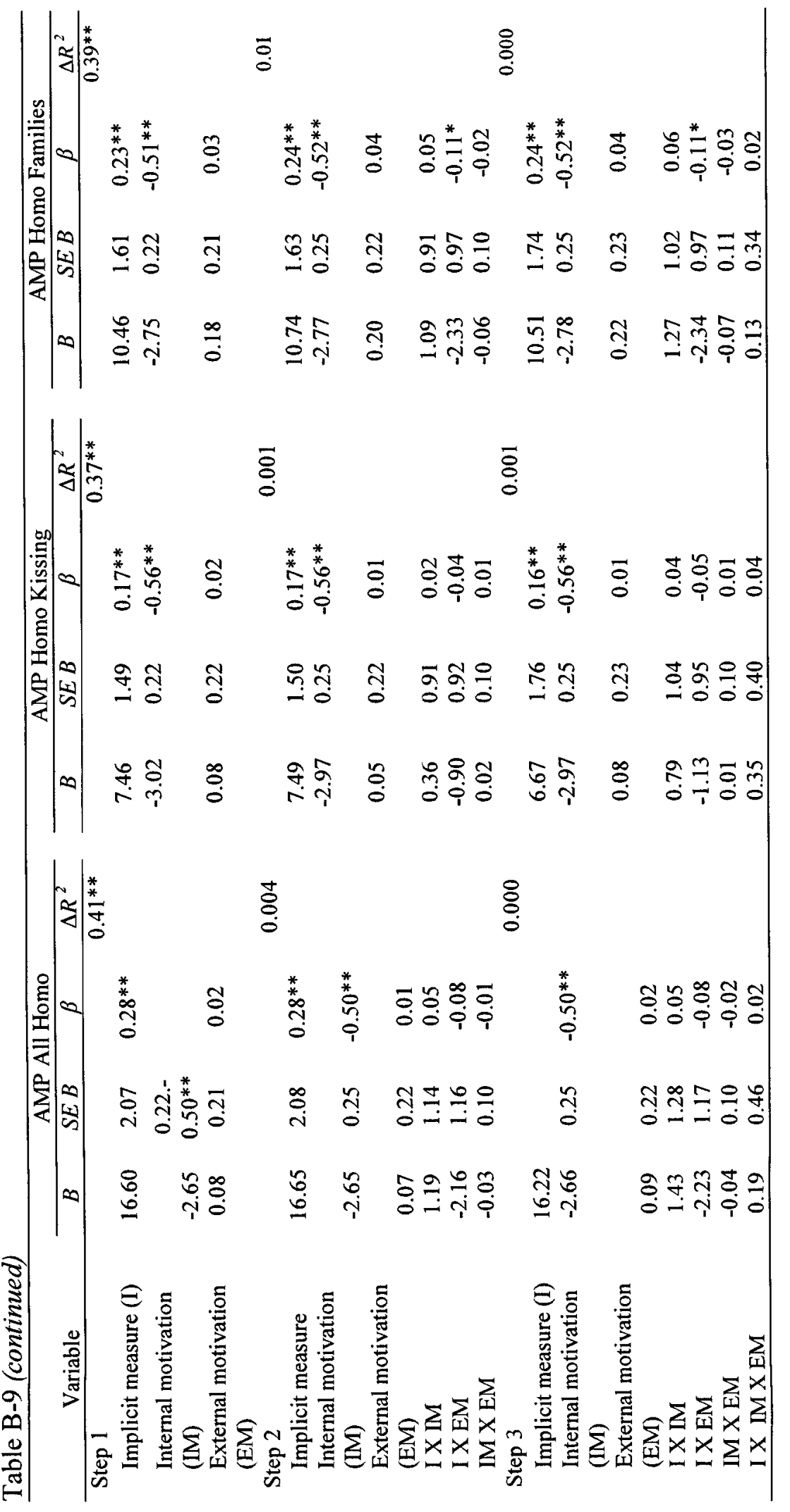




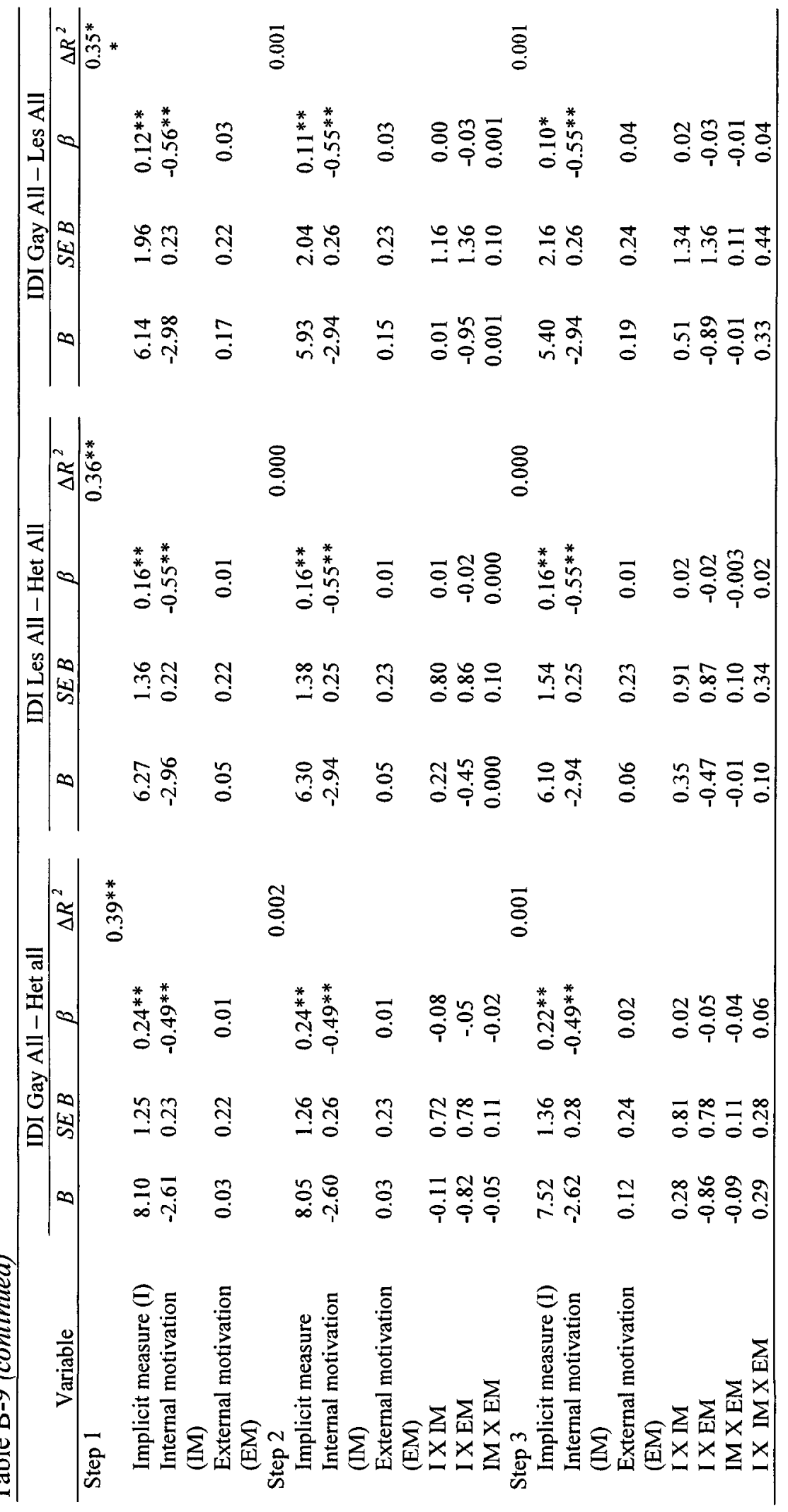




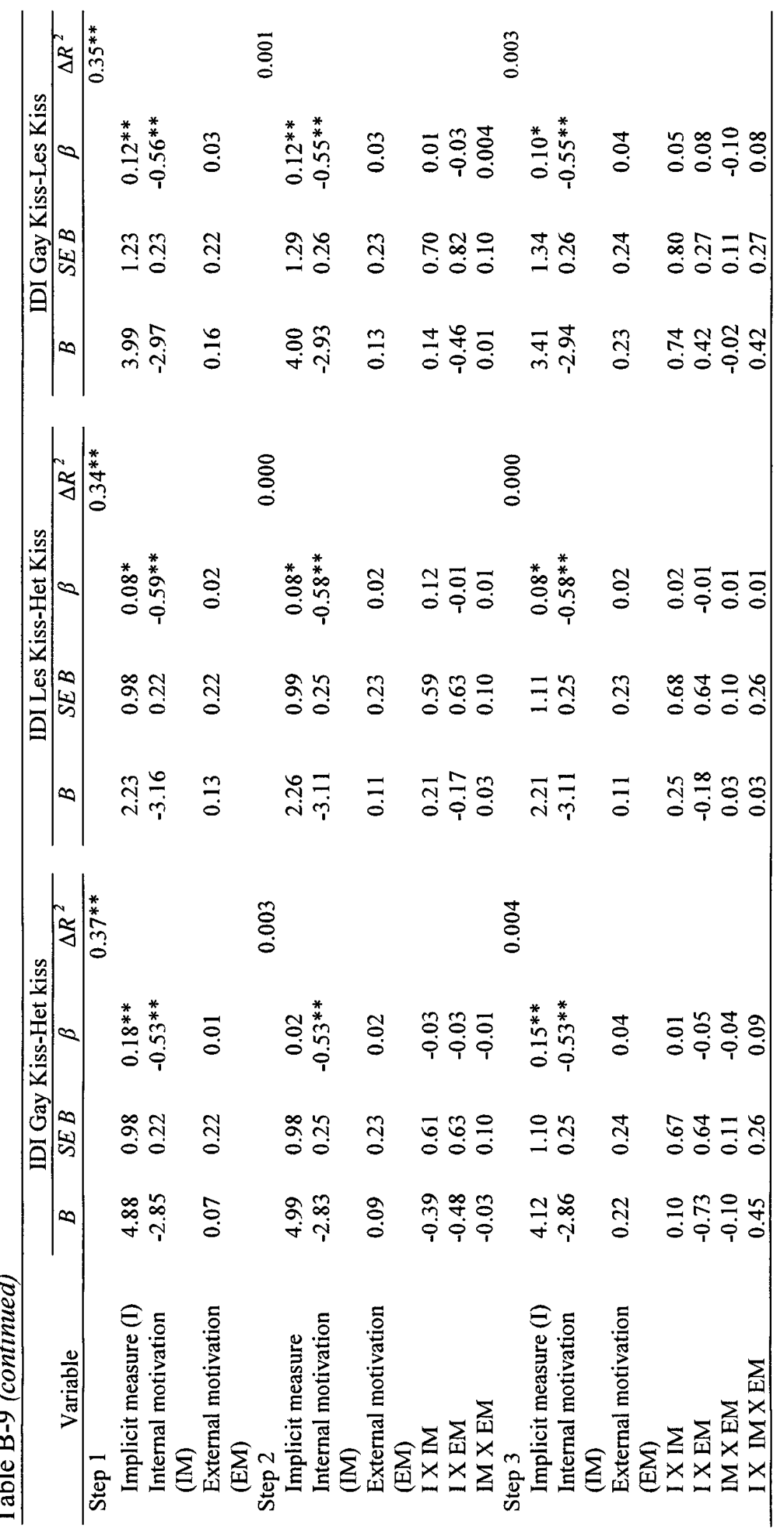




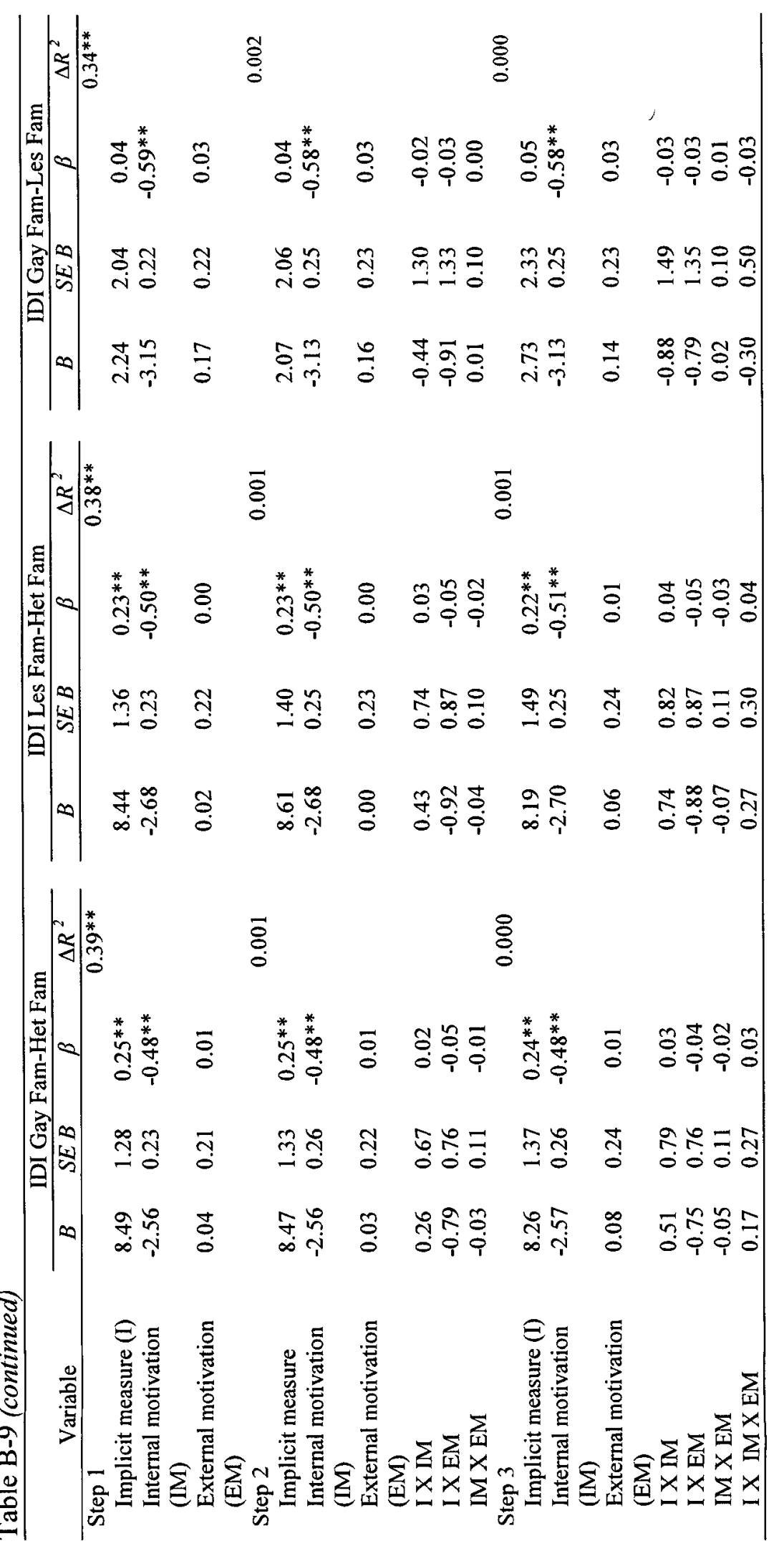




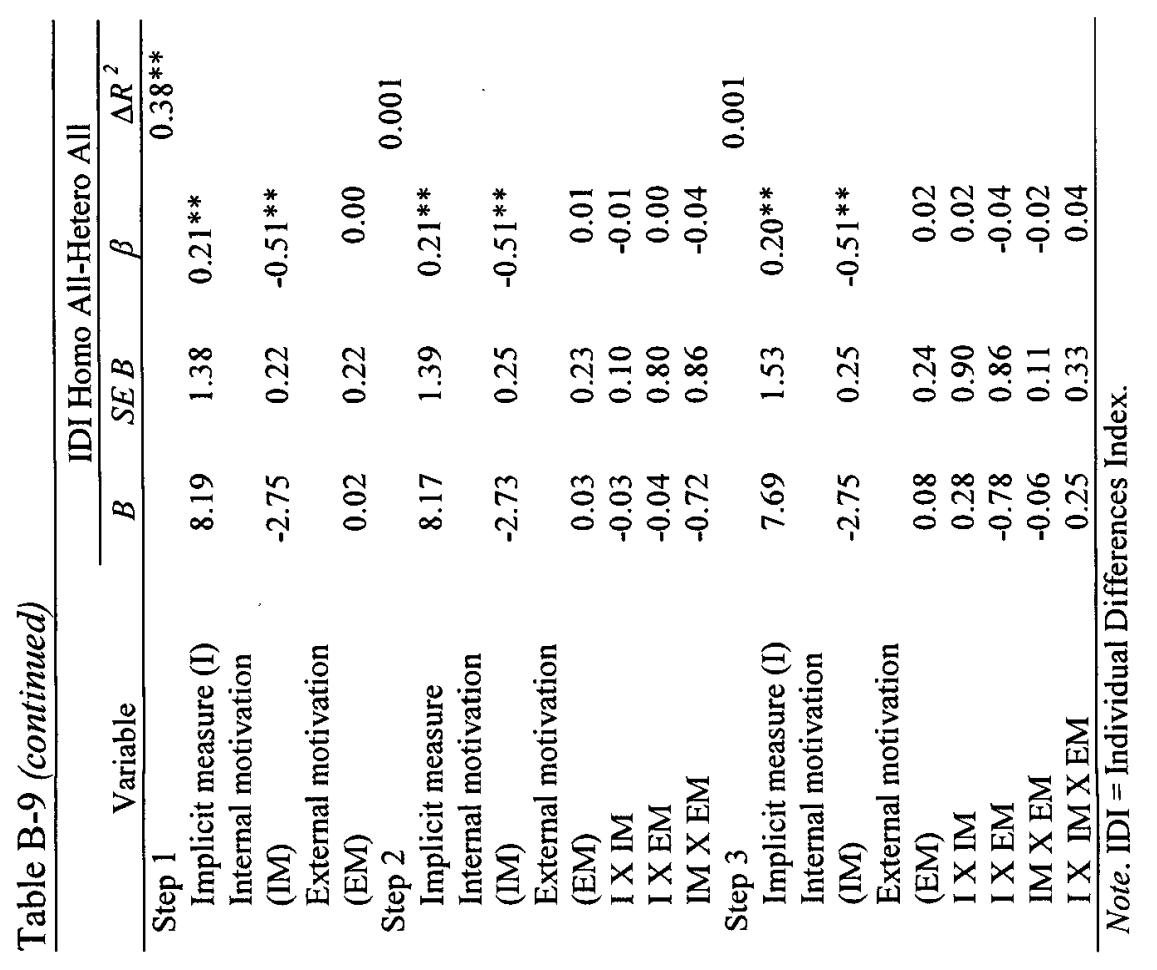




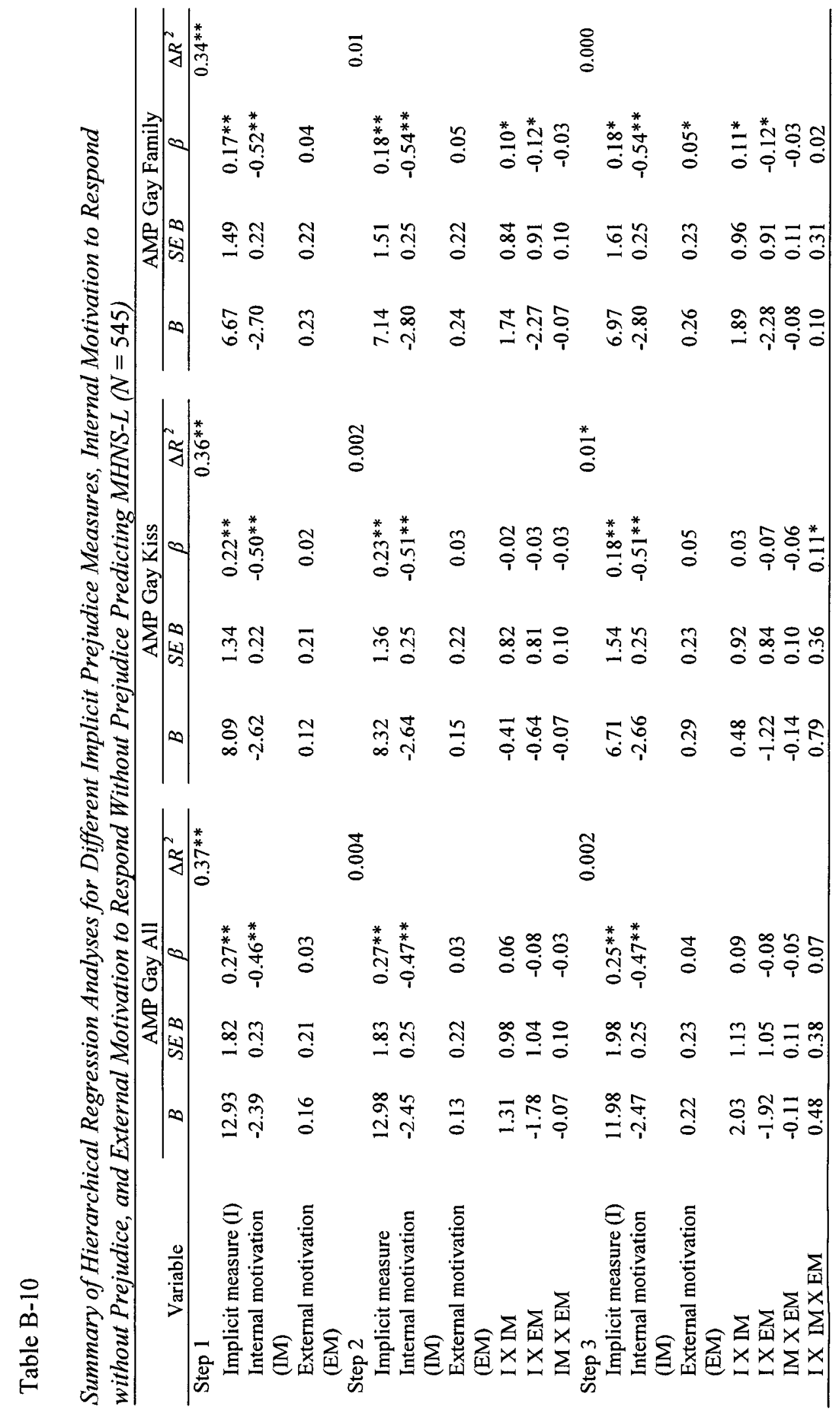




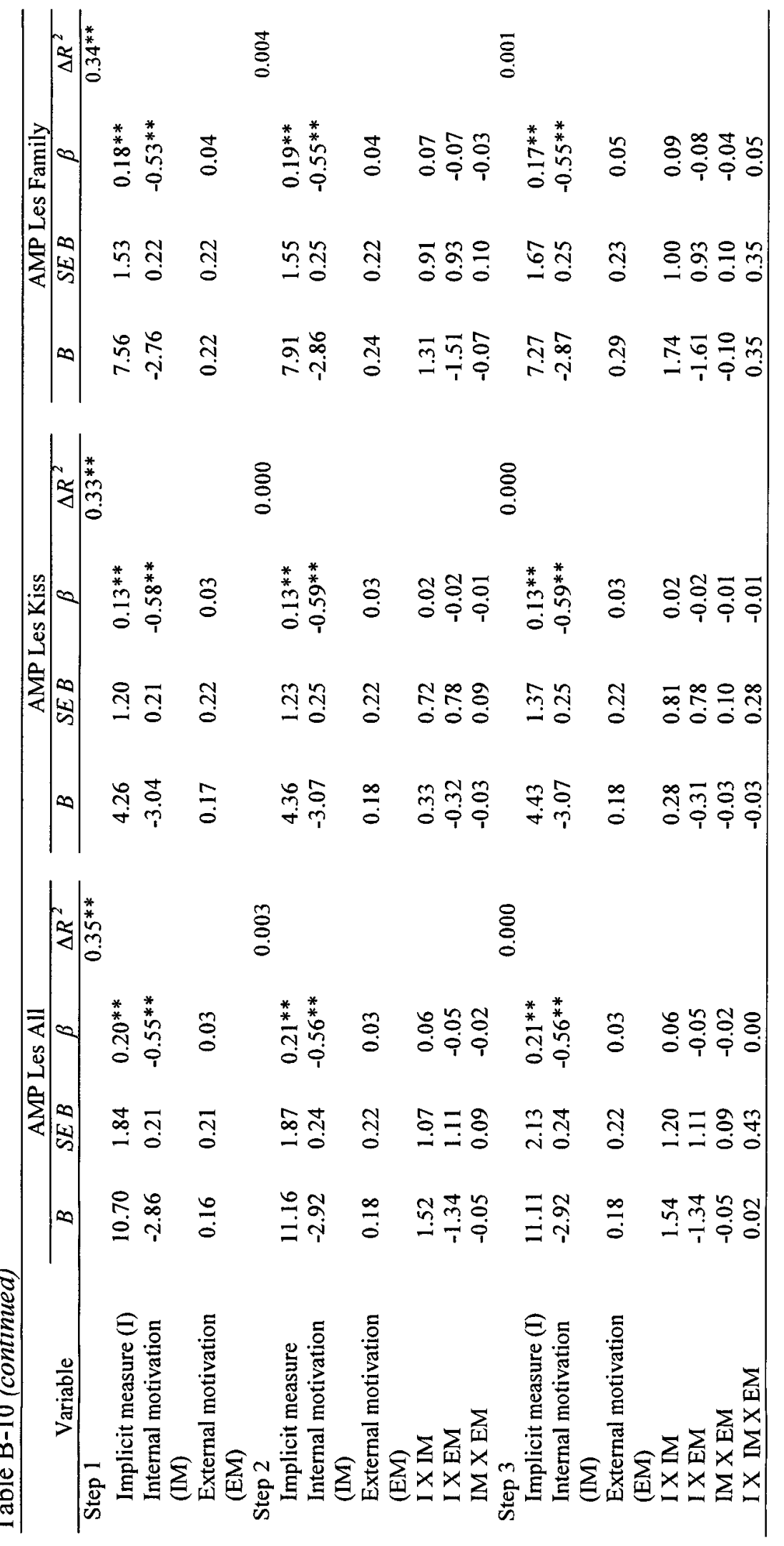




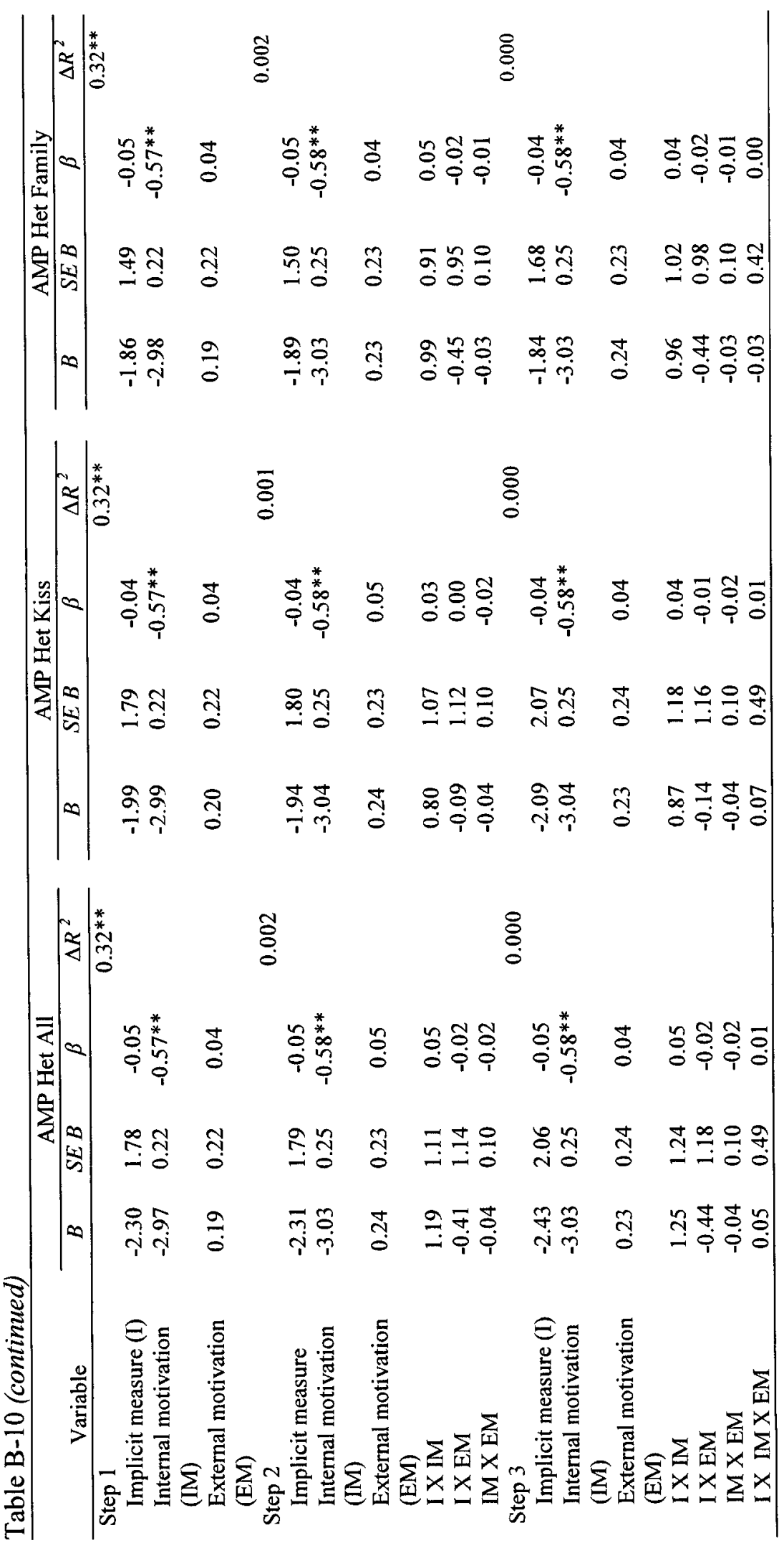




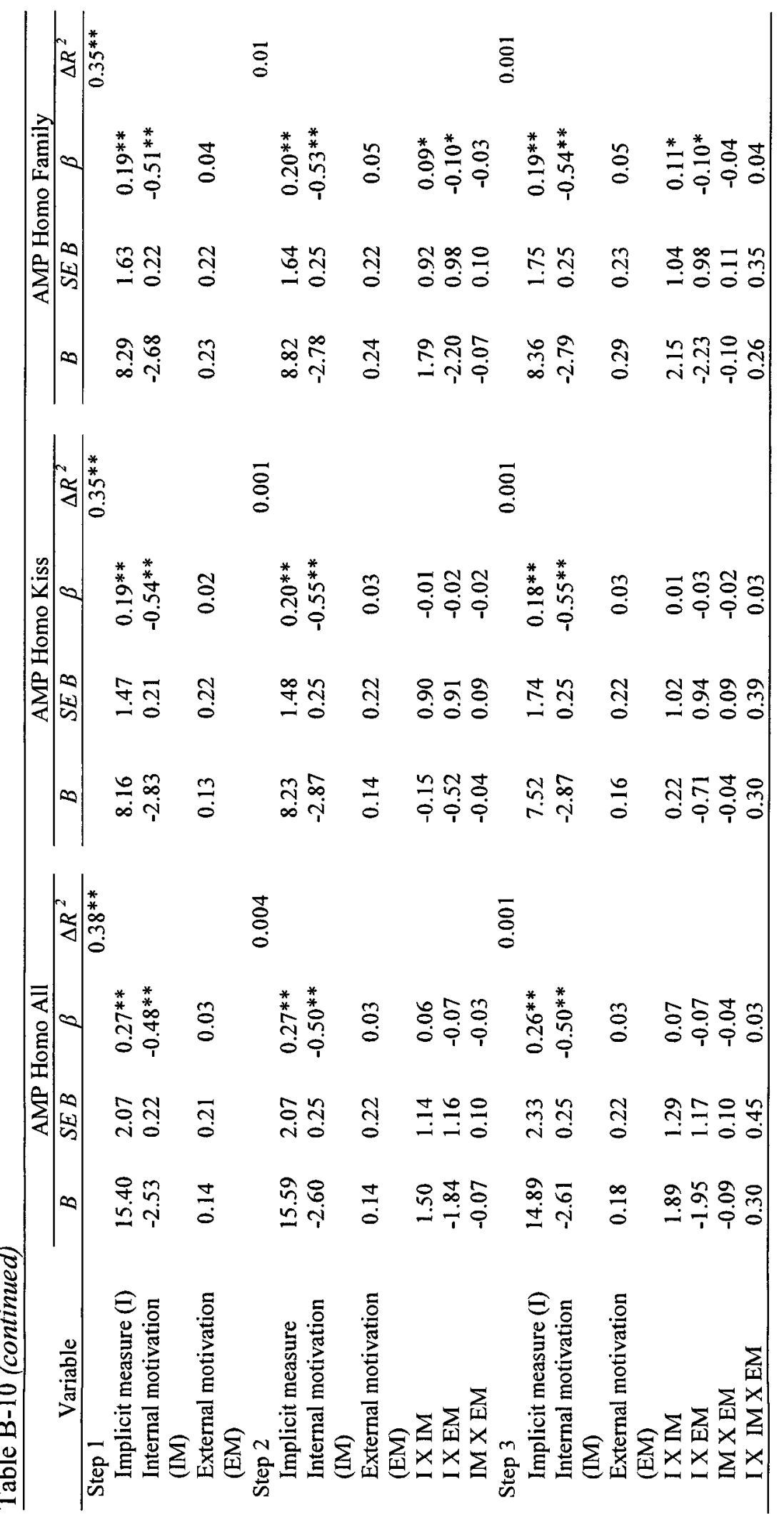




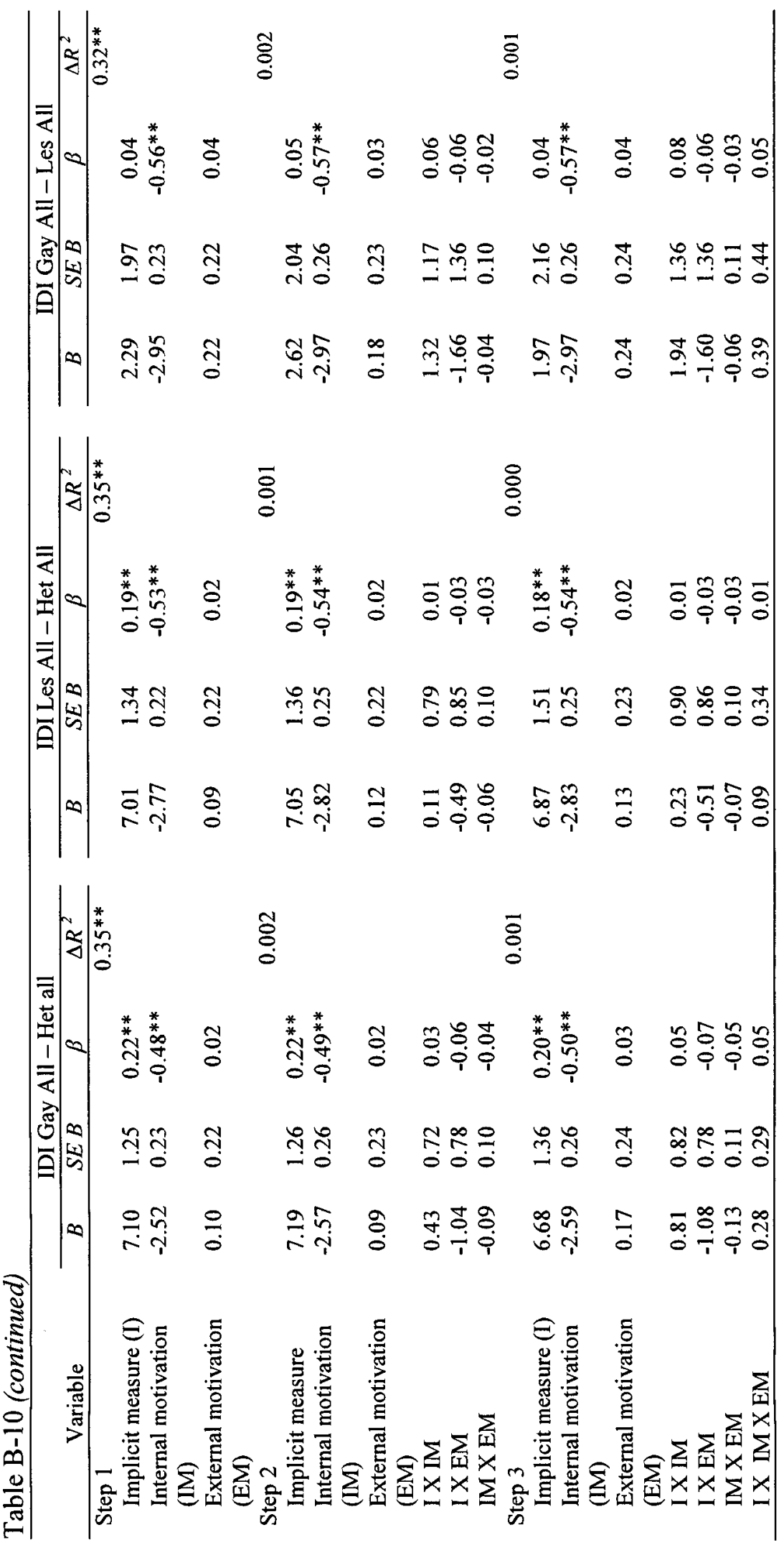




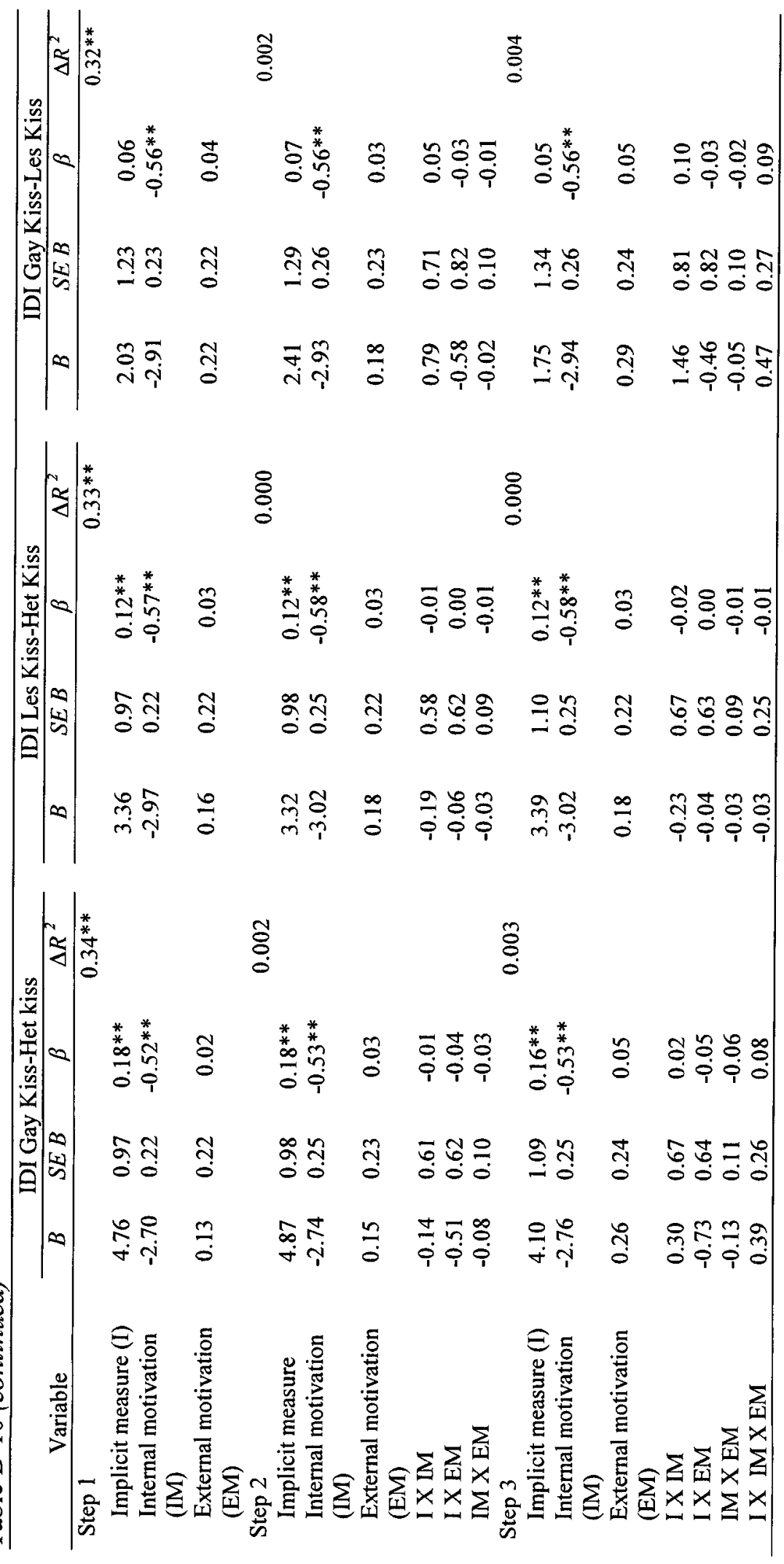




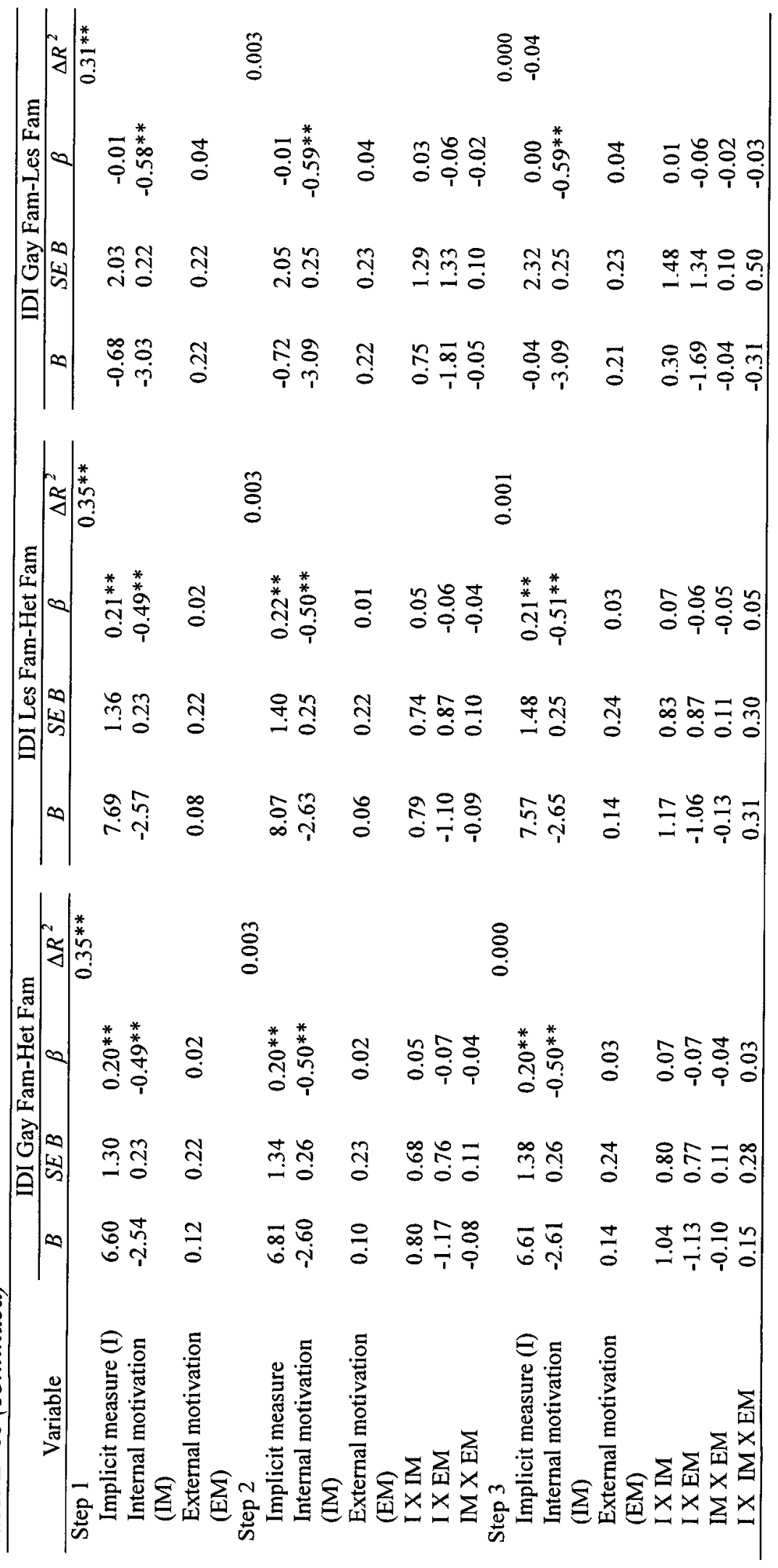




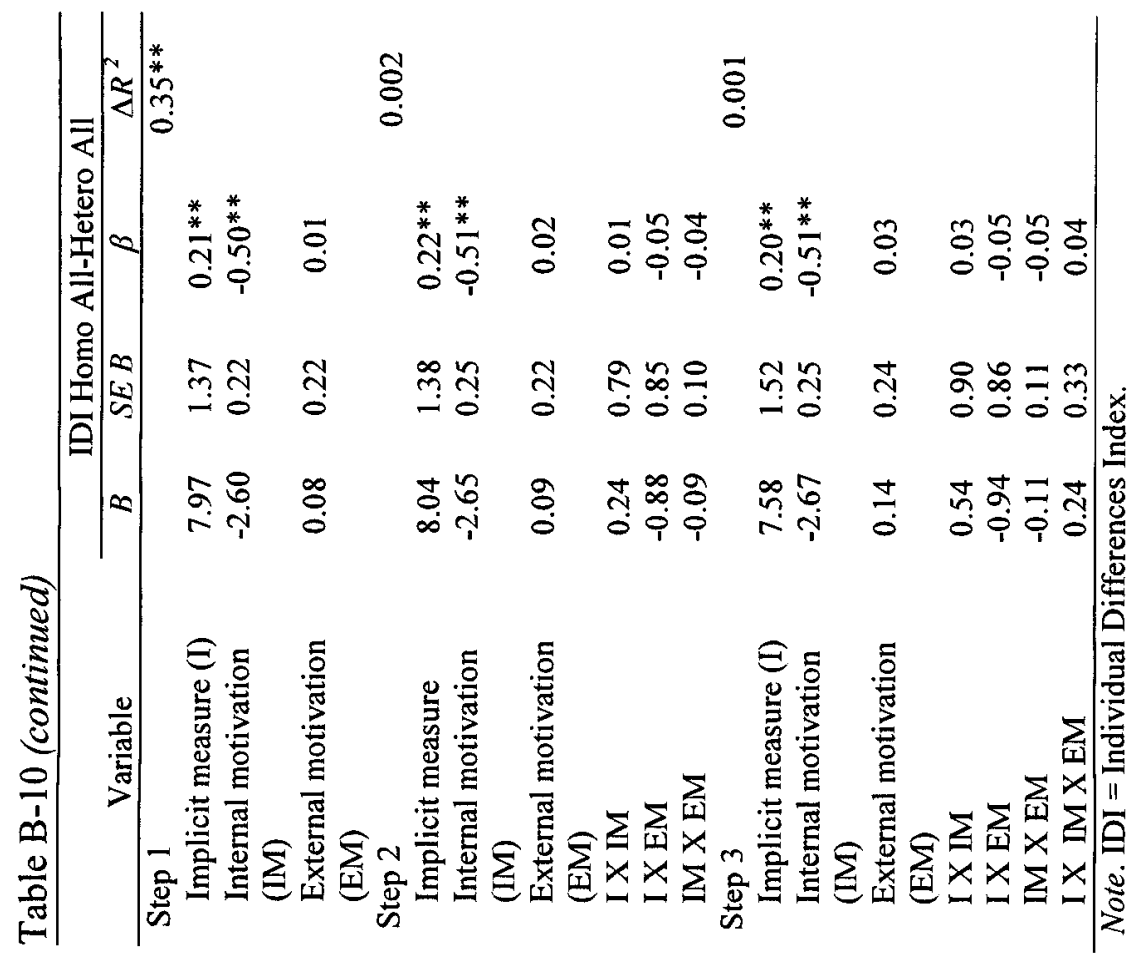


APPENDIX C

CORRELATION TABLE 


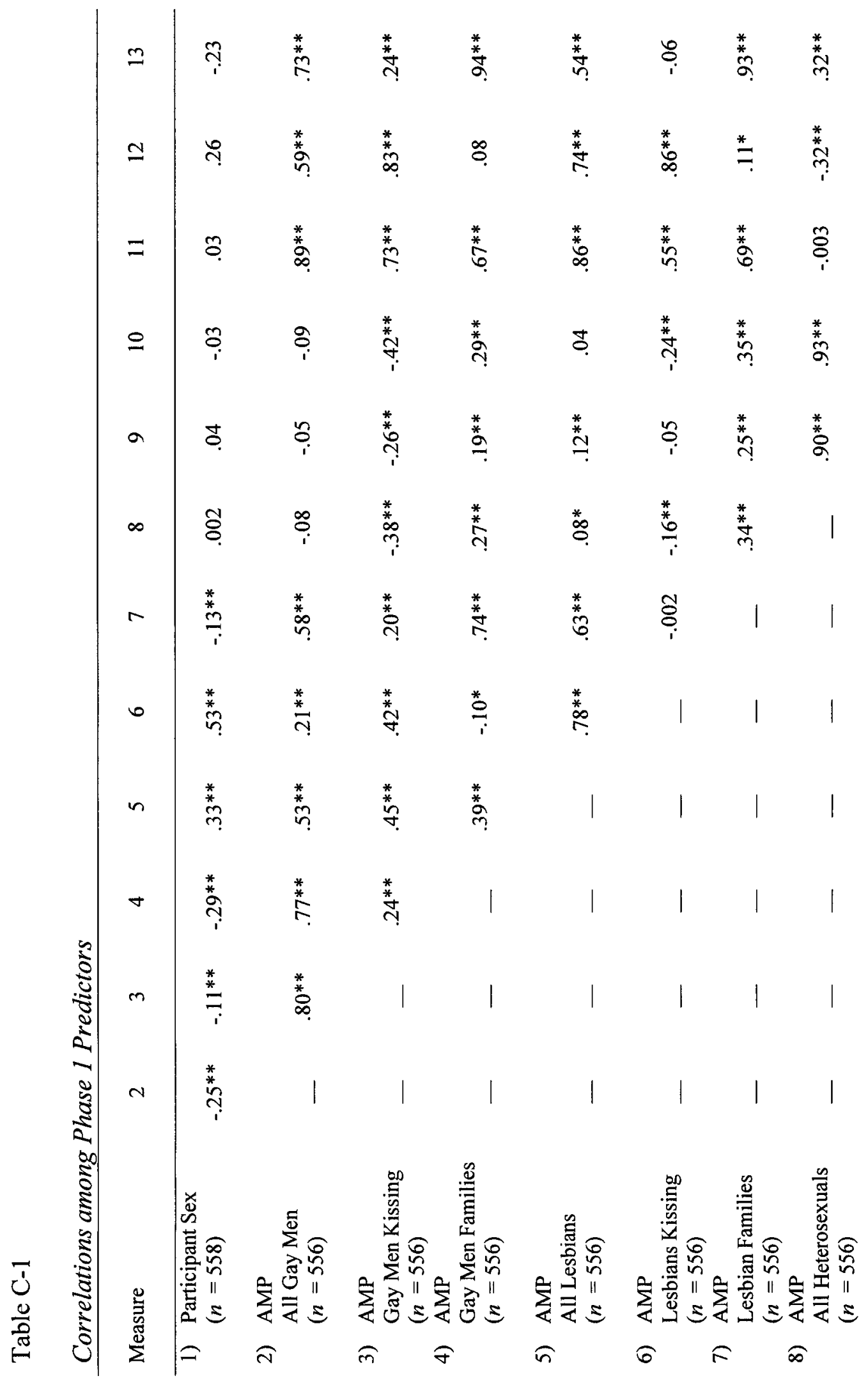




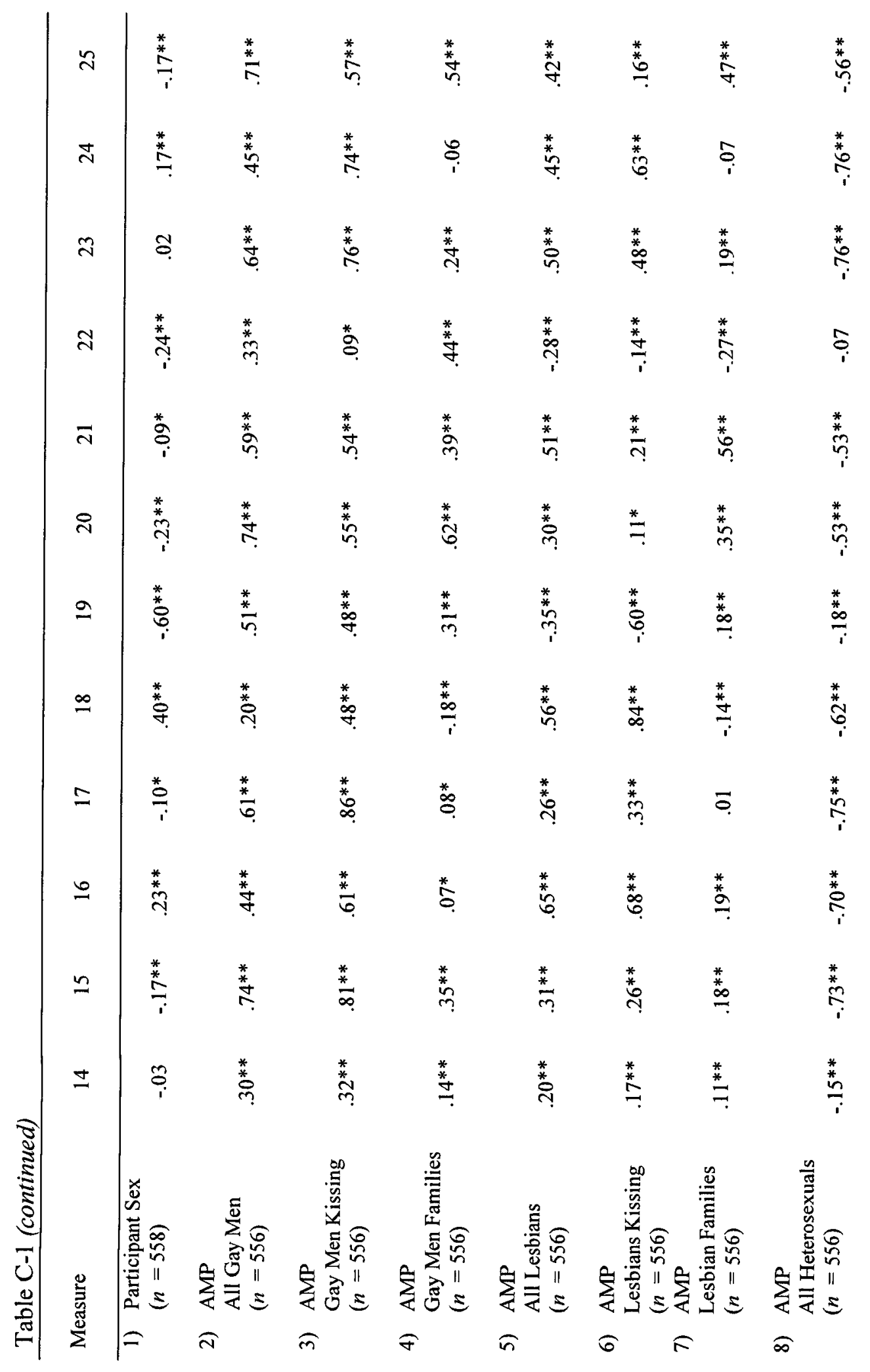




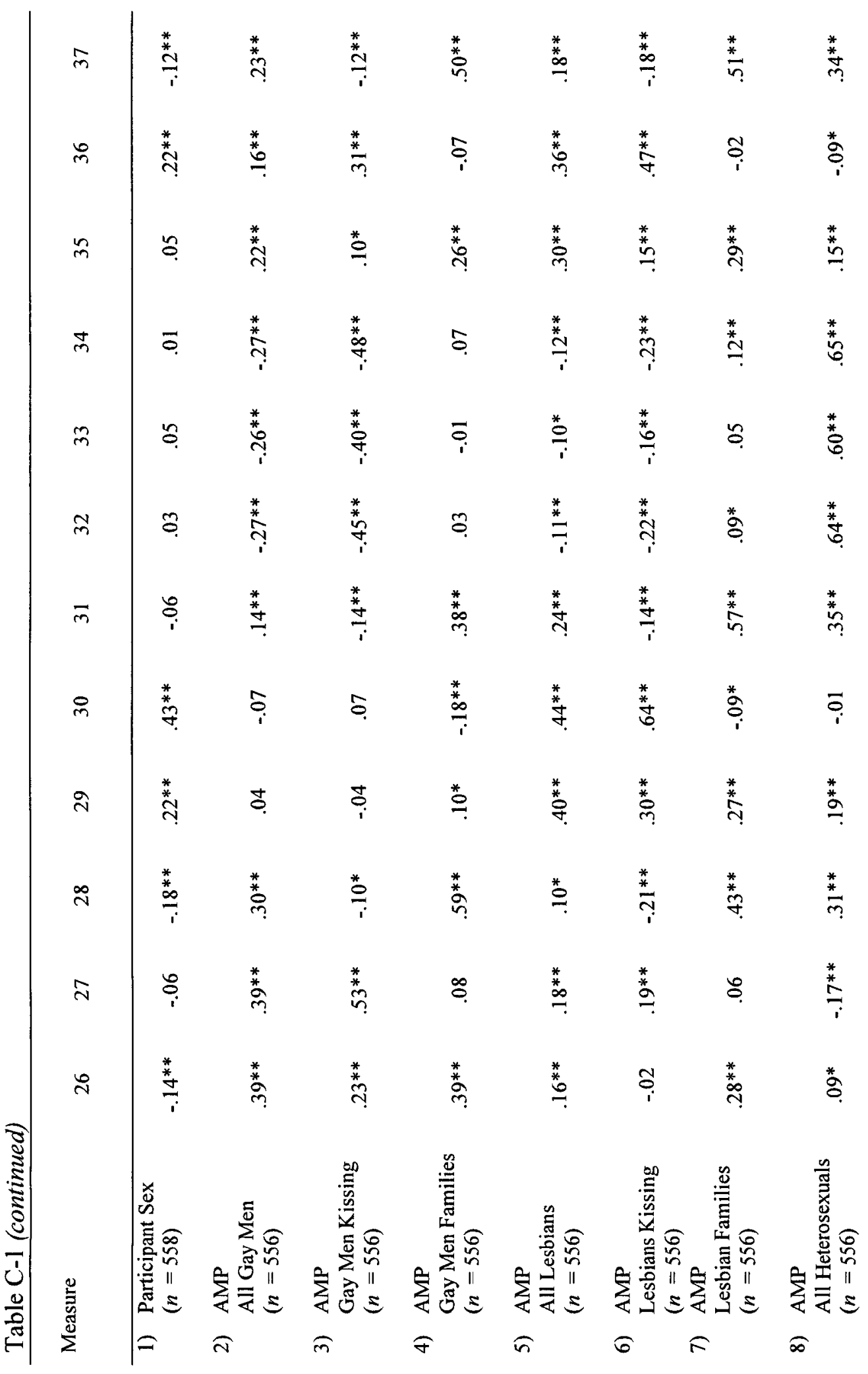




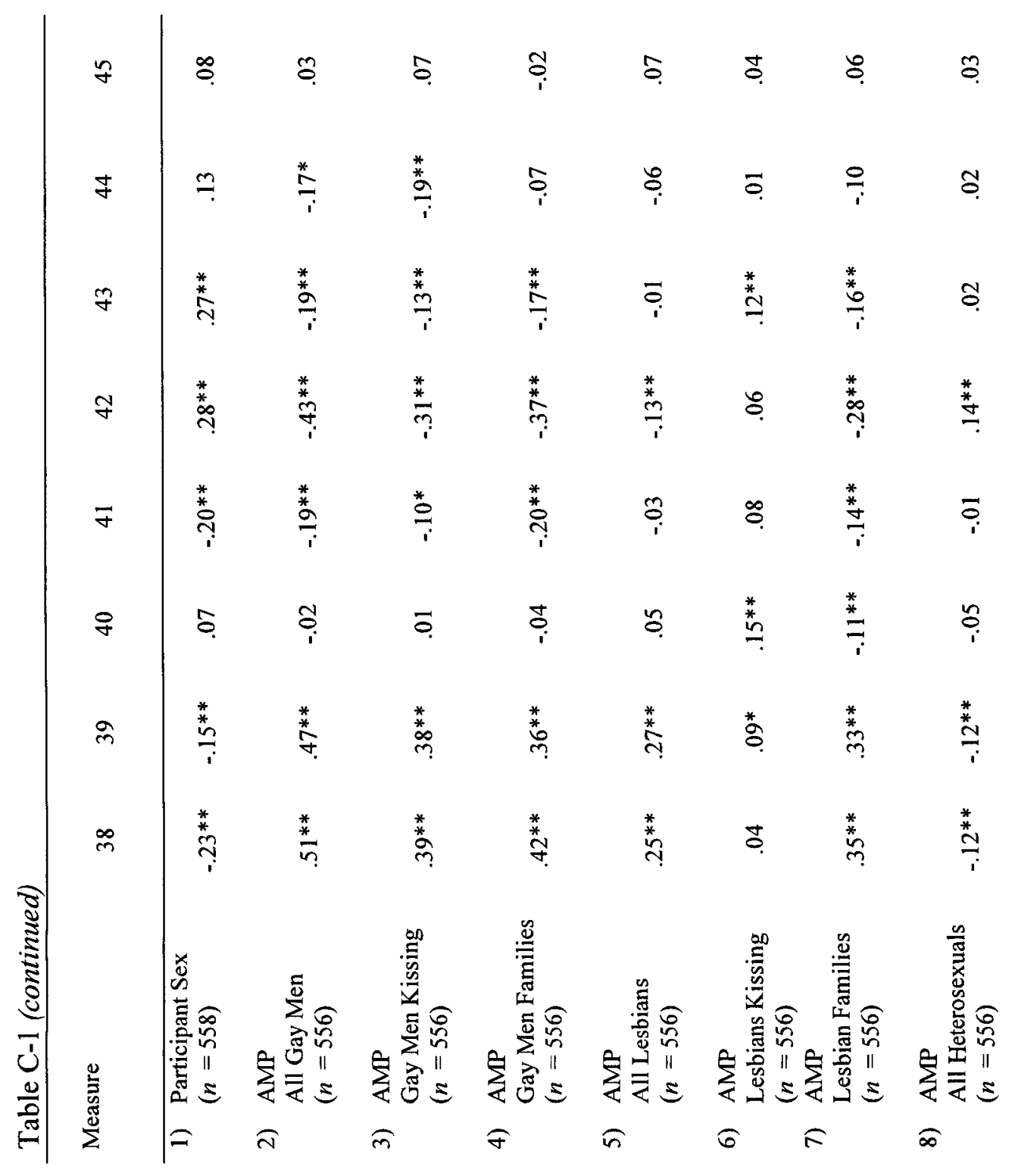




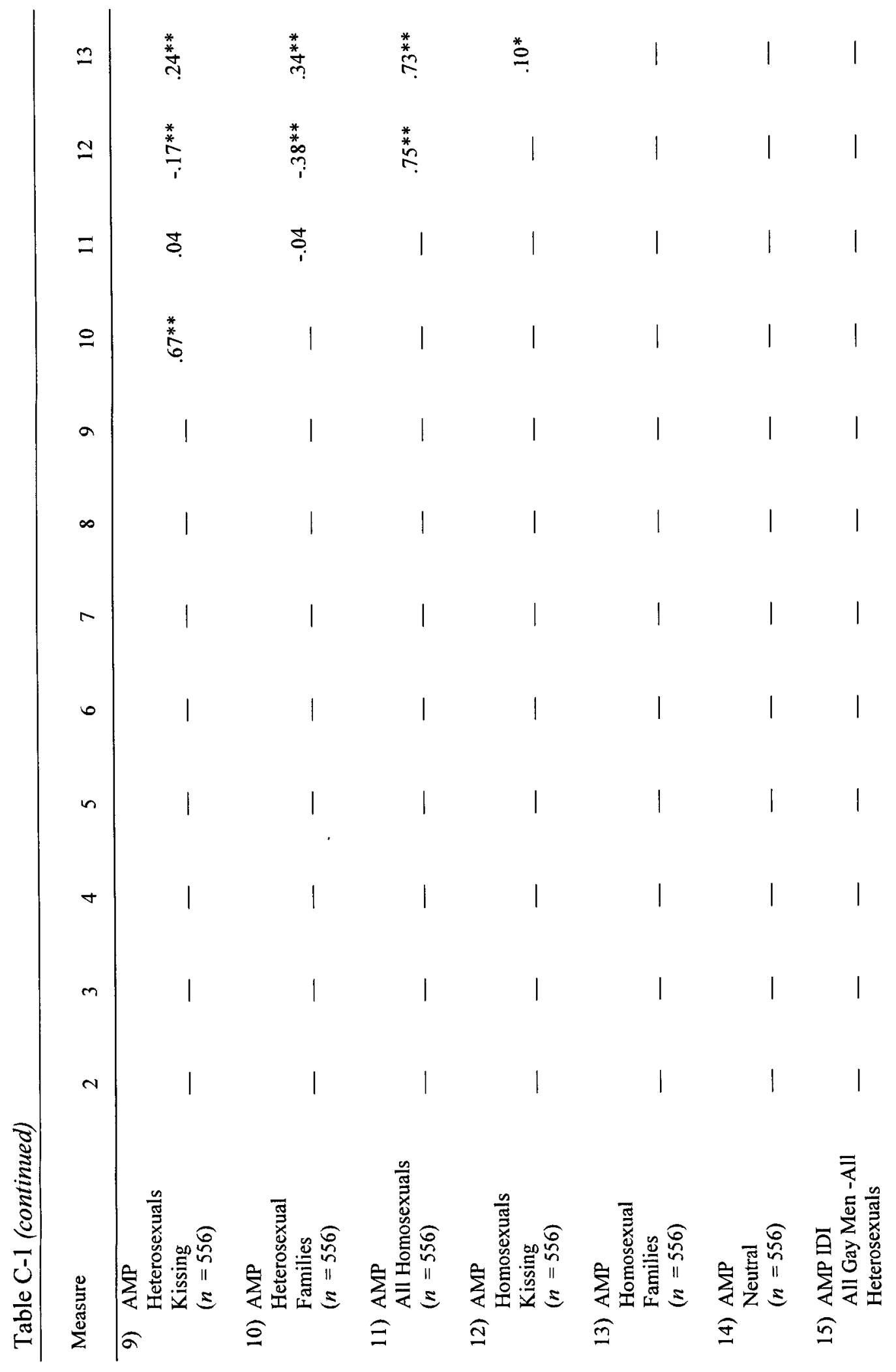




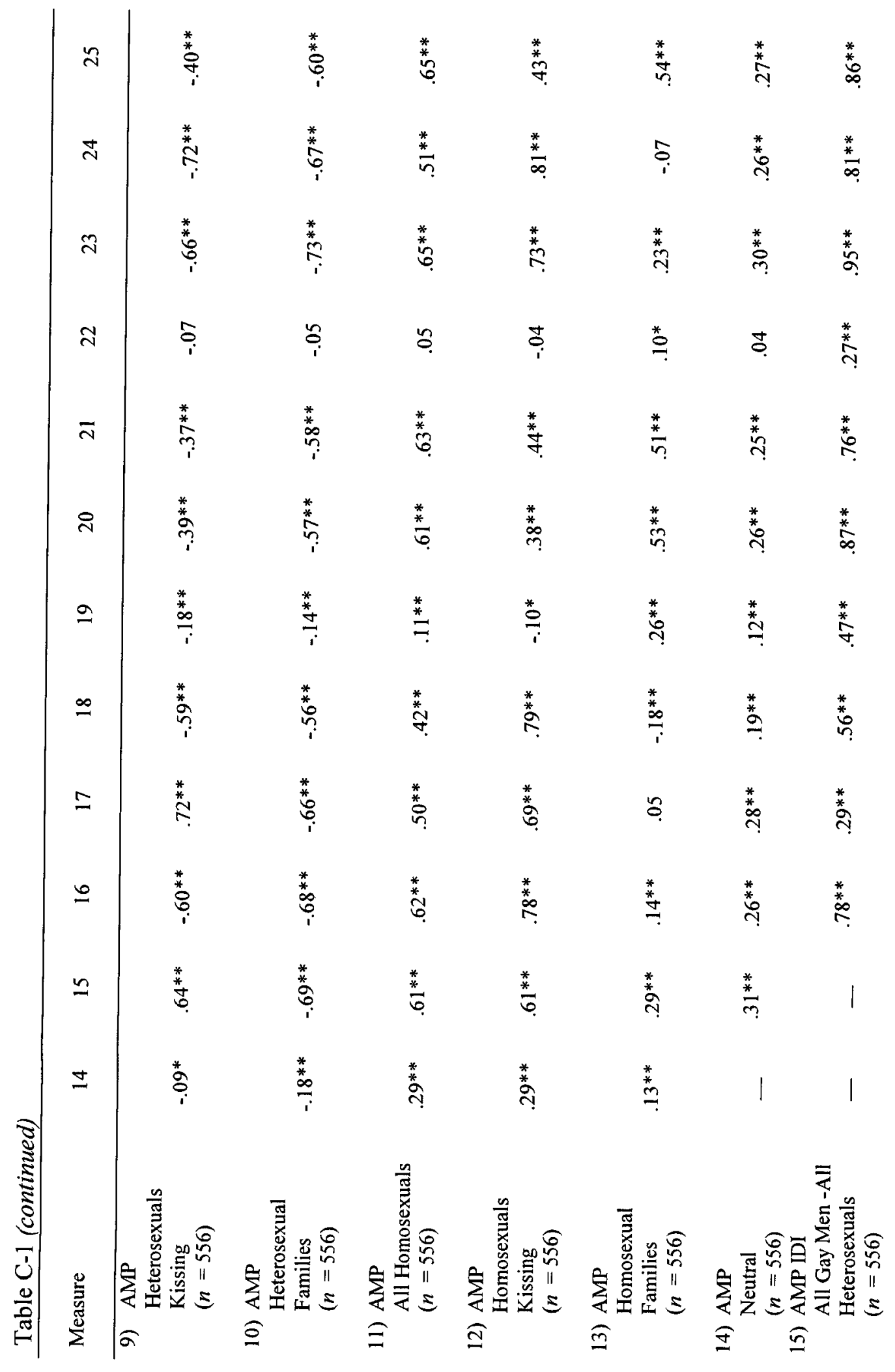




\begin{tabular}{|c|c|c|c|c|c|c|c|}
\hline$\hat{n}$ & $\stackrel{*}{\stackrel{*}{*}}$ & $\stackrel{*}{\stackrel{*}{*}}$ & $\stackrel{*}{*} \underset{\sim}{*}$ & $\stackrel{*}{\stackrel{*}{\infty}} \underset{i}{\longrightarrow}$ & $\stackrel{*}{*}$ & $\stackrel{*}{*} \stackrel{*}{\circ}$ & $\hat{o}_{i}$ \\
\hline in & $\mathbb{i}_{i}$ & $\stackrel{*}{\stackrel{*}{\leftrightarrows}}$ & 今ั & $\stackrel{*}{\stackrel{*}{\forall}}$ & $\stackrel{\sim}{c}$ & $\stackrel{*}{*}$ & $\stackrel{*}{\stackrel{*}{\leftarrow}}$ \\
\hline$\tilde{m}$ & $\stackrel{*}{=}$ & $\stackrel{*}{*}$ & خิ & $\stackrel{*}{*} \stackrel{*}{?}$ & $\stackrel{*}{\stackrel{*}{*}} \stackrel{\text { సे }}{ }$ & $\begin{array}{l}\stackrel{*}{*} \\
\stackrel{*}{\infty}\end{array}$ & $\approx$ \\
\hline$\dot{m}$ & $\stackrel{*}{*}$ & $\stackrel{*}{*}$ & $\stackrel{*}{\stackrel{*}{*}}$ & $\stackrel{*}{\stackrel{*}{q}}$ & $\stackrel{*}{0}$ & 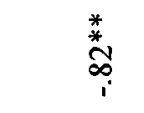 & $\stackrel{*}{\stackrel{*}{*}} \stackrel{i}{i}^{-}$ \\
\hline$m$ & $\stackrel{*}{6}$ & 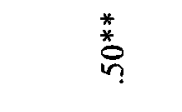 & $\stackrel{*}{\stackrel{*}{*}}$ & $\stackrel{*}{\stackrel{*}{*}} \stackrel{?}{?}$ & ș & $\begin{array}{l}\stackrel{*}{*} \\
\stackrel{*}{\infty} \\
i\end{array}$ & 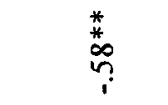 \\
\hline N & $\stackrel{*}{*}$ & $\stackrel{*}{*}$ & $\stackrel{*}{\stackrel{*}{*}} \underset{i}{*}$ & $\stackrel{*}{*}$ & s. & 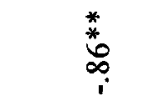 & $\underset{i}{\stackrel{*}{*}}$ \\
\hline $\bar{m}$ & $\stackrel{*}{*} \stackrel{*}{\sim}$ & $\begin{array}{l}* \\
\stackrel{*}{*} \\
\infty \\
\eta\end{array}$ & $\stackrel{*}{\stackrel{*}{\sim}}$ & $\stackrel{*}{\stackrel{*}{*}}$ & $\stackrel{*}{*}$ & $\stackrel{*}{*}$ & $\stackrel{*}{\stackrel{*}{ \pm}}$ \\
\hline 周 & $\Xi$ & $\Xi_{i}$ & $\stackrel{*}{*}$ & $\stackrel{*}{*}$ & $\stackrel{*}{\stackrel{*}{7}}$ & 莣 & $\Phi_{i}$ \\
\hline$\stackrel{\curvearrowright}{ }$ & $\stackrel{*}{*}$ & $\stackrel{*}{*}$ & $\stackrel{*}{*}$ & $\stackrel{*}{\stackrel{*}{*}}$ & $\stackrel{*}{\stackrel{*}{*}}$ & $\stackrel{*}{*}$ & $\frac{*}{i}$ \\
\hline$\stackrel{\sim}{\infty}$ & $\stackrel{*}{\sim}$ & $\stackrel{*}{*}$ & 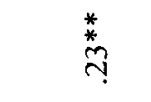 & $\stackrel{*}{\stackrel{*}{*}} \underset{i}{\stackrel{\infty}{*}}$ & $\stackrel{*}{*}$ & $\stackrel{*}{\stackrel{*}{*}}$ & §̊ \\
\hline$\hat{\lambda}$ & $\stackrel{*}{\stackrel{*}{*}} \underset{i}{*}$ & $\stackrel{*}{\stackrel{*}{\infty}}$ & $\stackrel{*}{*}$ & $\stackrel{*}{*}$ & $\hat{o}$ & $\stackrel{*}{*} \underset{i}{*}$ & $\begin{array}{l}\stackrel{*}{*} \\
\stackrel{*}{\infty} \\
?\end{array}$ \\
\hline$\stackrel{i}{i}$ & $\stackrel{0}{0}$ & $\stackrel{*}{*}$ & $\stackrel{*}{*} \underset{\sim}{\stackrel{*}{n}}$ & $\stackrel{*}{=}$ & $\begin{array}{l}\stackrel{*}{*} \\
\stackrel{*}{0}\end{array}$ & $\stackrel{*}{\stackrel{*}{*}}$ & $\stackrel{*}{\stackrel{*}{0}}$ \\
\hline 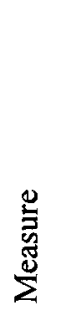 & 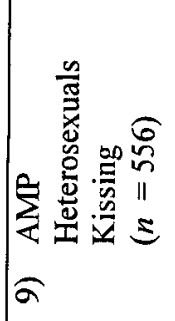 & 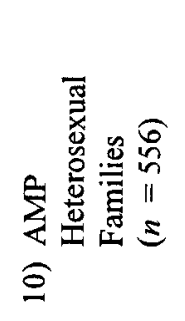 & 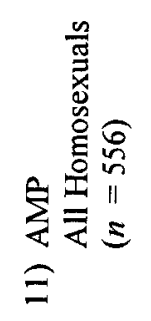 & 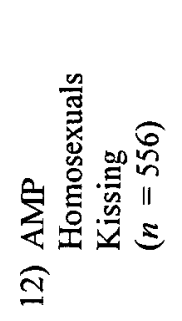 & 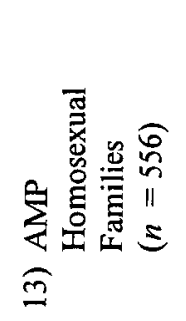 & 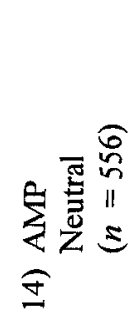 & 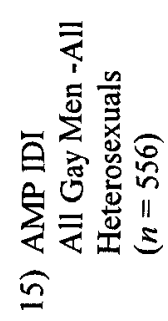 \\
\hline
\end{tabular}




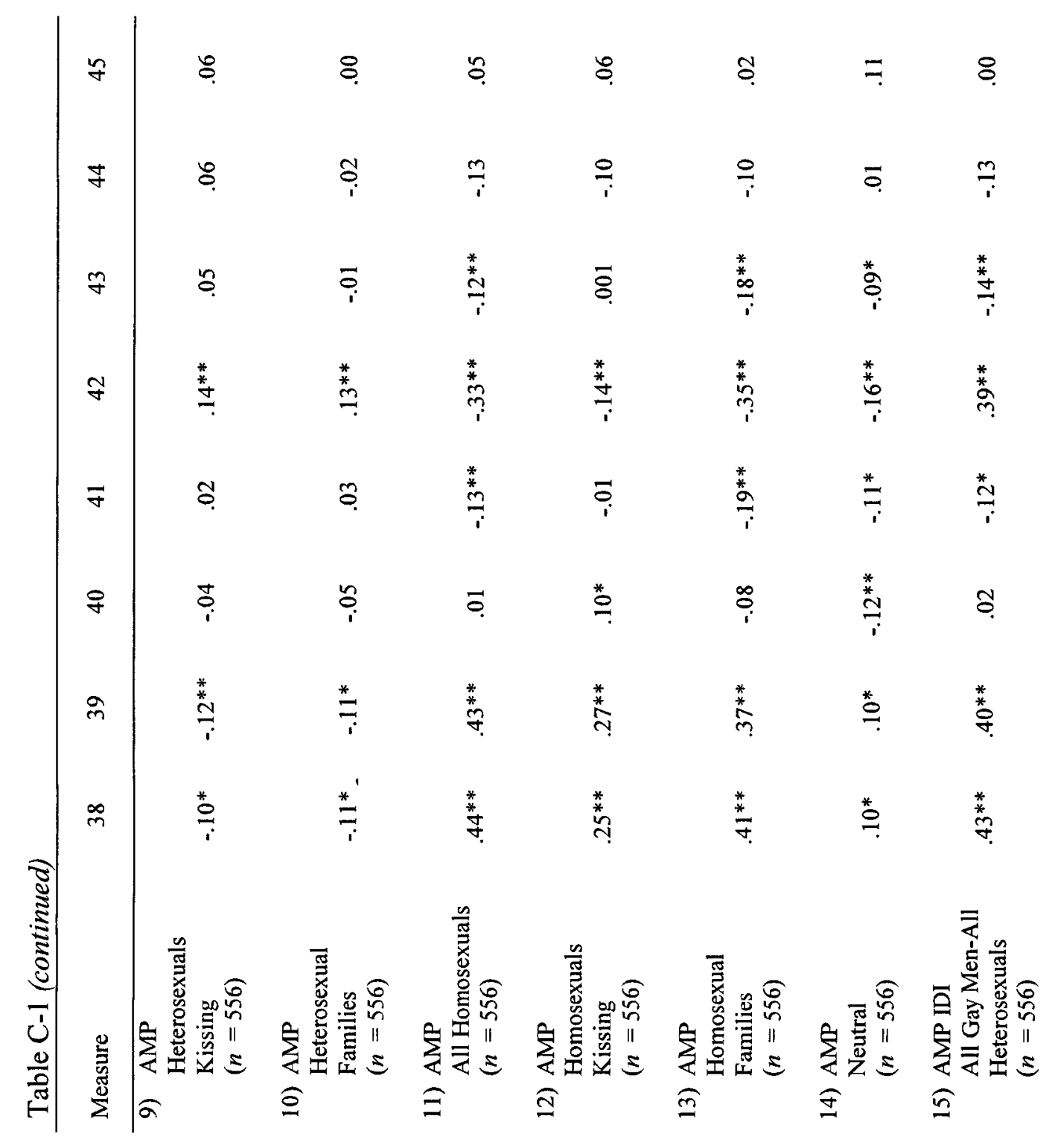




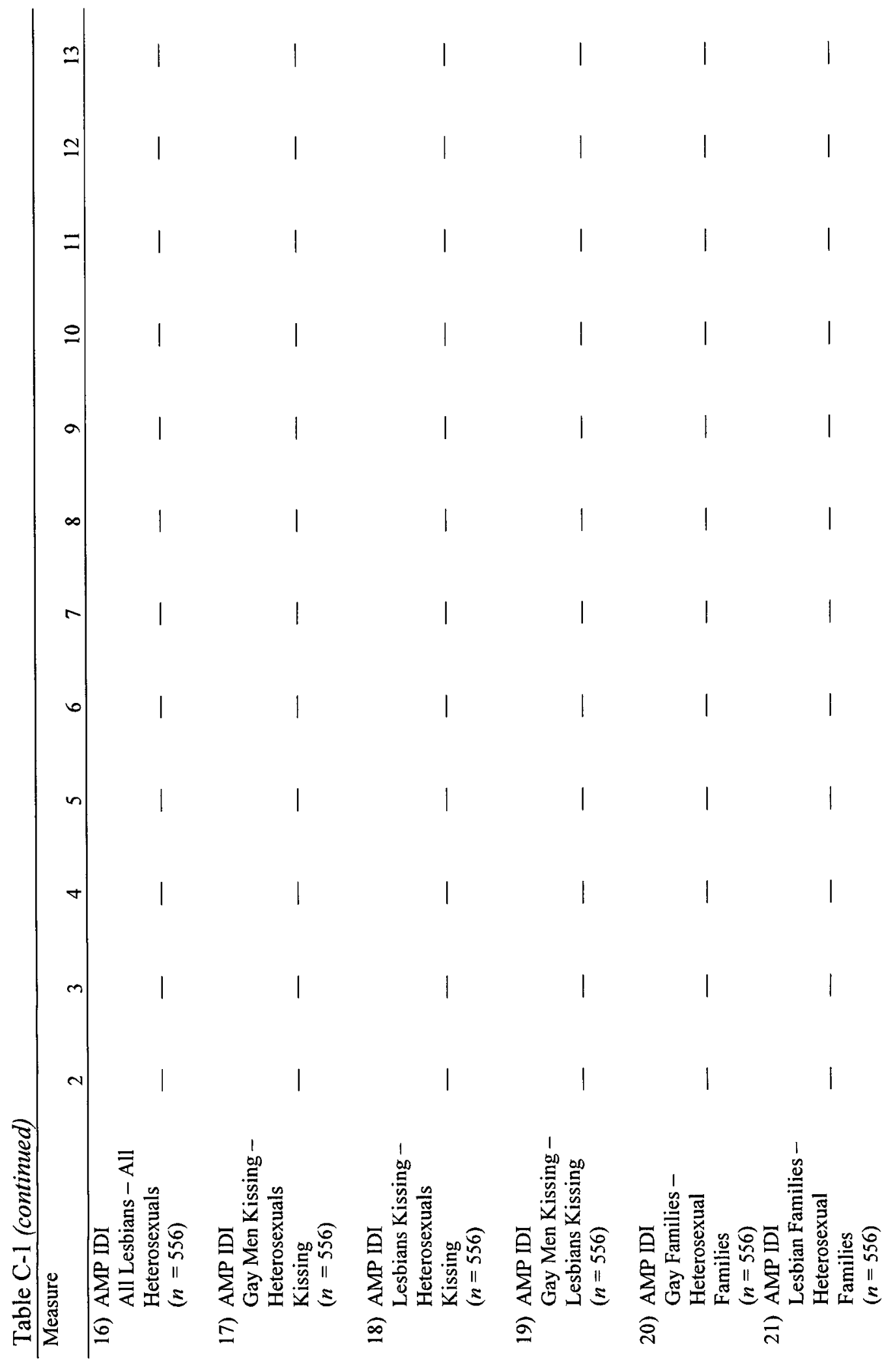




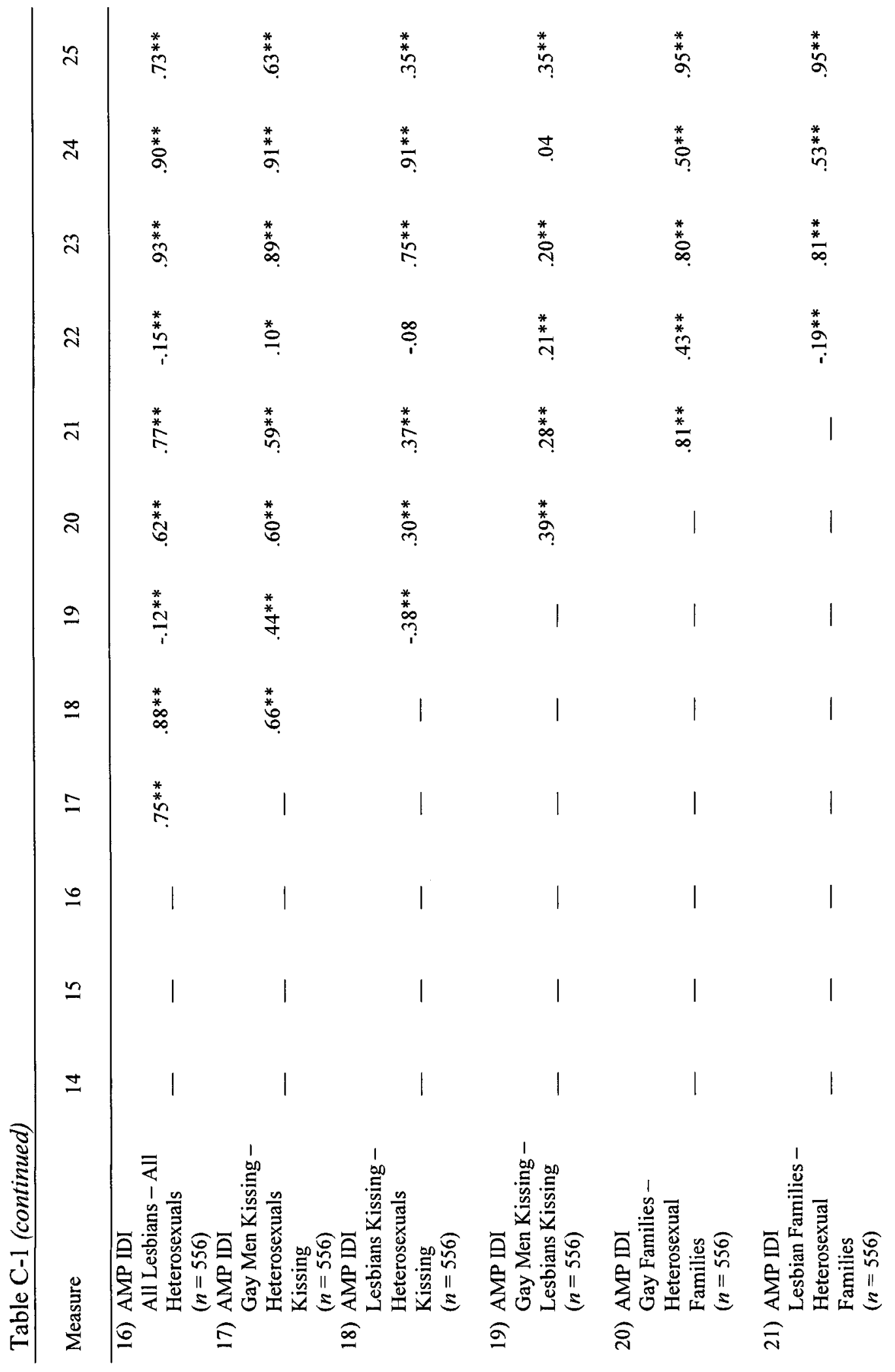




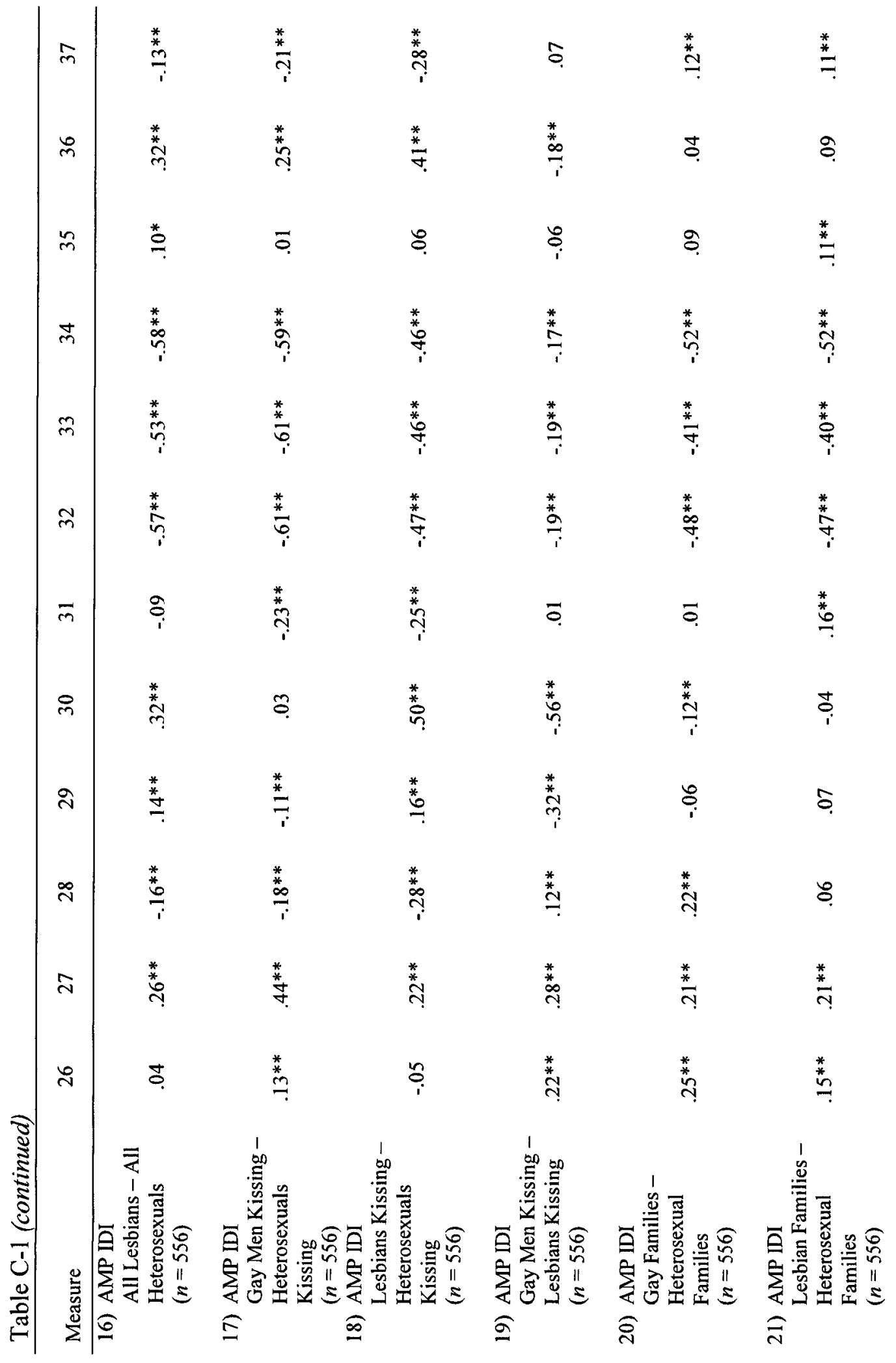




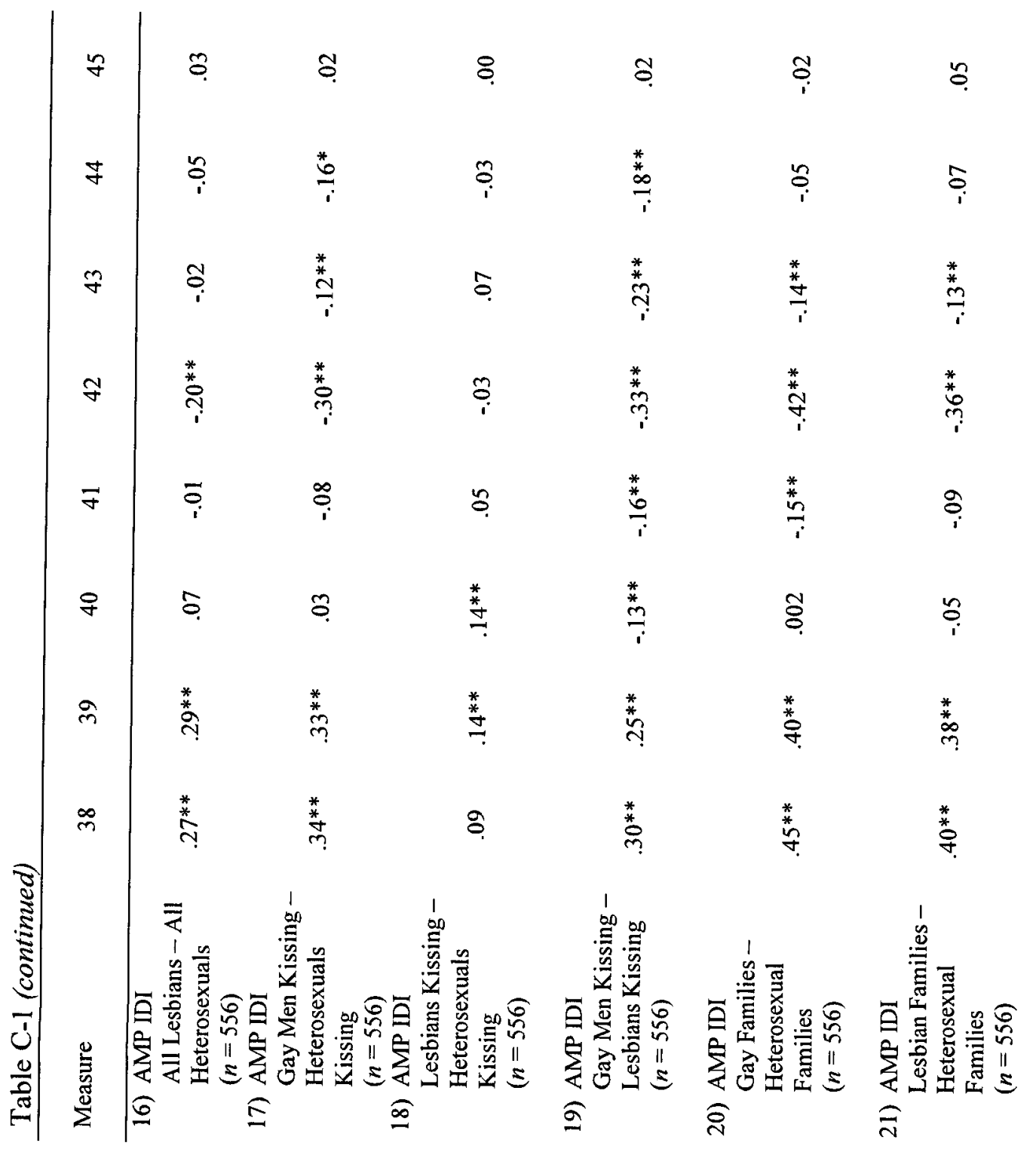




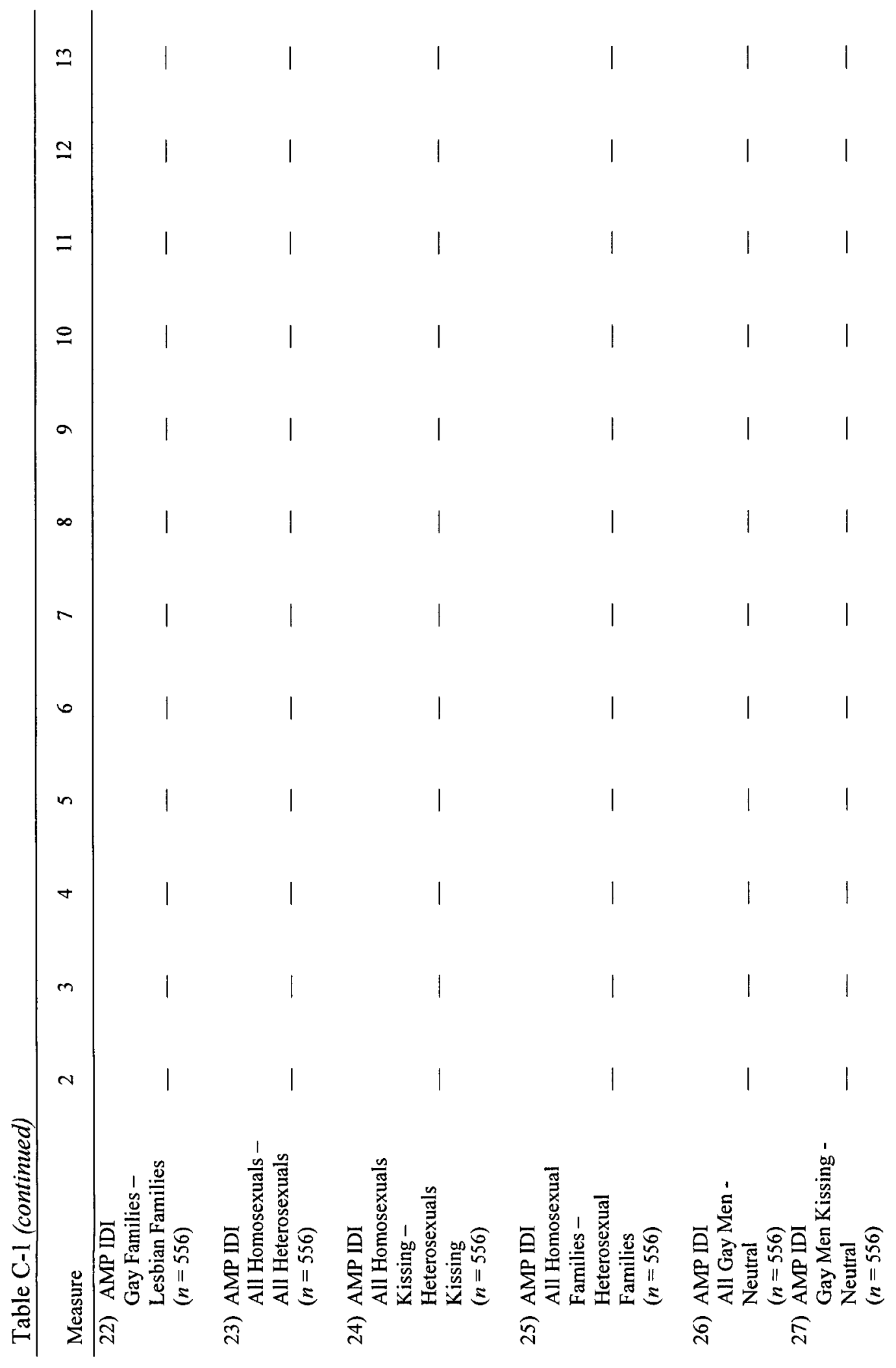




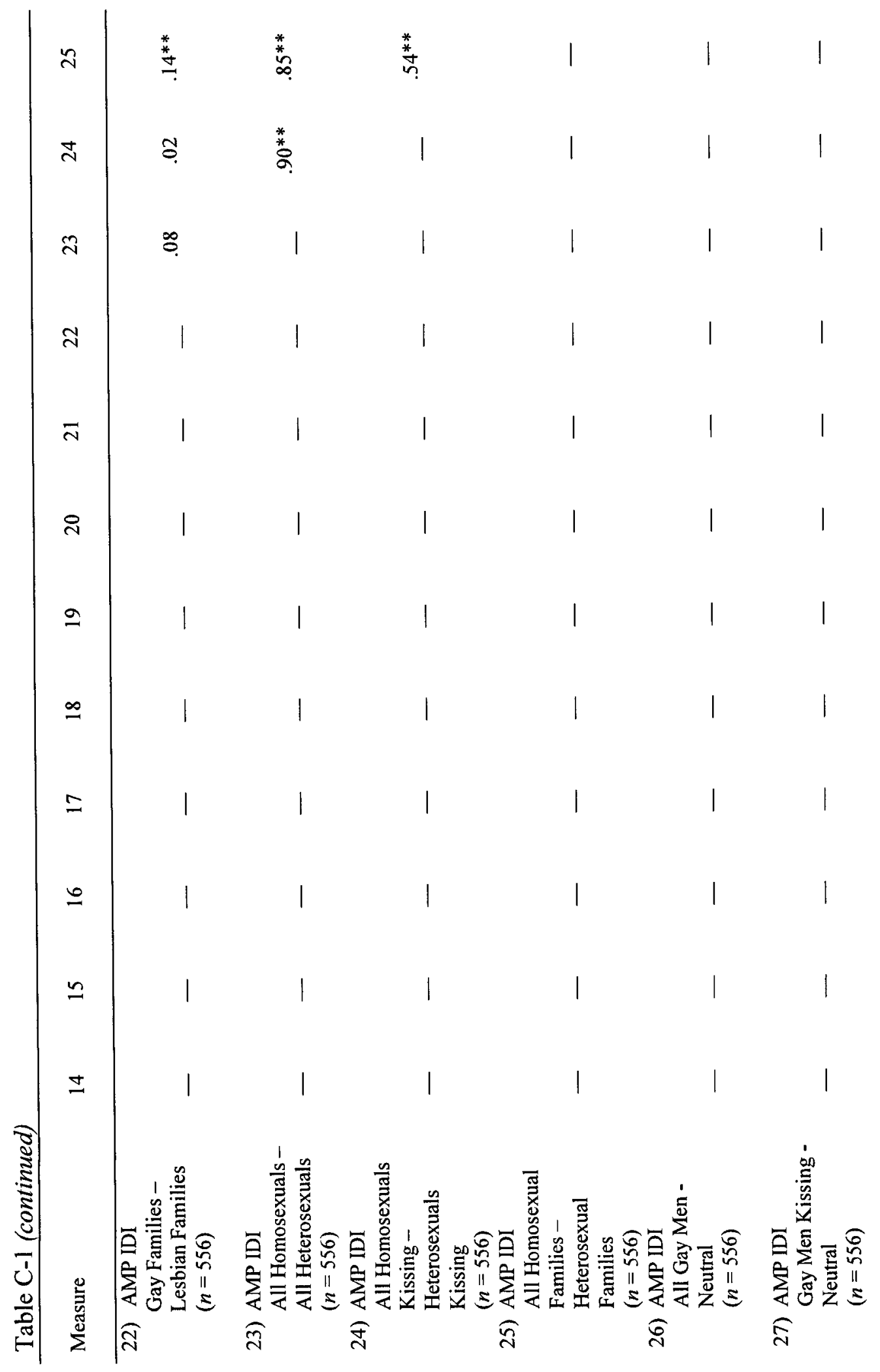




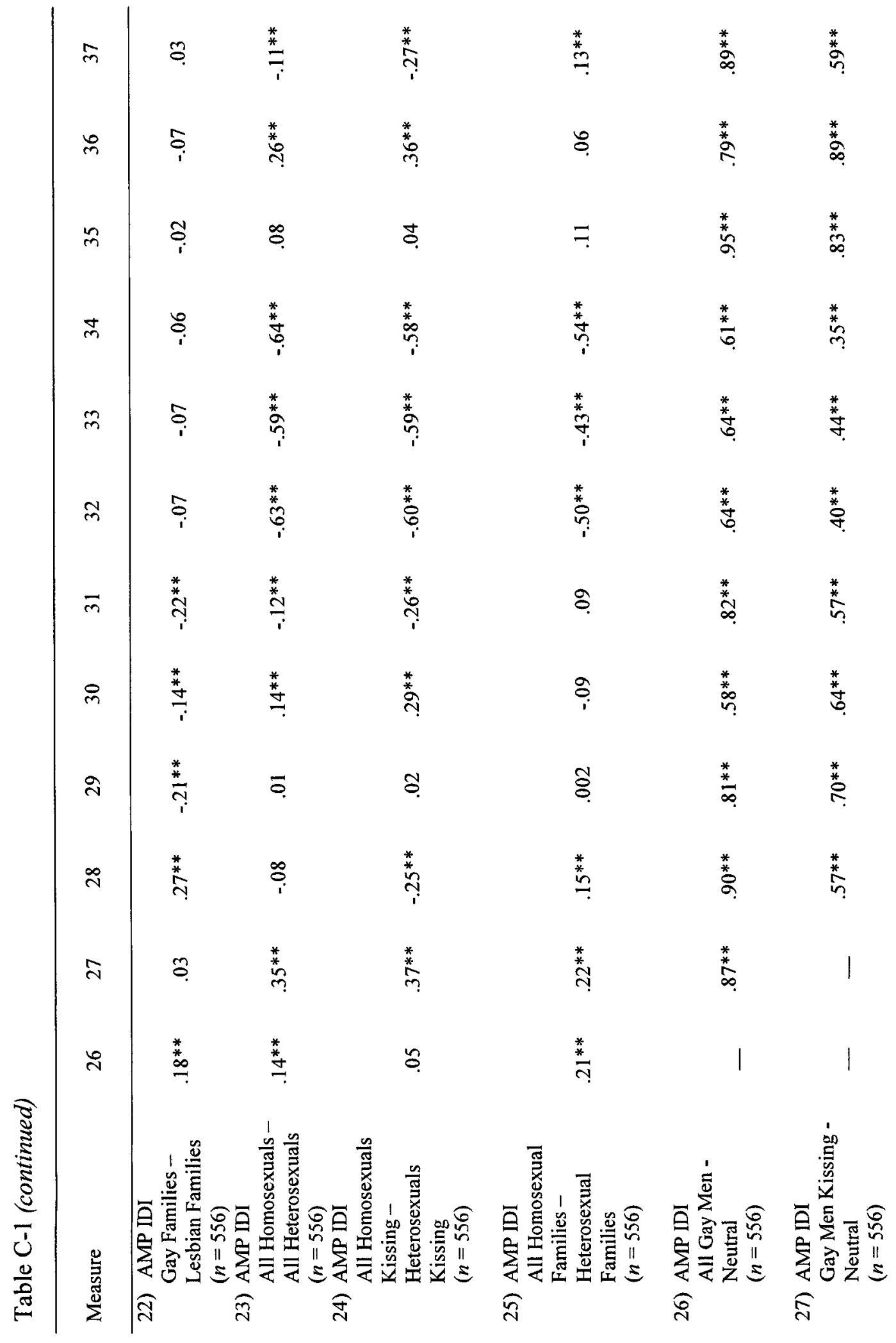




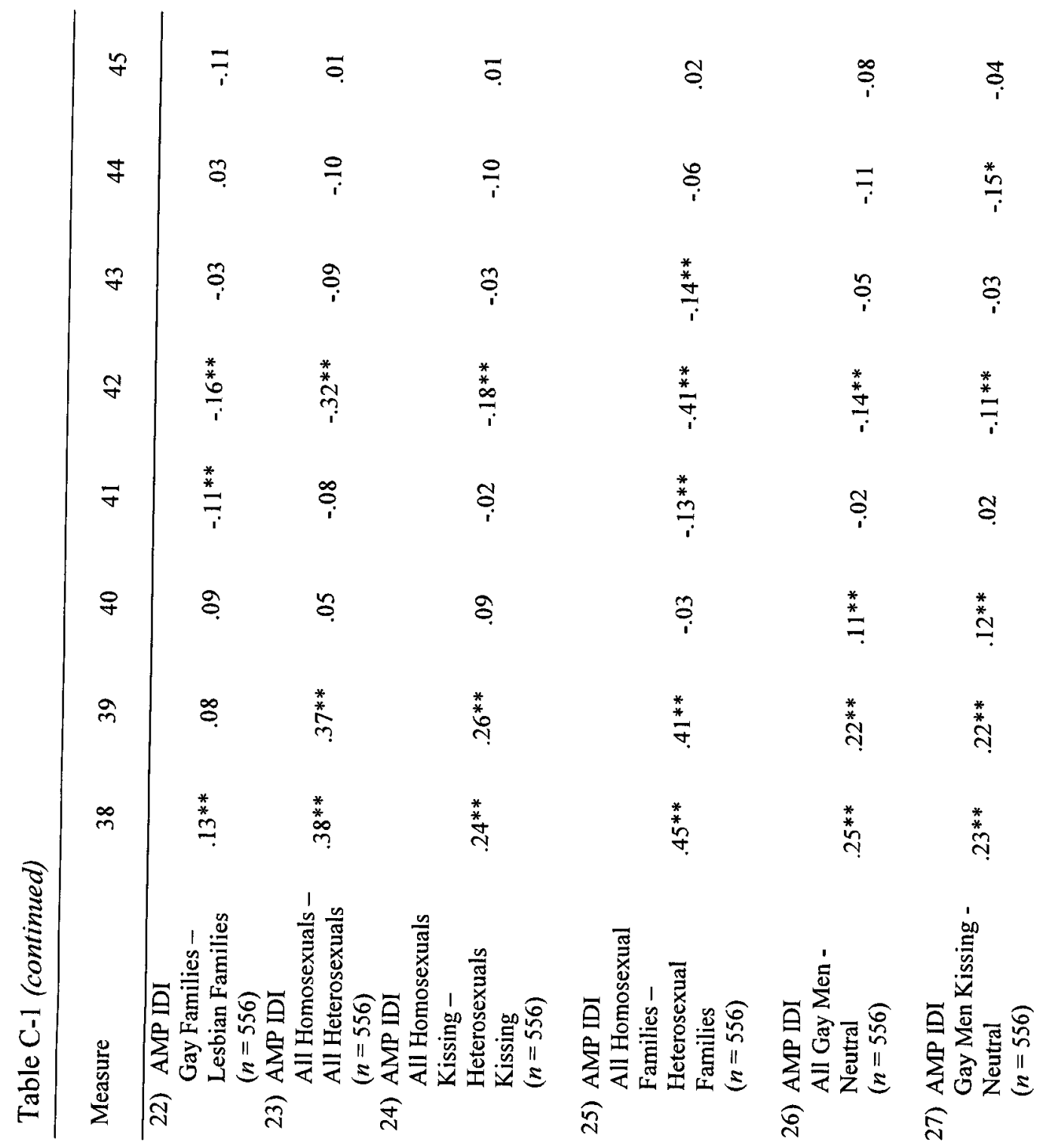




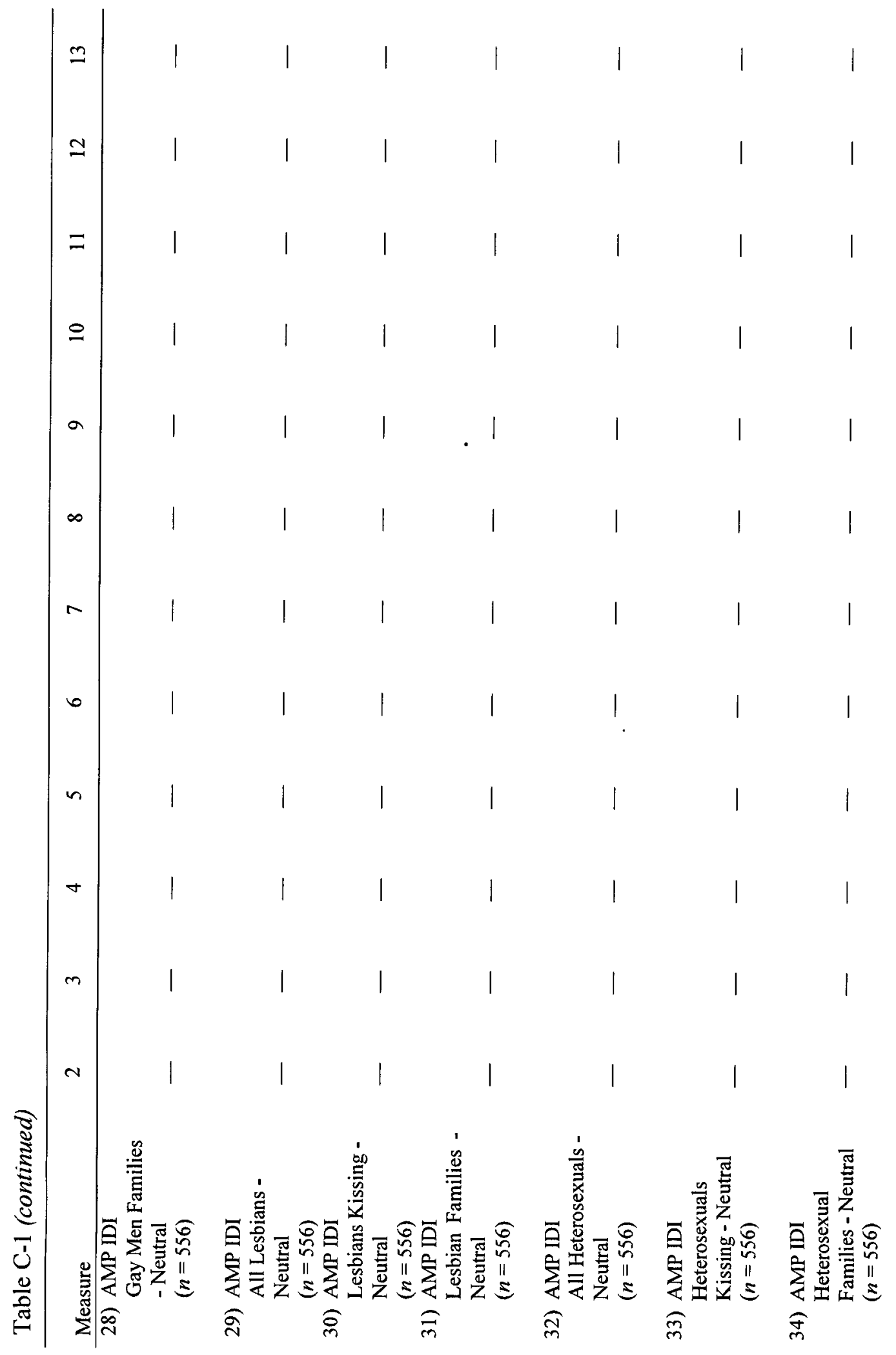




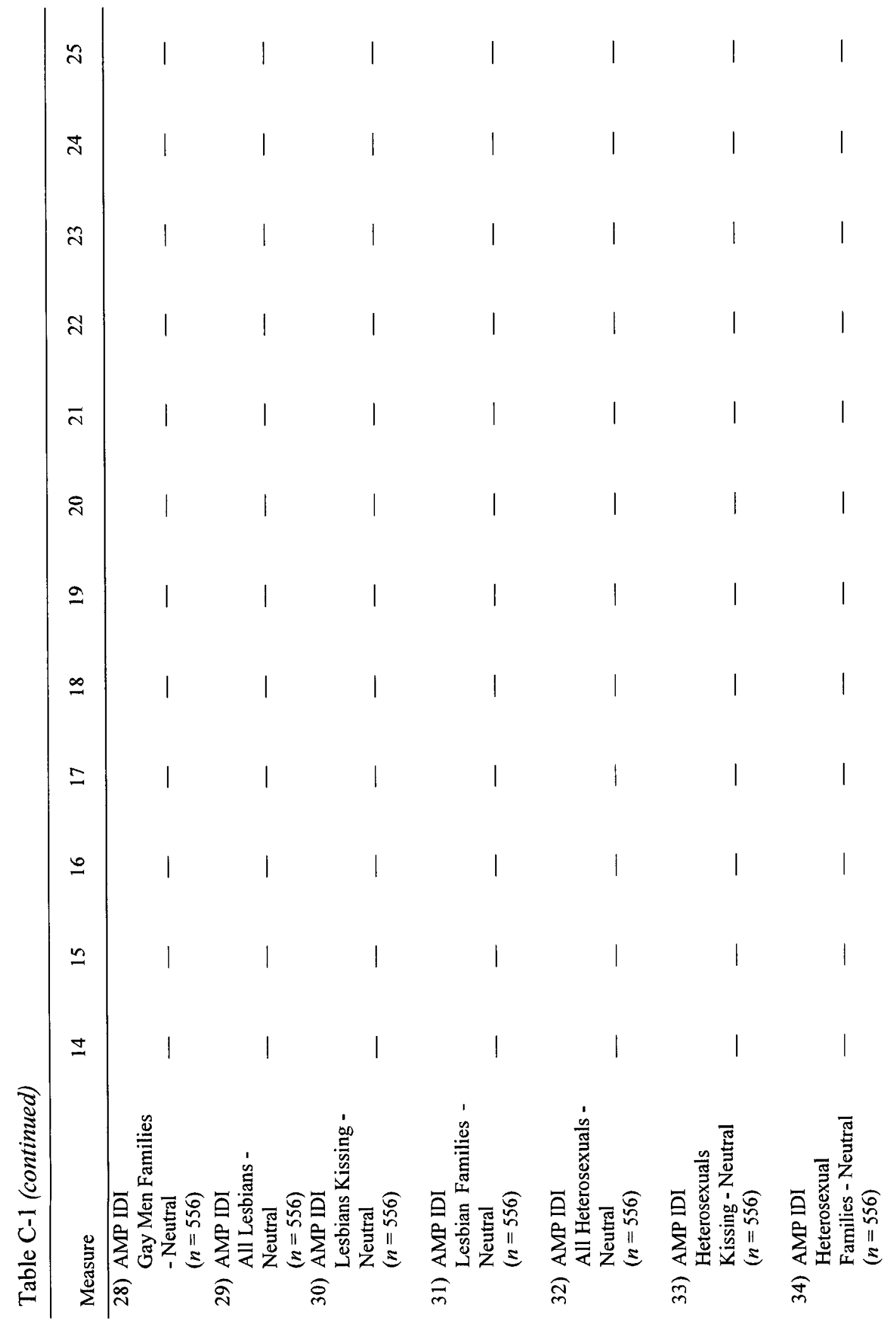




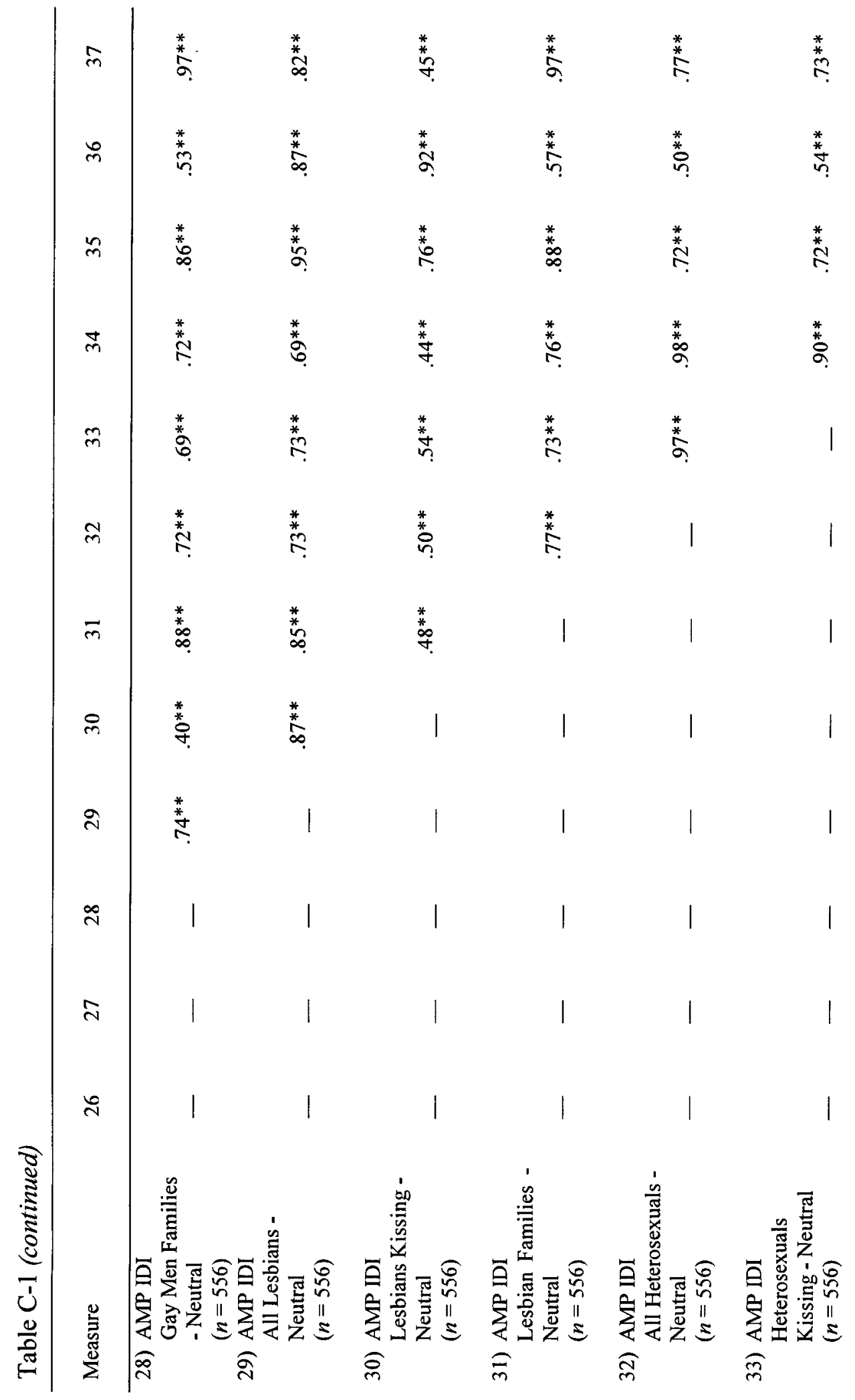




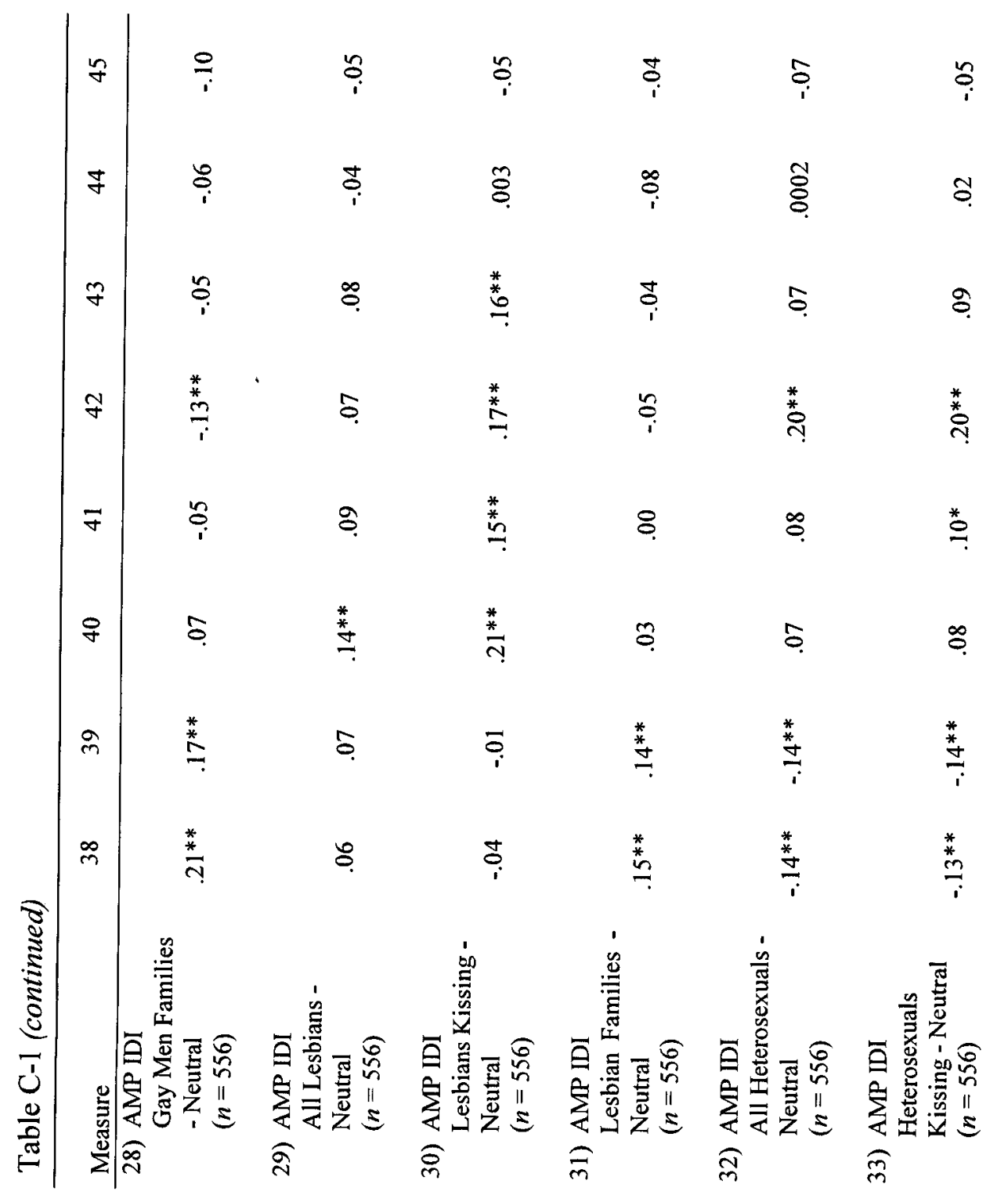


266

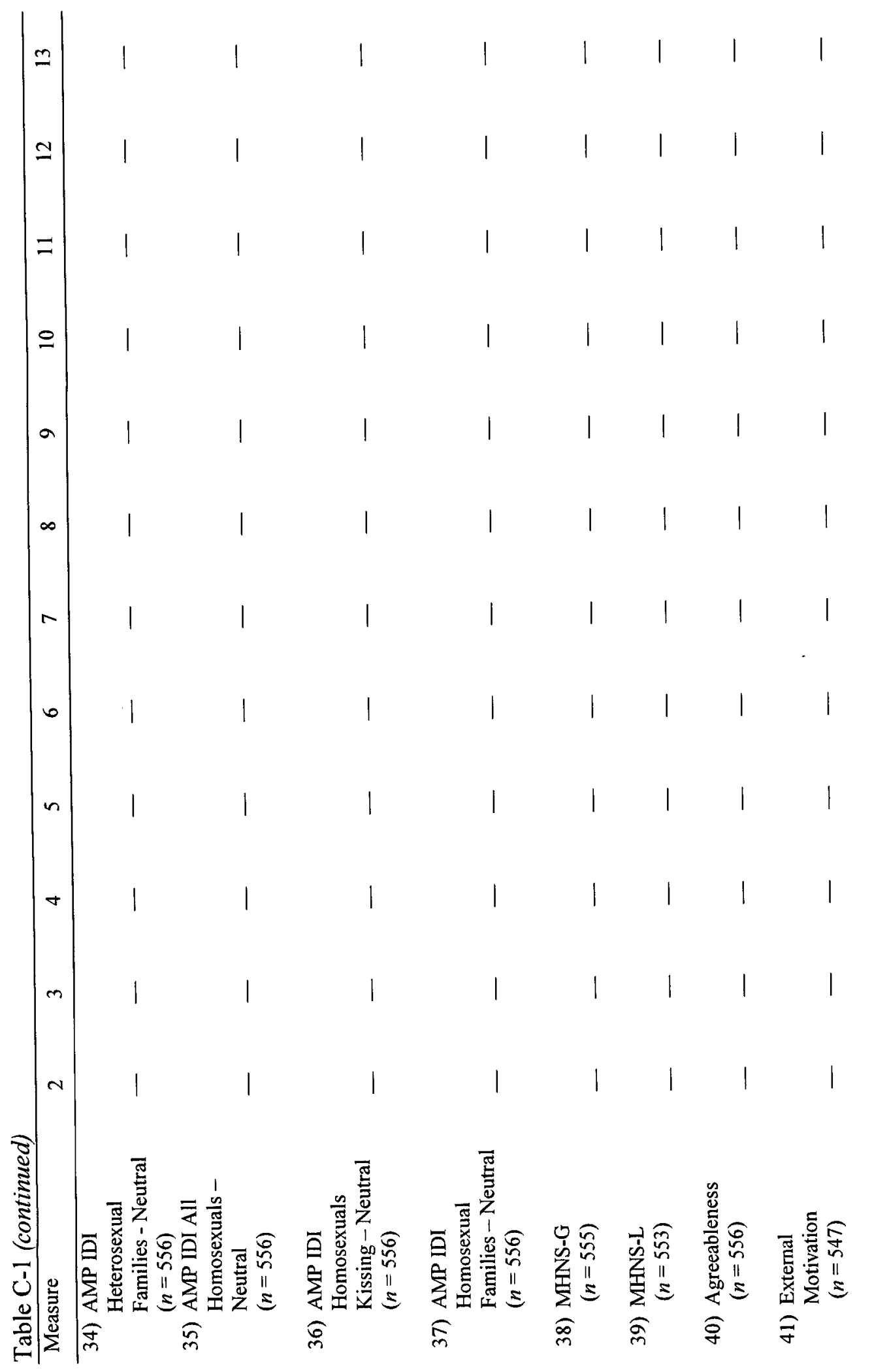


267

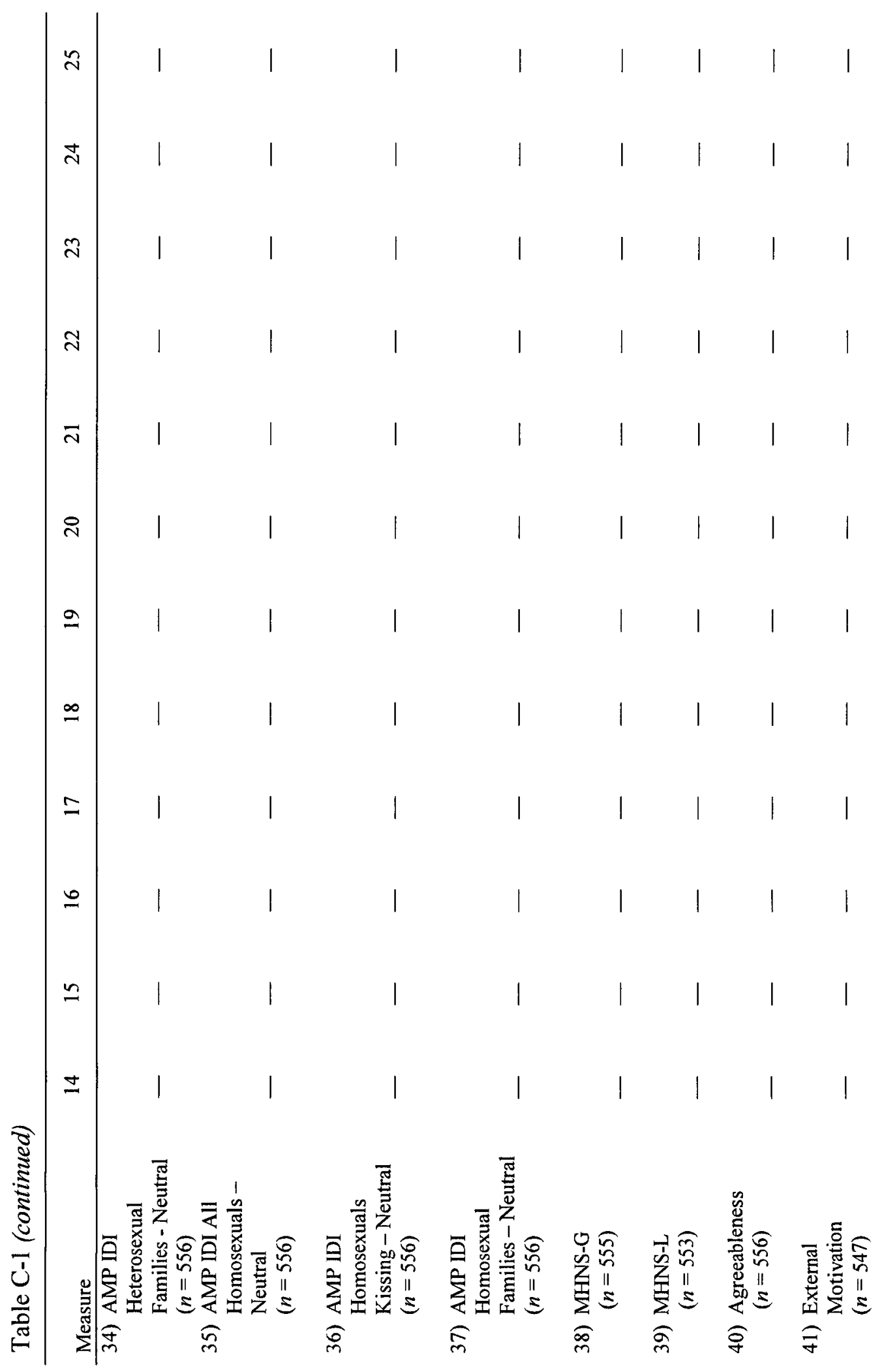


268

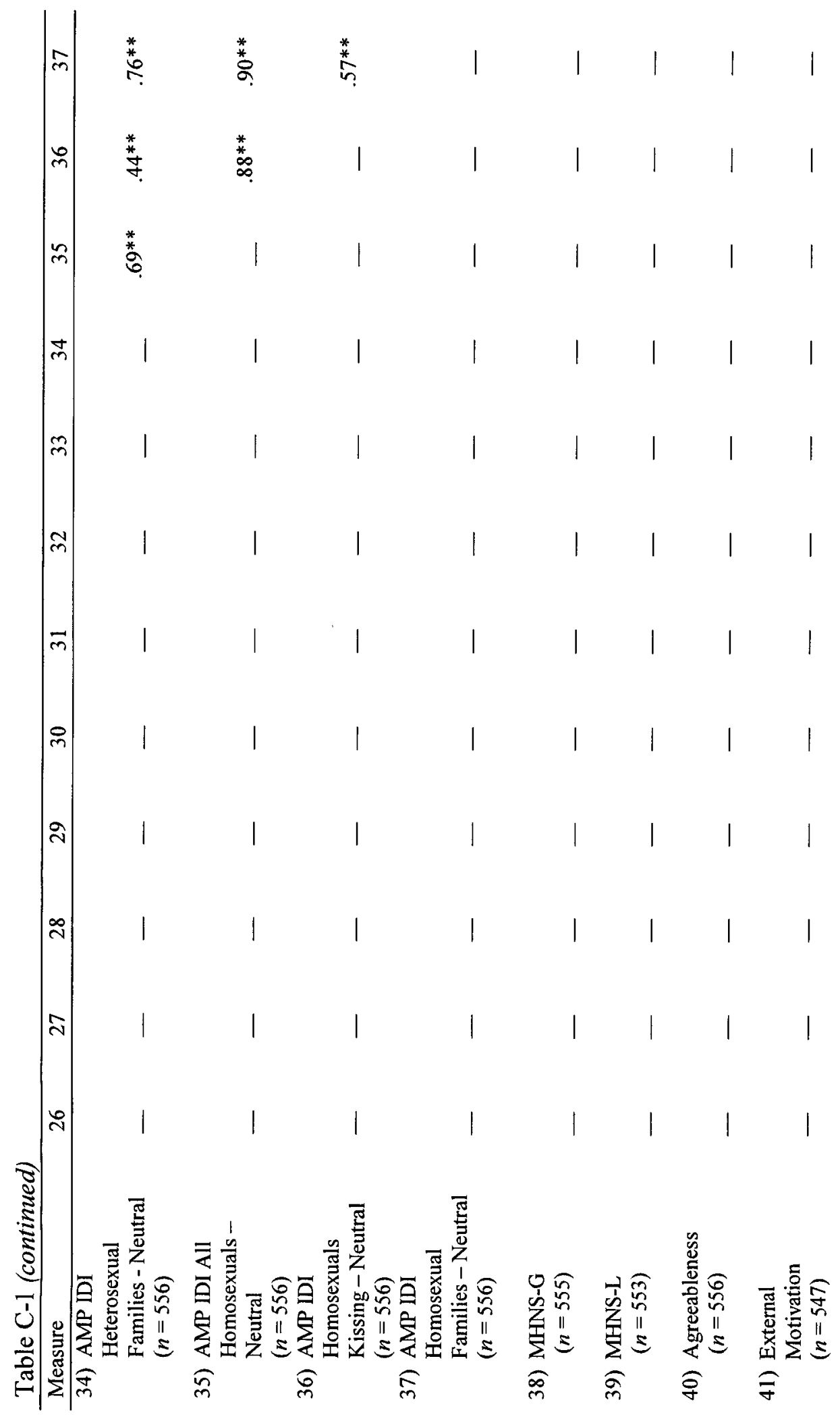




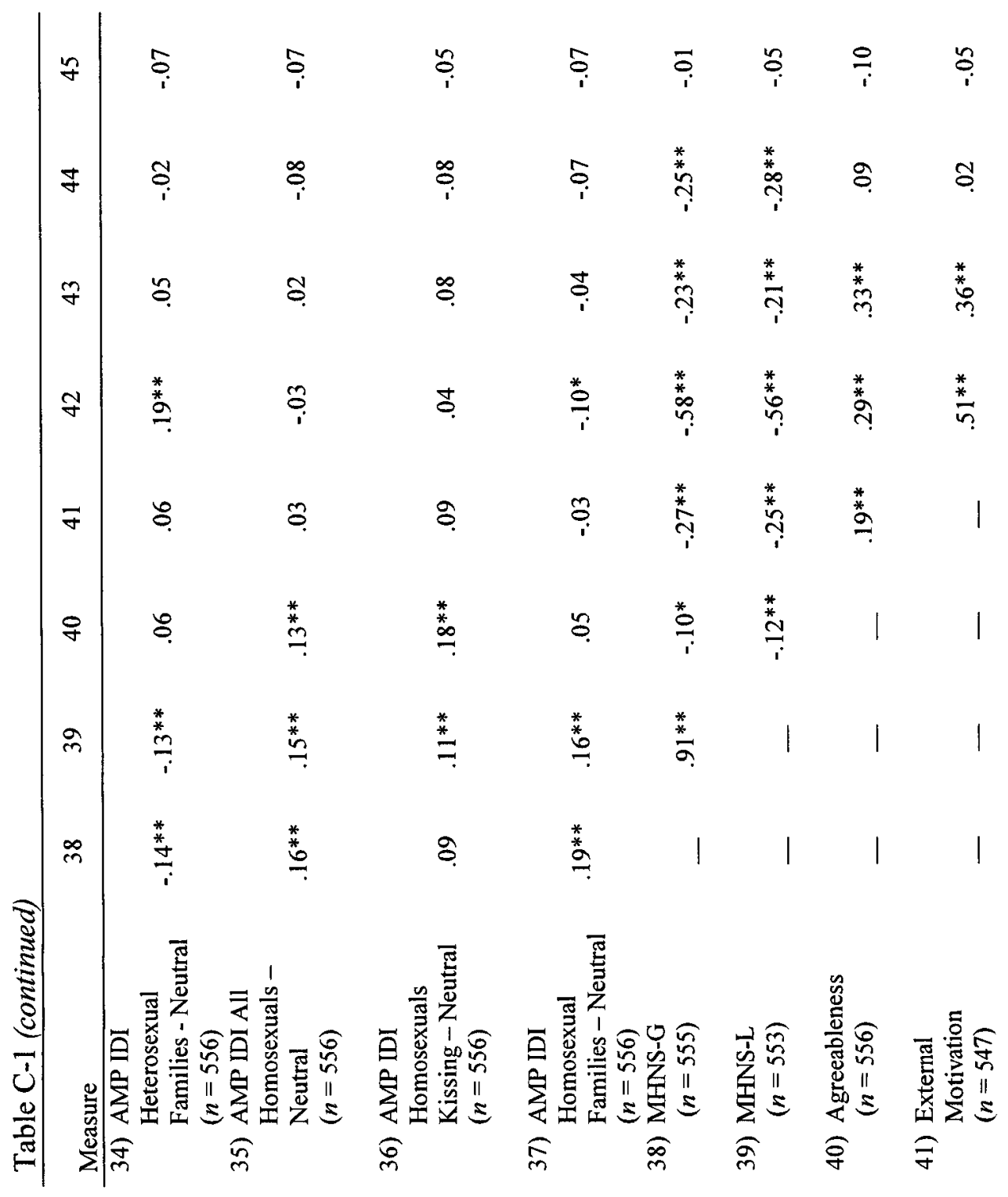




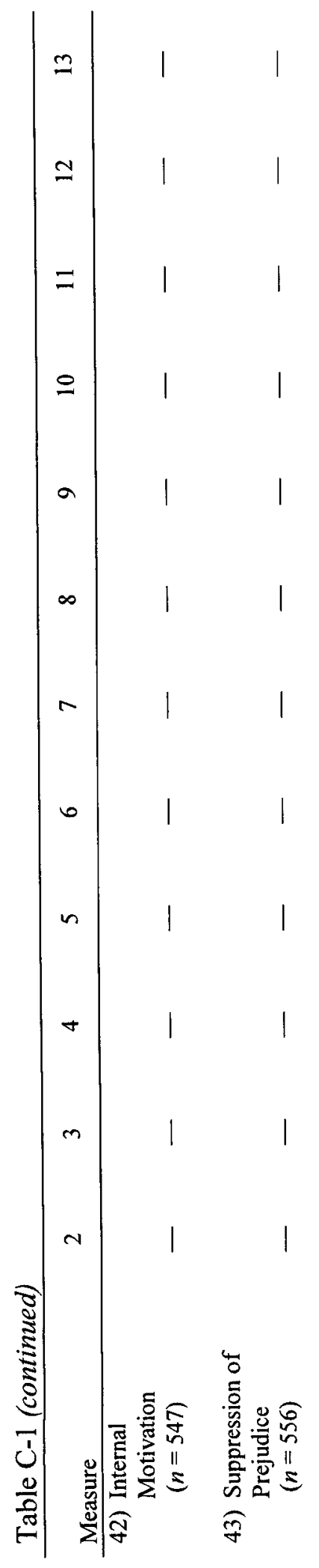




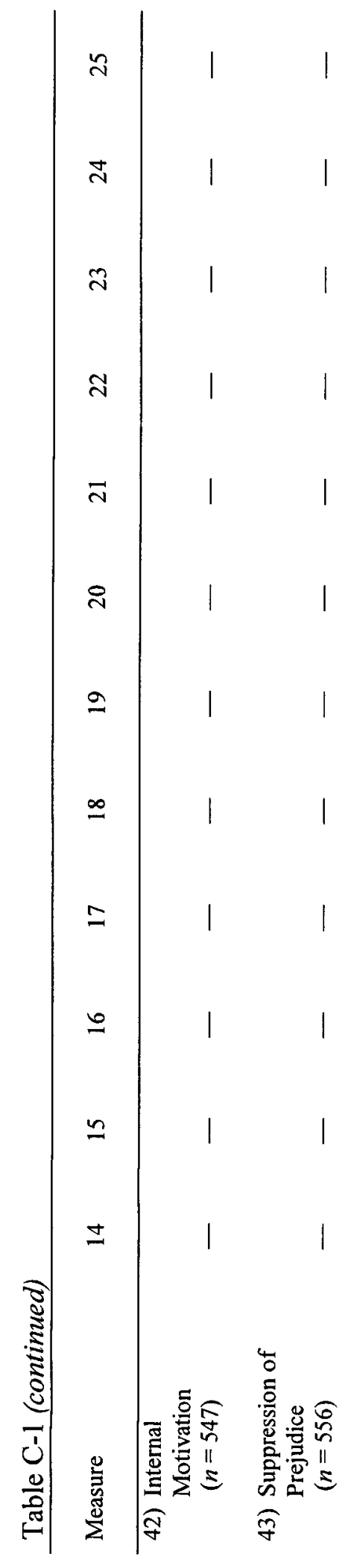




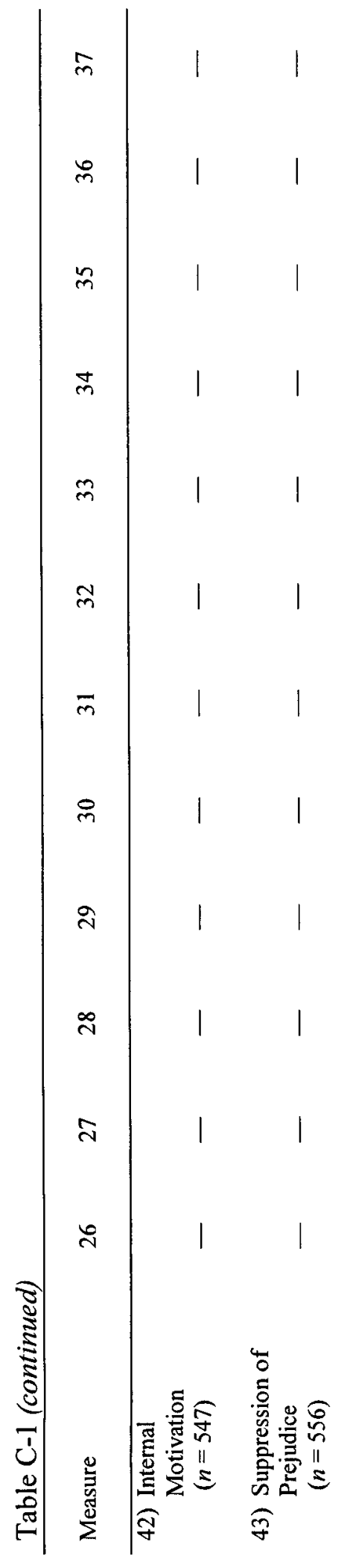




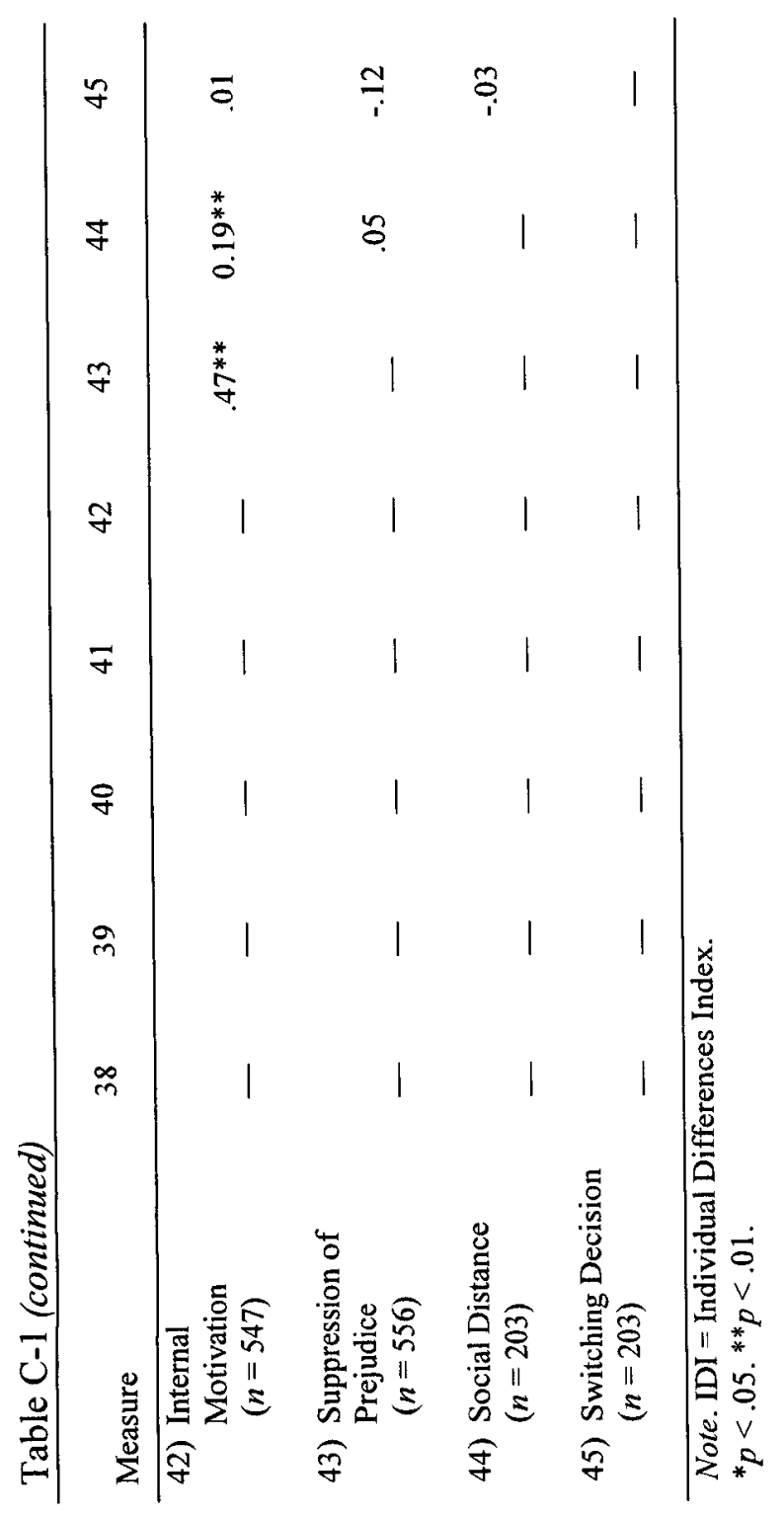

